Circling Communities

(a) $+\varepsilon$ 


\section{Circling Communities}

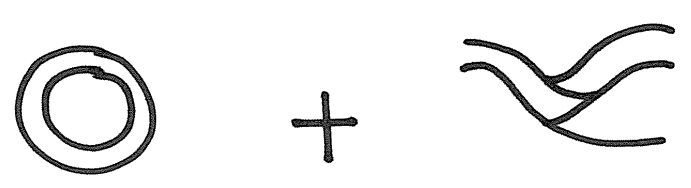

Philippa Barr

A 120 point thesis submitted in partial fulfilment of the requirements for the Master of Architecture [Professional]

Victoria University of Wellington, School of Architecture 


\section{acknowledgements}

Firstly I would like to acknowledge my cohort who's humour, support, friendship and byo's have made my time at university that much more enjoyable.

To my supervisor Sam Kebbell, your critical and engaging guidance this year has allowed me to learn more than I ever would have expected.

To my friends and flatmates, thank you for your kind and encouraging words when I have needed it most.

To my Mum and Dad, words cannot describe how appreciative I am for your endless love, support and life lessons. Thank you for always being there.

Last but not least, to Zac, thank you for always listening to me, laughing with me and forever believing in me. 


\section{abstract}

There are works of architecture that are concerned with the user and others that are heavily concerned with form. Although the best buildings are concerned with both, it is often that one is compromised for the other.

The site for this thesis is contested by four diverse communities; a surf club, a recreational park, a holiday park, and the surrounding houses. In developing a proposal for the site, the aim of this thesis is to explore design processes and formal strategies that will create an architecture concerned with both.
Throughout this thesis there are a series of design experiments which view the building from different directions according to the design medium. When using diagrams and mass models I have viewed the building from above (plan). When using a refined drawing technique I have viewed the building from the side (section). I have then used both physical and digital models as a way of translating the twodimensional views into a three-dimensional building.

This shift in design media has revealed that the plan and section can have opposing formal qualities. These qualities, simplicity in plan and complexity in section, have allowed me to address both the social and formal concerns of designing on a site like this. 


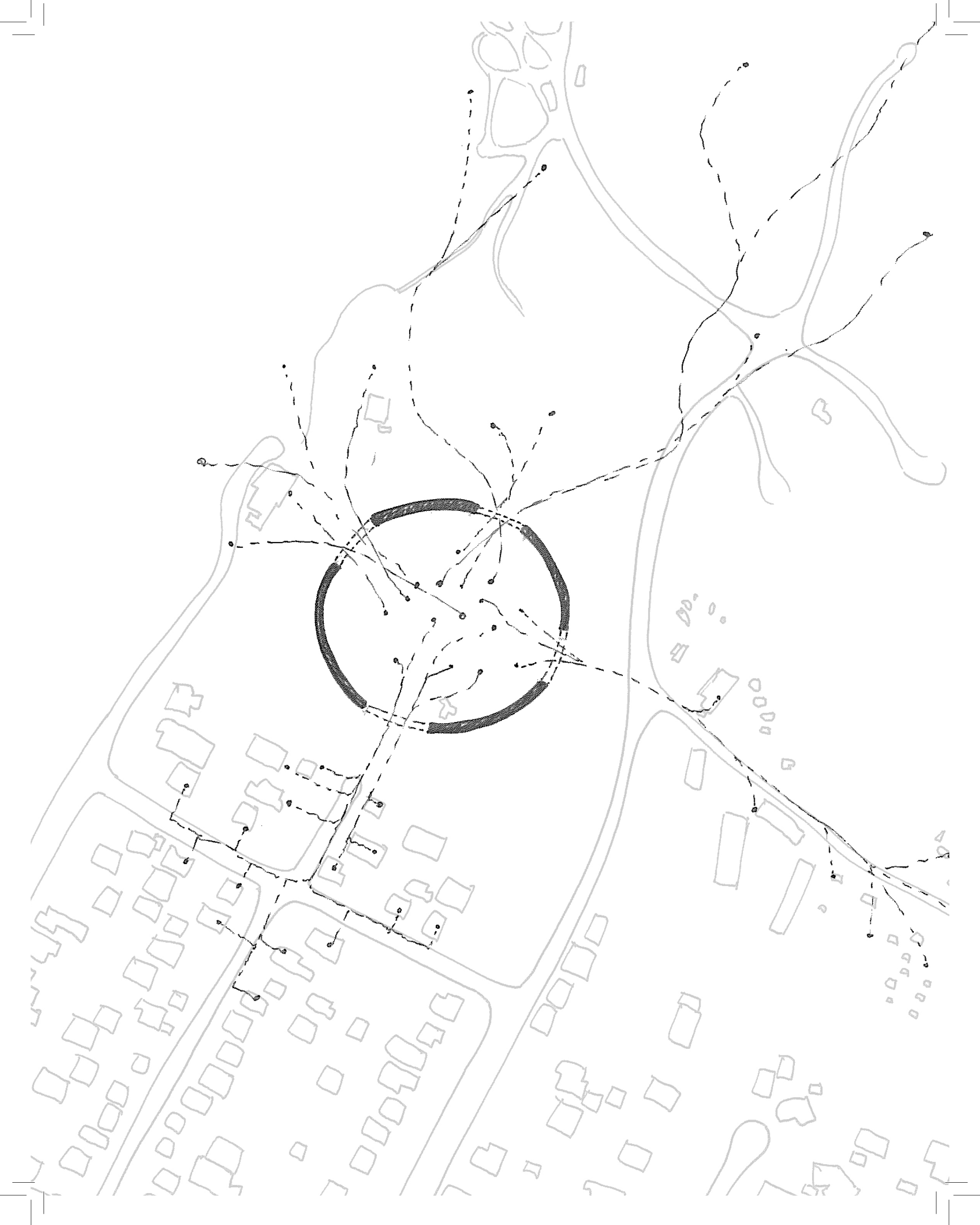




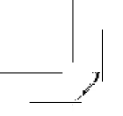

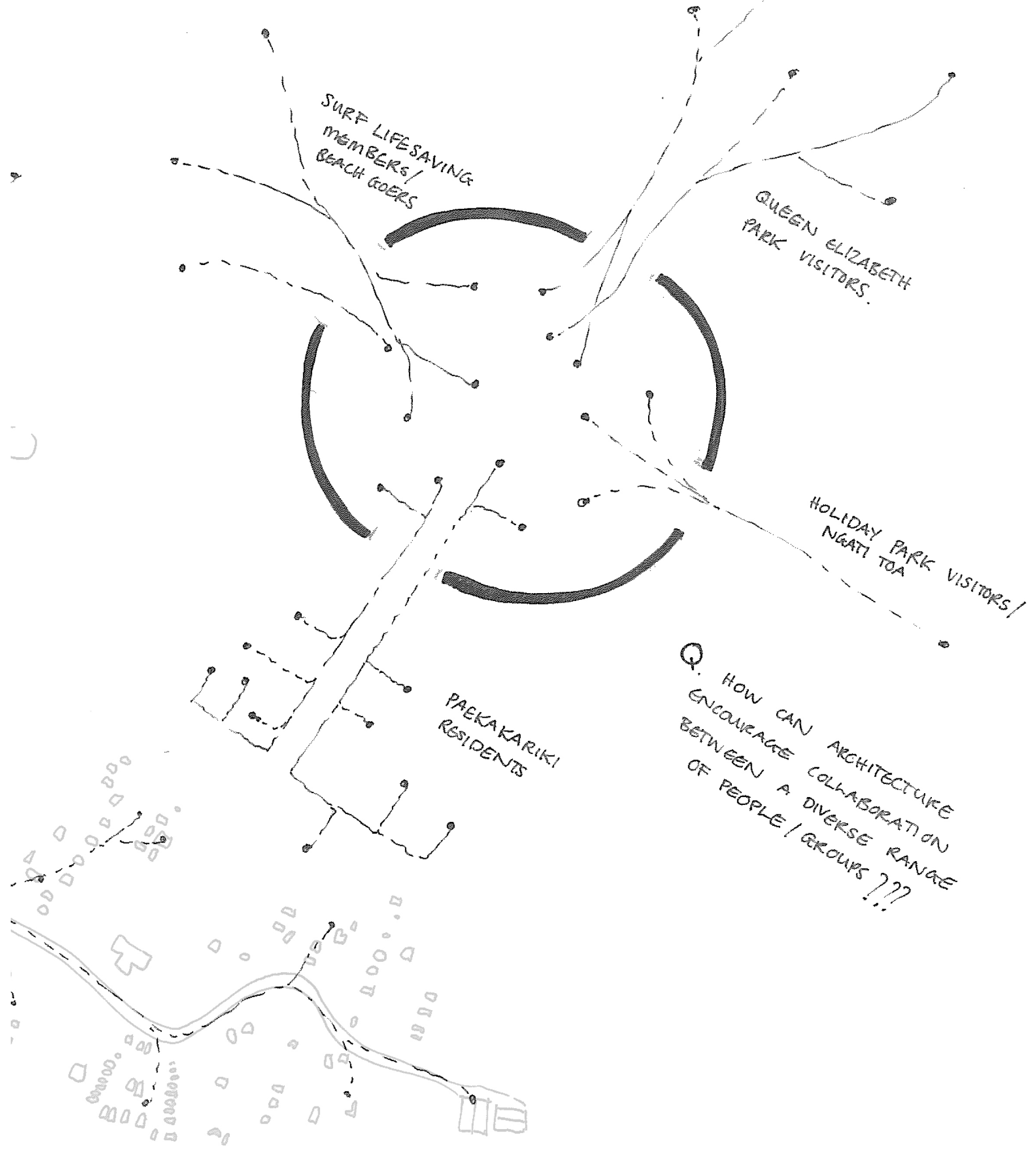

Y

$\wedge \quad$ Figure 1. This early drawing shows how the different communities could come together on the site. 


\section{contents}

Acknowledgments

Abstract

Contents

Introduction

\{pg. 1-5\}

1. Four Communities, One Site \{pg. 6-33\}

2. A Circular Building

\{pg. 34-75\}

3. A Simple and Complex Form

\{pg. 76\}

+ Plan

\{pg. 80-95\}

+ Section

\{pg. 96-157\}

+ Building

\{pg. 158-201\}

Conclusion

\{pg. 205\}

Bibliography

Figures List 


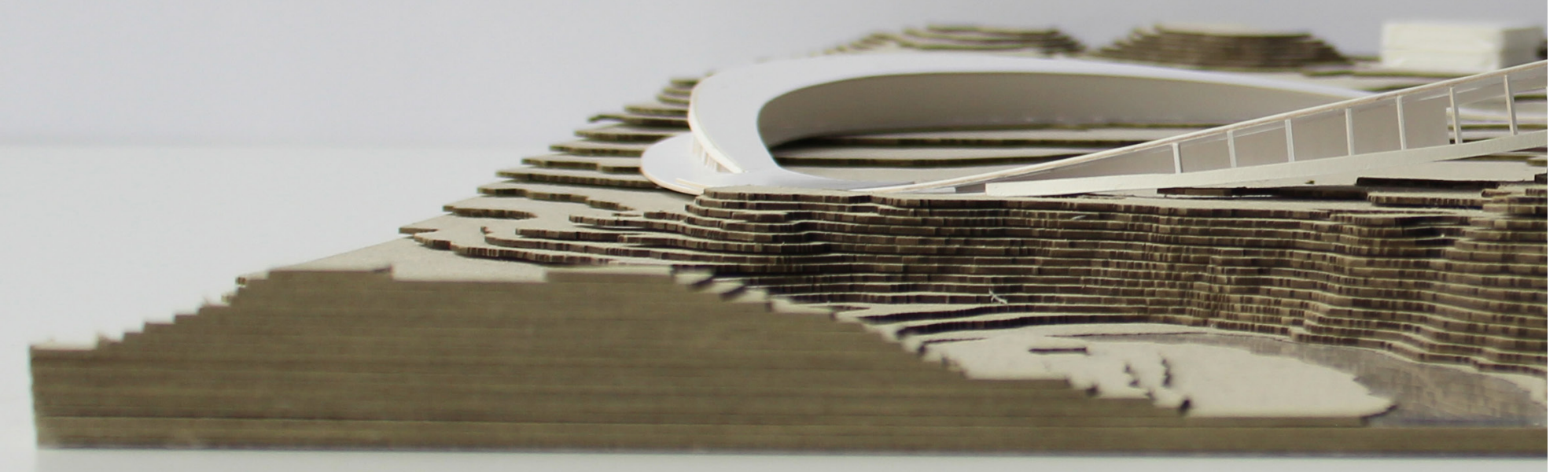




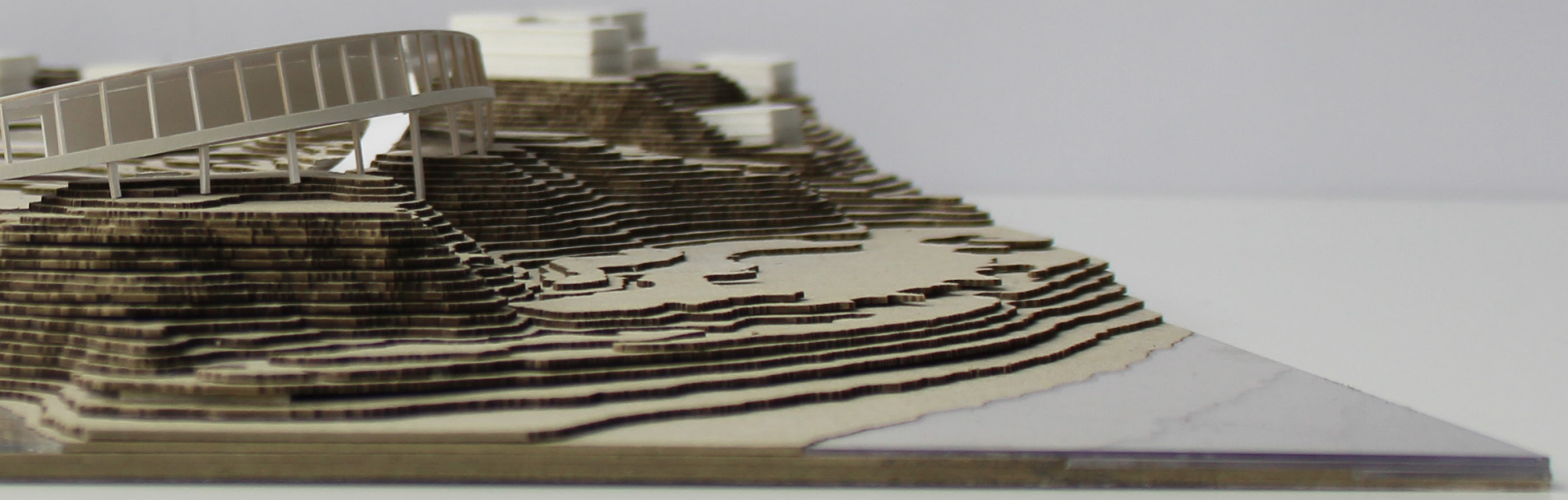


introduction 
There are works of architecture which are heavily concerned with the social and others that are heavily invested in form. While successful buildings bring these two concerns together, often one is compromised in favour of the other. In 'Complexity and Contradiction in Architecture,' Robert Venturi has criticised modern architects for being too concerned with form. He argues that although architects like Mies van der Rohe create beautiful buildings, they tend to be ignorant of the complexities inherent in a project. Although Venturi's critique was directed towards modern architects, circa 1960s, his argument of them being selective in what issues they want to solve is still a relevant problem in practice today. There are also many architects who comparatively design directly for the user resulting in formally weak buildings.

The site for this thesis is fronted by four diverse communities. The main issue is that one of these groups has proposed to shift on to the site. This has caused a concern among the other communities as each has a strong connection to the site. The challenge with this situation is trying to collectively accommodate these communities when they have such diverse identities and values. As architect Junya Ishigami has said, "it is becoming increasingly difficult for preconceived building types and/or functions to respond to our current circumstances" (Gadanho, 221). The architecture discipline needs to consider how we, as architects, can design buildings to suit the diverse identities and values of our occupants. No longer can we design our community buildings for one community at a time when we are faced with much more complex situations like this.

The question for this thesis is whether there is a design strategy which can help architects create building's that resolve multiple issues. In this specific proposal, the issues are the compromise of form for social concern or vice versa. This thesis aims to explore a design approach that focuses on maintaining a strong form while resolving the sites social concerns.
The research method for this thesis is design led. As a reflection of this, I introduce the site and the issues relating to it, followed by the final design solution. This allows the discussion to focus on the design process and critically analyse whether the formal strategy resolved the social issues of the brief and was successfully translated into the final design.

I have structured this discussion around 'a simple and complex form'. This is split into three parts, 'a plan', 'a section', and 'the building'. Under each part, there are a series of architectural experiments varying in media according to the direction in which the building is being viewed. In shifting between plan and section views, I was able to critique the design.

In the first chapter, I have used diagrams and mass models to find a form for the site. In viewing the site from above (plan) I was led to a circular design. This decision is explained further along with the implications of the circle.

In the second chapter, I have developed a refined drawing technique which has allowed me to explore the circular form from a side on perspective (section). This technique captures light and shadow, and the experience of the building from the user's perspective.

Finally, in the third chapter, I have used physical and digital models to help translate the two-dimensional views, plan and section, into a three-dimensional building.

I will then conclude with a critical analysis of the final design to question whether the plan and section approach achieved a balance between formally strong and socially accommodating architecture. 


\section{introduction}

$\rightarrow 1 . \quad$ four communities, one site

$\rightarrow 2$. a circular building

$3 . \rightarrow$ a simple and complex form

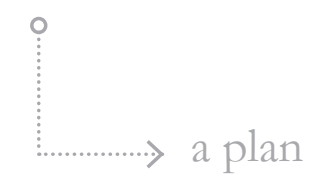

(2)

a)

(6)

秉 4

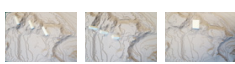

$\sqrt{20}$

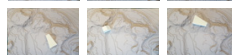

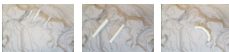

एव

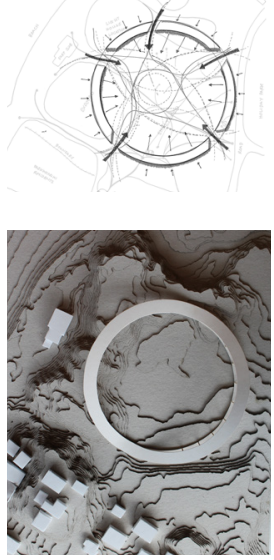

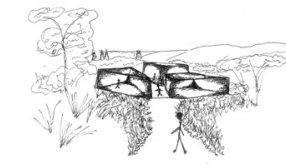

Com

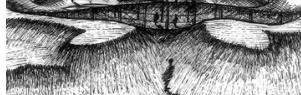

政

sin

$2 y$

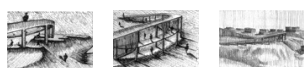

플
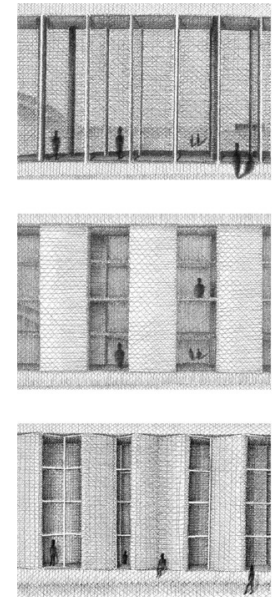

$\wedge$

Figure 3. This diagram explains the structure of the thesis and the design process. 

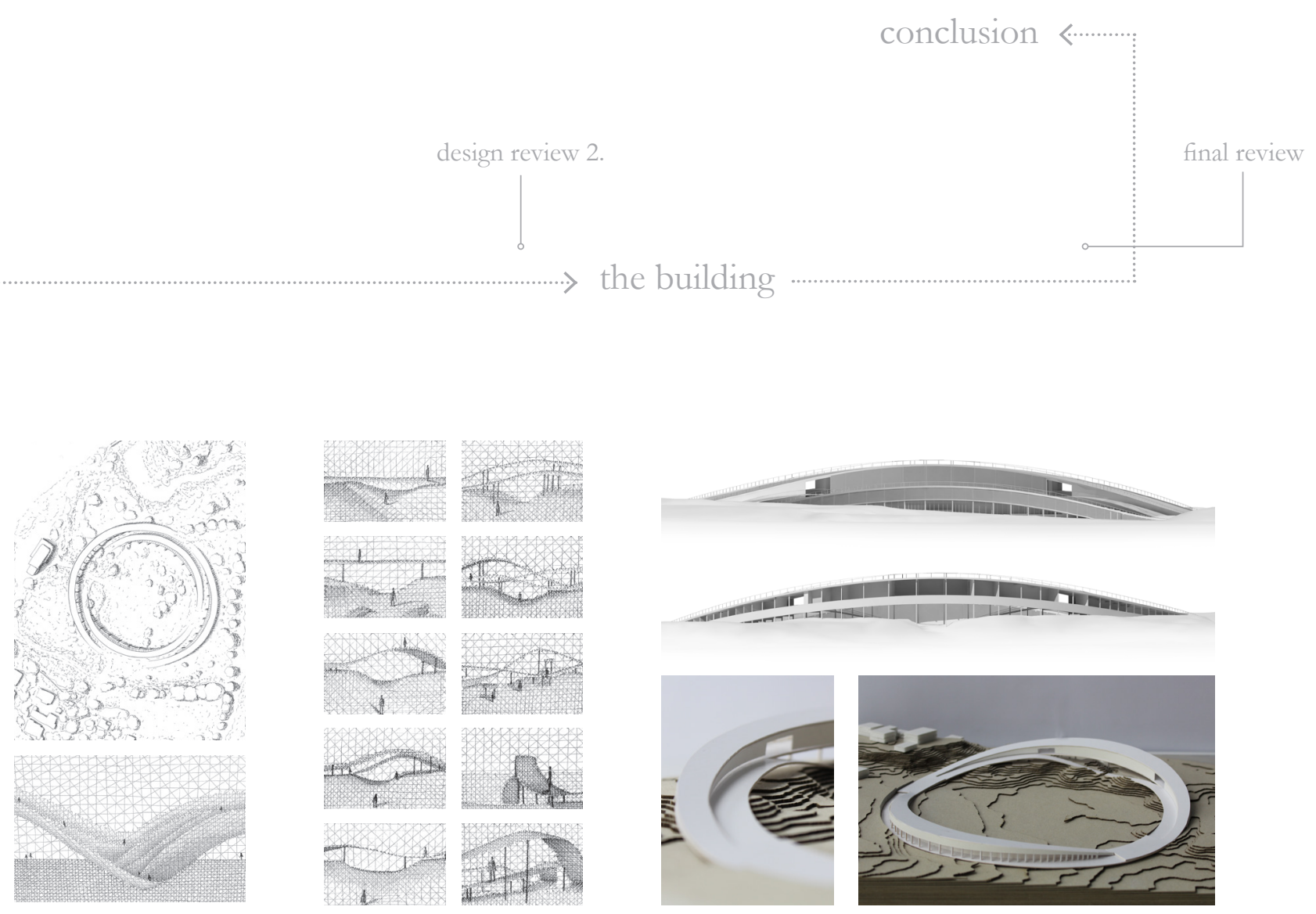


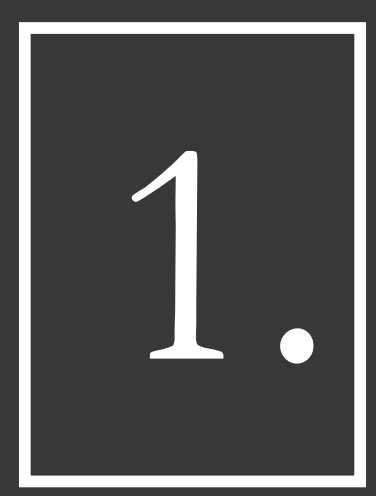




$$
\begin{gathered}
\text { four } \\
\text { communities, } \\
\text { one site }
\end{gathered}
$$




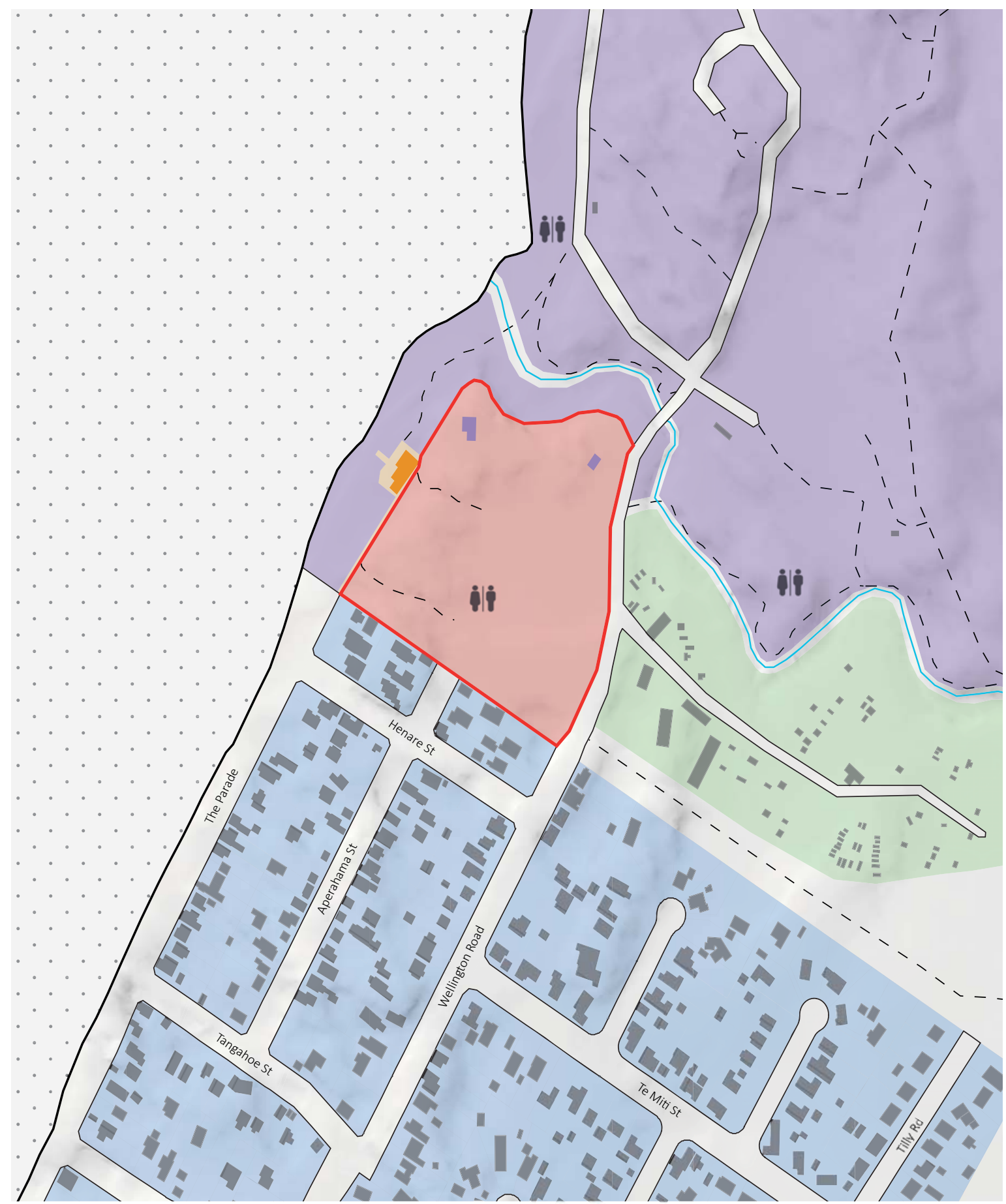

$\wedge$

Figure 5. This map shows the location of the surrounding communities in proximity to the site.

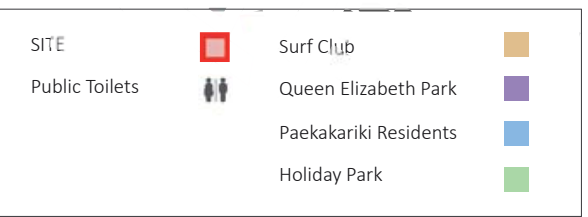

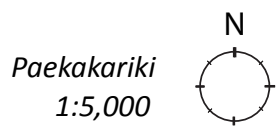


Located at the northern end of Paekakariki beach, the site sits between four diverse communities; the Paekakariki Surf Club, Queen Elizabeth Park, the Paekakariki Holiday Park, and the surrounding houses. Recently the Surf Club has proposed to shift onto the site in retreat from the rising sea level. This proposal is controversial as it threatens the public use and strong connection each community has with the site. Currently, it is heavily used by the public for its access to the beach and QE Park. There is also rising tension between the different communities due to the convoluted history of the site. For example, Ngati Haumia, a hapu of Ngati Toa, who currently manage the Holiday Park, is decedents of the great Maori warrior Te Rauparaha. Before European settlement, the area had a violent history; this was mainly due to Te Rauparaha's massacres. He used the beach to launch his attacks against a combined alliance of Kurahaupo tribes during the battle of Waiorua (Ngati Toa Rangatira). Still today, the iwi have a strong spiritual tie to this site and are finding their ancestors remains buried on the beach directly in front.

Seeing as the different communities are highly invested in the site, it is important that they are all catered for in the proposal as a way of preventing future disputes. In that case, this thesis will produce a more accommodating alternative to the Surf Clubs proposal. 


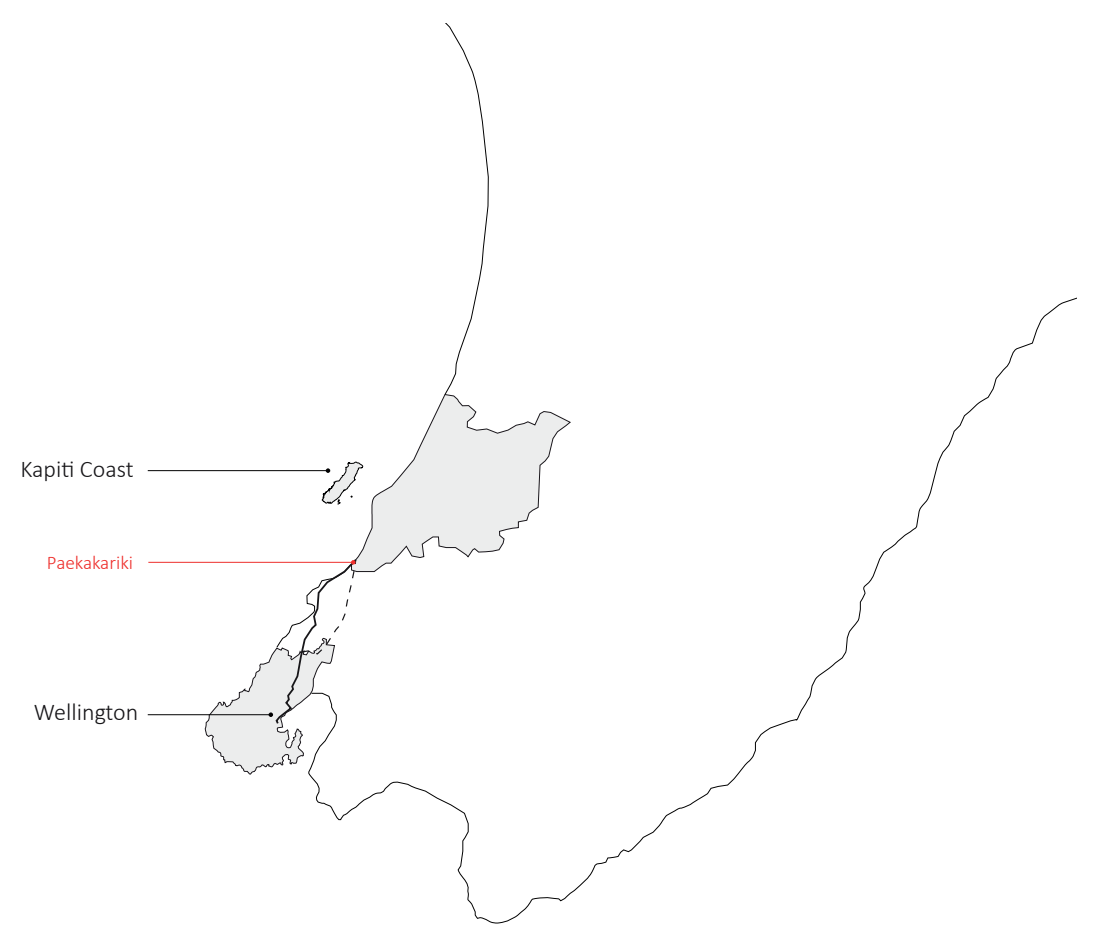




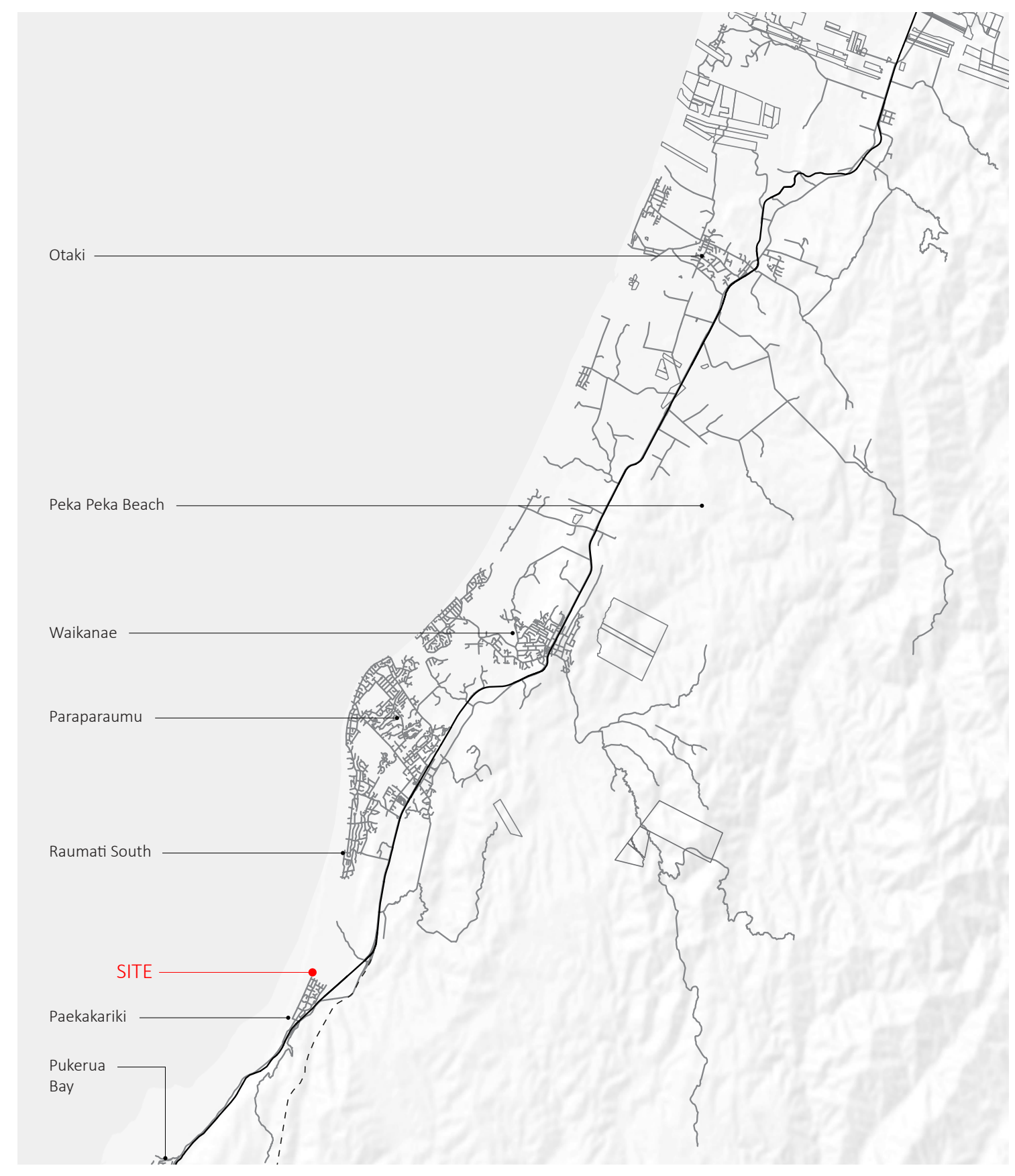

$\wedge<$

Figure 6. Map of New Zealand (left), and a map of the Kapiti Coast (above). 



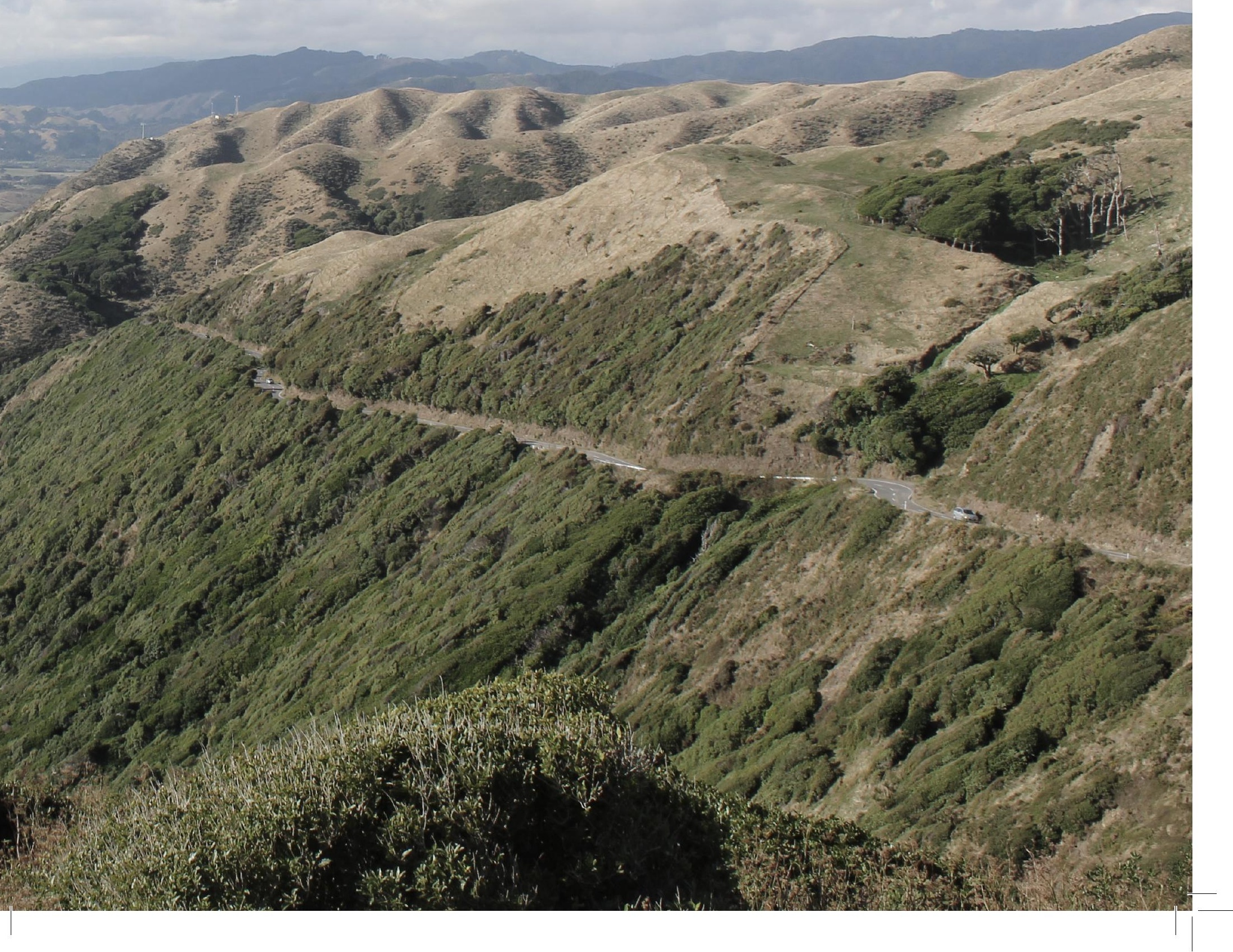


Paekakariki is a small town on the Kapiti Coast, 40 minutes' drive north of Wellington. It has a unique situation where the sea, hills, main roads and QE Park, all prevent the town from expanding. This situation helps to maintain Paekakariki's tight-knit community.

Despite the small population, the main street at the southern end of the town has been thriving since the opening of the Paekakariki escarpment walkway and bike trail. This increase in visitors has brought huge economic benefit for the cafes and other amenities in the village.

With this in mind, there is the equal potential that the site at the far northern end of Paekakariki could be equally successful. The area is already a popular destination with the holiday park, surf club and the entrance to Queen Elizabeth Park, all in proximity to each other but lacks amenities and a community space. 


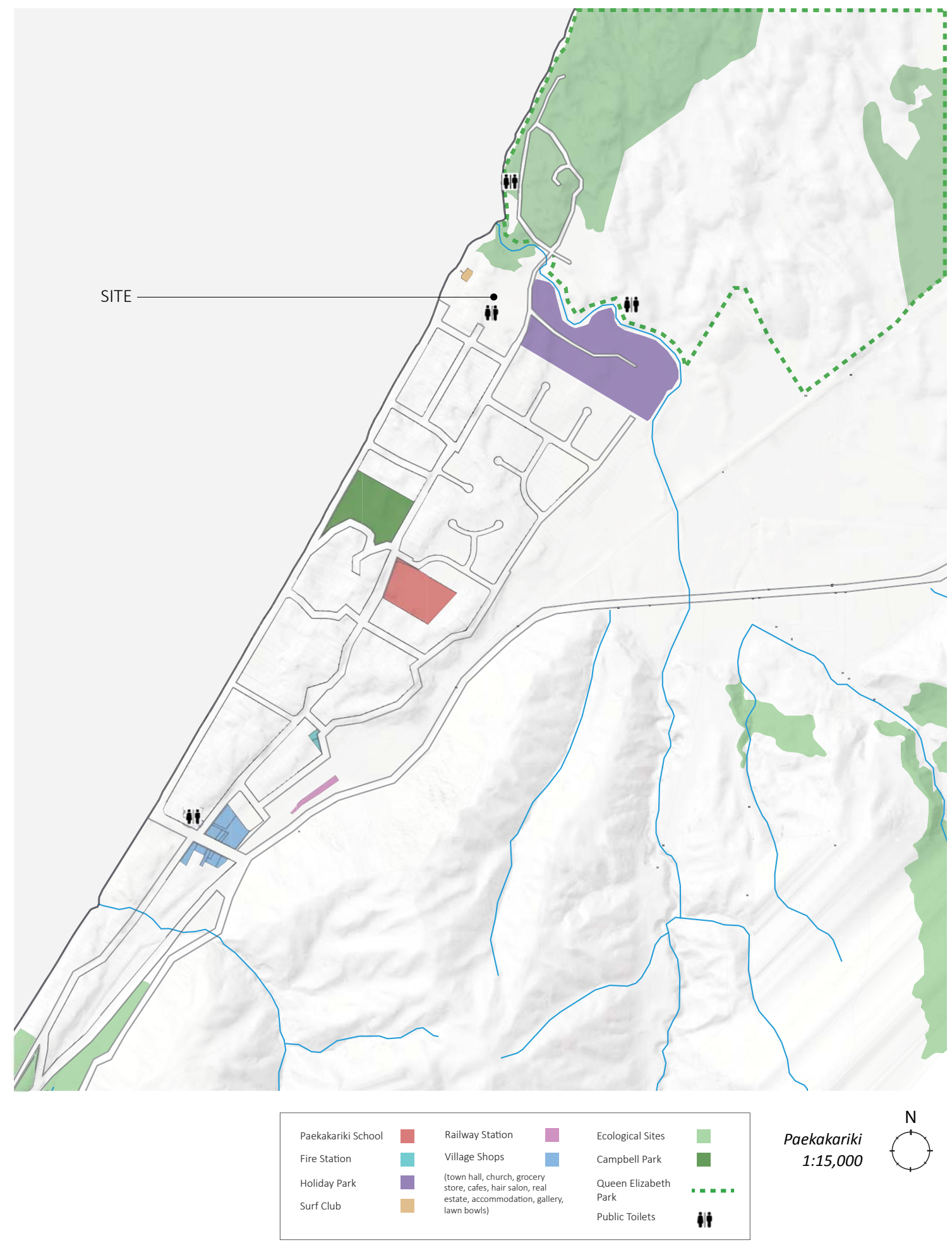

Figure 10. Most of the amenities in Paekakariki are located in the village and are close to the train station. Aside from this, there is a Primary school, a few recreational parks, a holiday park and a surf club located north of the village. 


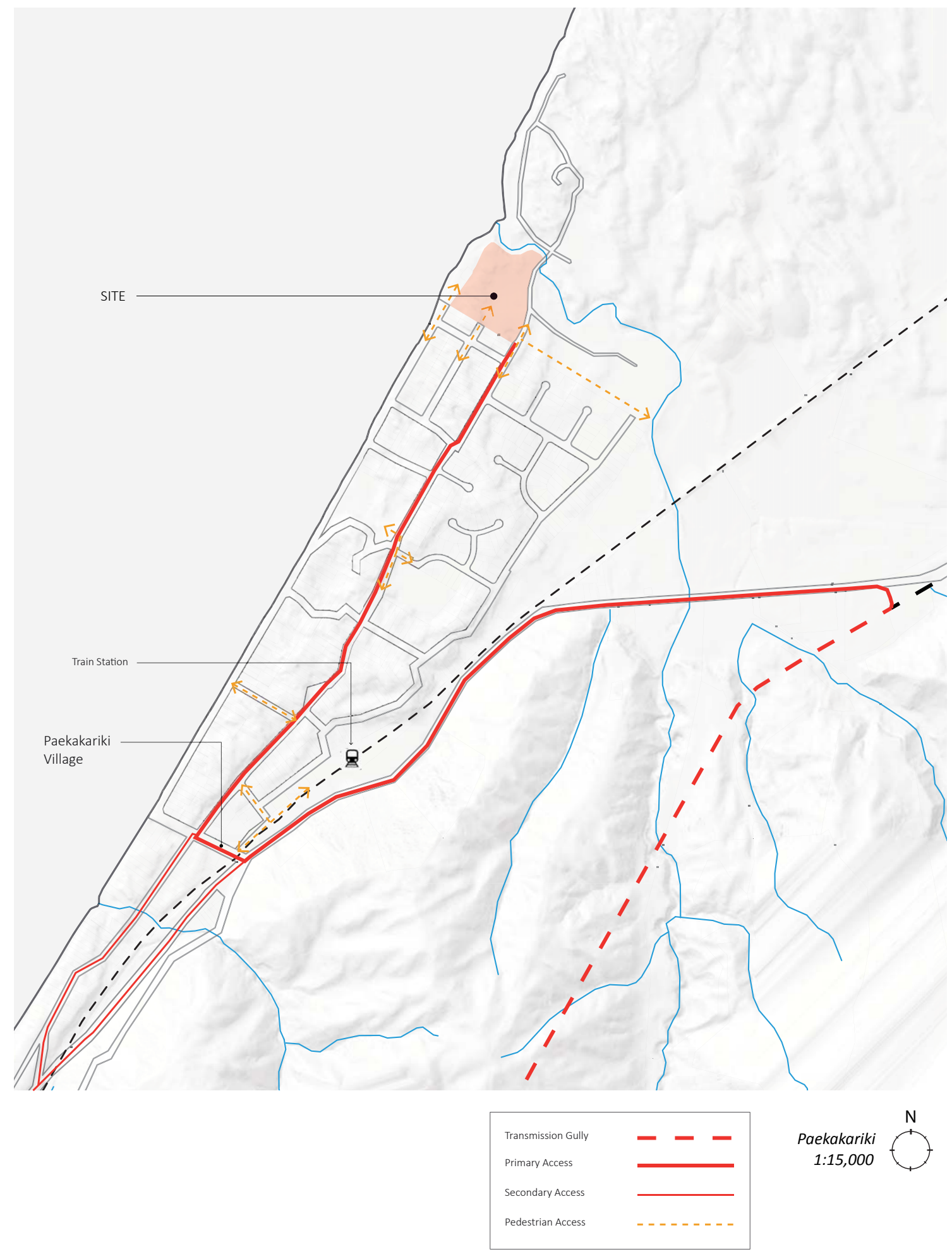

$\wedge$

Figure 11. Situated along SH1 and the main railway line Paekakariki is very accessible. However, with the new addition of Transmission Gully which will bypass the town, visitors will have to backtrack a few 100 metres to reach the village. 


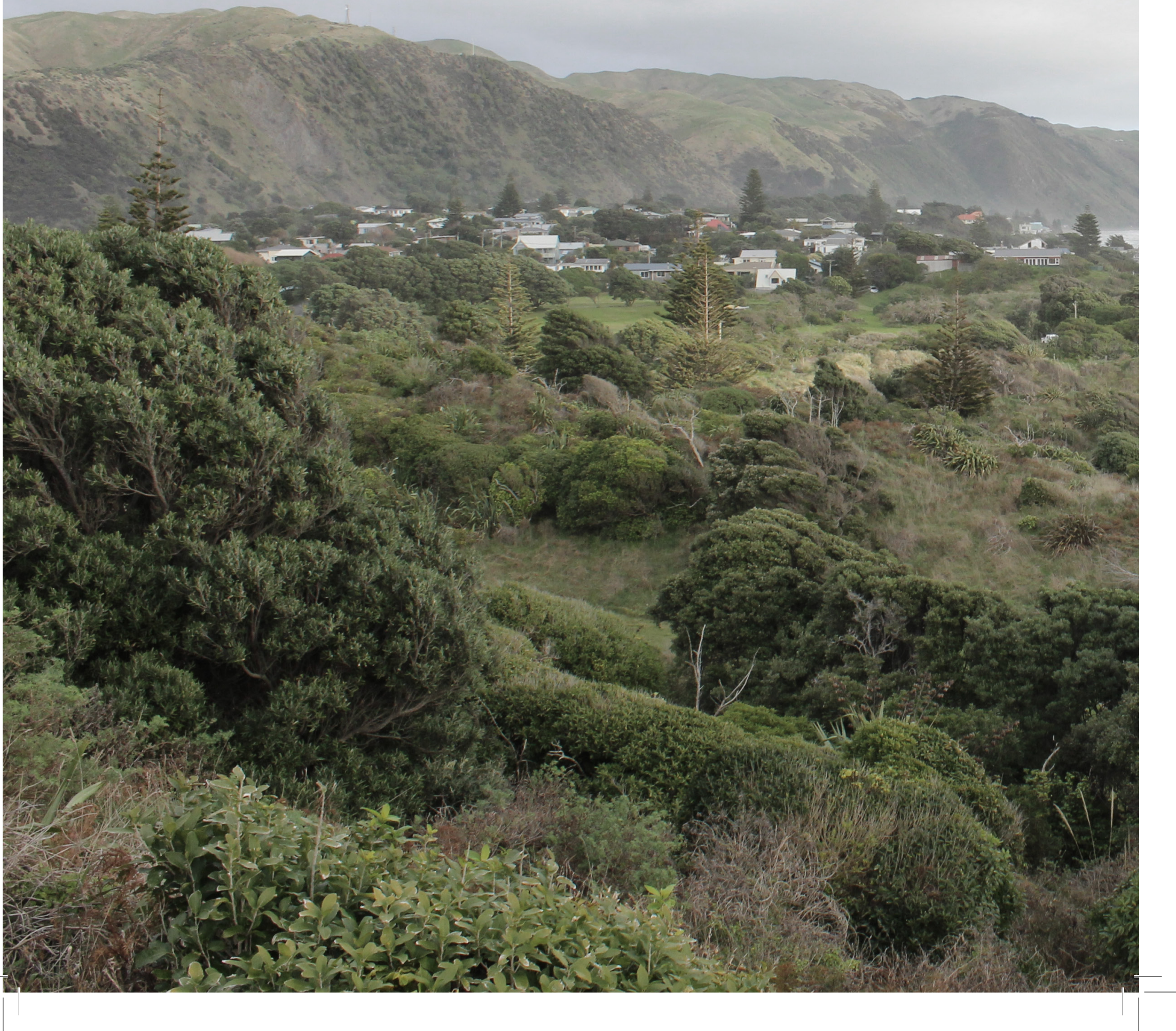




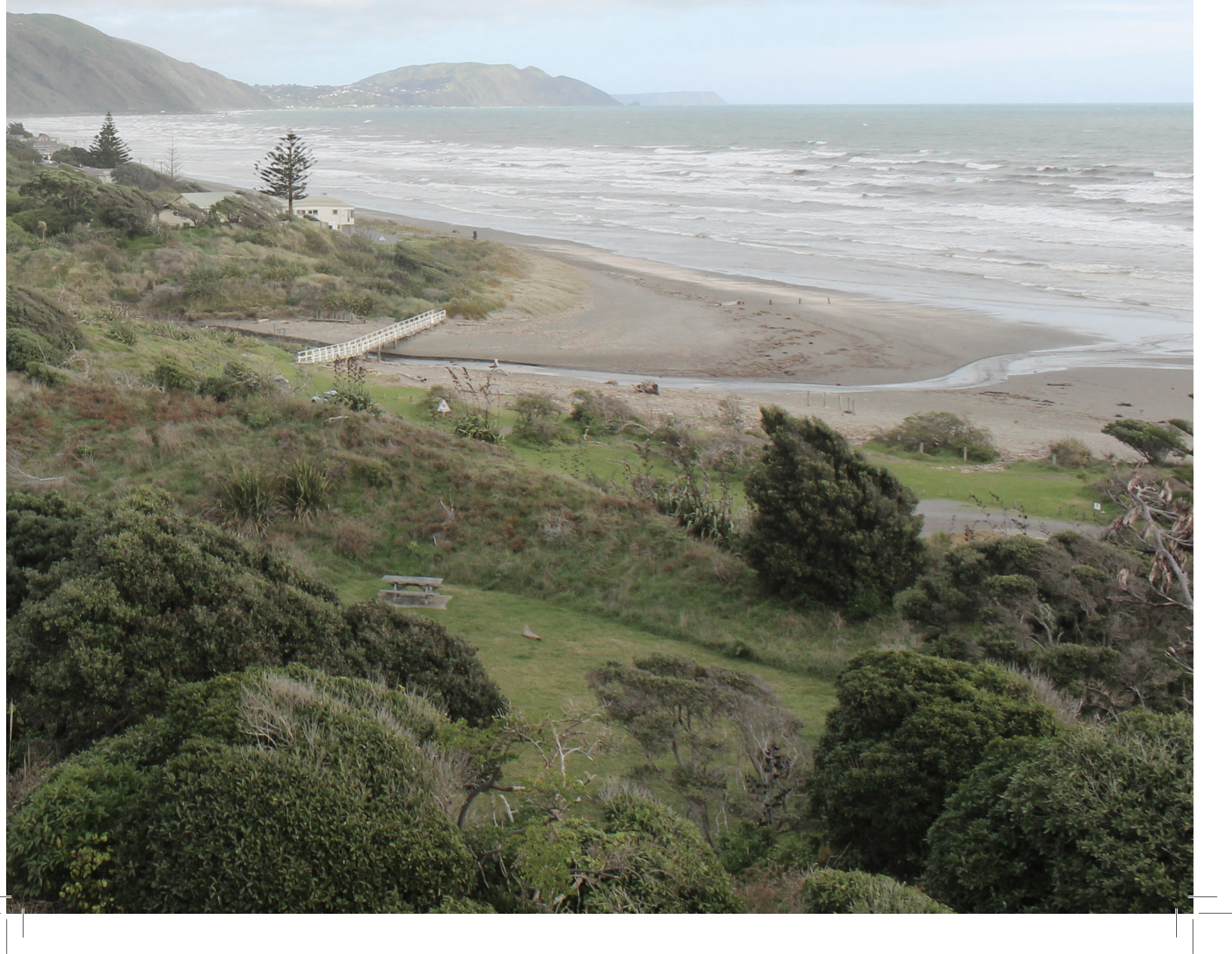



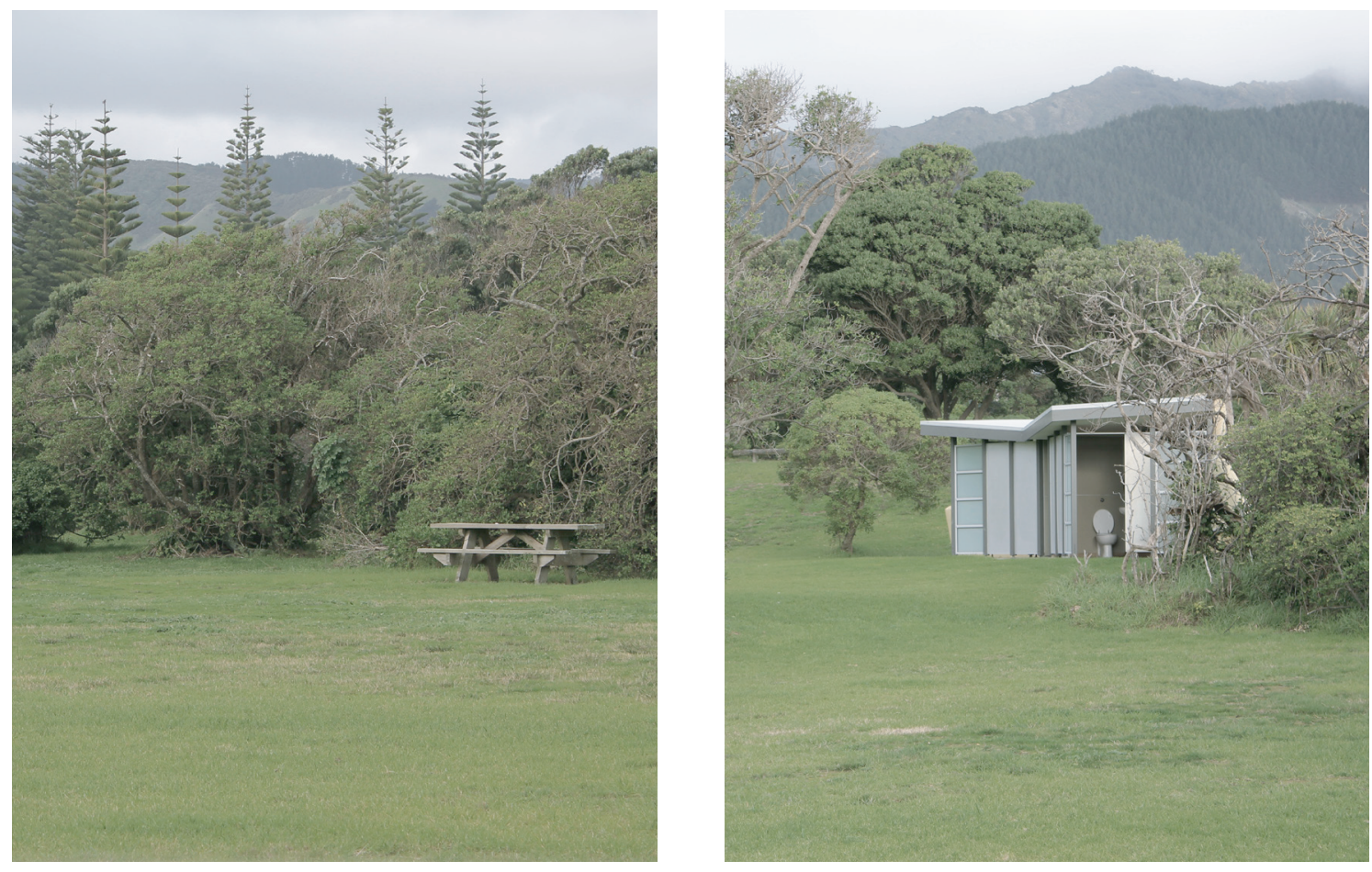

$\wedge$

Figure 13. The site which is set back from the beach and sheltered by the dunes, is scattered with picnic tables and public toilets. 


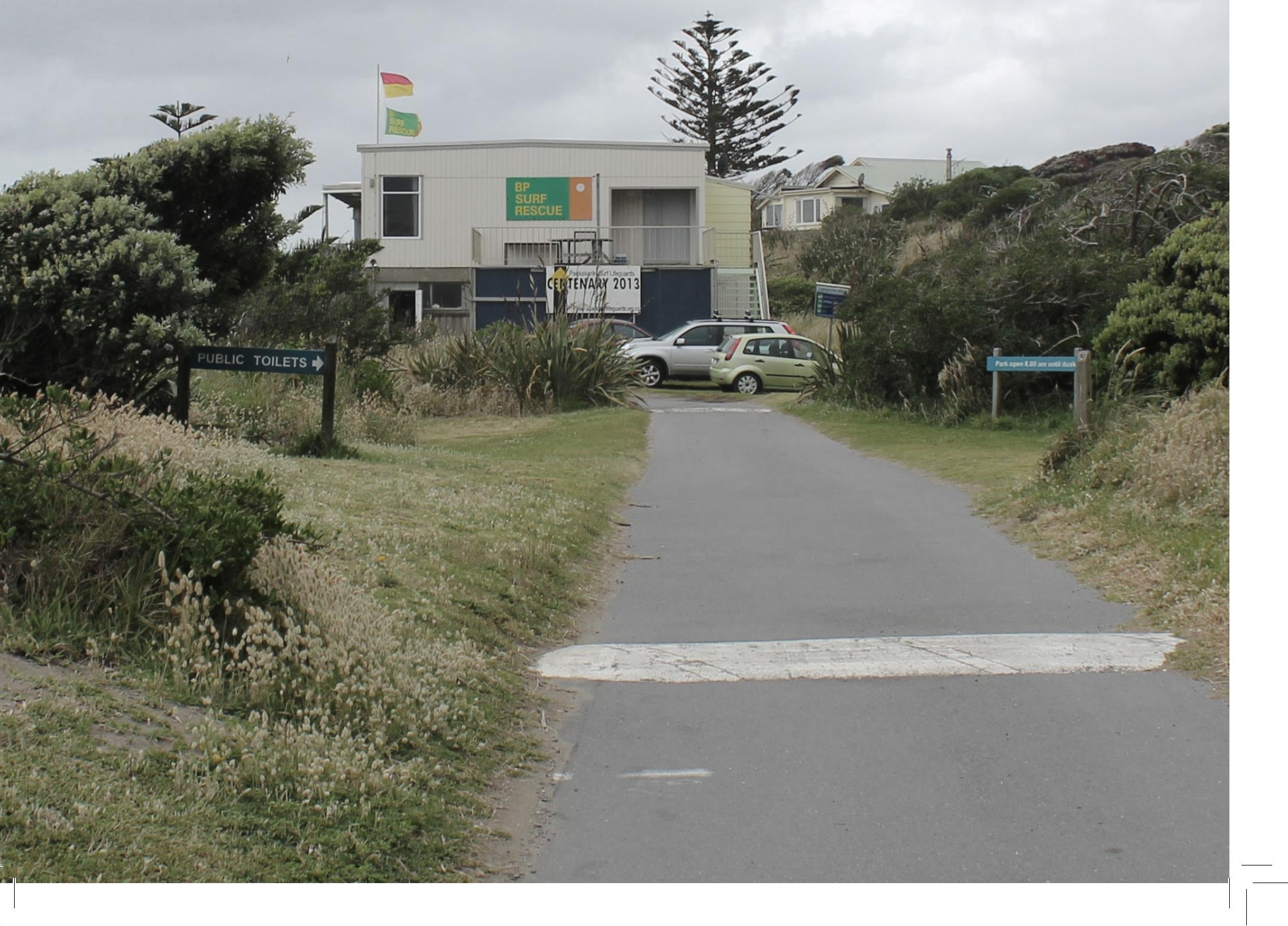



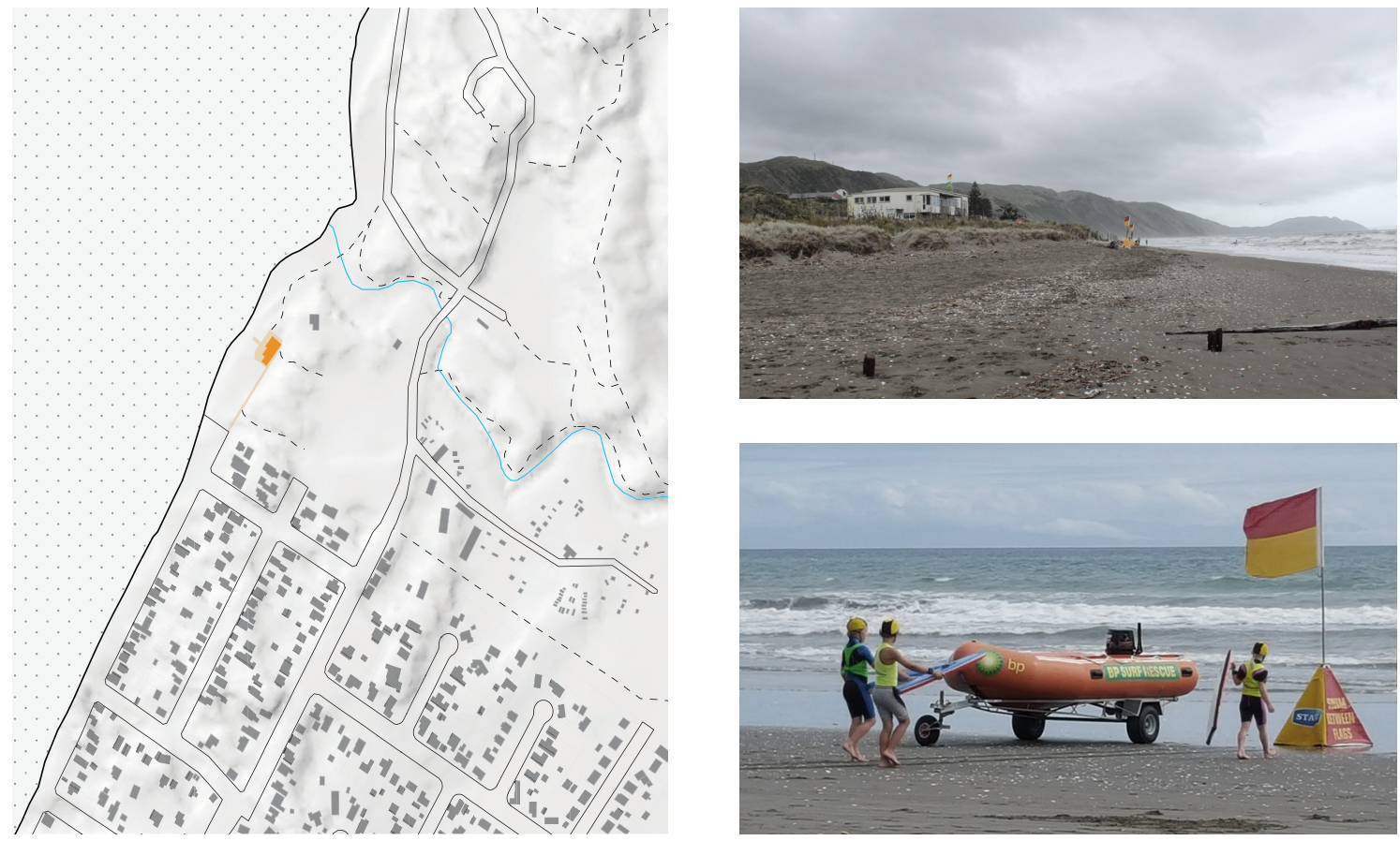

$\wedge$

Figure 14. Paekakariki Surf Club Location (left), and images of the Club in action (right).

The Paekakariki Surf Club, established in 1913, has a long-standing history on Paekakariki Beach (Paekakariki Surf Lifeguards). Recently celebrating their centenary, the club building is in much need of some remedial work. Currently located on the beach, the club is hoping to shift back onto the site in retreat from the rising sea level and coastal erosion. This proposal raises an issue around property ownership as Queen Elizabeth Park completely surrounds the clubhouse. 


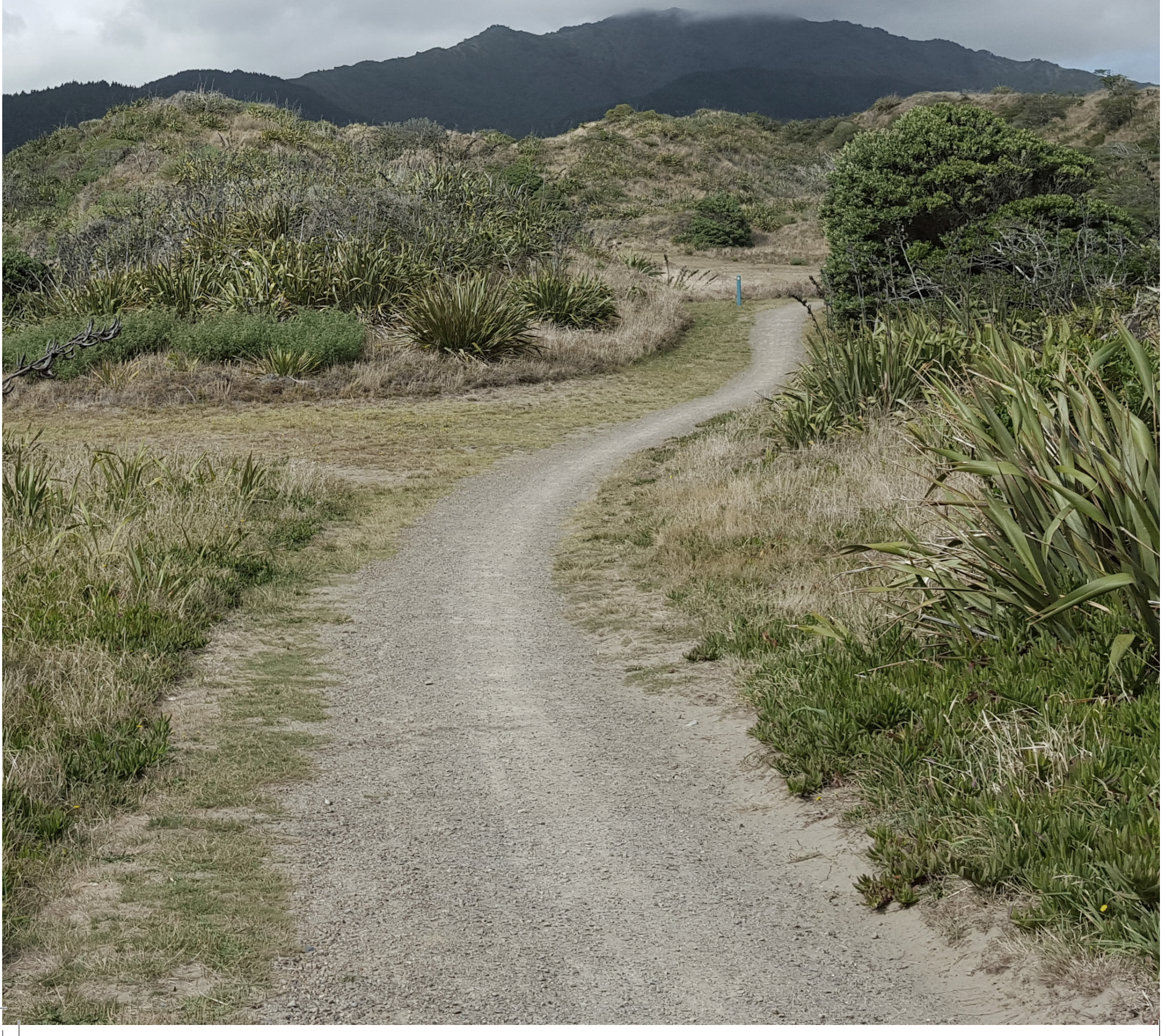



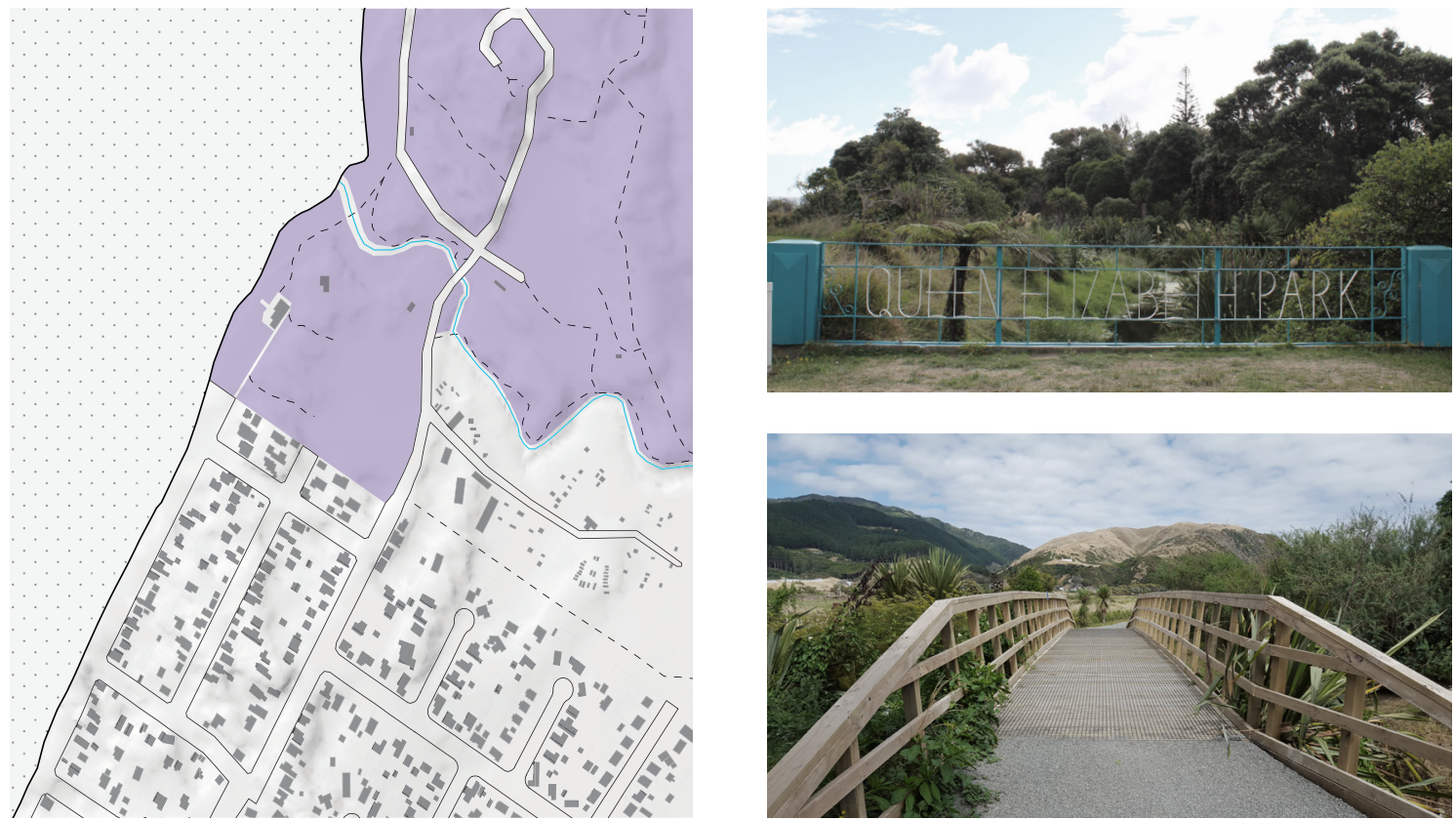

Figure 16. Queen Elizabeth Park Location (left), and images of Queen Elizabeth Park (right).

Queen Elizabeth Park is a recreational park that spans between Paekakariki and South Raumati. The park has a complex history. There are two Pa sites, Wainui and Whareroa, and a memorial for the US Marines. The park is currently owned by the department of conservation and is managed by the Greater Wellington Regional Council (Queen Elizabeth Park, Resource Statement). It contains the last area of natural dunes on the coast and surrounds Paekakariki with a green belt. 
tis.

(1)

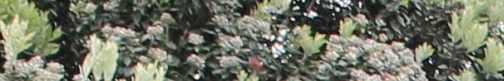

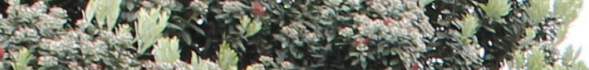

B.

1.2.

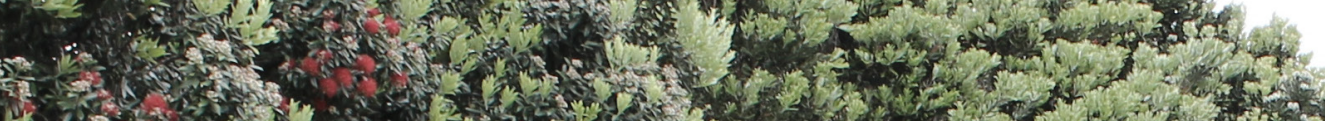

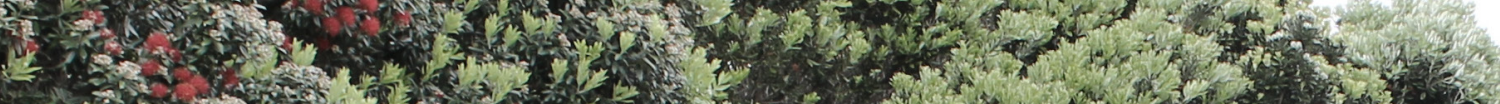

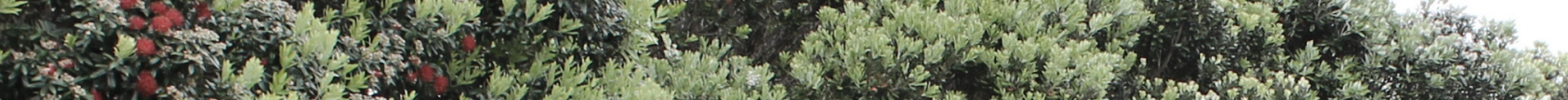

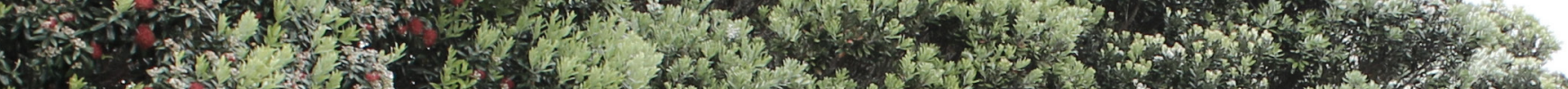

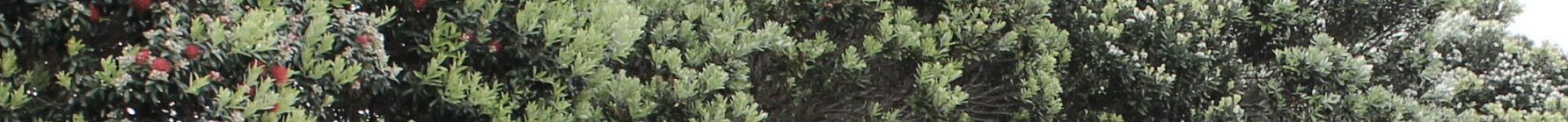

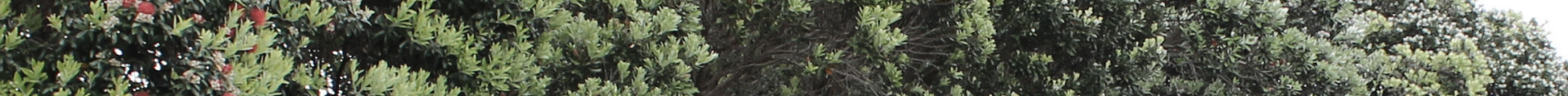

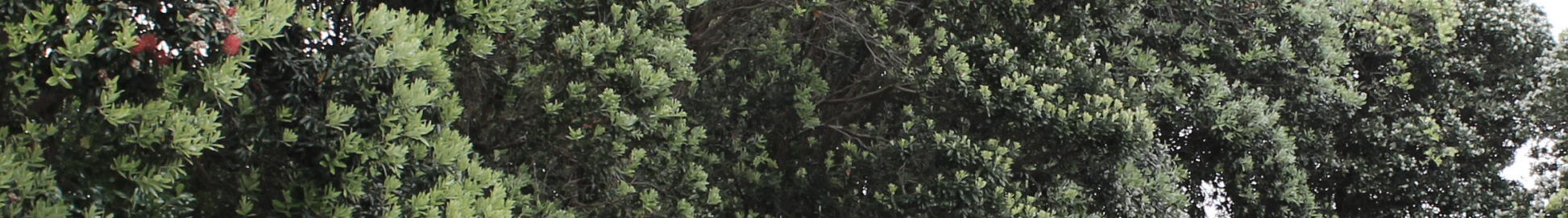

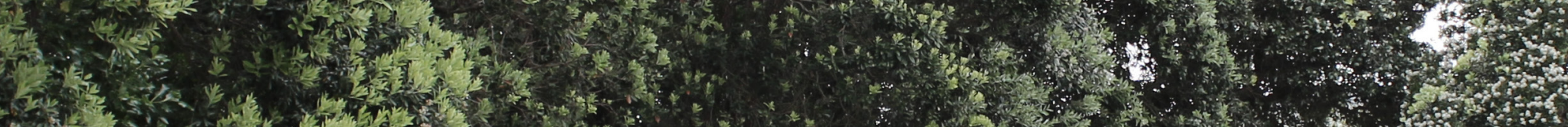

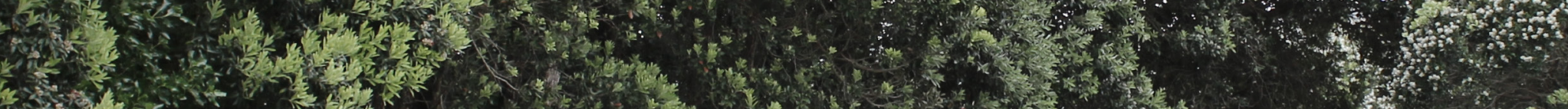

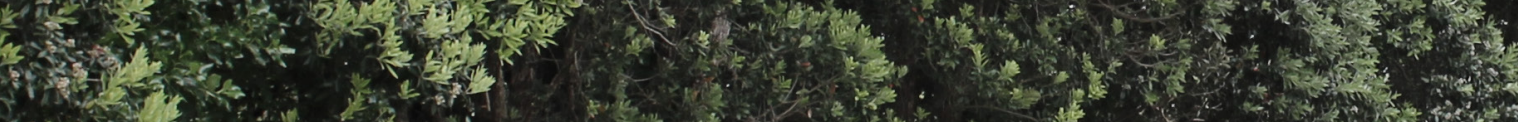

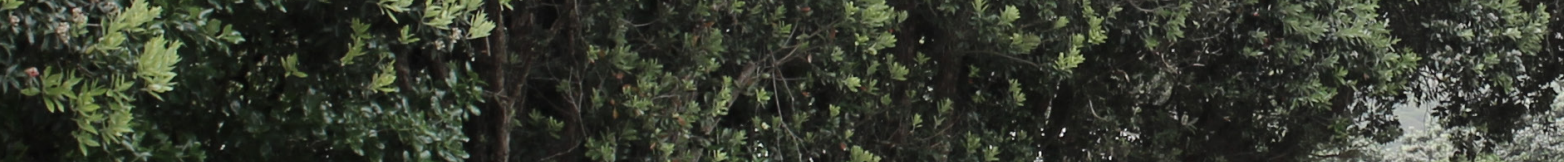

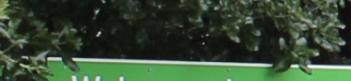
(3): Welcome to....

E.

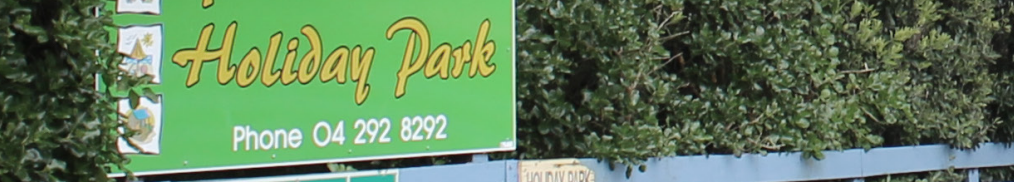

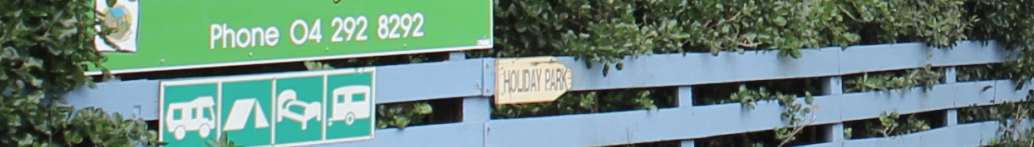
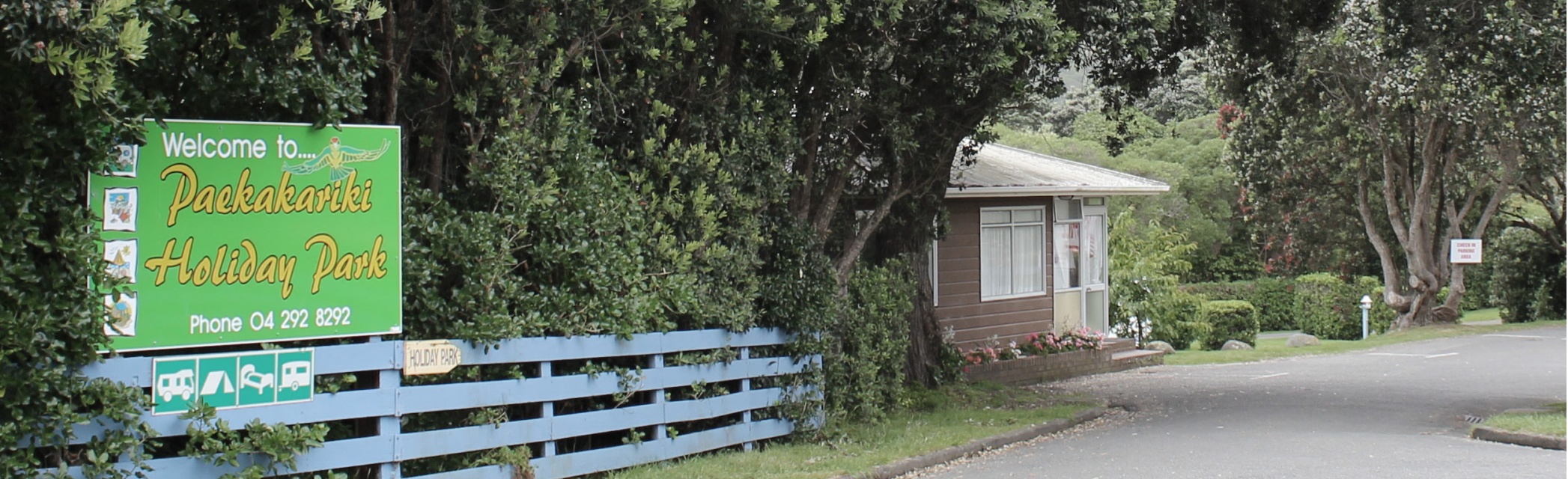

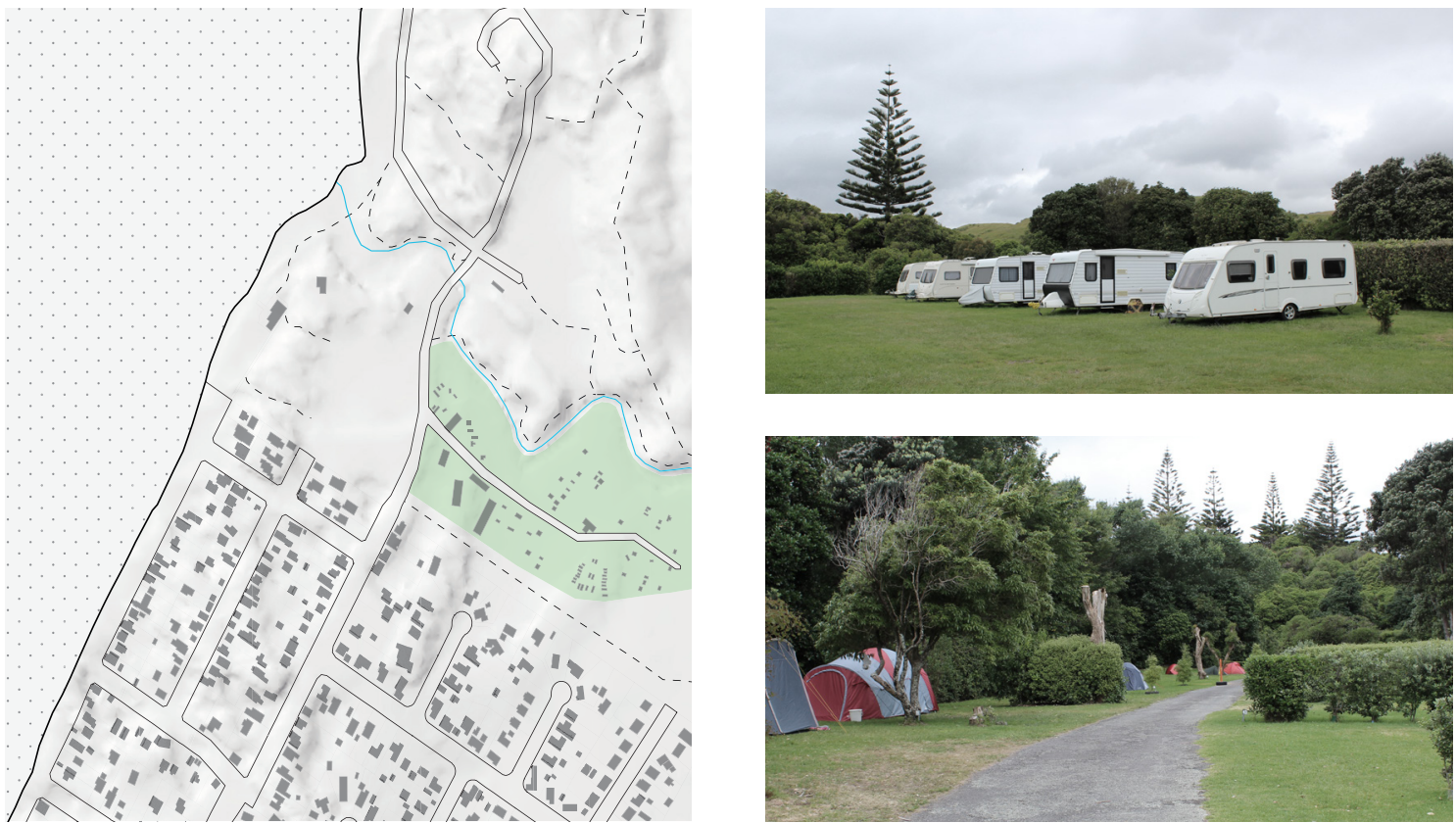

$\wedge$

Figure 18. Paekakariki Holiday Park Location (left), and images of Queen Elizabeth Park (right).

The Paekakariki Holiday Park is a popular destination, especially for those travelling through to Wellington. It is one of the few campgrounds before arriving into the city. Due to its location, visitors of the Holiday Park use the site for its access to the beach.

Ngati Haumia, a hapu of Ngati Toa, currently manage the Holiday Park (Paekakariki Holiday Park). 


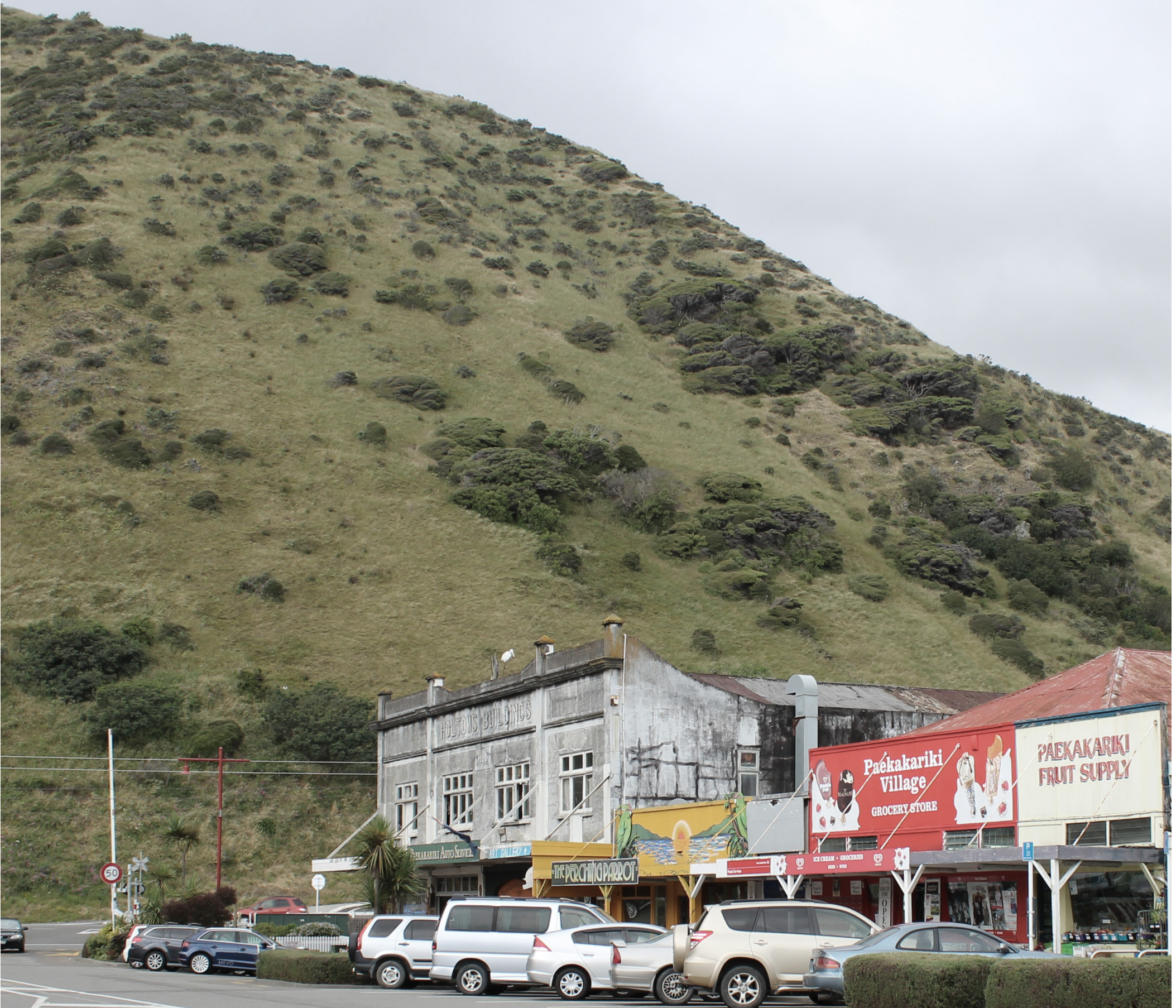



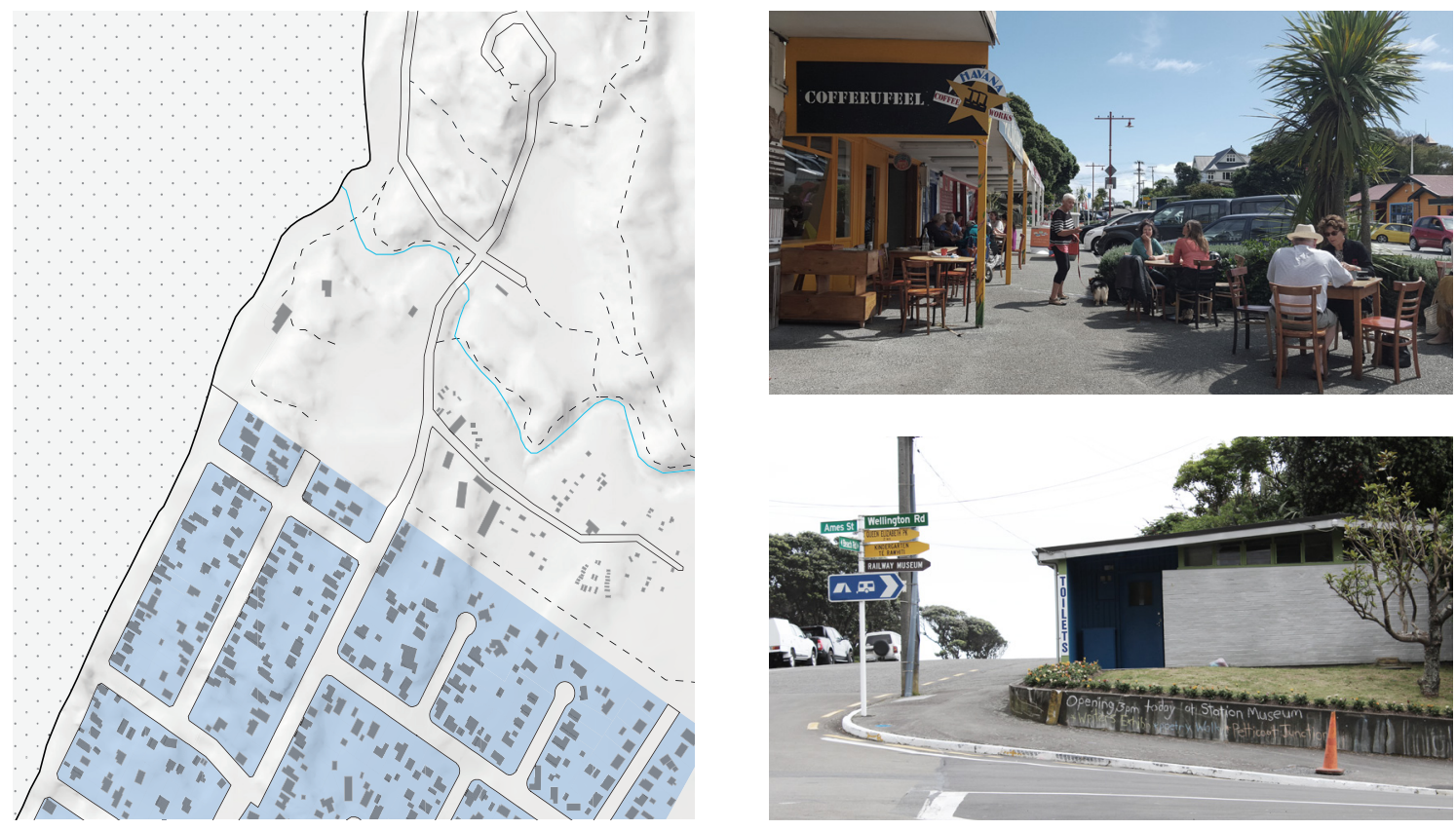

$\wedge$

Figure 20. Location of Paekakariki Residents (left), and Images of Paekakariki Residents (right).

Paekakariki is a small town with a population of 1,665 and only 705 occupied dwellings (Statistics NZ). In comparison to the rest of the Kapiti Coast, especially Waikanae which is known for having an older demographic, Paekakariki has a relatively young population. There is also a mixture of people that live in the town, ranging in ages, ethnicity, and wealth.

As a result of the town's diversity, Paekakariki has a very strong community that supports each other and rally together when required. There is even a local radio station which shares community information. 


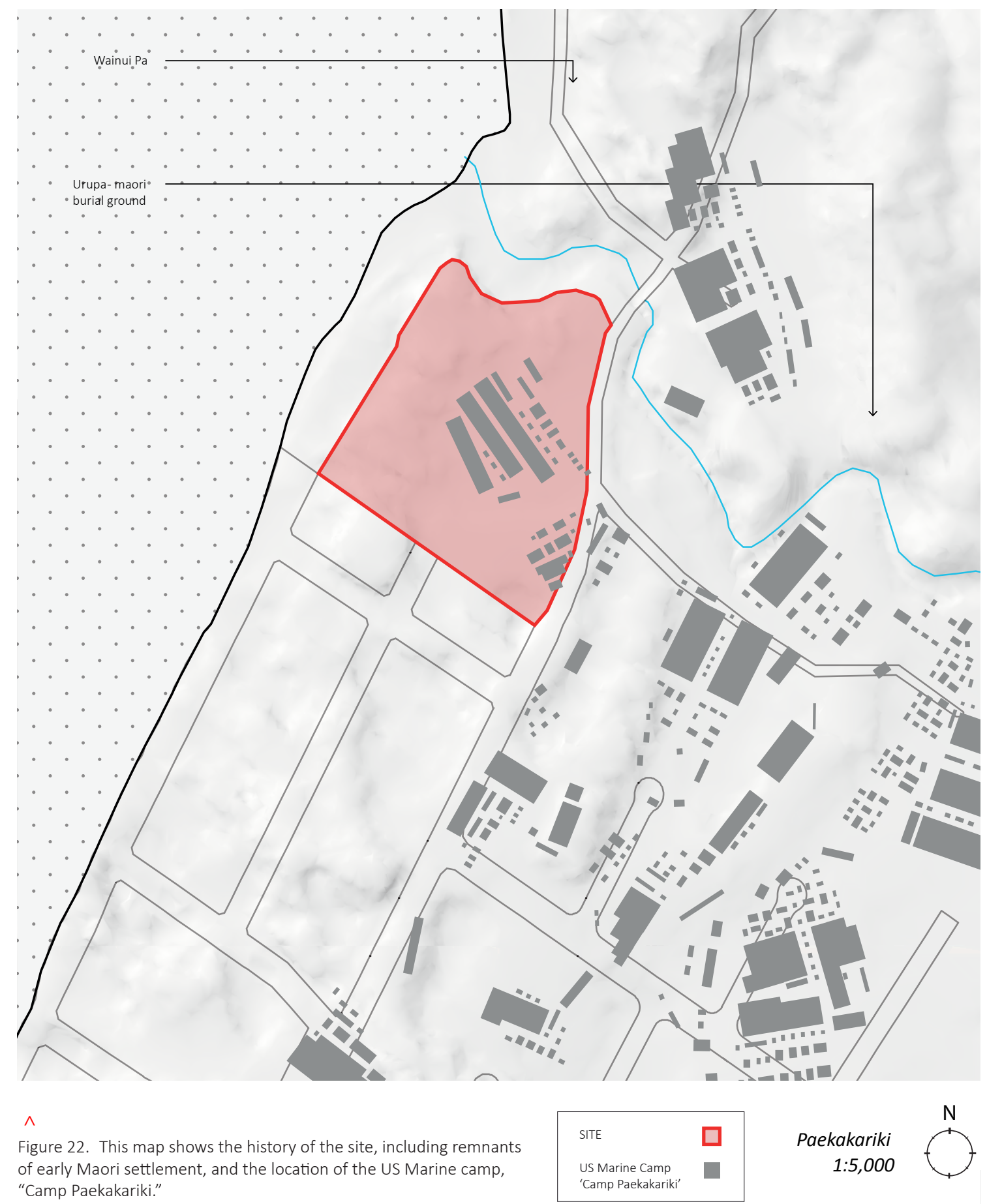




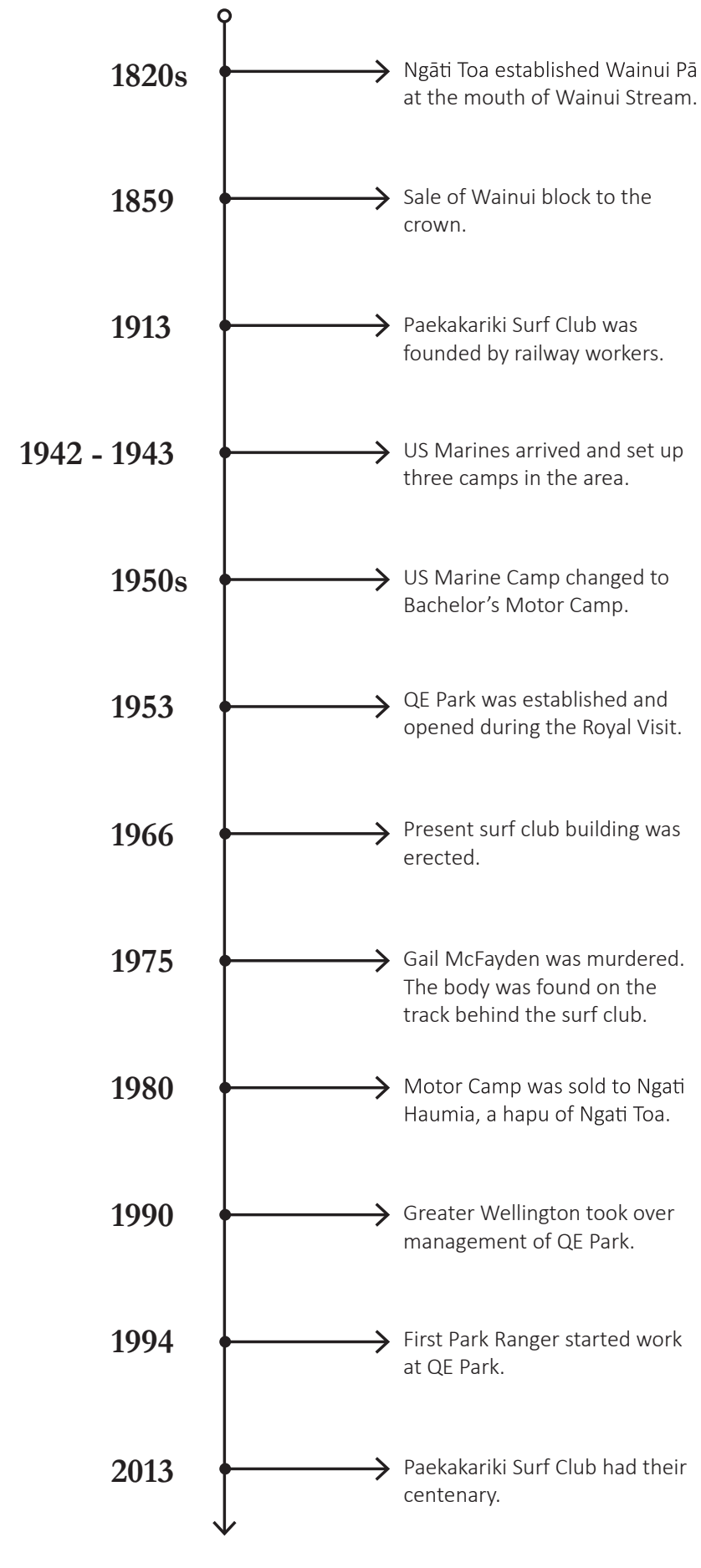

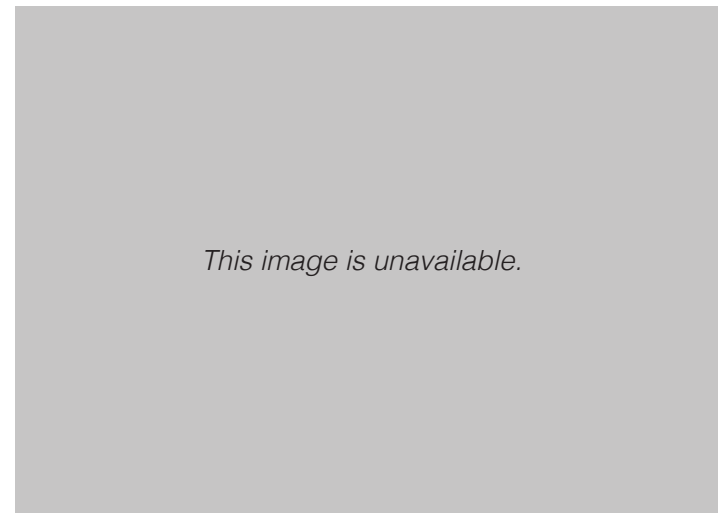

$\wedge$

Figure 24. Aerial photograph of Camp Paekakariki. Source: Kapiti Coast District Council.
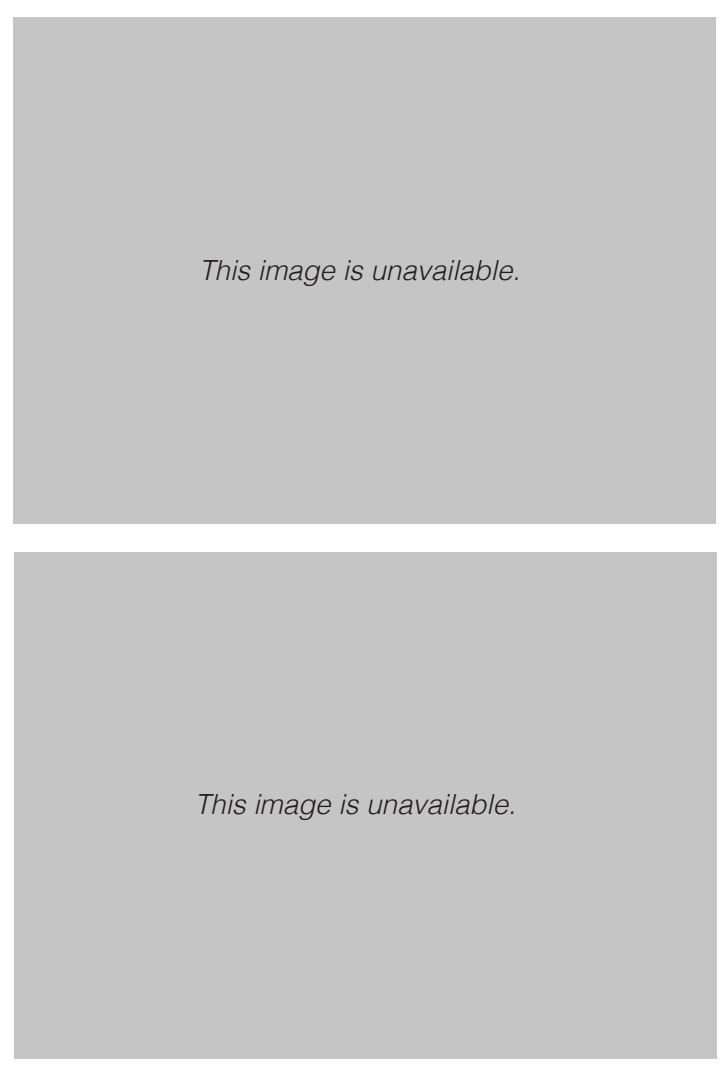

$\wedge$

Figure 23. Paekakariki Surf Club photographed in the 1920s. Source: A crowd at the Surf Club (bottom), Paekakariki Beach (top). 


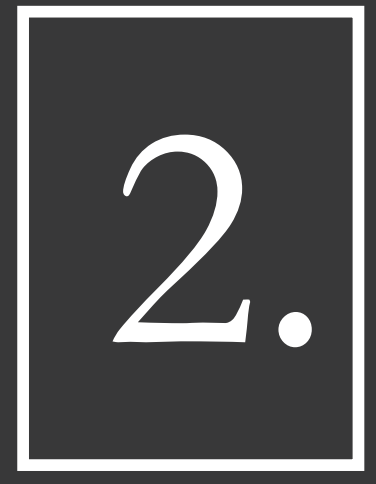




\section{a circular \\ building}




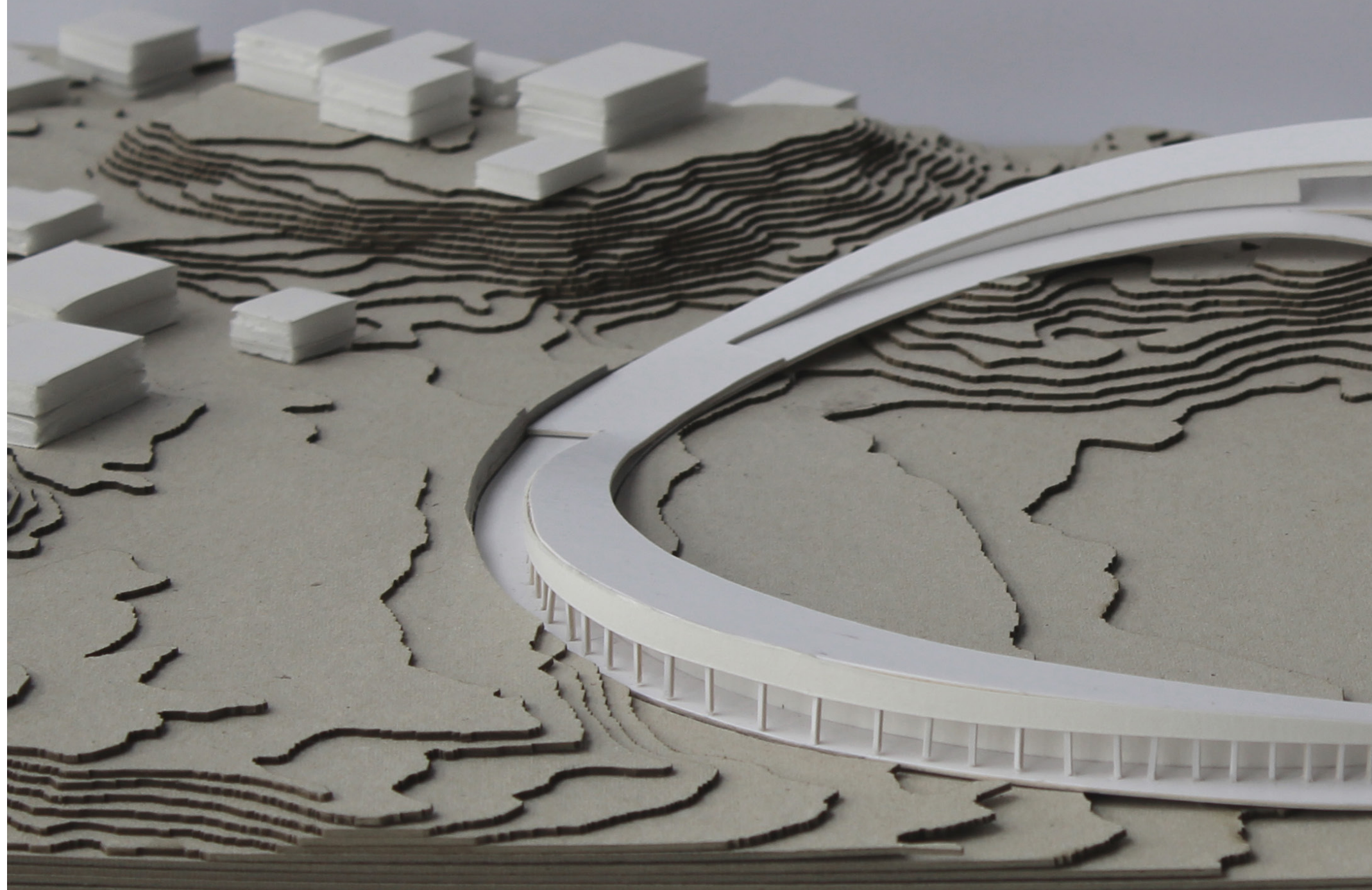



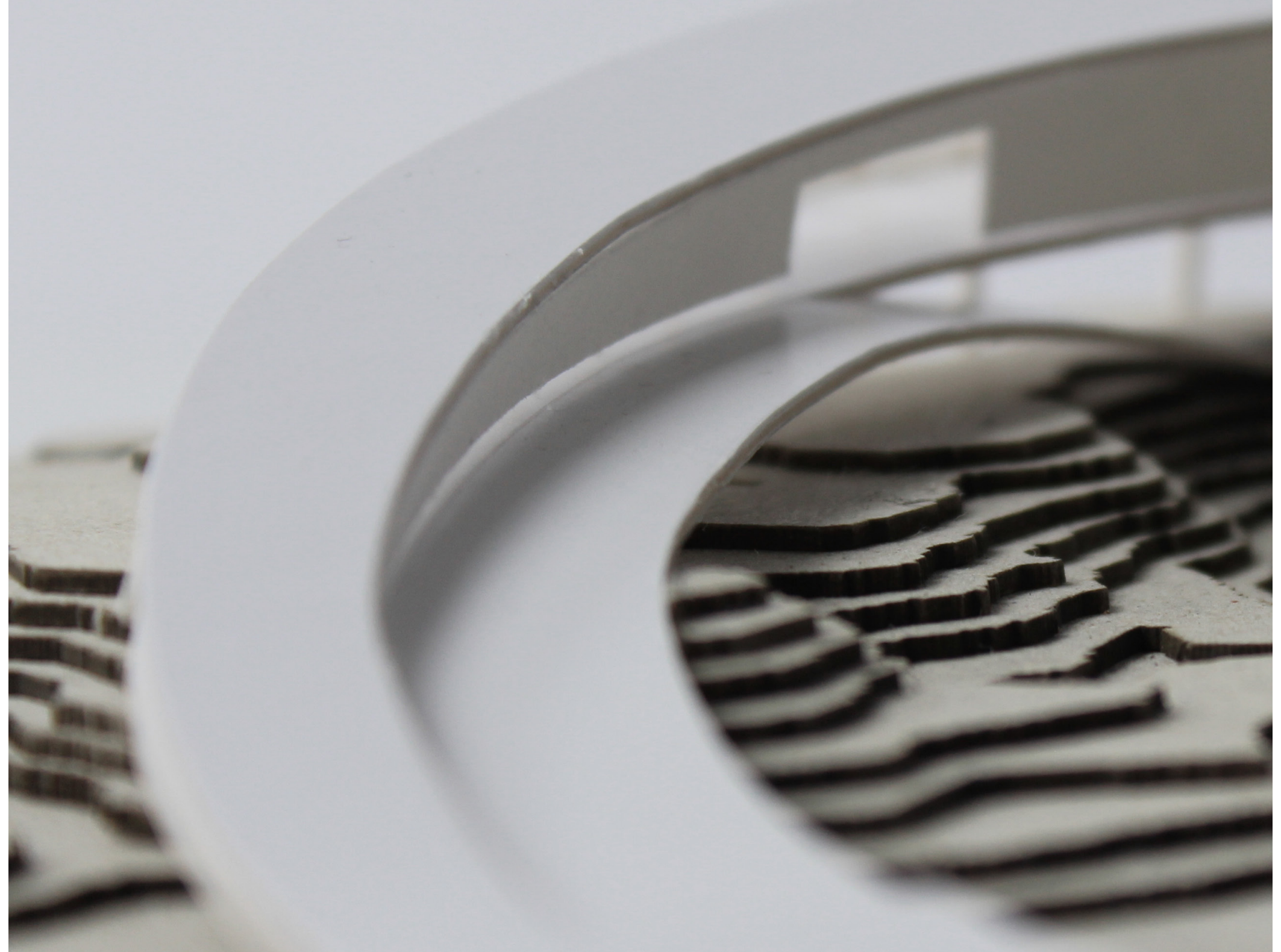
The final scheme for this thesis is a circular building which brings together the different communities on the site. The building is one continuous undulating loop with two high points facing each other on the western and eastern sides and two low points on the northern and southern. One high point fronts the road, and the other sits above the dunes facing the ocean. The road side is a double height space with a ramping mezzanine floor. This is occupied by a coffee shop, a book shop and a flexible gallery space.

The seaside face is single storied and houses the Surf Club and the Queen Elizabeth Park Ranger. These two high points are connected with a ramp which runs underground to form public toilets, changing room spaces, storage for the stage/exhibition space, and a workshop for the Park Ranger.

The roof of the building is designed as a boardwalk allowing people to walk, run or bike over and around the structure. This also creates a connection between the beach, QE Park and one of the side roads entering onto the site.

On the inside edge of the circle there is an open air stage. This gives the communities an opportunity to hold events. The form encourages people to gather through its inwards focus. The centre of the circle has been retained as an open grass field designed to encourage flexibility as a market space, for concerts, or even to play a game of cricket. 



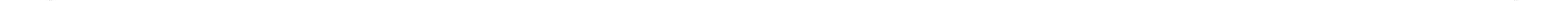



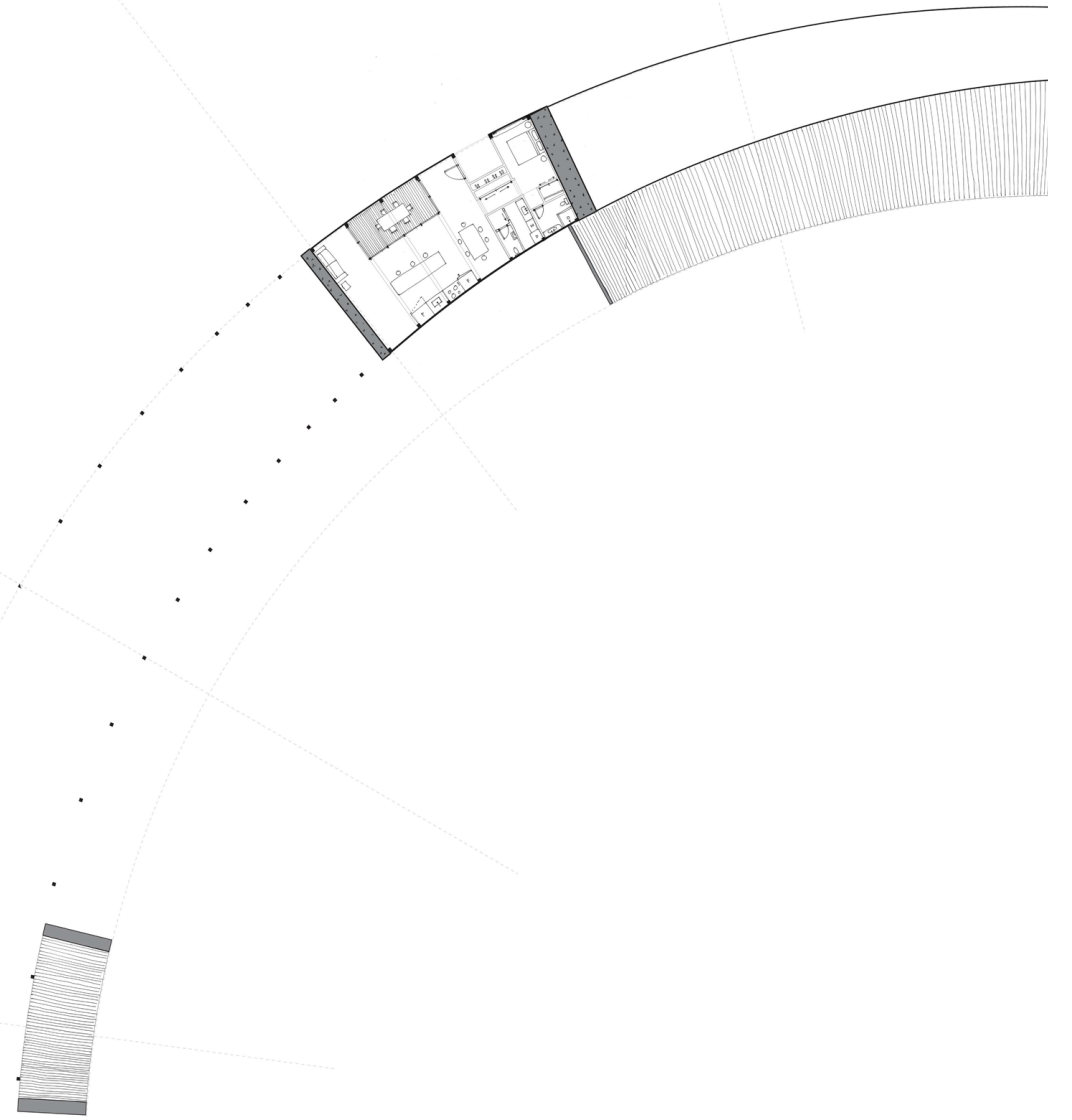

$$
\text { . }
$$

$$
\text { . }
$$$$
\cdot \cdot
$$$$
\cdot
$$

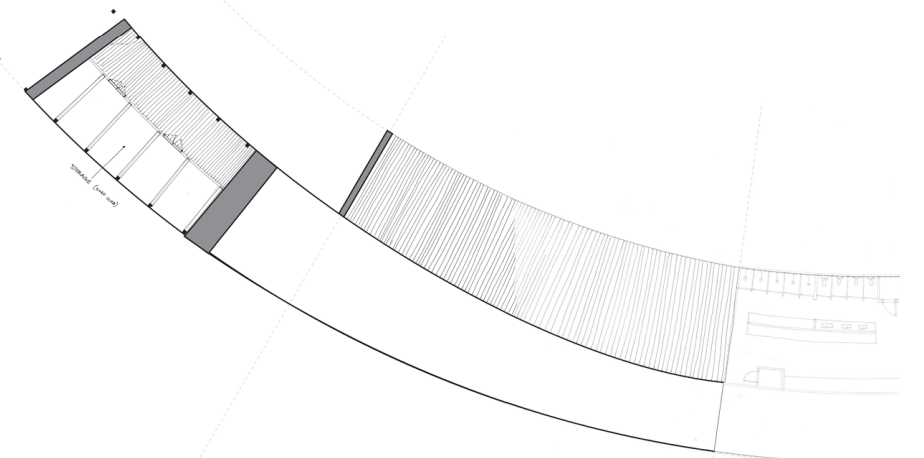

Figure 28. Ground Floor Plan - Whole Building 


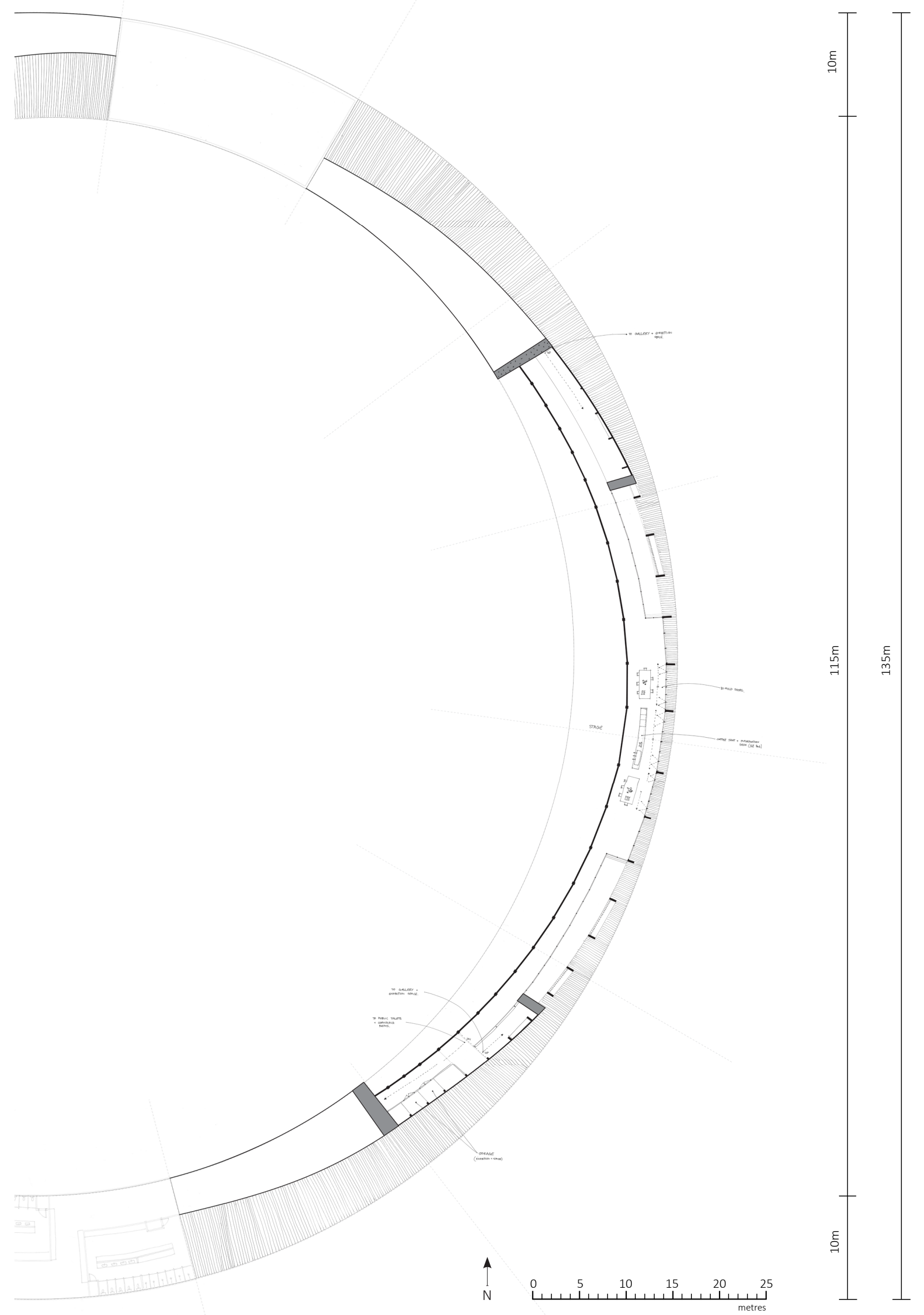




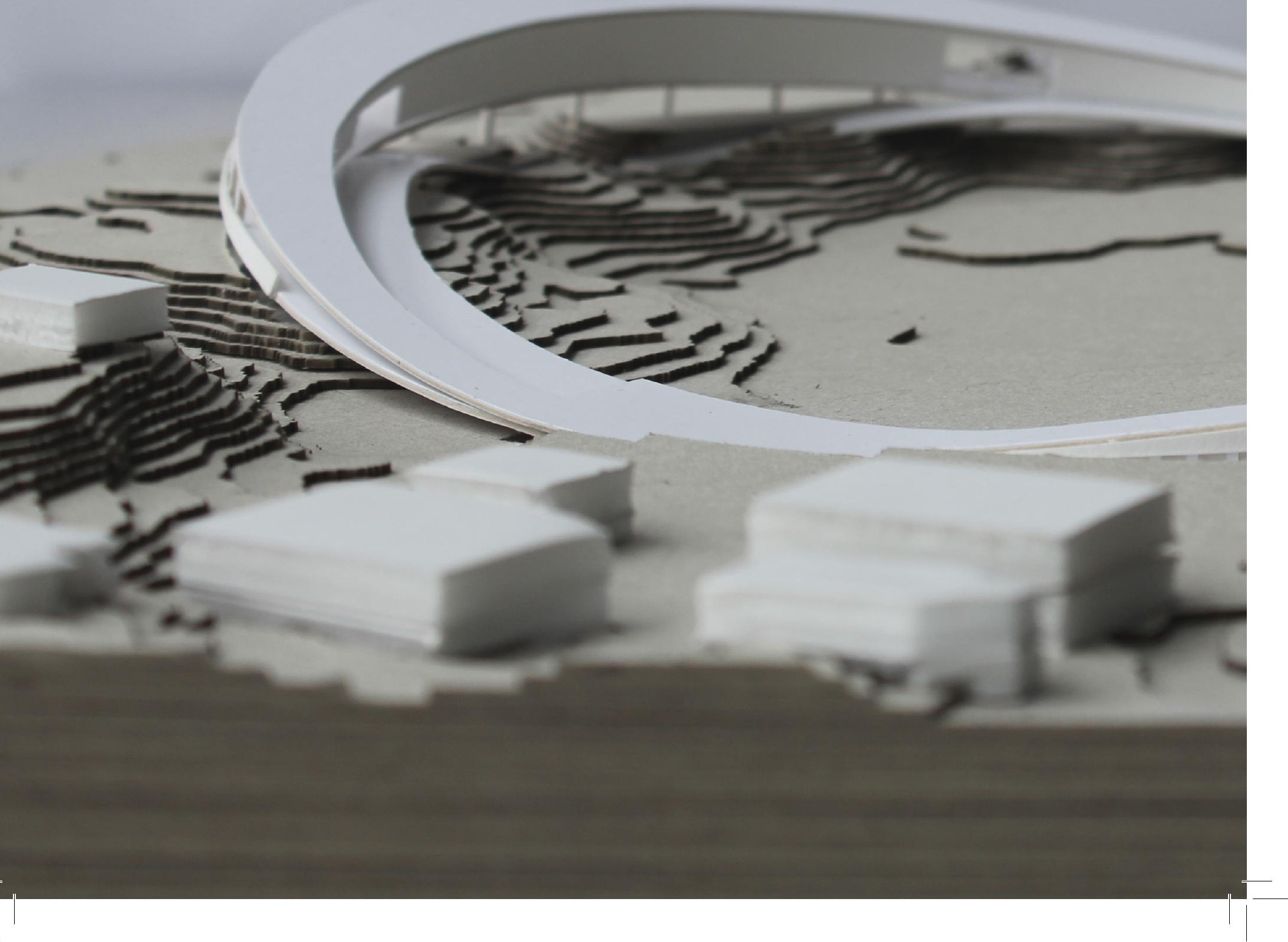




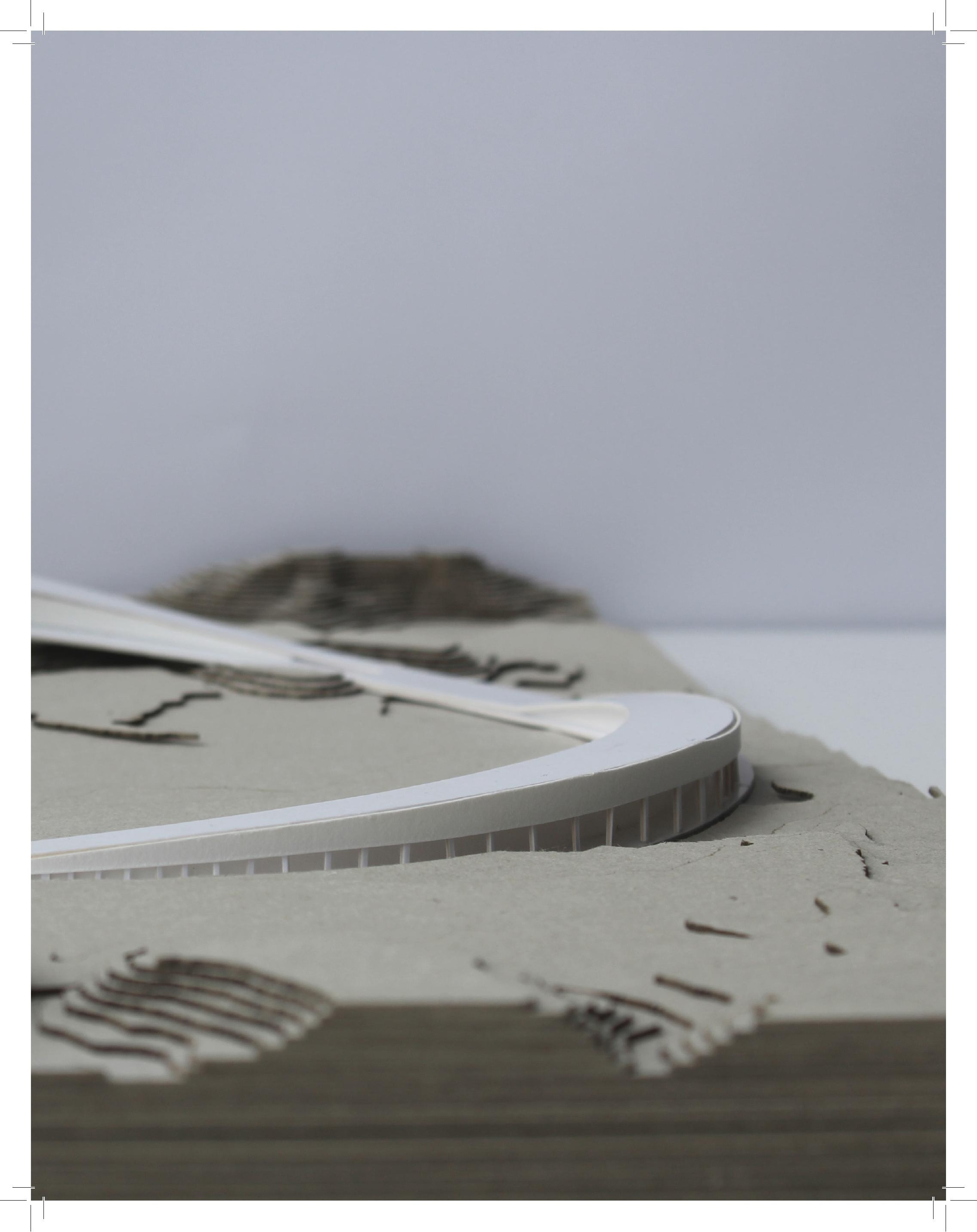




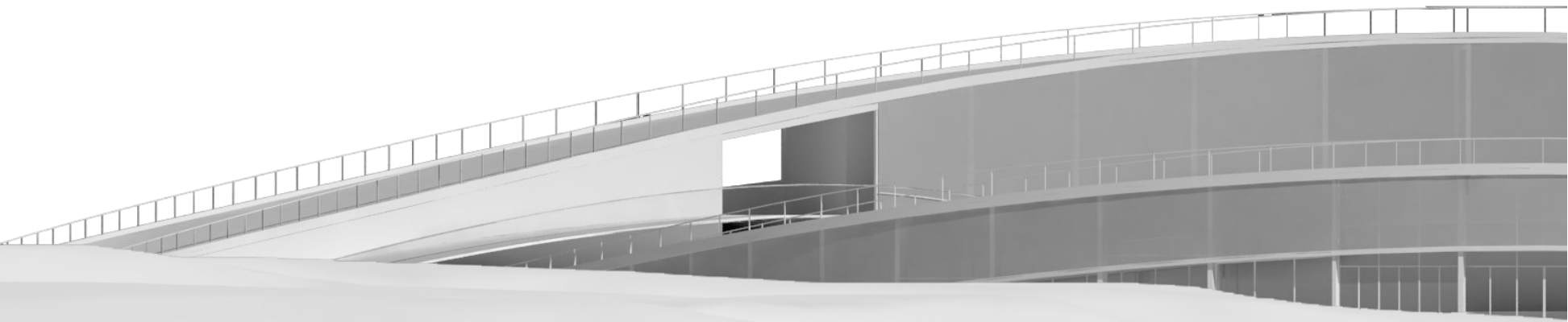

Figure 30. Roadside Elevation - The upper panel is to provide shading to the exhibition space behind 


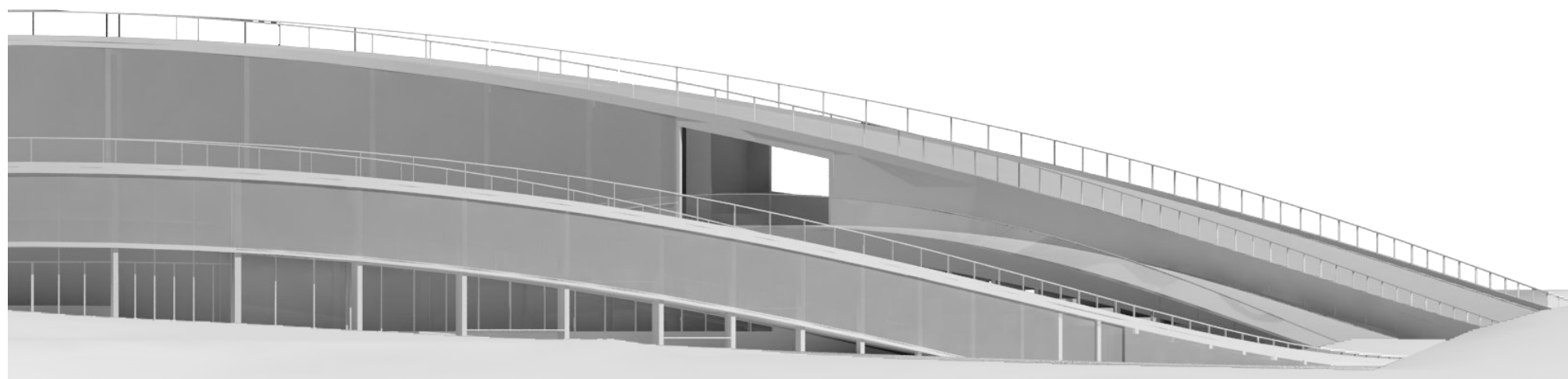




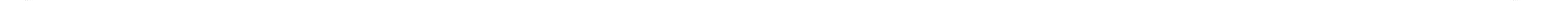




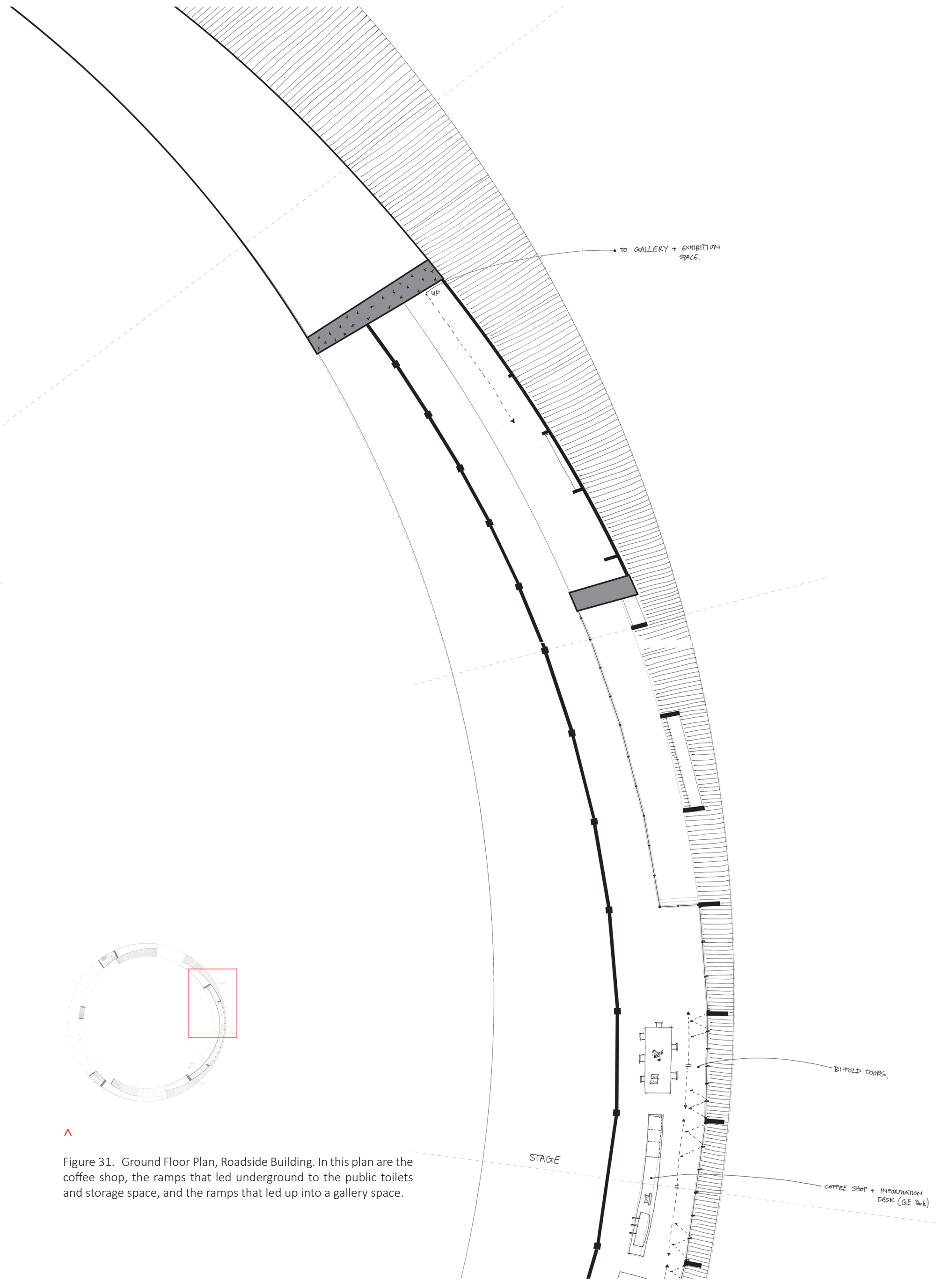




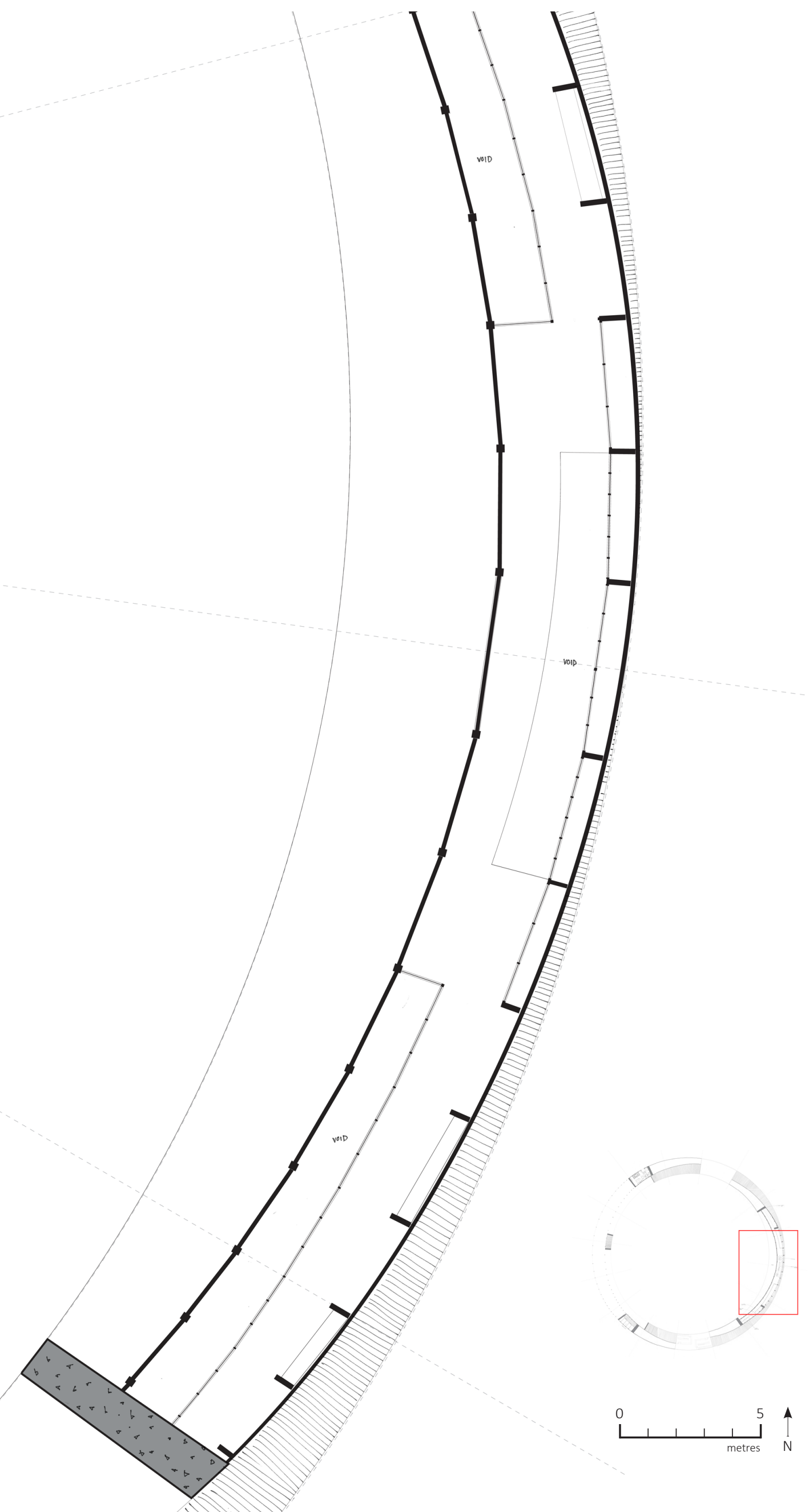




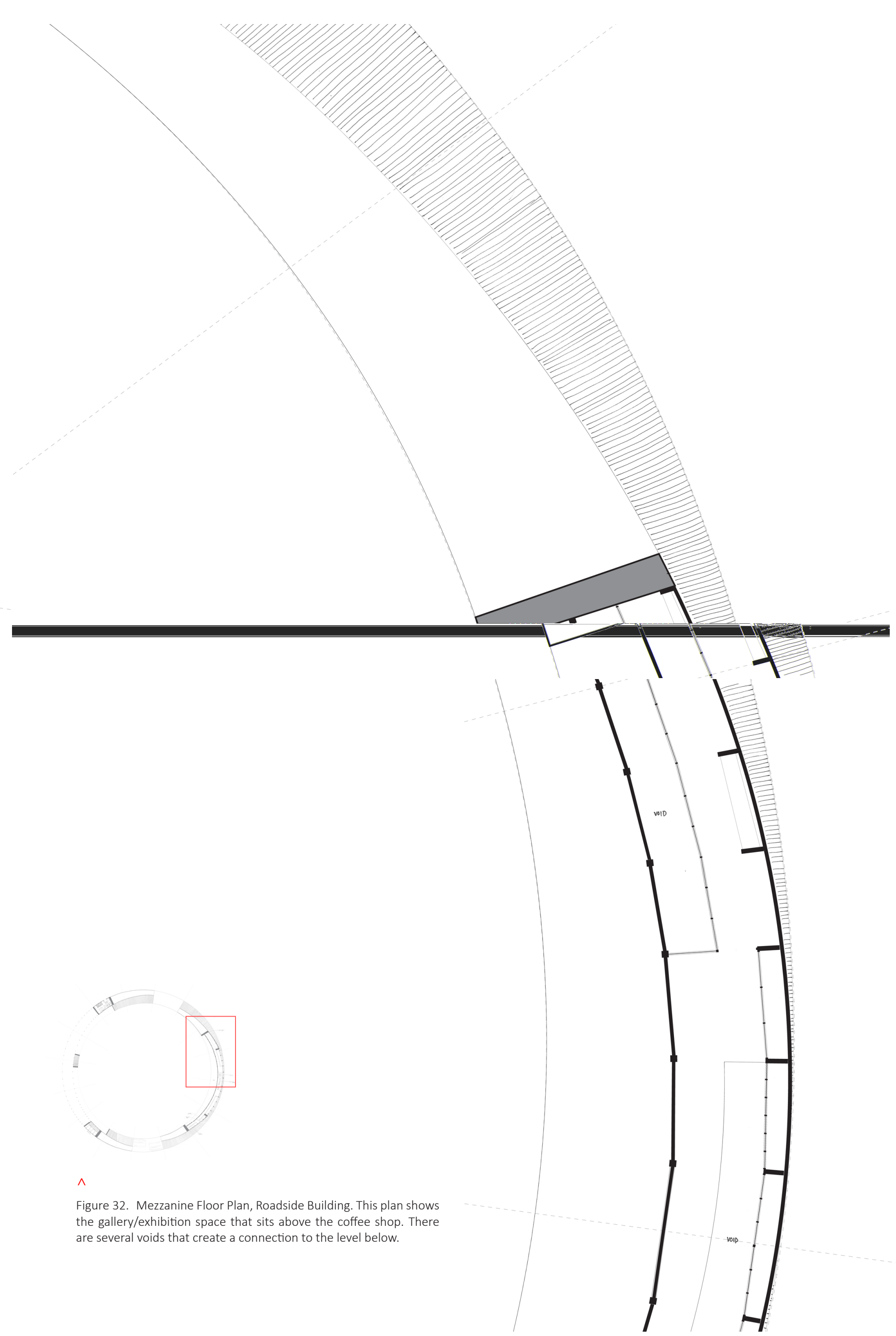



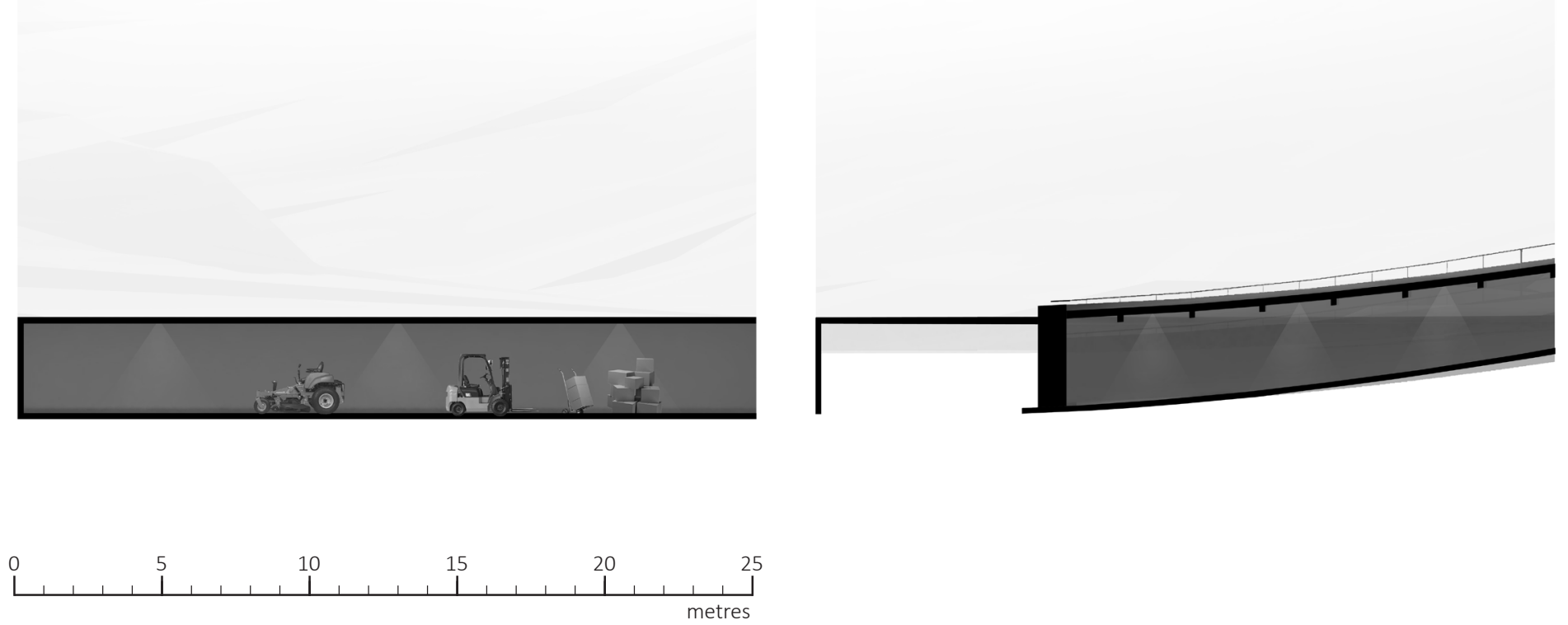

$\wedge$

Figure 33. Stitched Section through Roadside Building showing the high and low points along the circle.

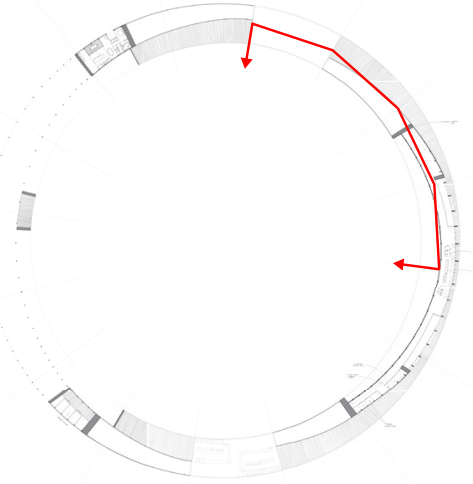



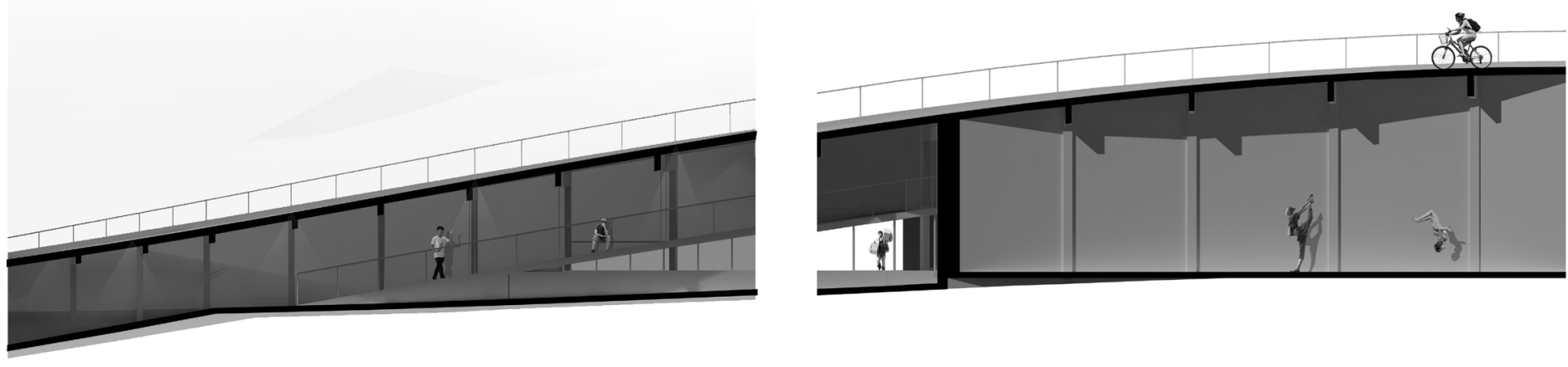

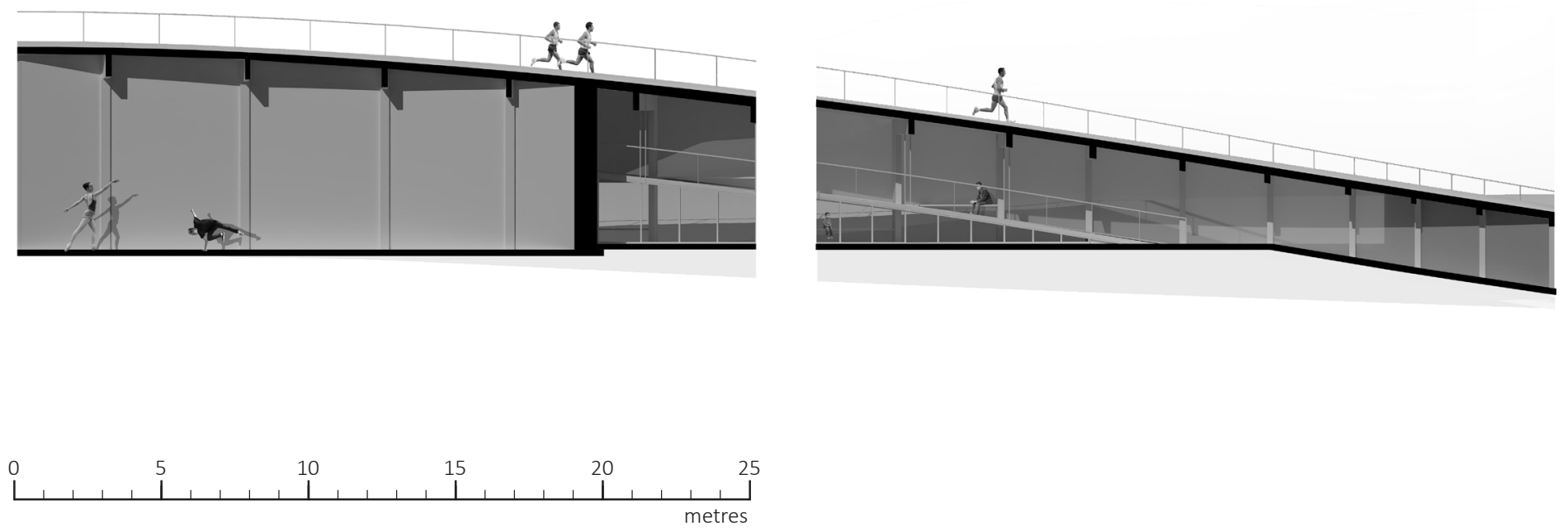

$\wedge$

Figure 34. Stitched Section through Roadside Building.

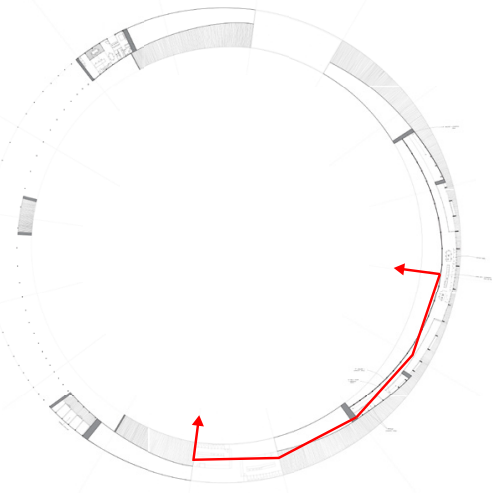




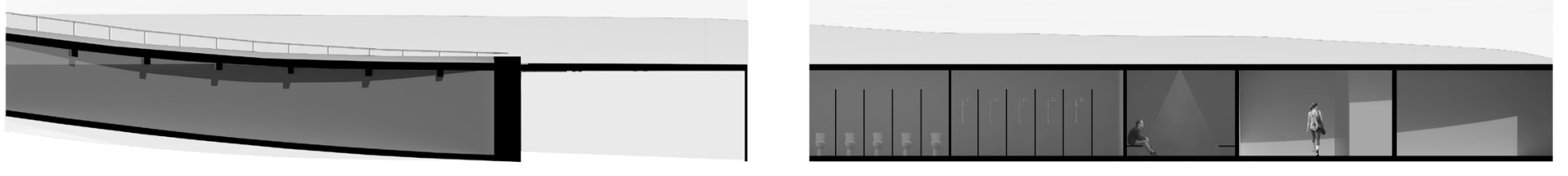




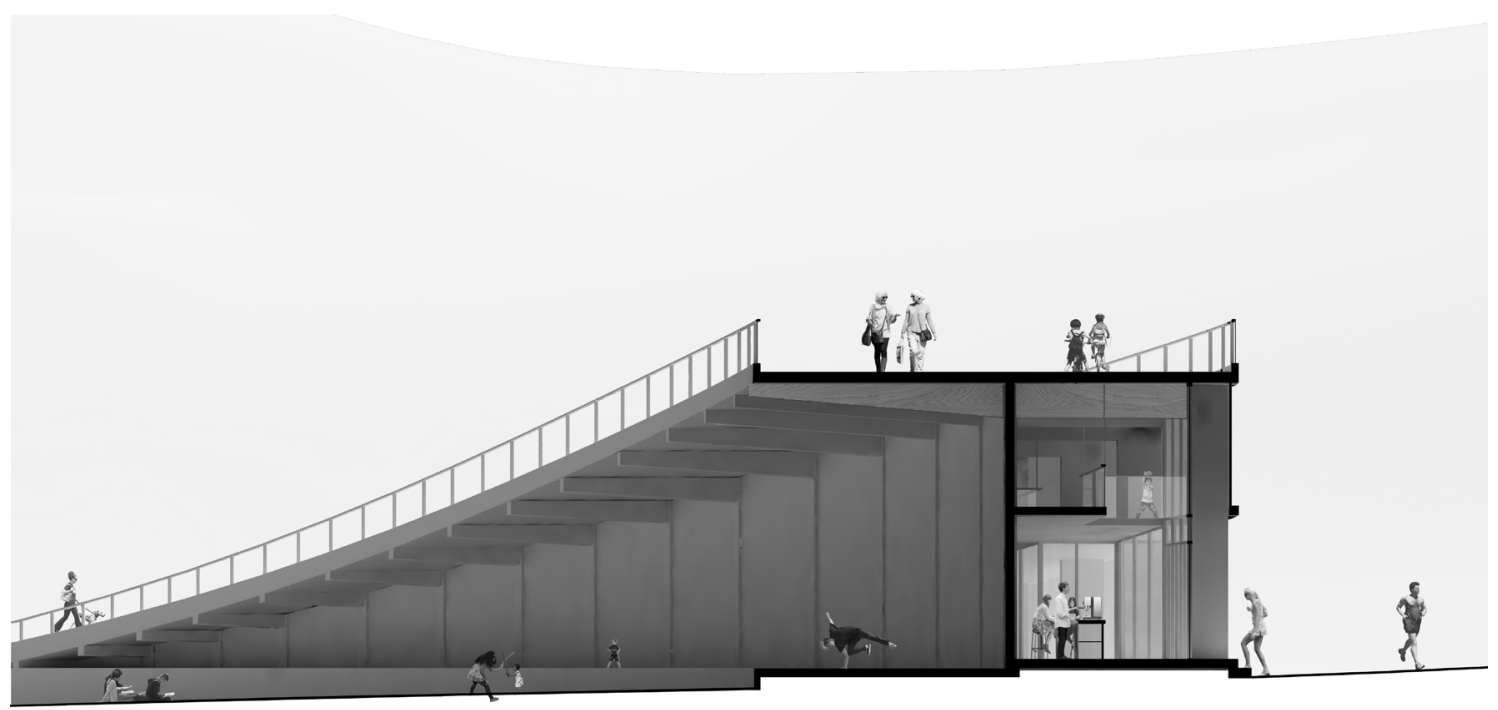

Figure 35. Transverse Section through Roadside Building.

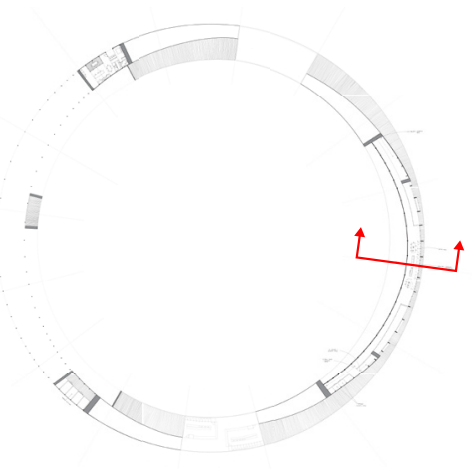




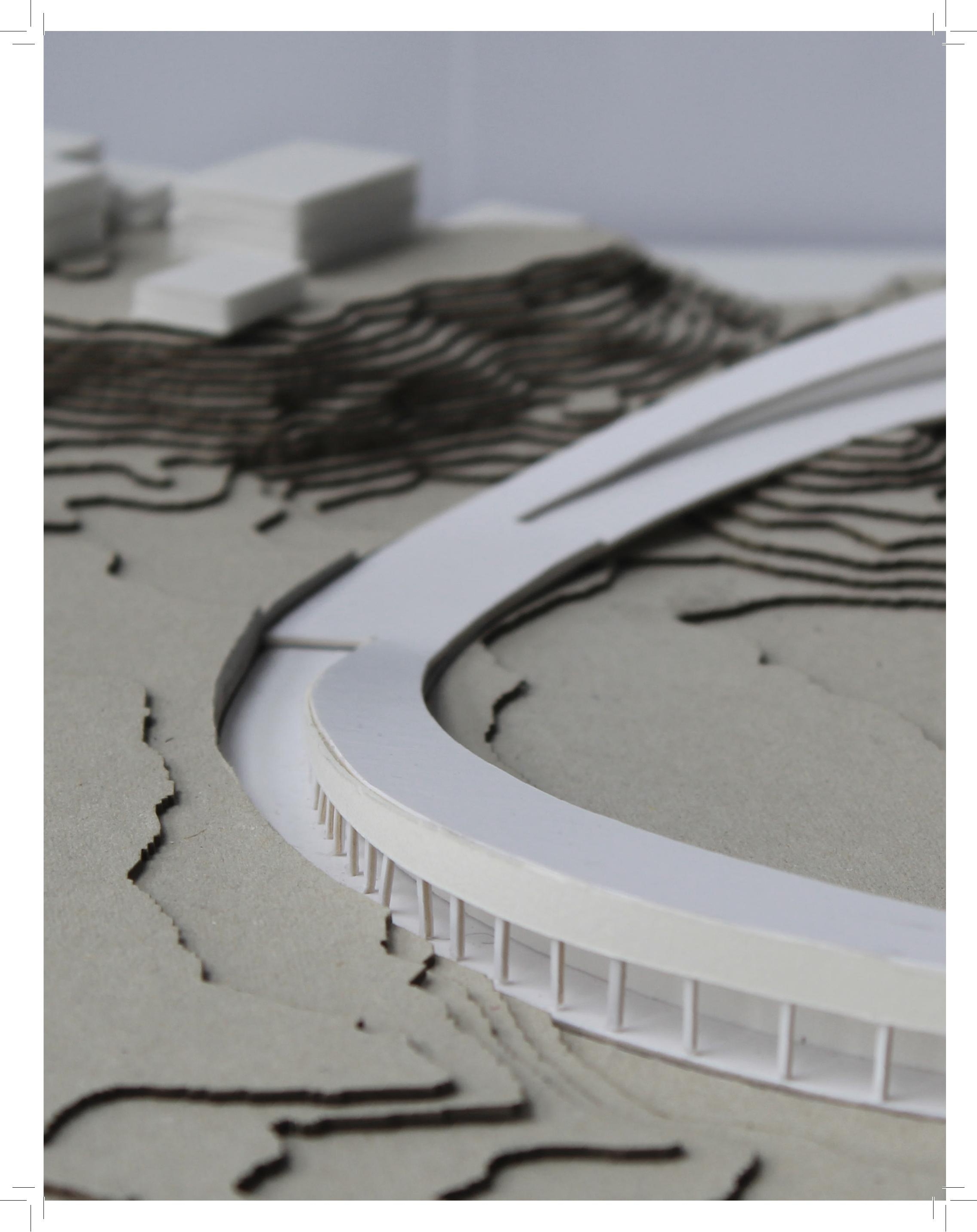




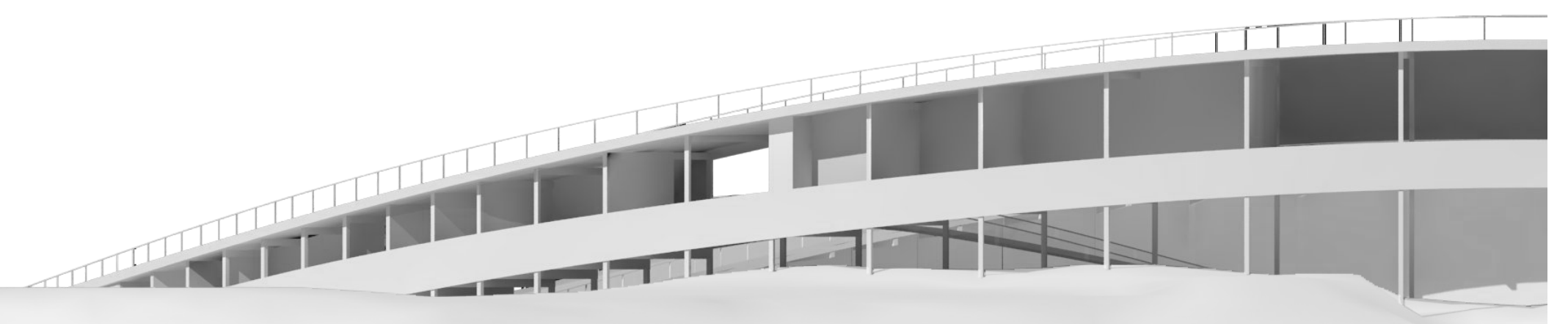

$\wedge$

Figure 37. Seaside Elevation - this drawing shows the building raised up above the dunes. The curving spandrel is to help maintain the sloping aesthetic despite the offsetting floor behind. 


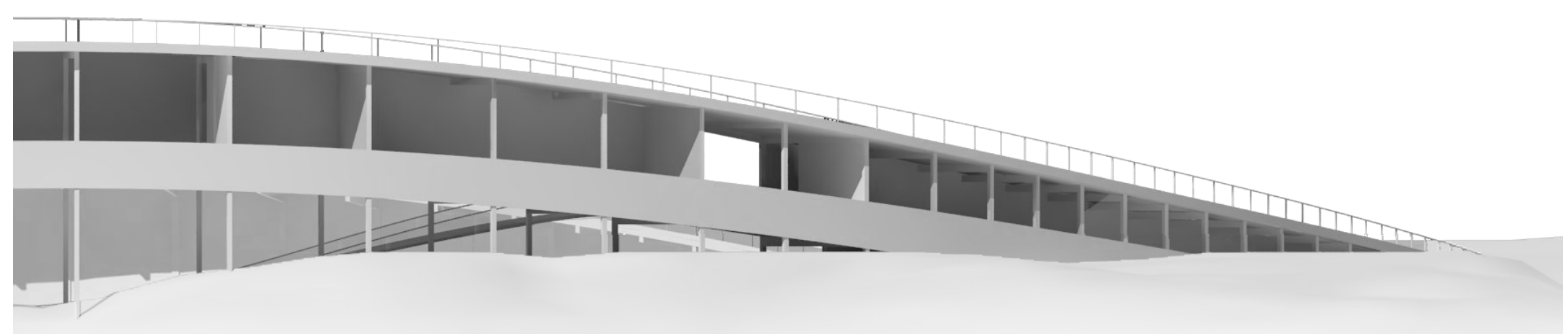




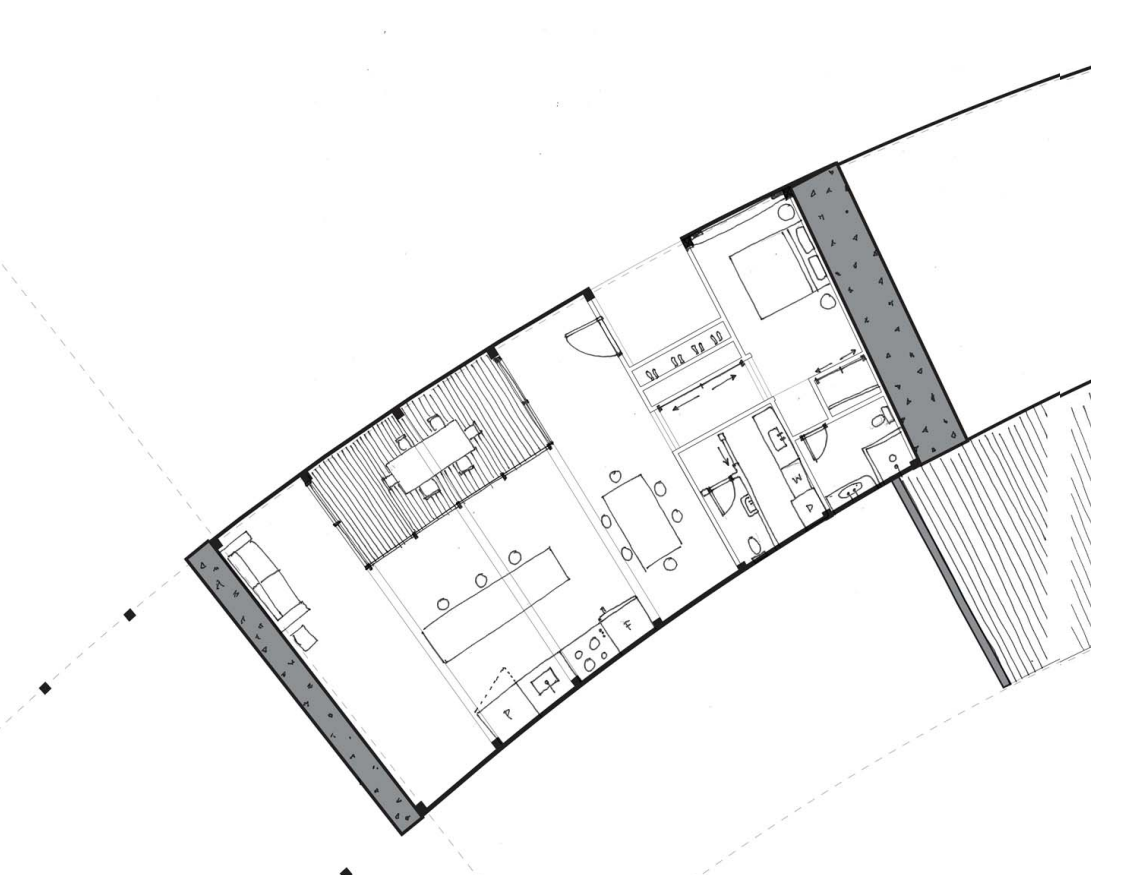





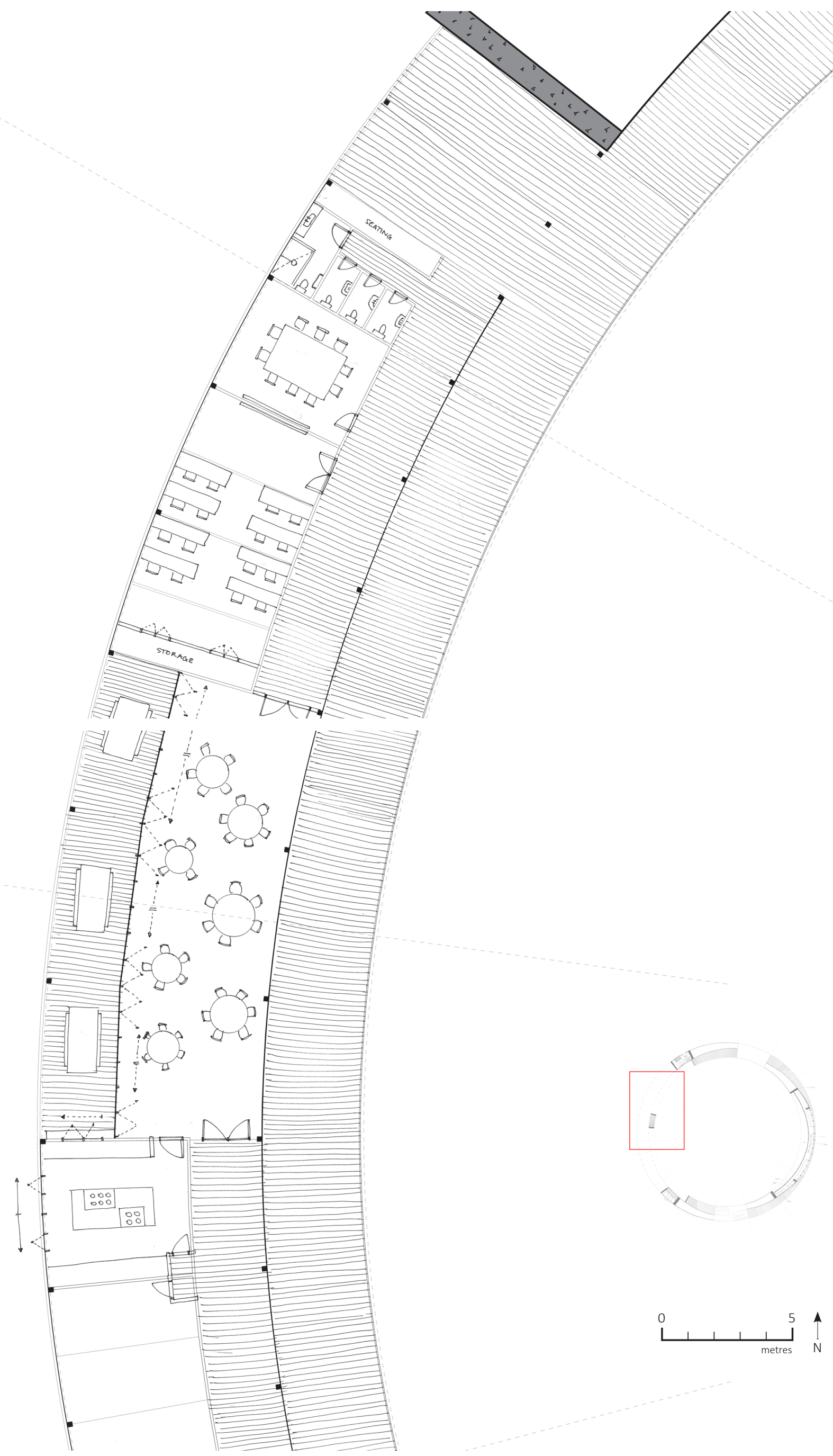


$\underbrace{}_{-y}$

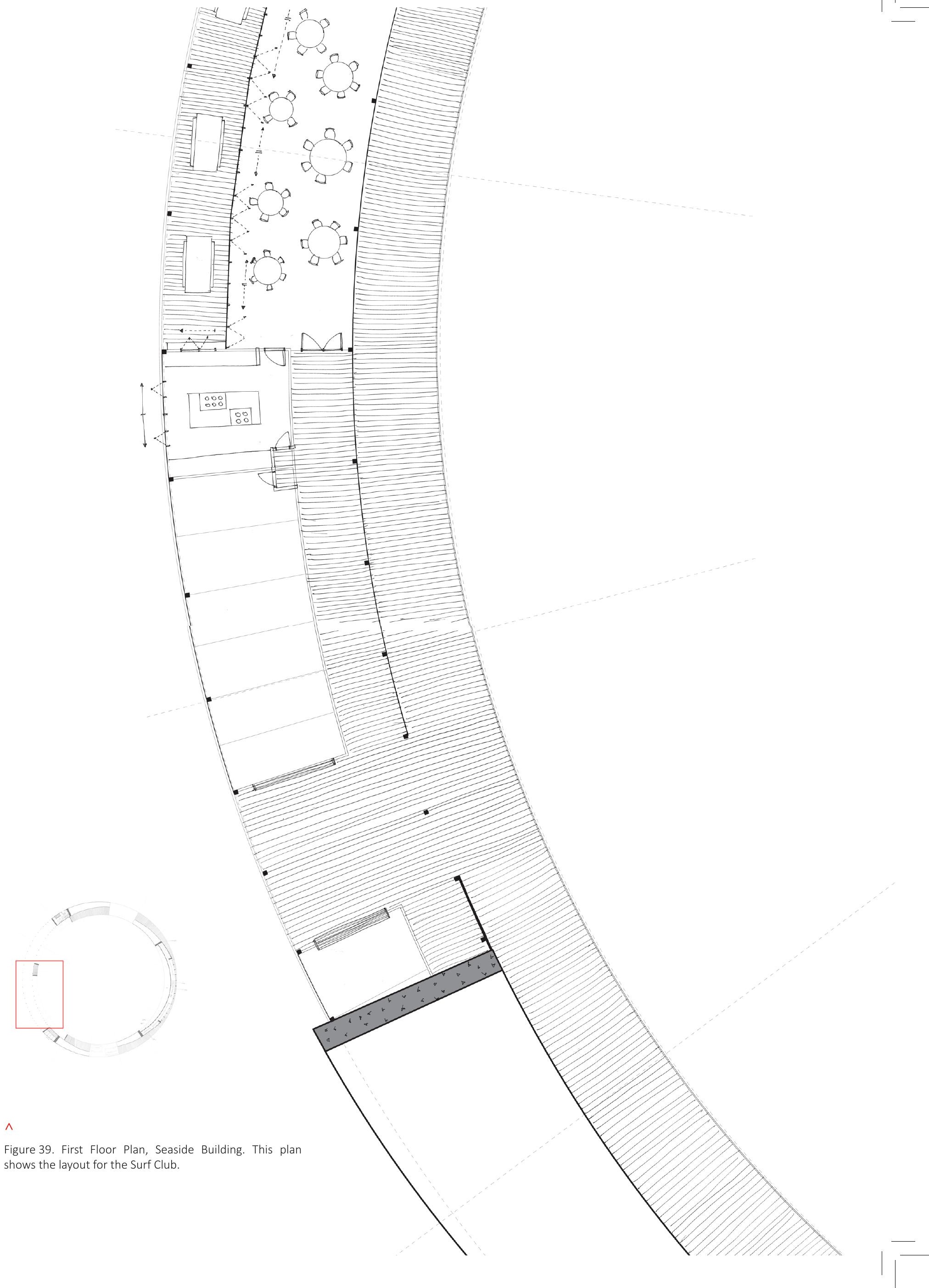





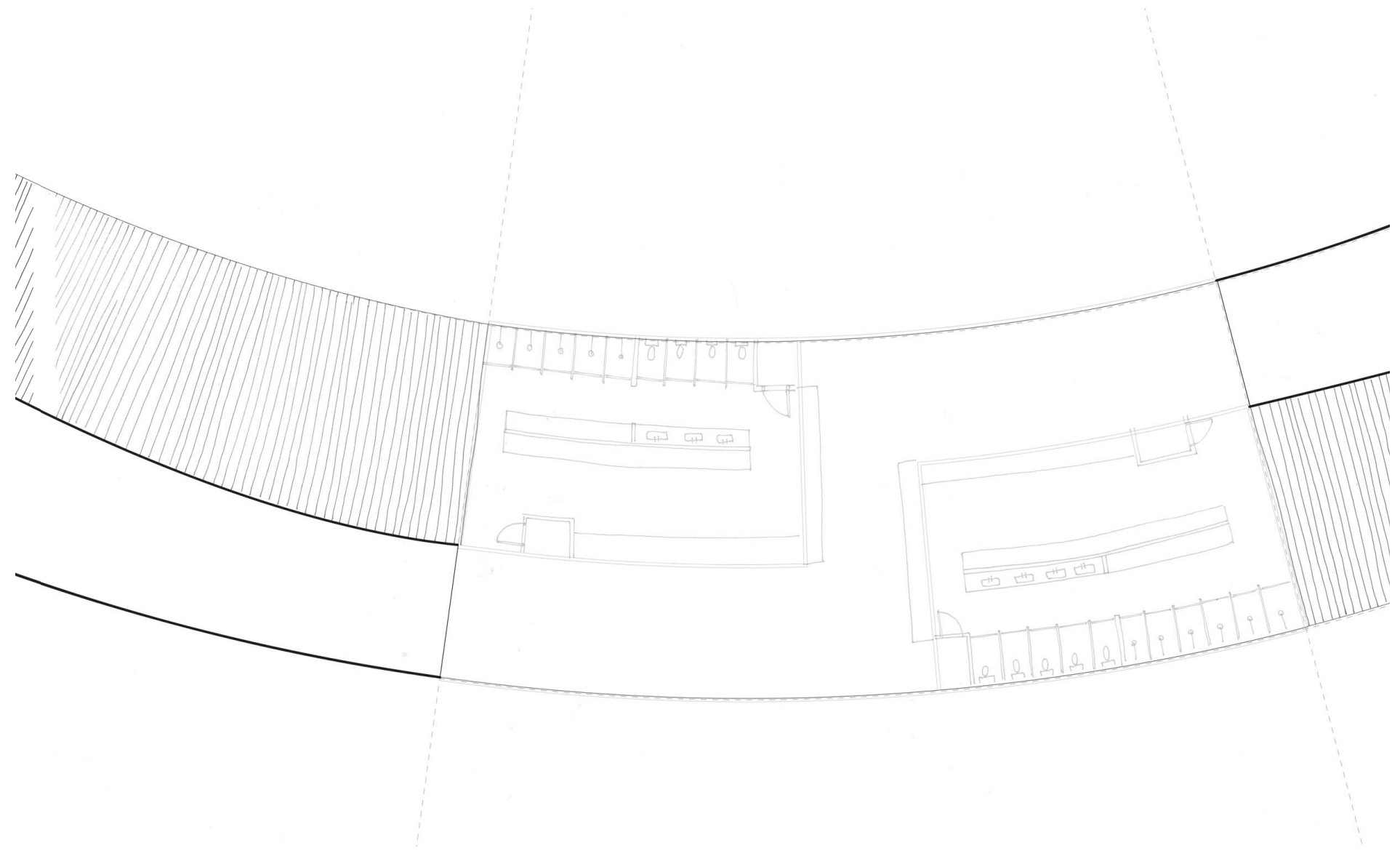



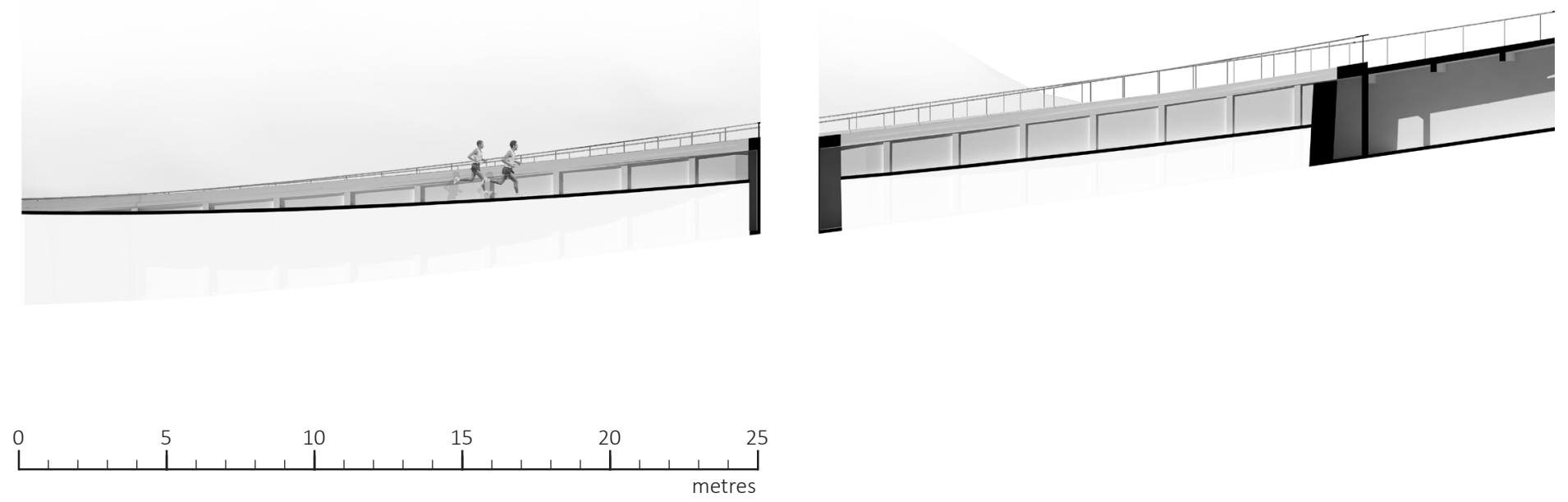

$\wedge$

Figure 41. Stitched Section through Seaside Building.

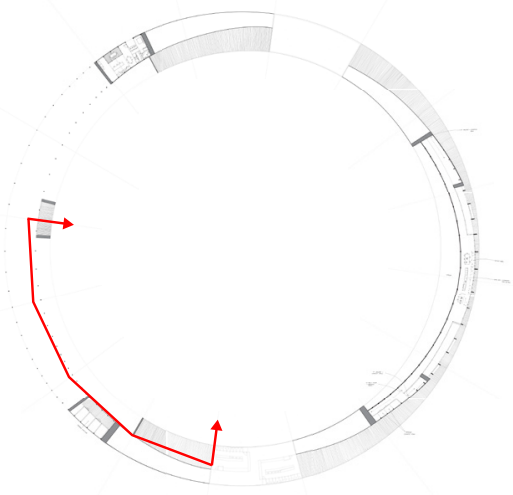




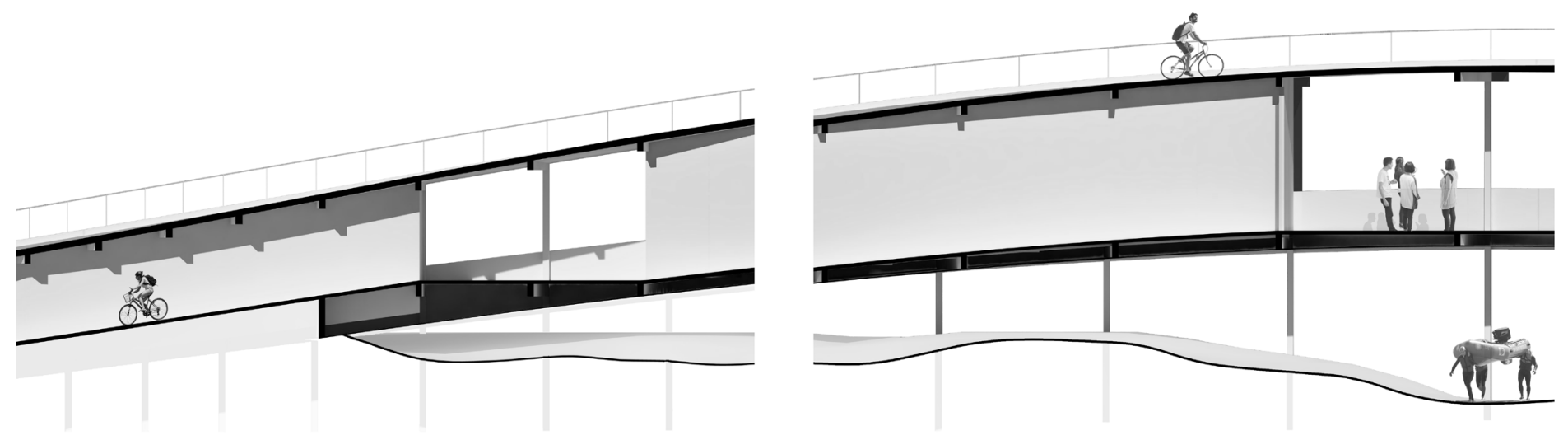



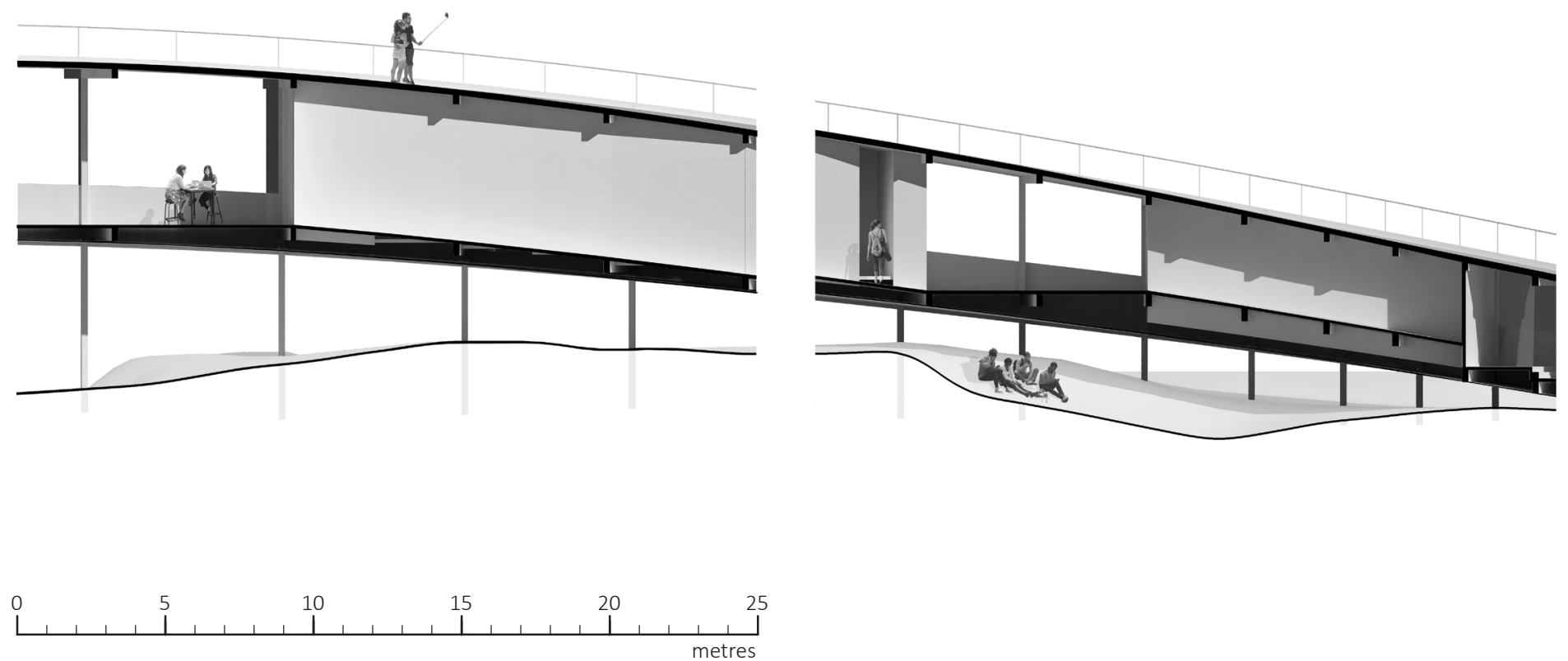

$\wedge$

Figure 42. Stitched Section through Seaside Building

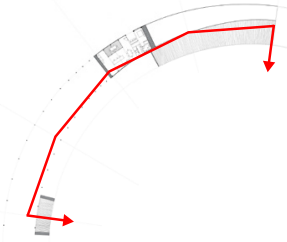




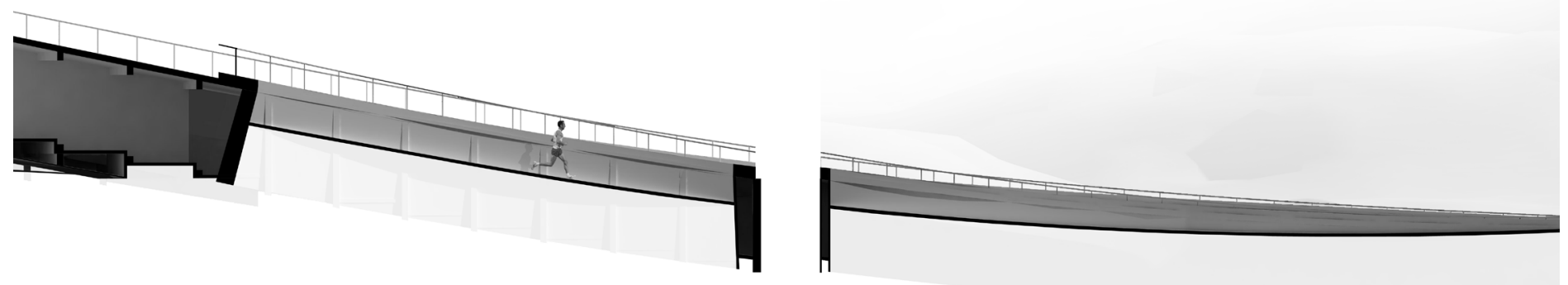




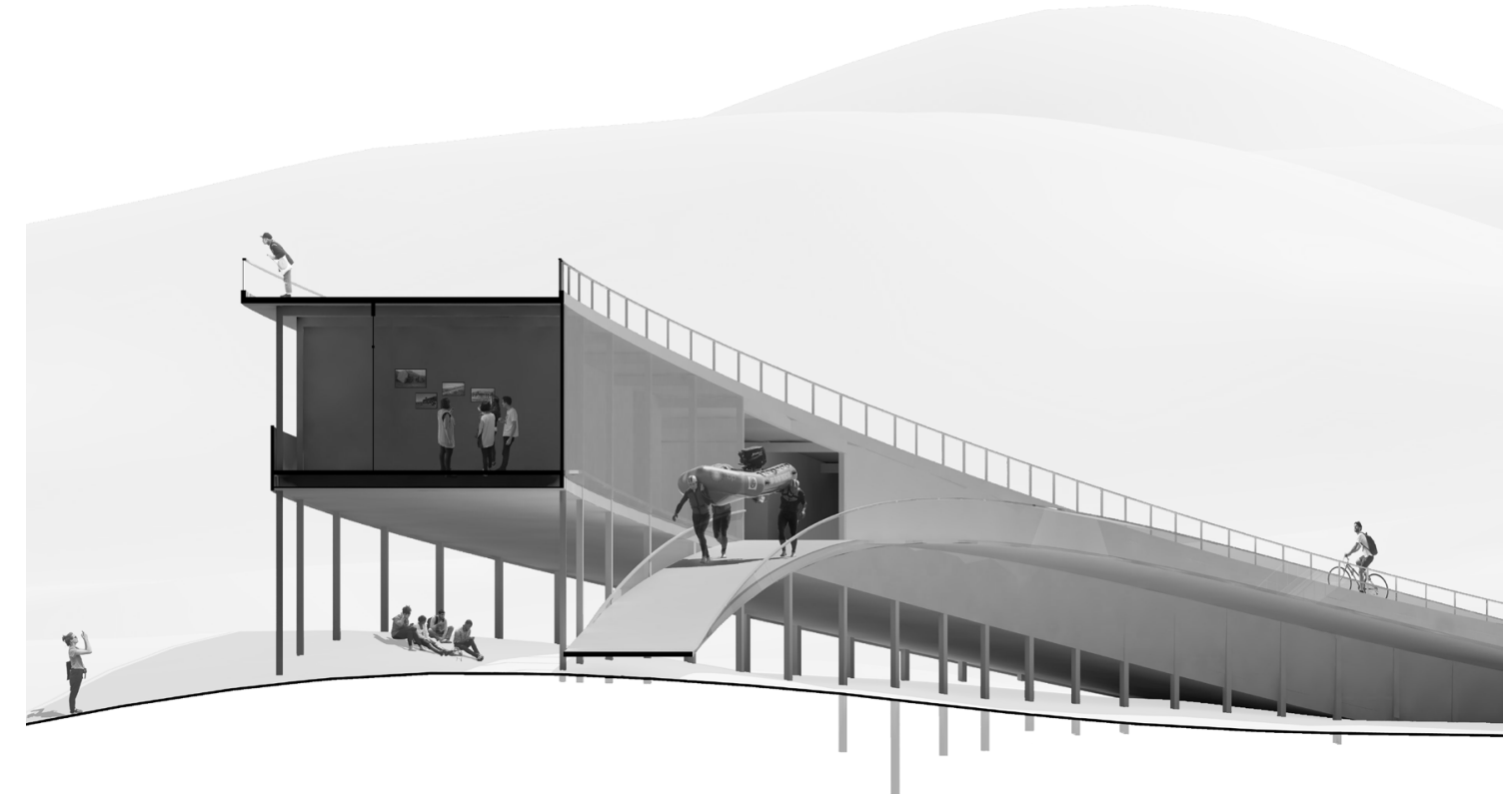

Figure 43. Transverse Section - this section shows the connection between the main hall of the Surf Club and the ramp that provides access down to the beach.

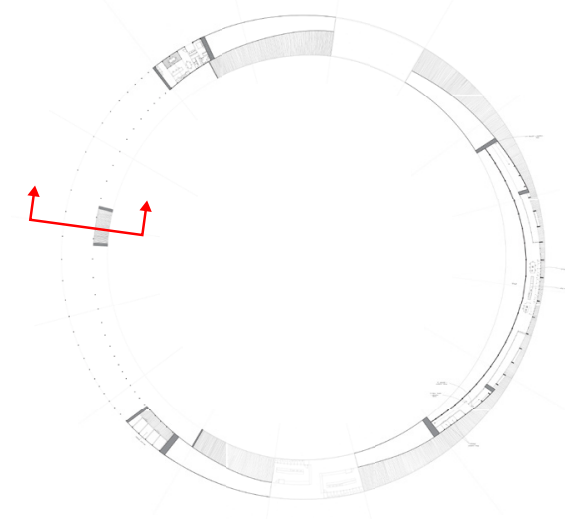



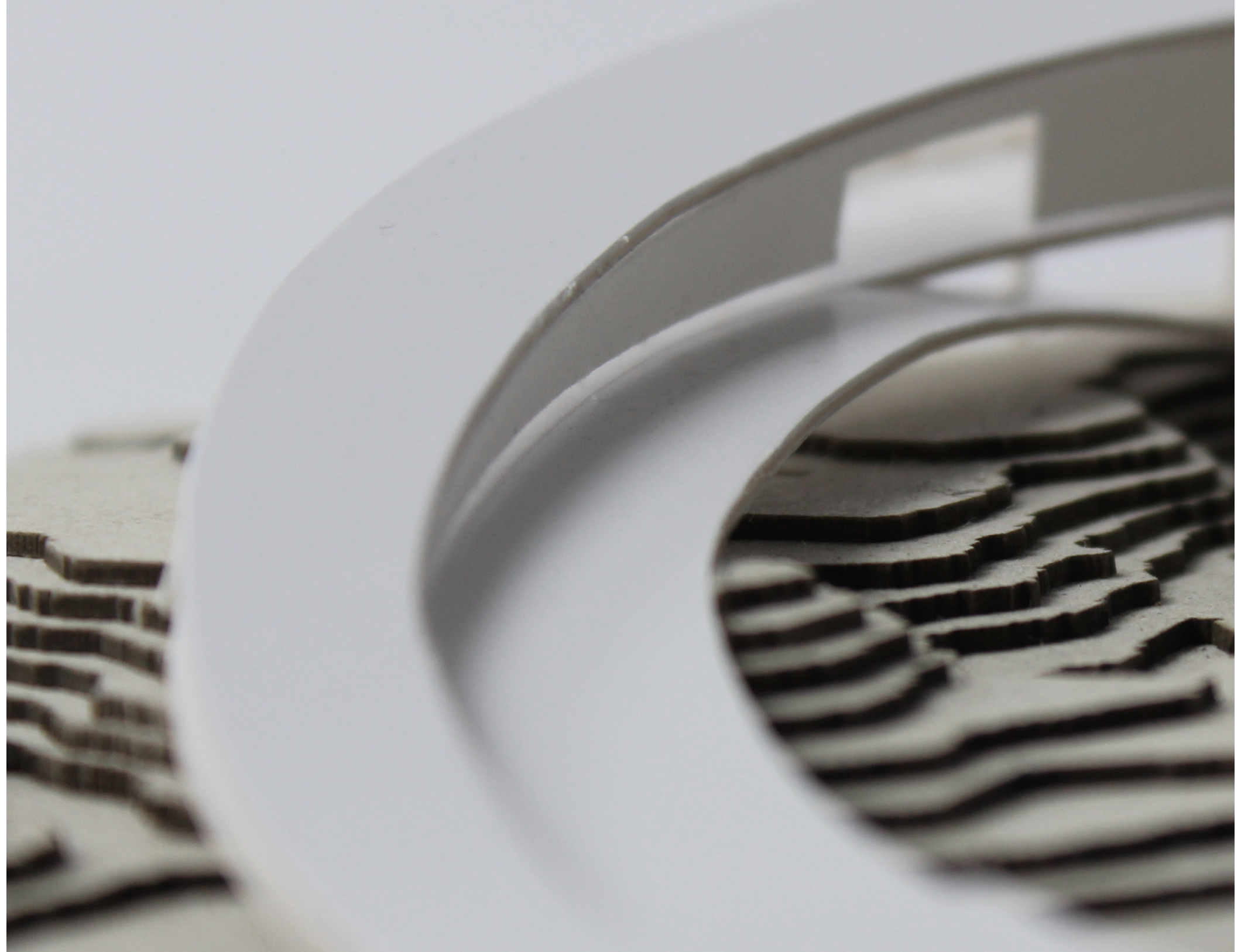



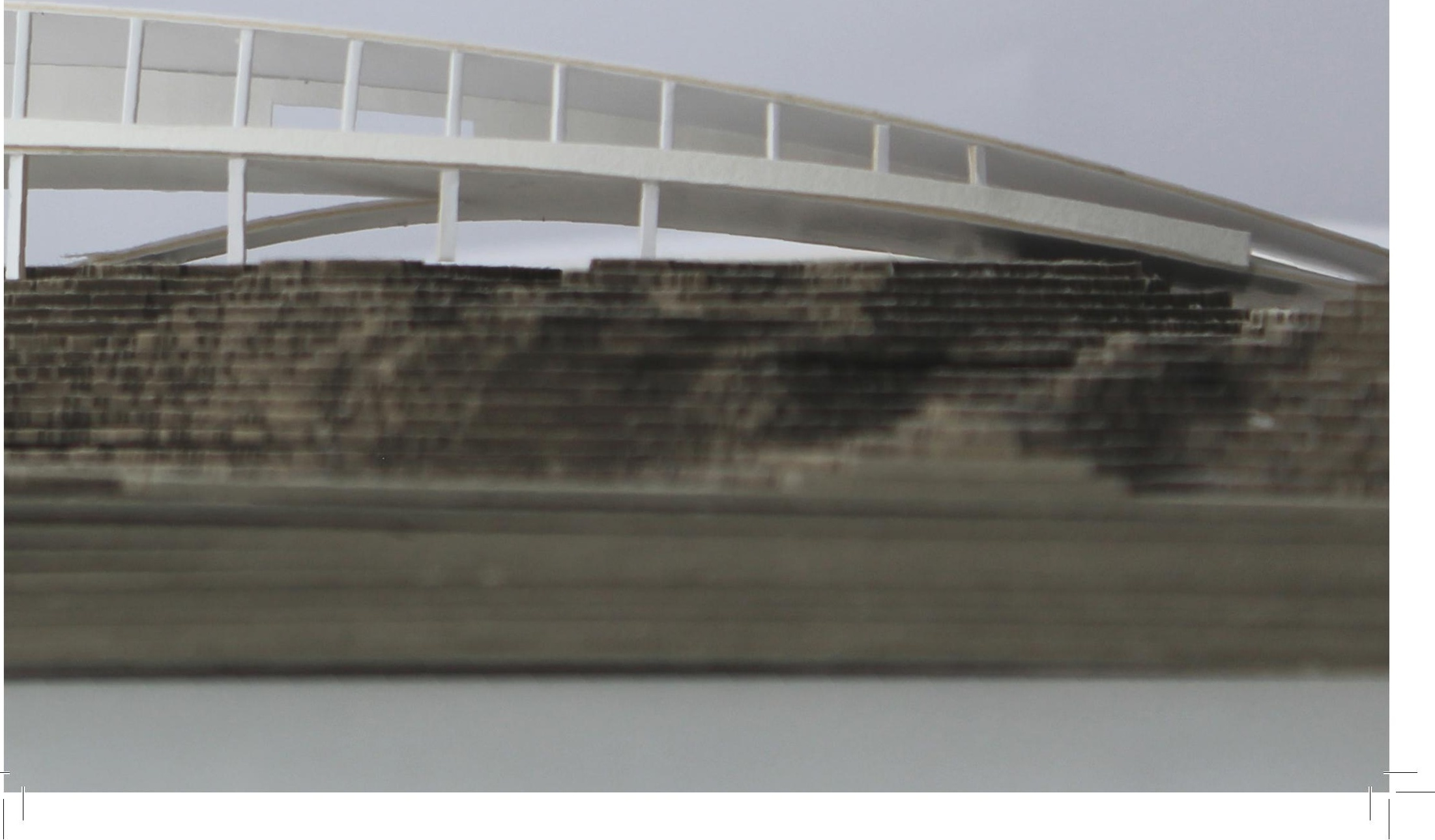




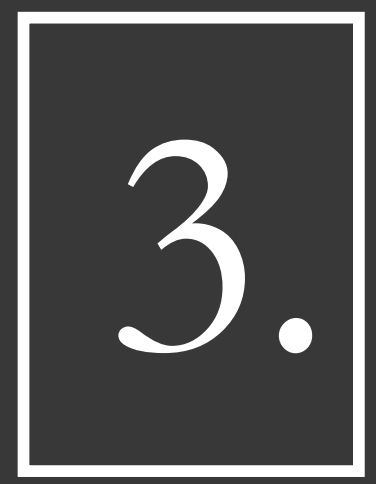




\subsection{Discussion: A Simple and Complex Form}

3.1 Plan

\{pg. $80-95\}$

In this first chapter, I will explain why I chose to place a circular form on the site and the implications it has had.

3.2 Section

$\{$ pg. $96-157\}$

In the second chapter, I have continued to explore the circular form from a side on perspective (section). In switching between the plan and section, I have developed a vision of the form being simple yet complex.

\subsection{Building}

$\{$ pg. $158-197\}$

The third chapter will demonstrate the challenge of taking these two-dimensional visions, a simple plan and a complex section and translating them into a threedimensional building.

Where to next?

Conclusion

\{pg. 199\}

\{pg. 205\} 


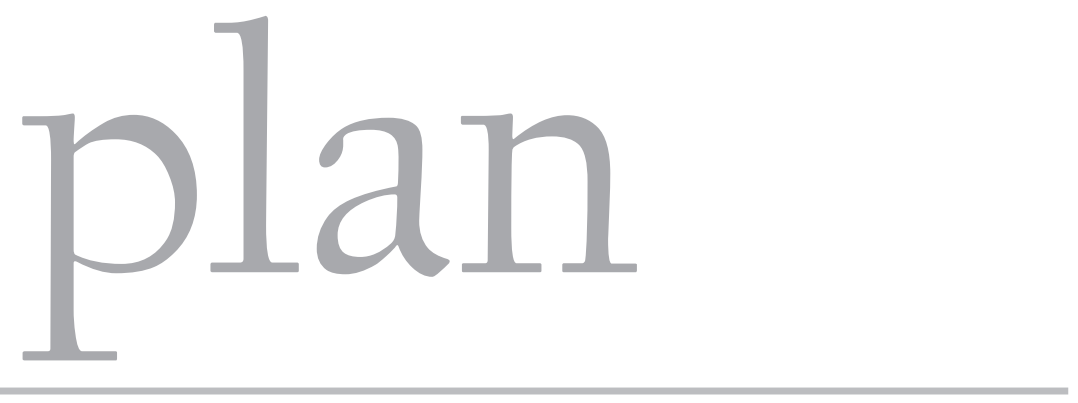


(0) 
After several formal experiments, I decided on a circular form as it fits neatly in the existing topography and addresses each of the surrounding communities evenly.

As you will see in the following experiments, the circle connects two key features in the landscape, the road and the sand dunes. This connection was difficult to make as the distance between the two features is vast.

In regards to the issue of the communities, the circle has several unifying qualities. Firstly, there is no defined entrance or exit that might prove closer to one community over the other; and secondly, the circle directs focus towards the centre of the site encouraging the communities to gather. Aside from this, I was also attracted to simple elegance of the circle. 

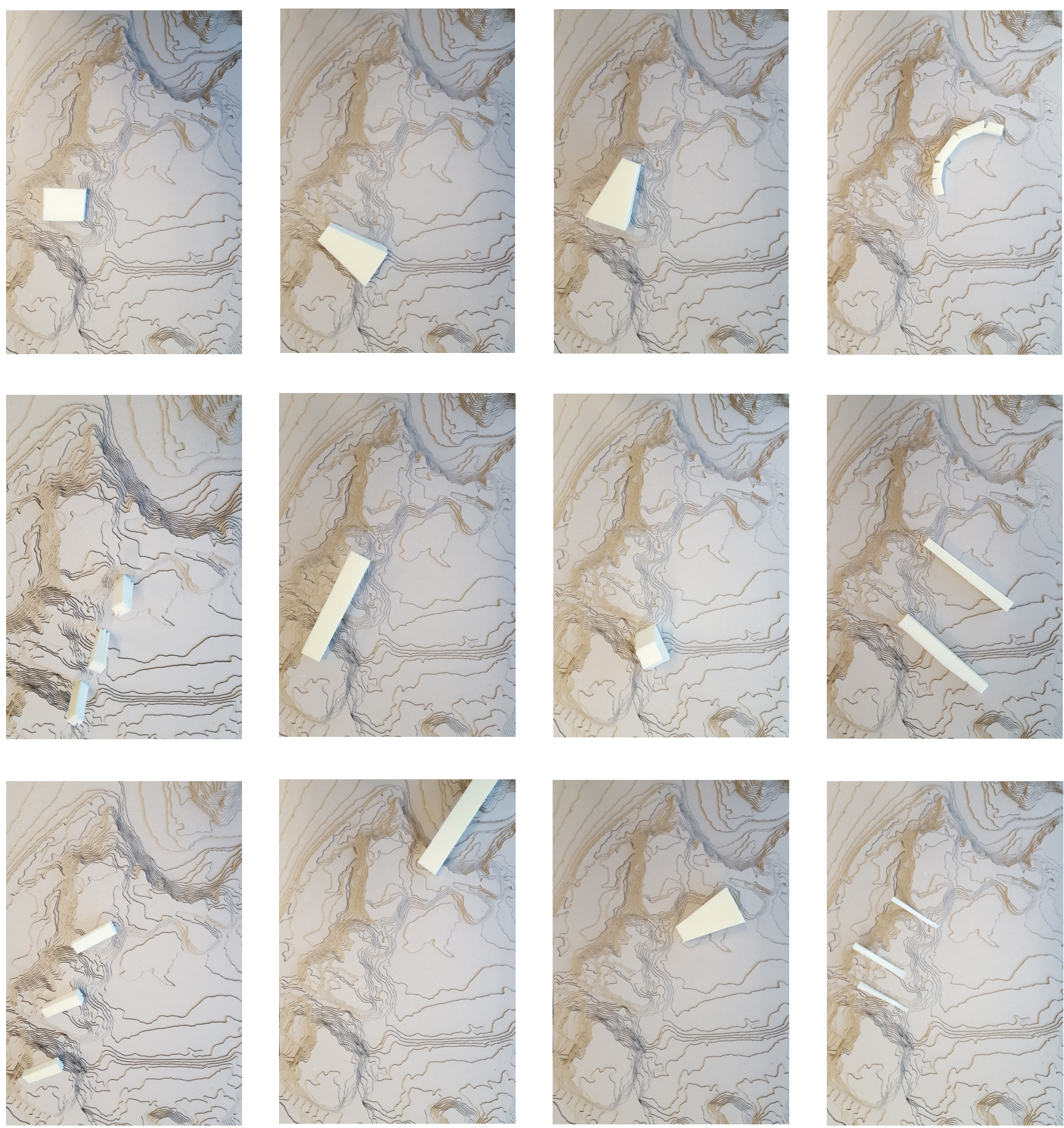

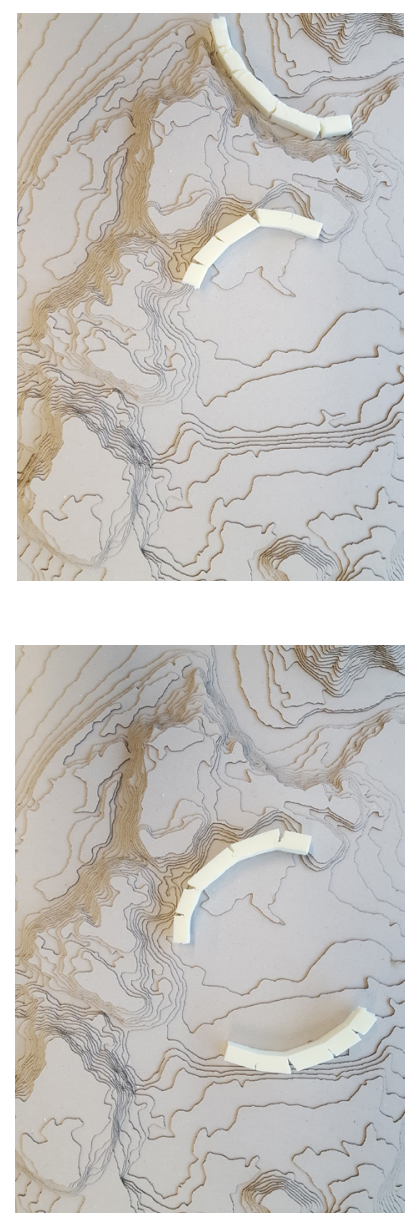

what is the best formal solution for the site?

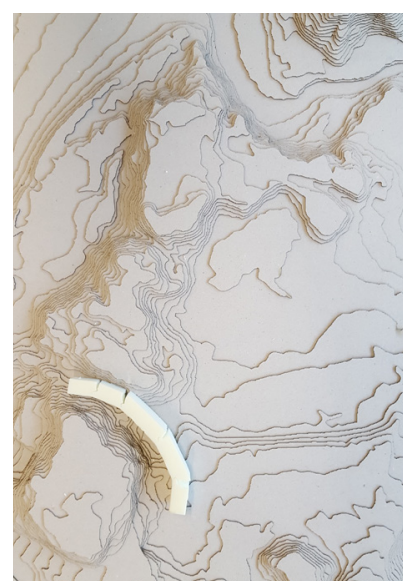

$<$

Figure 45. As you will see in these photographs, I have used mass models at a scale of 1:500, to explore different formal solutions for the site. Through analysing these different iterations, it is clear that the curving forms are more considerate of the landscape than the rigid forms. This consideration is important as it will help the different communities to accept the design proposal. 


\section{where is the best location for the design solution?}

Figure 46. In these diagrams, I have explored different areas on the site where I could place the design proposal. This experiment was beneficial as I realised that to create a building which is accessible to all of the different communities, it must be situated equally between them. If the building was located closer to one community over the other, there is a risk that the building might be claimed and used by one community more than another. 

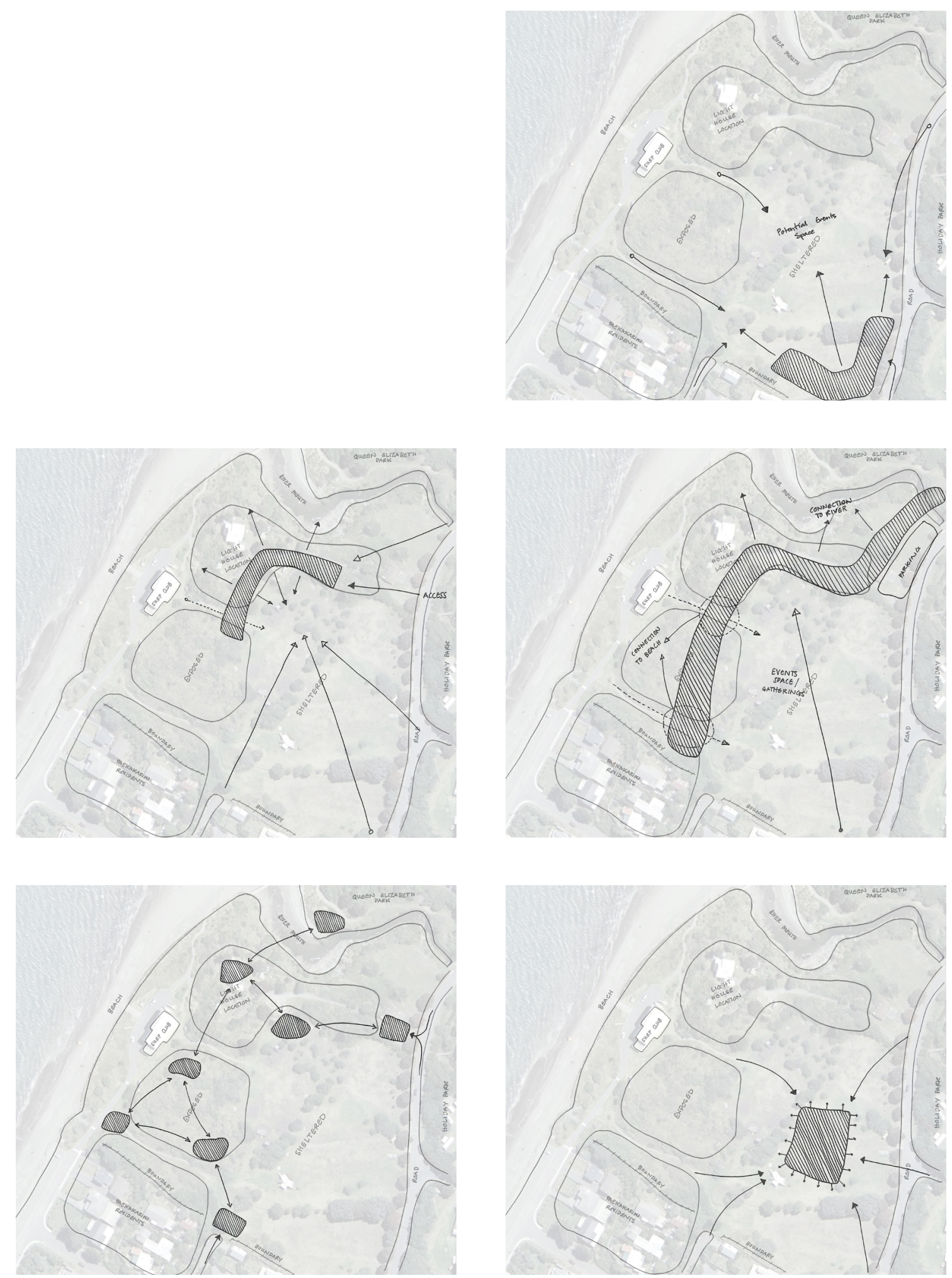

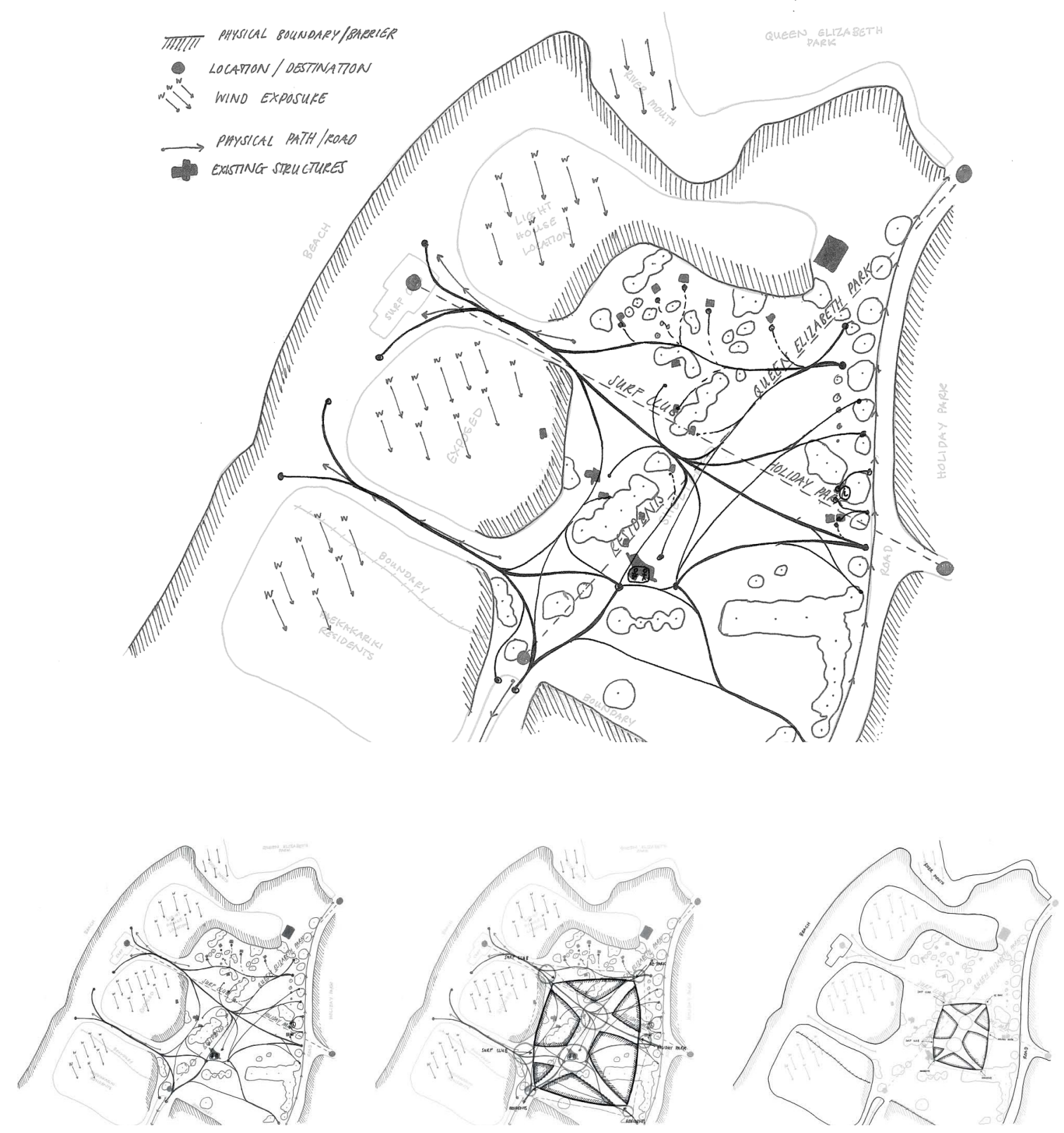

Figure 47. This diagram is an analysis of the circulation routes on the site. This has helped me to identify that the different groups commonly use the site as a transition zone and for its access to the beach and OE Park. 

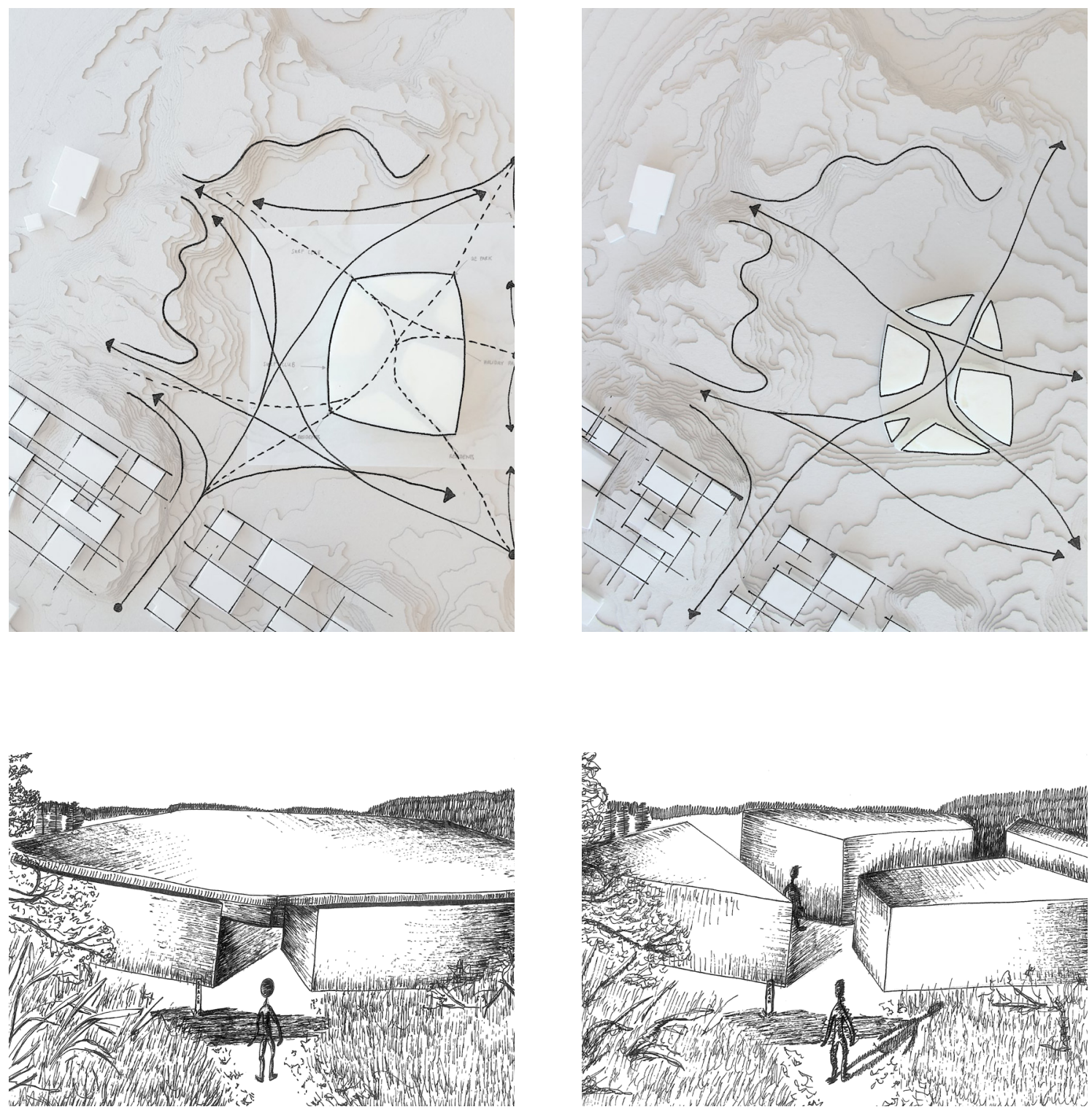

Figure 48. From this analysis of the site, I designed two formal iterations, one which is a series of individual buildings, and the other which is a series of spaces enclosed in one building. Both these iterations celebrate the existing pathways on the site. What is interesting from these drawings is how the addition of a roof can change the quality of space and therefore impact the way people approach the form. In these two drawings, I have developed a technique which uses light and shadow to help express the quality of space of these forms. 

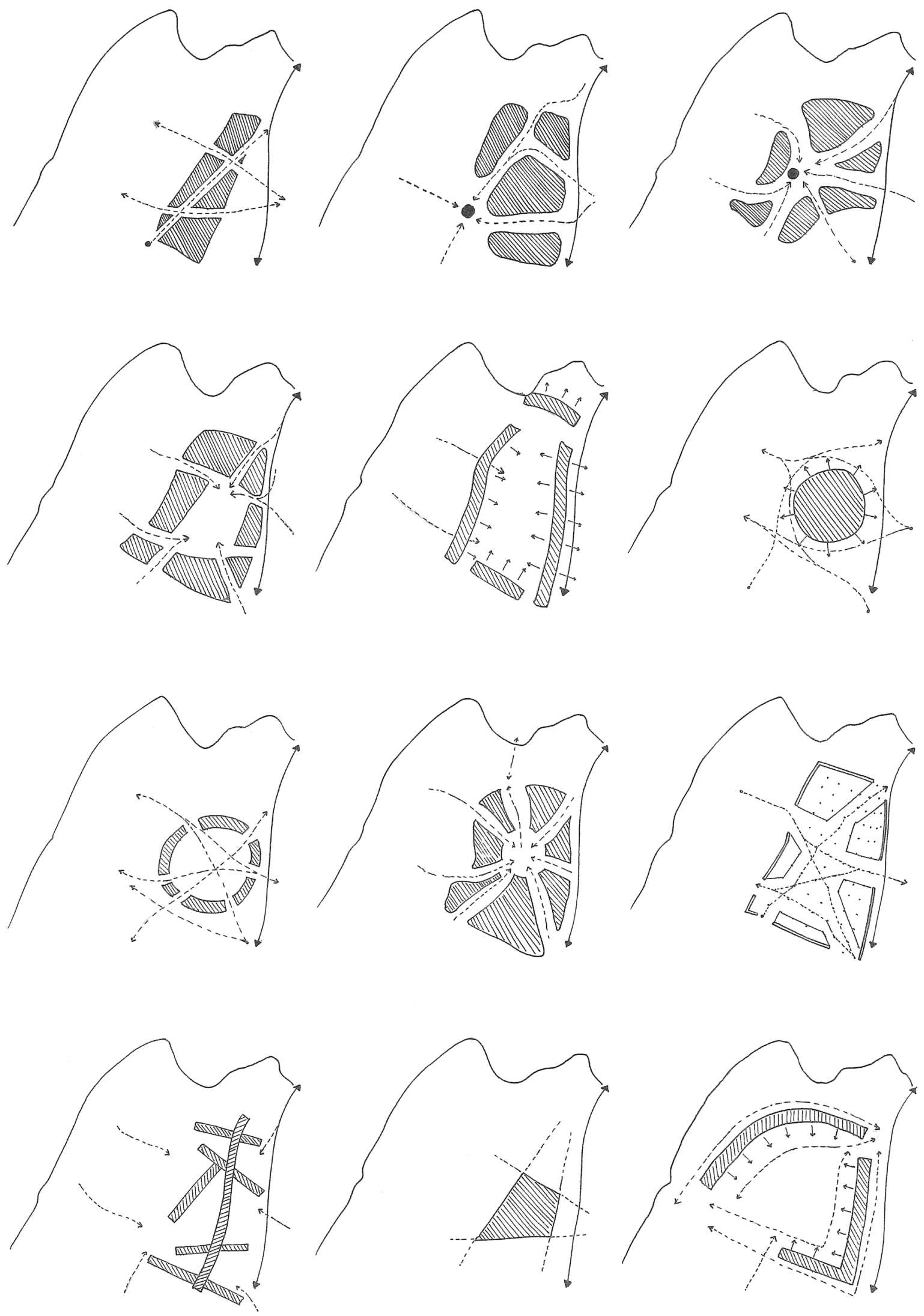

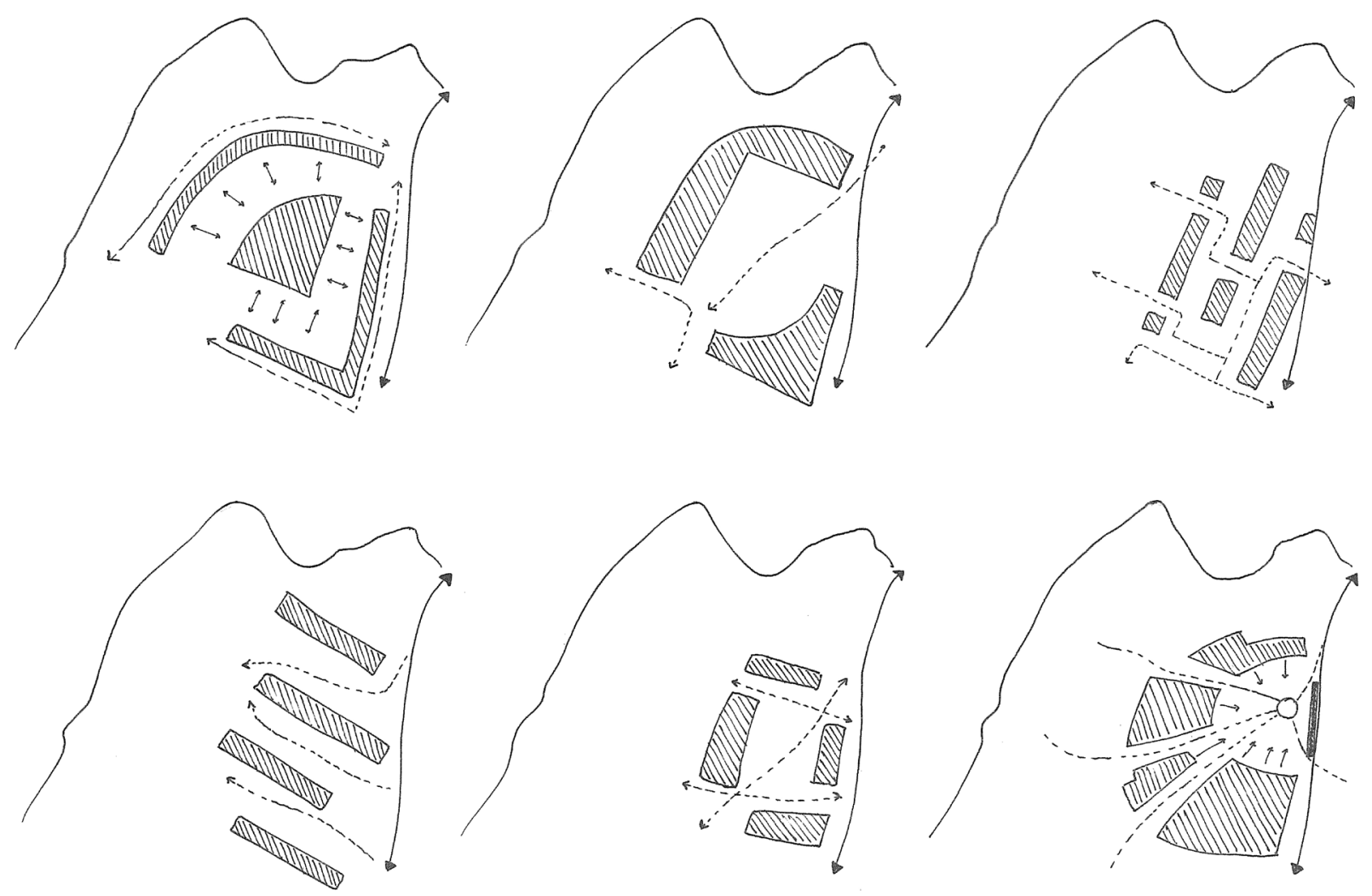

$<\wedge$

Figure 49. These drawings further explore how the arrangement of buildings can determine the way people occupy a space. Although I was drawing in plan, I inherently imagined the quality of space and how the occupant might react to the design. For example, when designing the size of space between the buildings, I was very aware that narrow spaces will cause people to move swiftly where as the open spaces will cause people to dwell.

whats the best

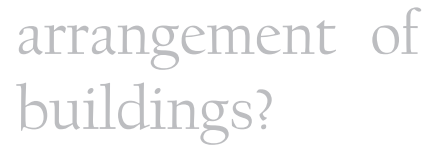



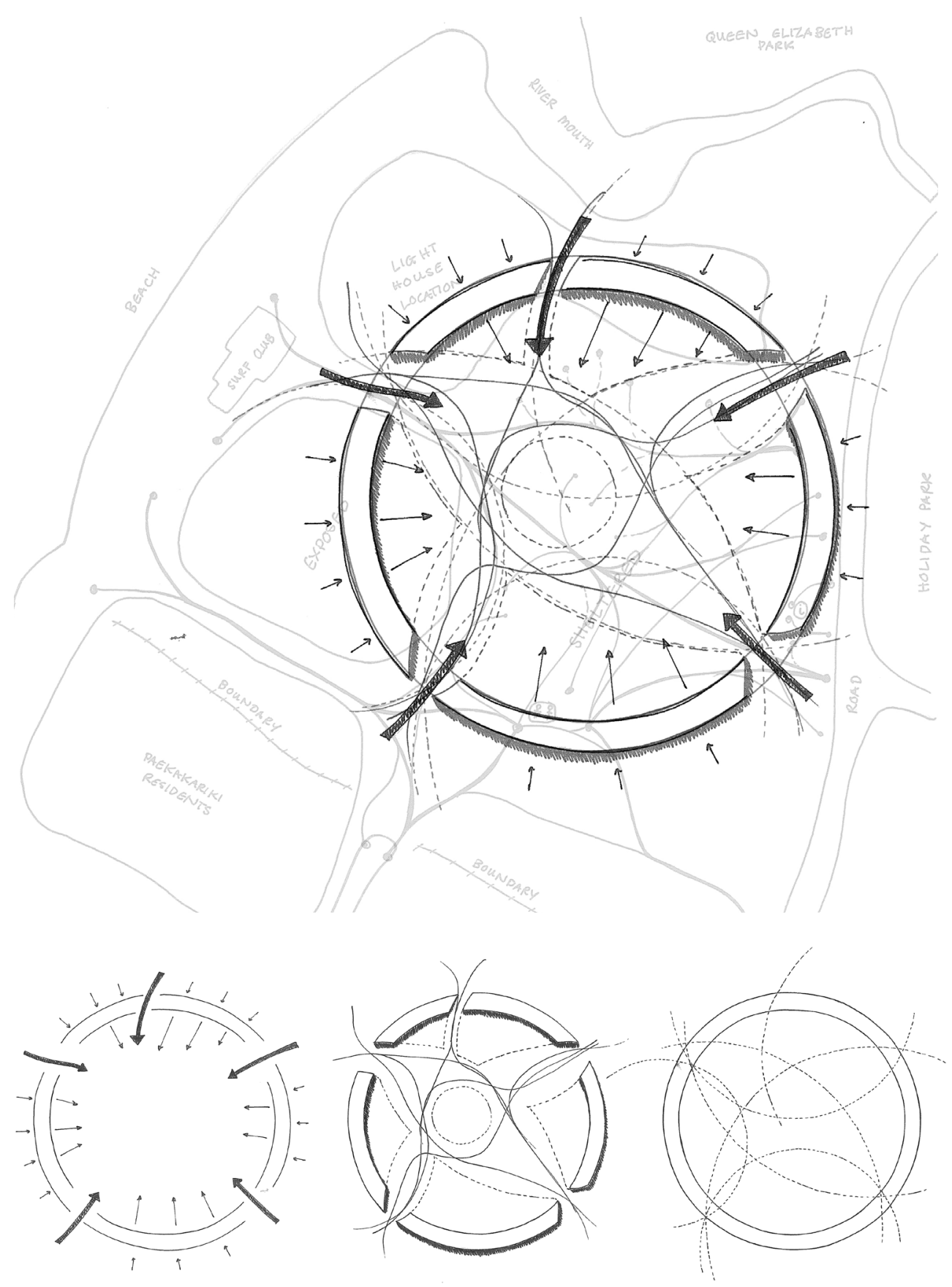

Figure 51. At this stage in the experiments, I began to explore the possibility of a circular form and how this might encourage people to dwell on the site.
Figure 50. In this experiment, I have started to explore the three-dimensional form of the circle. In using physical modelling, I have been able to view the form from different angles. Focusing on the connection between the form and the landscape, I have experimented with raising and lowering sections of the circle to allow people to pass under and over the building. 

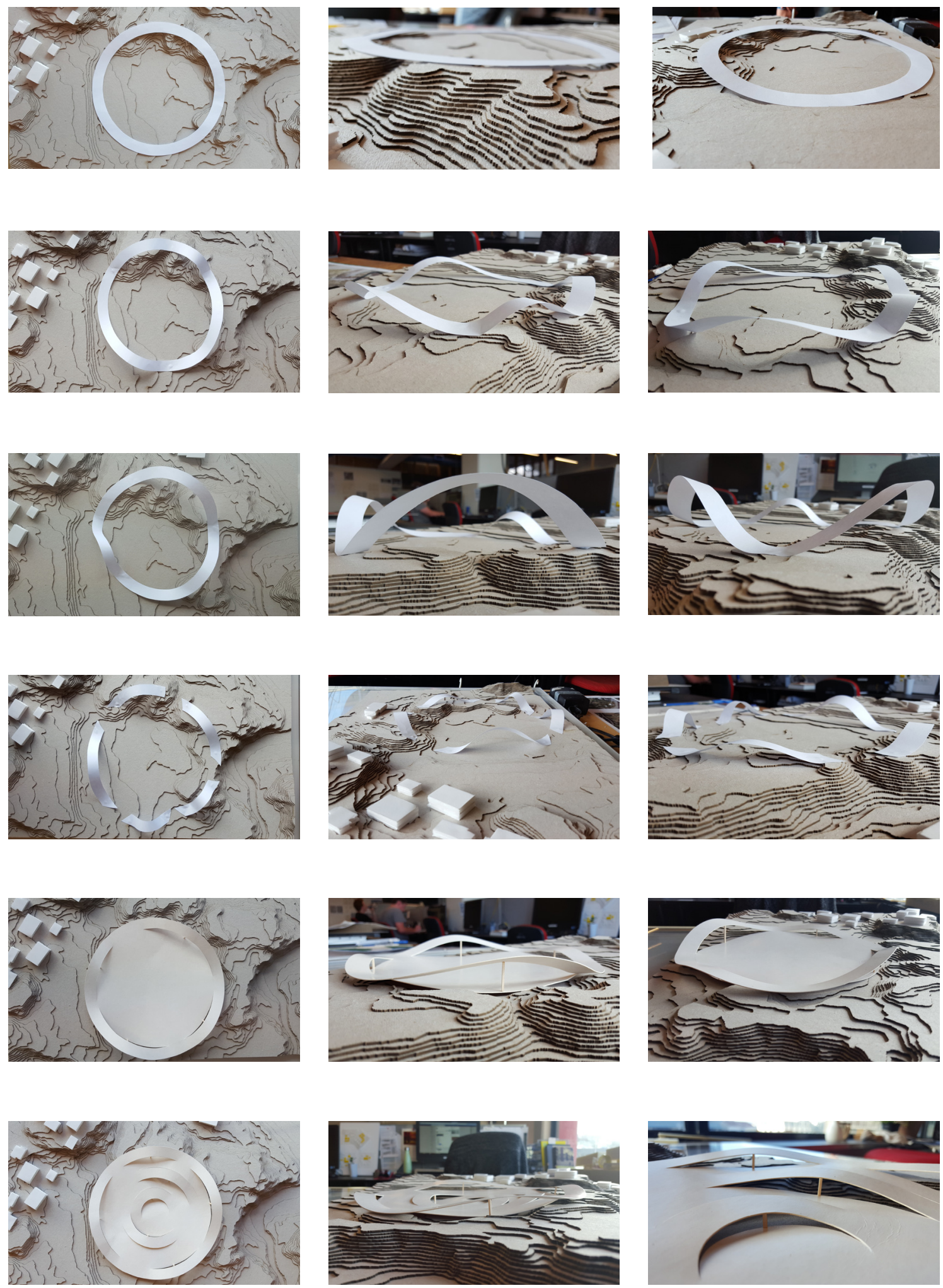


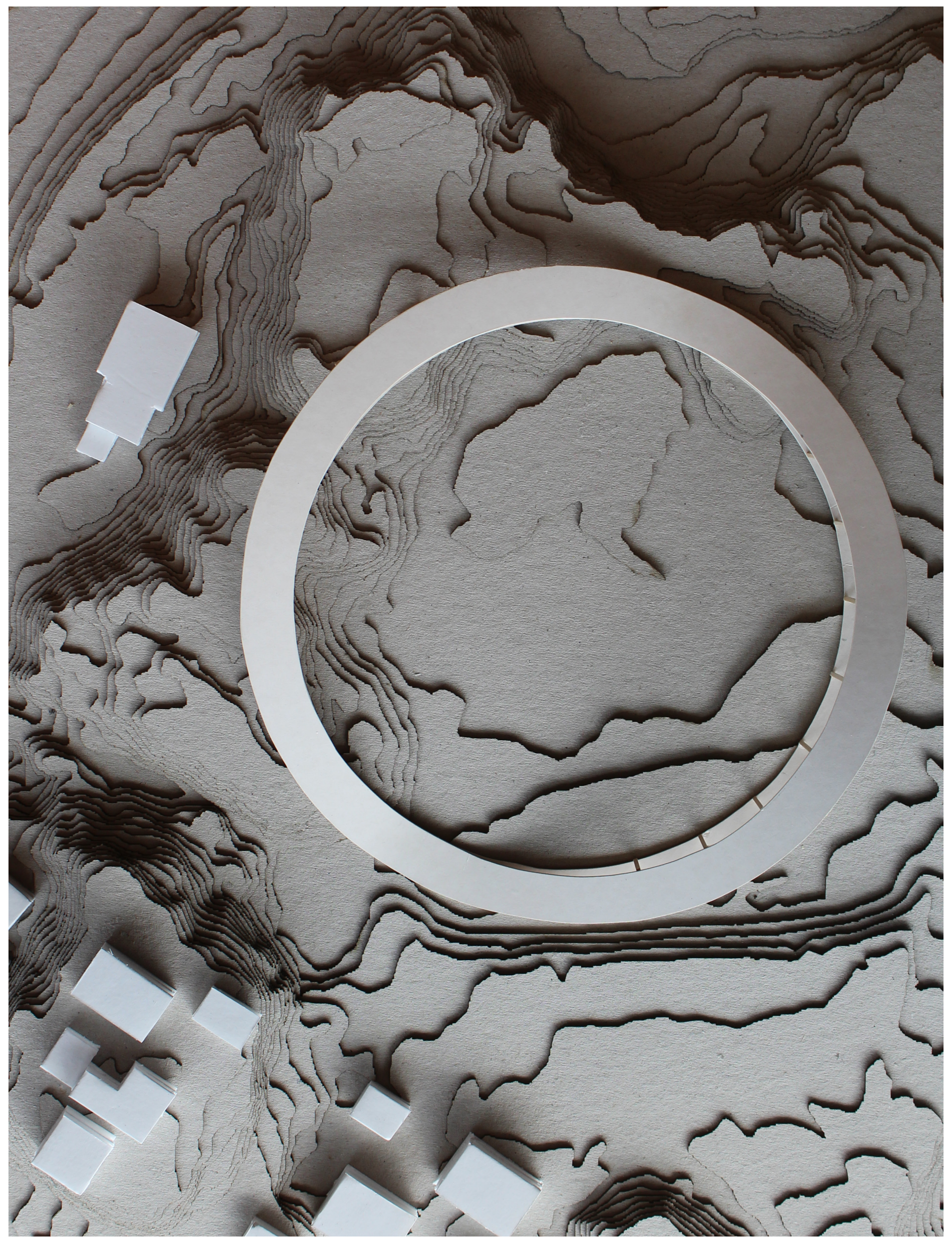



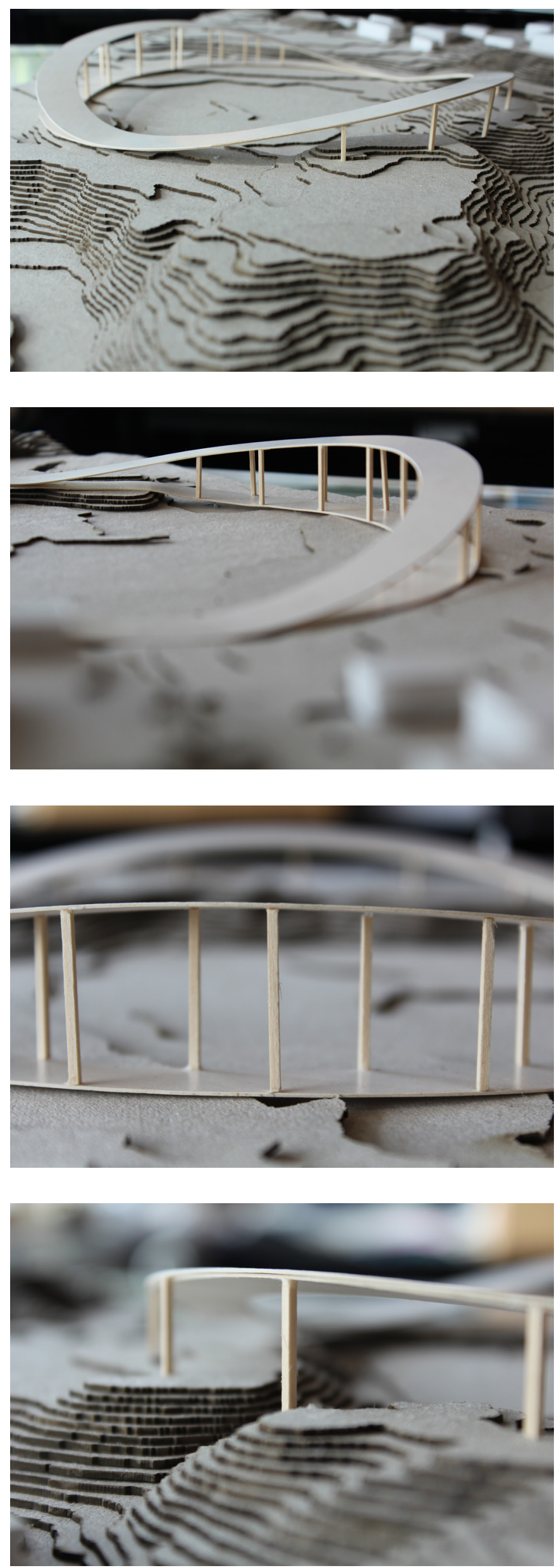

$<$

Figure 52. While I was testing the three-dimensional form of the circle, I created this design iteration. There were several motivations behind this design which are noted below:

- I have designed the form to sit up above the dunes to avoid any issues which may arise from the shifting of the sand dunes.

- I have designed the form to front the road with the aim of drawing people into the site.

- I have lowered two sections of the circular form. This lowering will encourage the communities to occupy the centre of the circle and allow them to walk up and over the roof of the building. 


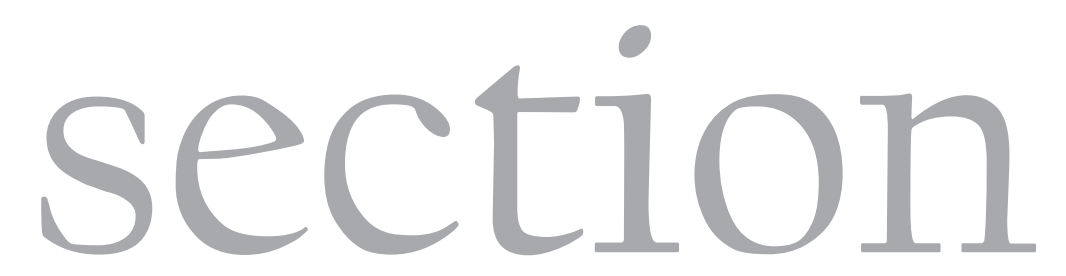




$$
0+£
$$


In this chapter, I have developed a drawing technique which has enabled me to explore the circular form from a side on perspective (section). As a result, these drawings have revealed a complex section which is far more accommodating and expressive of the sites diverse communities than a simple section. In that case, I have developed a vision of the form having a simple plan and a complex section. 


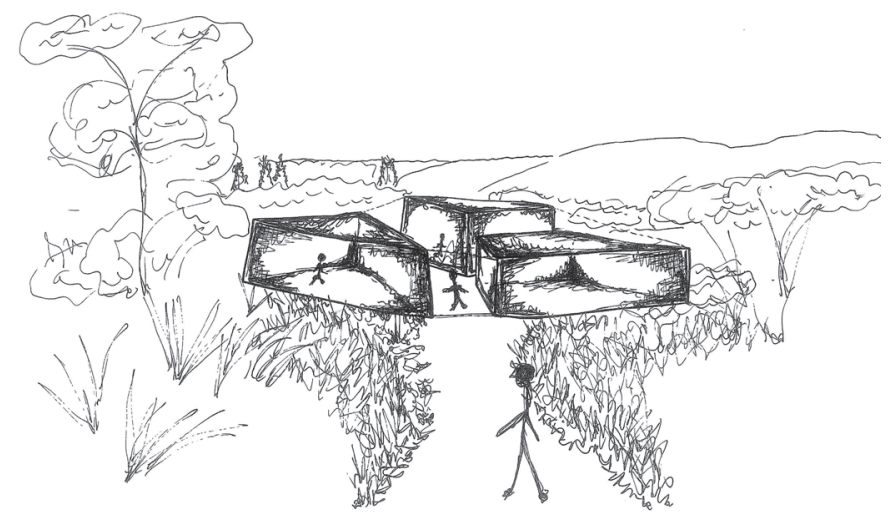

$\wedge$

Figure 54. While I was producing the experiments in the previous chapter, I was also trying to understand what the experience of the form would be like from a user's perspective. In that case, I drew this relatively naive sketch which prompted me to further develop the technique in the refined drawings that follow.
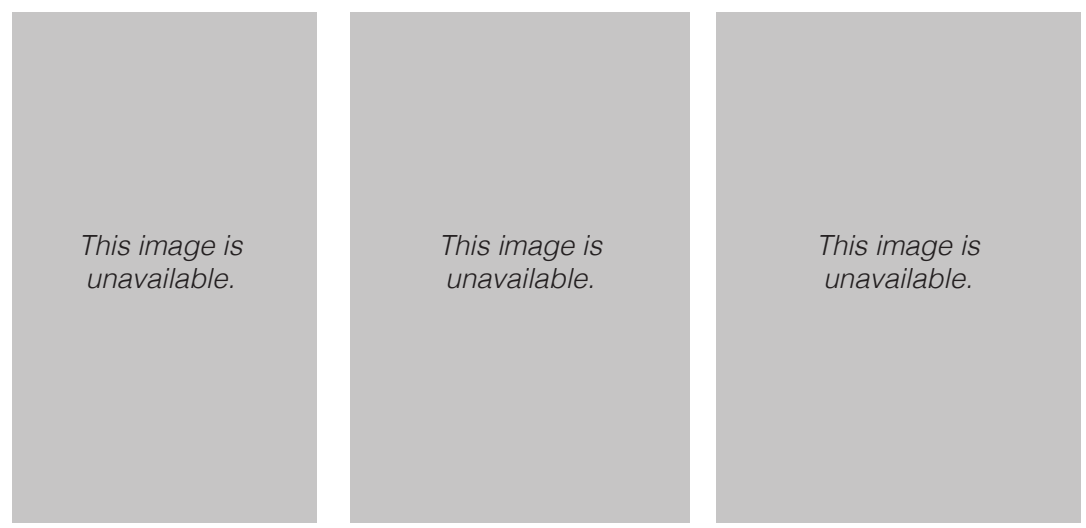

$\wedge$

Figure 53. I looked at these drawings by Alberto Giacometti, and work of other artists, as a way of reviewing the different techniques people use and the direction that I wanted to develop my drawings (Source: Alberto Giacometti). 

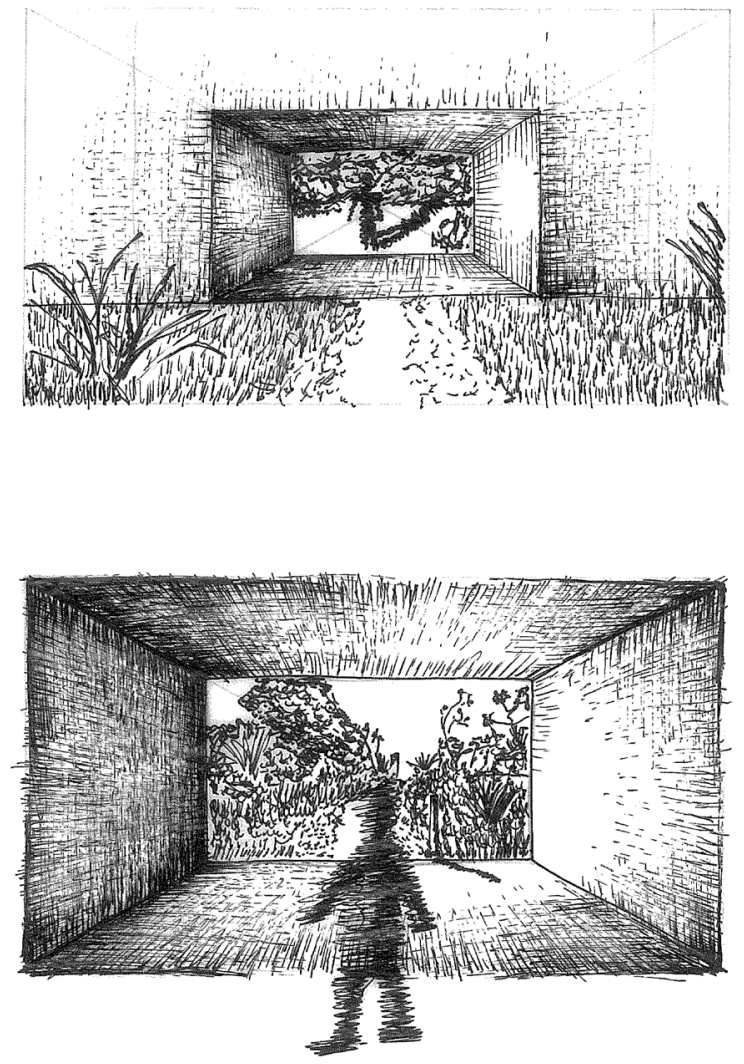

Figure 55. These drawings continue to develop the drawing technique and explore the form as a threshold on the site. 

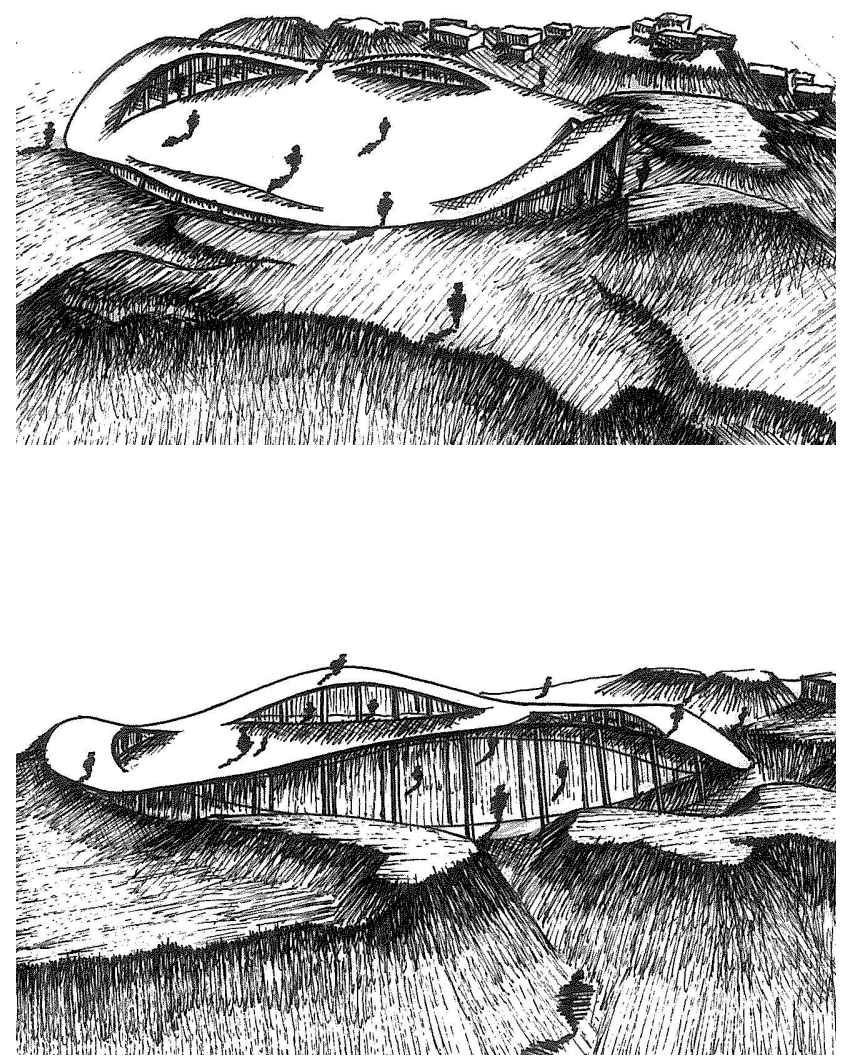

$\wedge>$

Figure 56. In these drawings, I have captured the different forms sitting in the site's existing topography. 

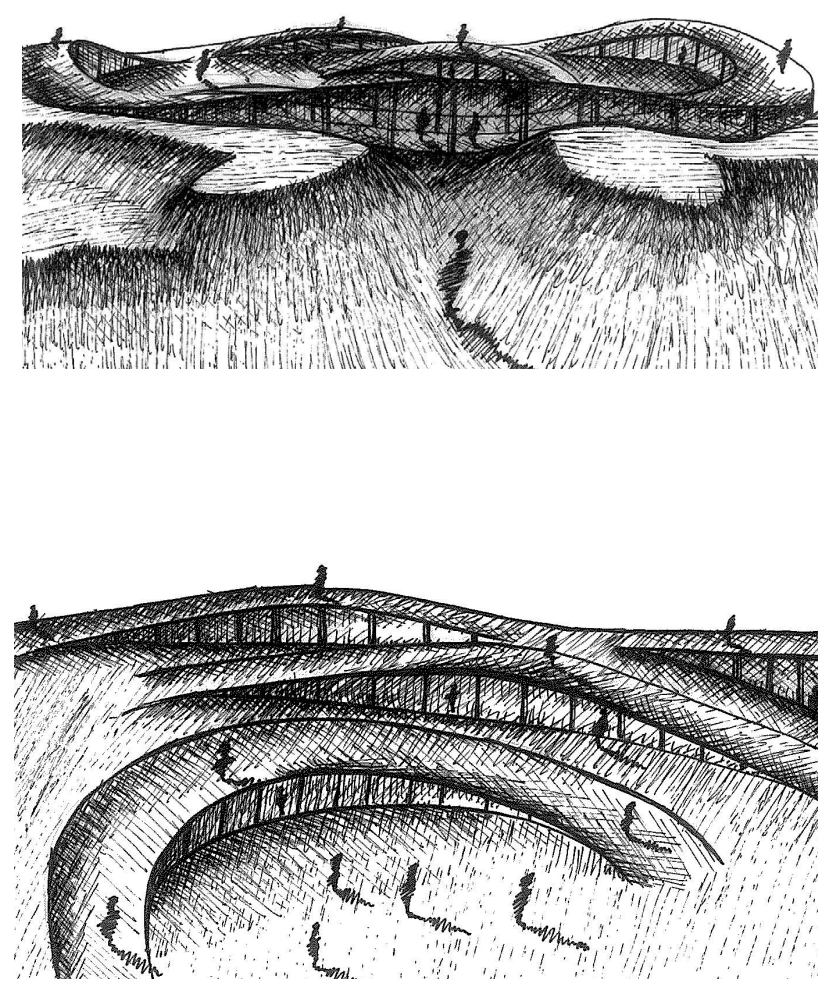

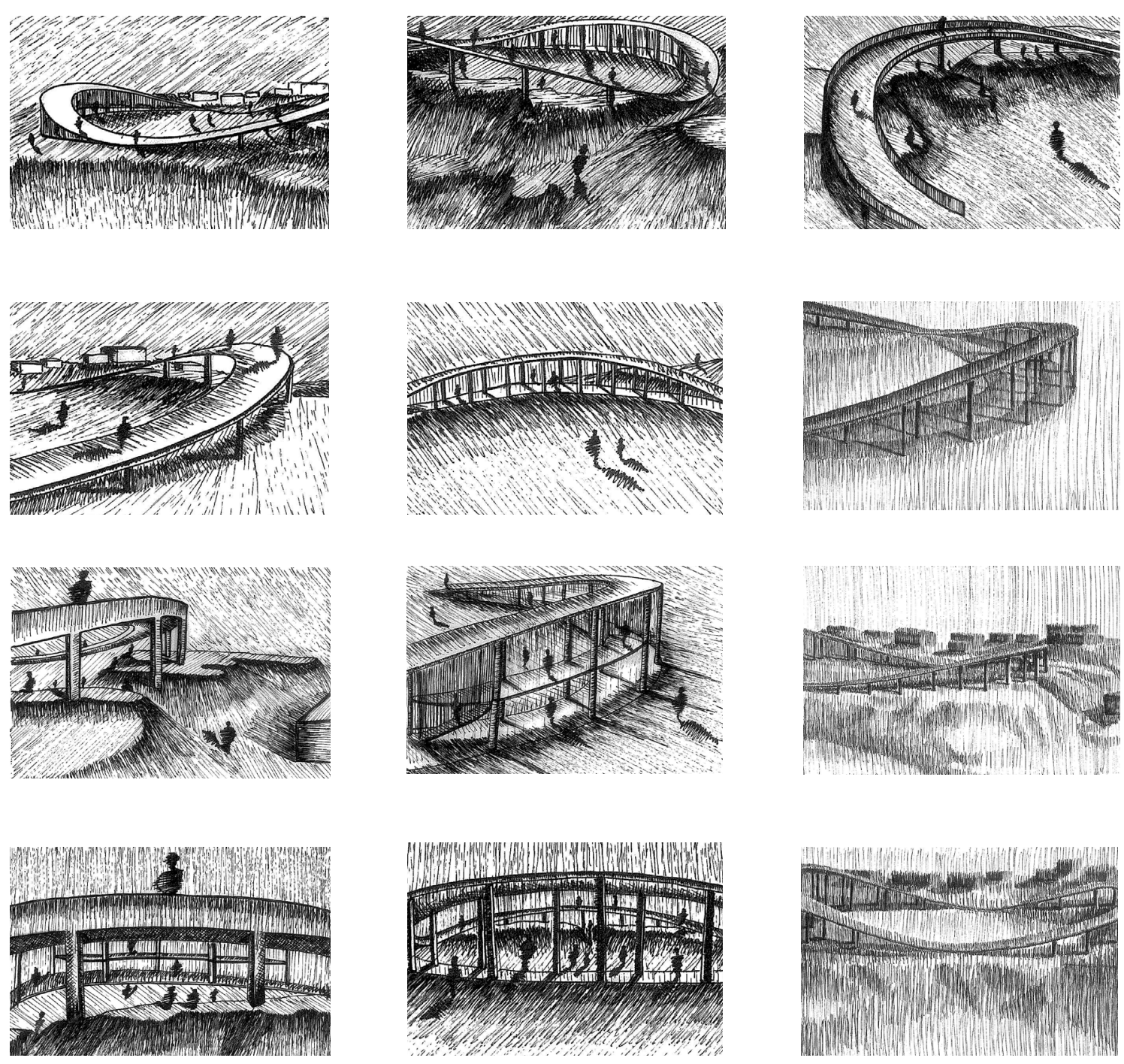

$\wedge$

Figure 57. In these drawings, I was focused on developing my drawing technique. This involved experimenting with the direction of the hatch and the thickness of the pen. 


\section{establishing a drawing technique to capture the light and spatial qualities experienced by the user.}

In contrast to the diagrams and physical models in the previous chapter, this drawing technique focuses on capturing light and shadow and the experience of the building from a users perspective. As you will see in these drawings, the overlapping of the dunes has blurred the line between the form and the landscape. This ambiguity has revealed a complexity to the form that is accommodating and expressive of the diverse communities. The complex form provides a flexibility that a simple form lacks. This flexibility opens the possibility for a diverse range of people to occupy the space. 


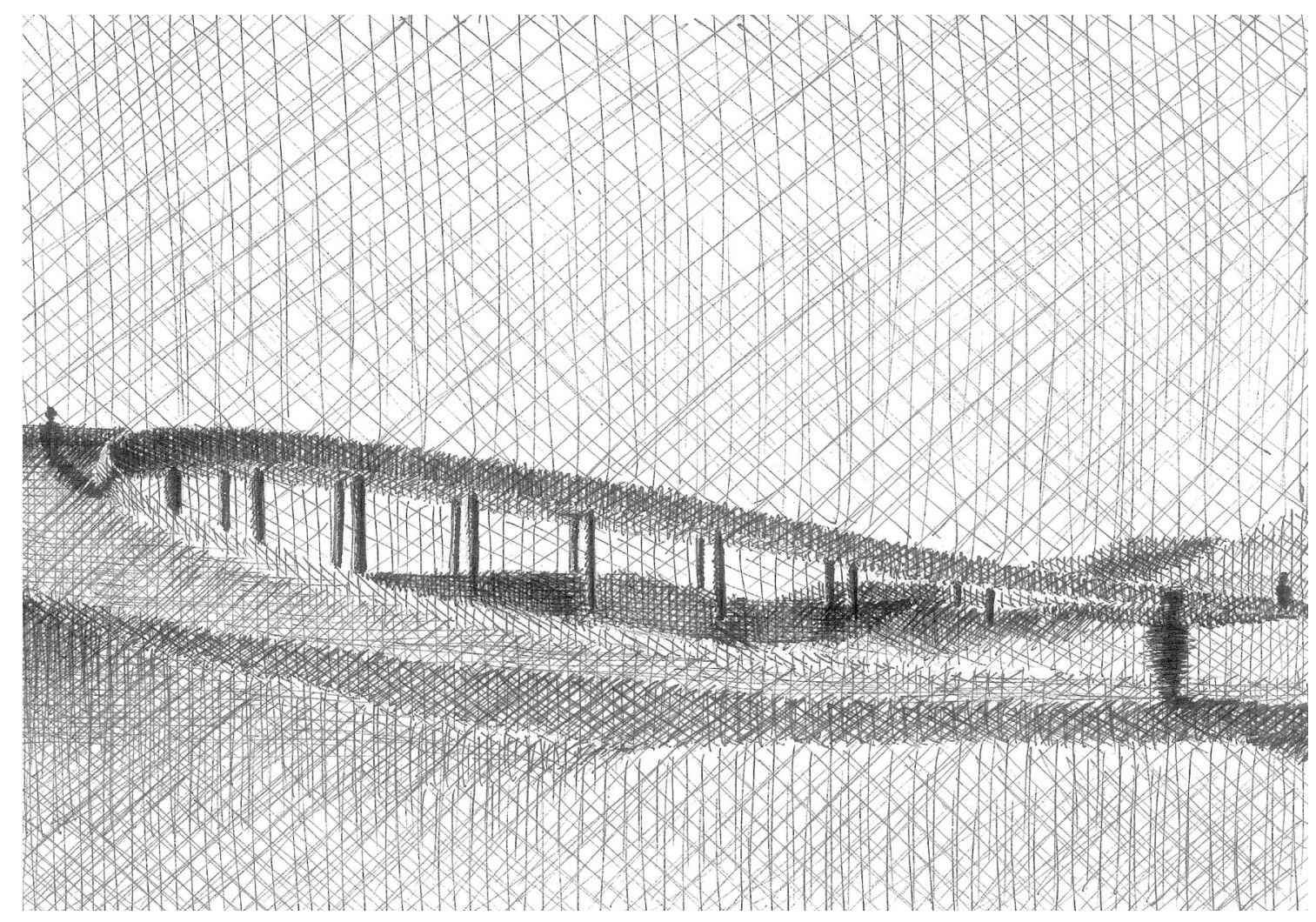

$\wedge>$

Figure 58. These two drawings show the low point along the circle which leads up into a boardwalk spanning over the dunes.

In this set of drawings, I have started to scale down and focus on smaller sections of the building. As these drawings have developed, I can see that the architecture has become slightly simpler as the drawings lose the dunes from view. It is lumpier and more complex in the previous drawings.

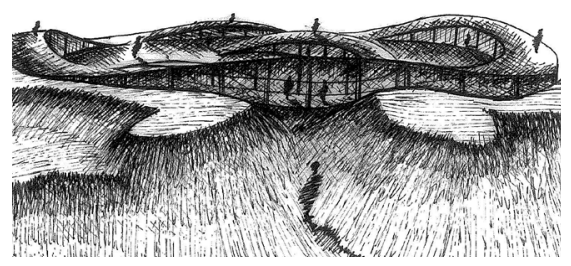




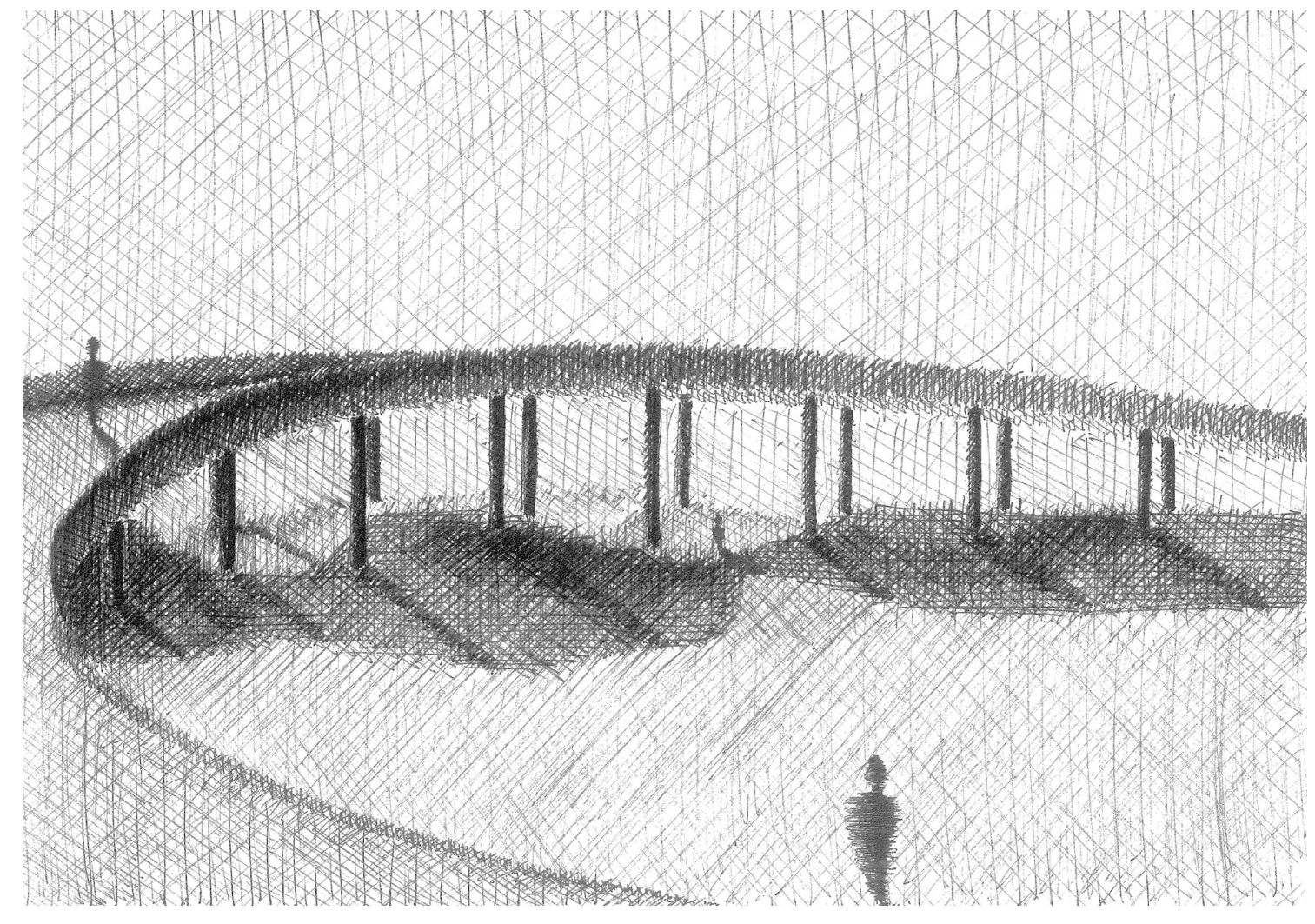




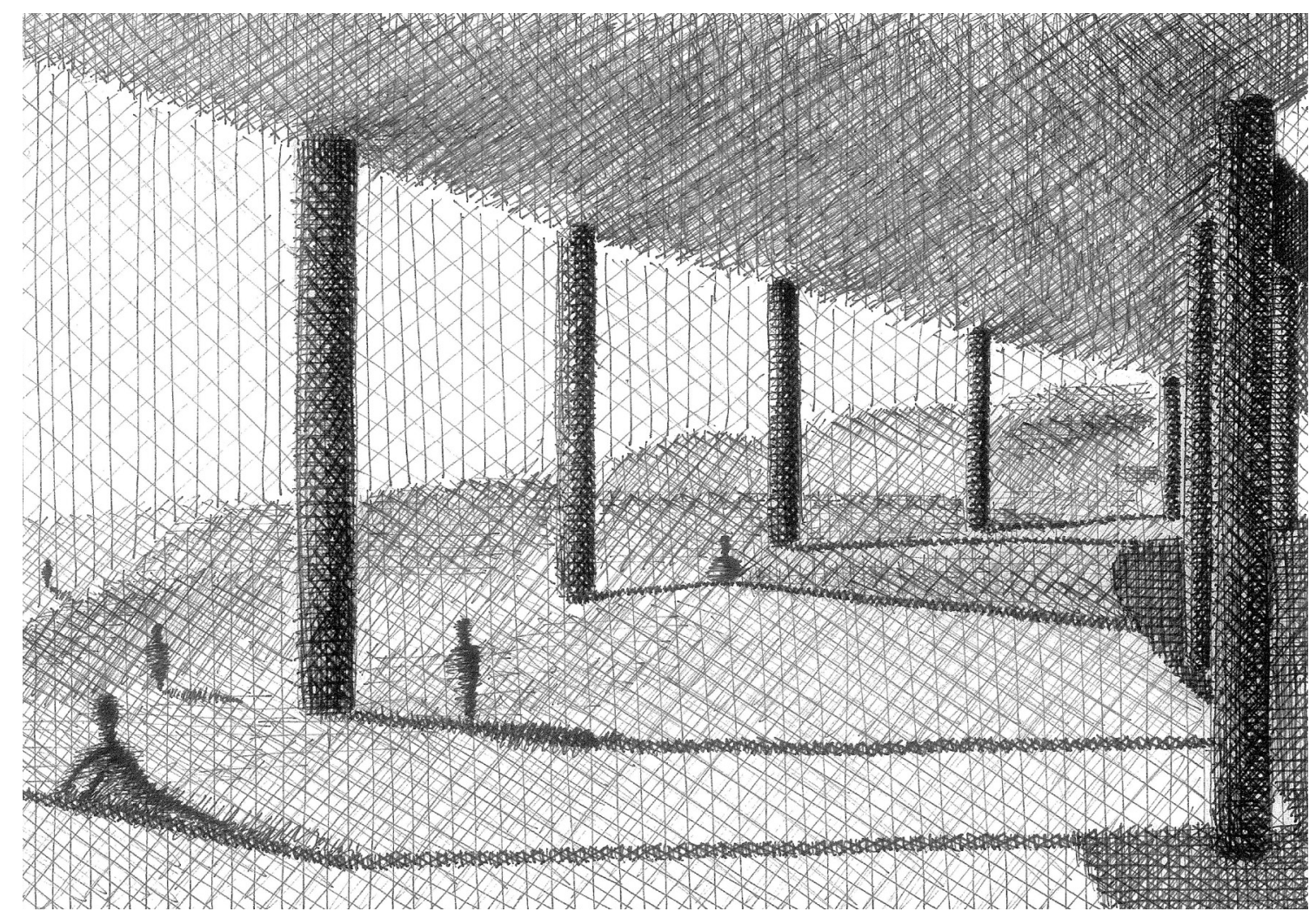

$\wedge$

Figure 59. This drawing shows the sheltered space underneath the boardwalk. 


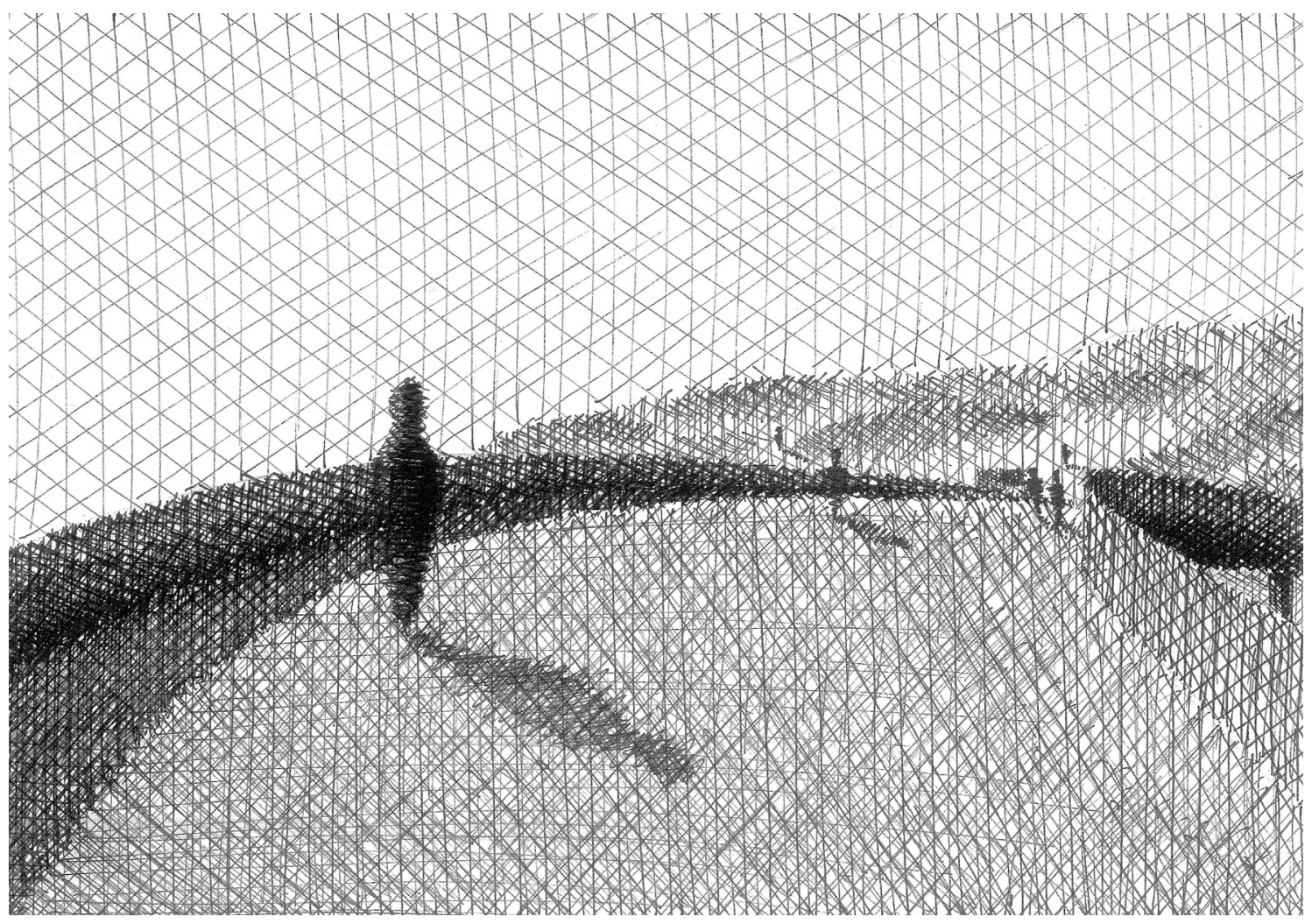

Figure 60. This drawing shows the view from the top of the boardwalk. 


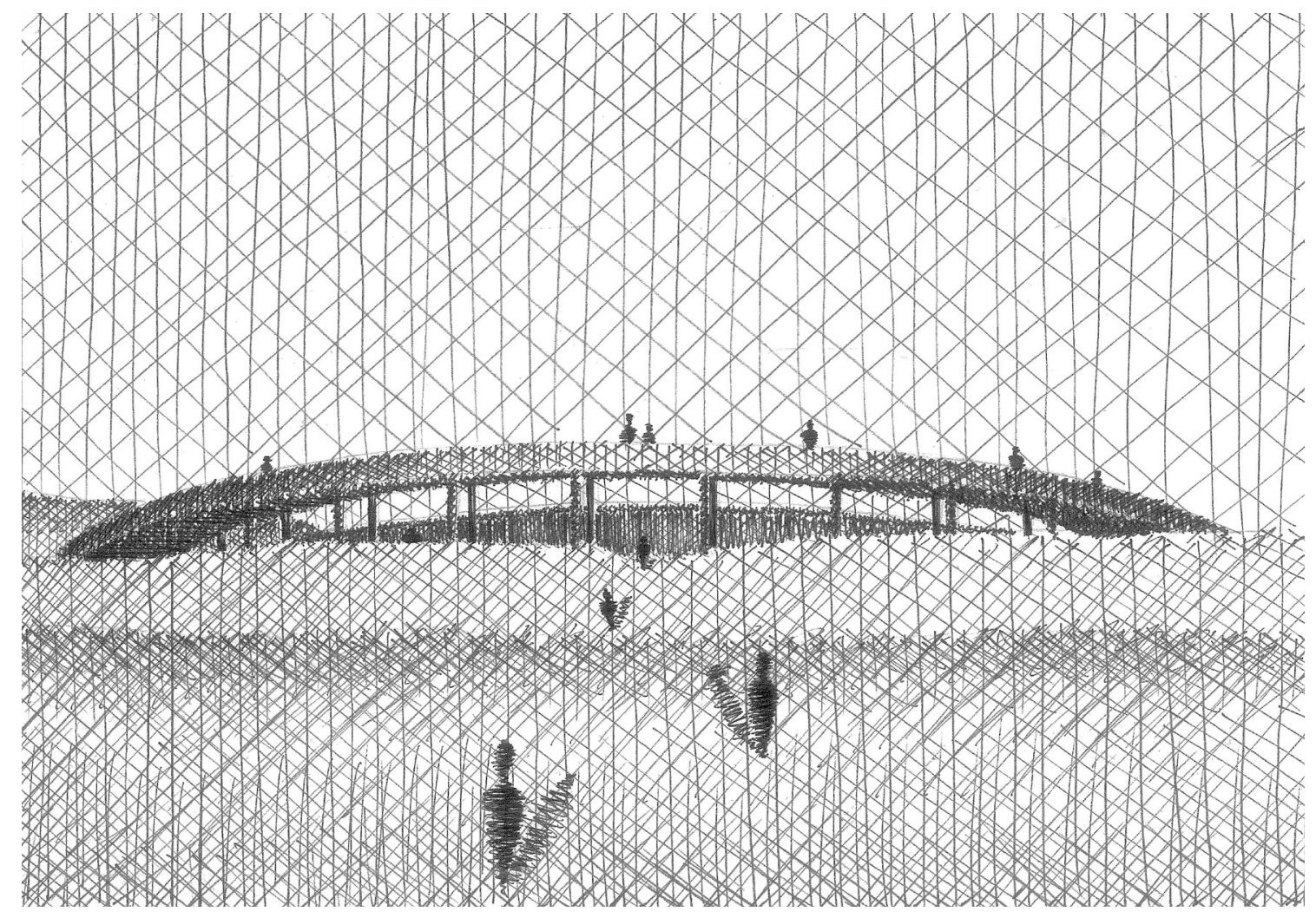

$\wedge$

Figure 61. This drawing shows the boardwalk spanning over the dunes viewed from the beach. 


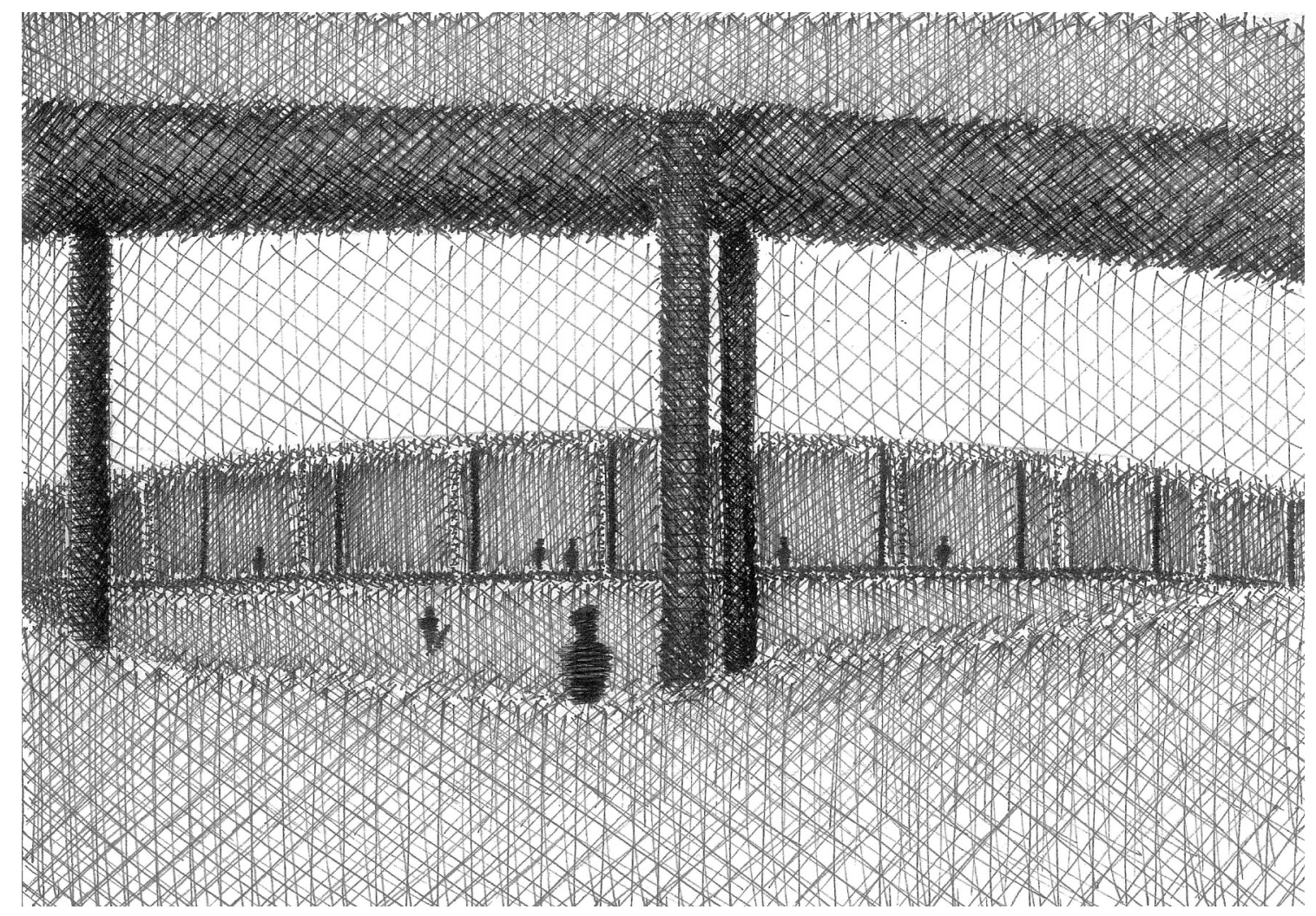

$\wedge$

Figure 62. I drew this drawing from the perspective of an occupant moving through the dunes to access the open site ahead. 


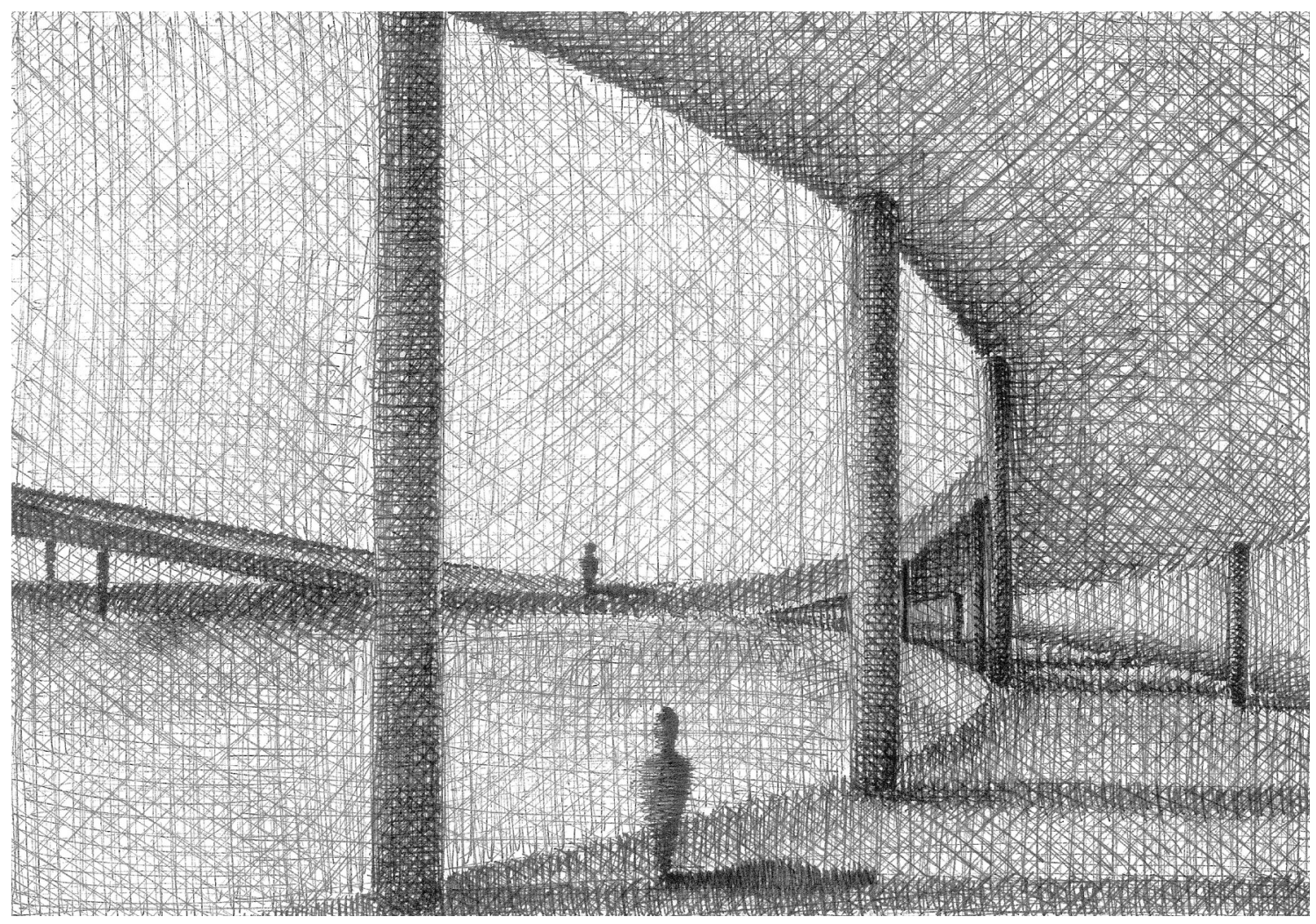

$\wedge$

Figure 63. This drawing shows the interior of the roadside building looking towards the centre of the site. 


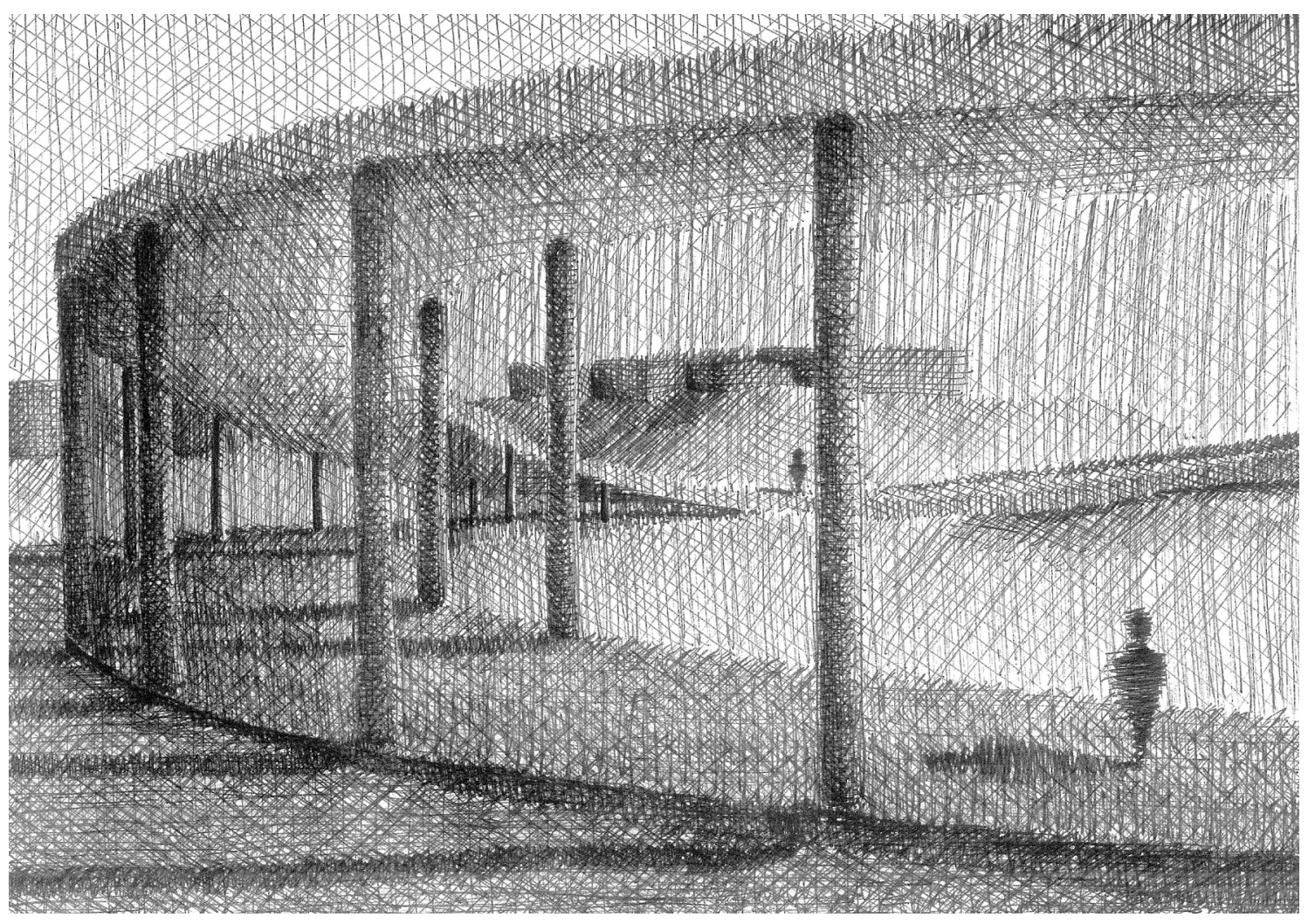

$\wedge$

Figure 64. This drawing illustrates the view one would get when driving south from Queen Elizabeth Park. At this stage in the experiments I had not given much thought to the interior and therefore the building acts more like a pavilion. 

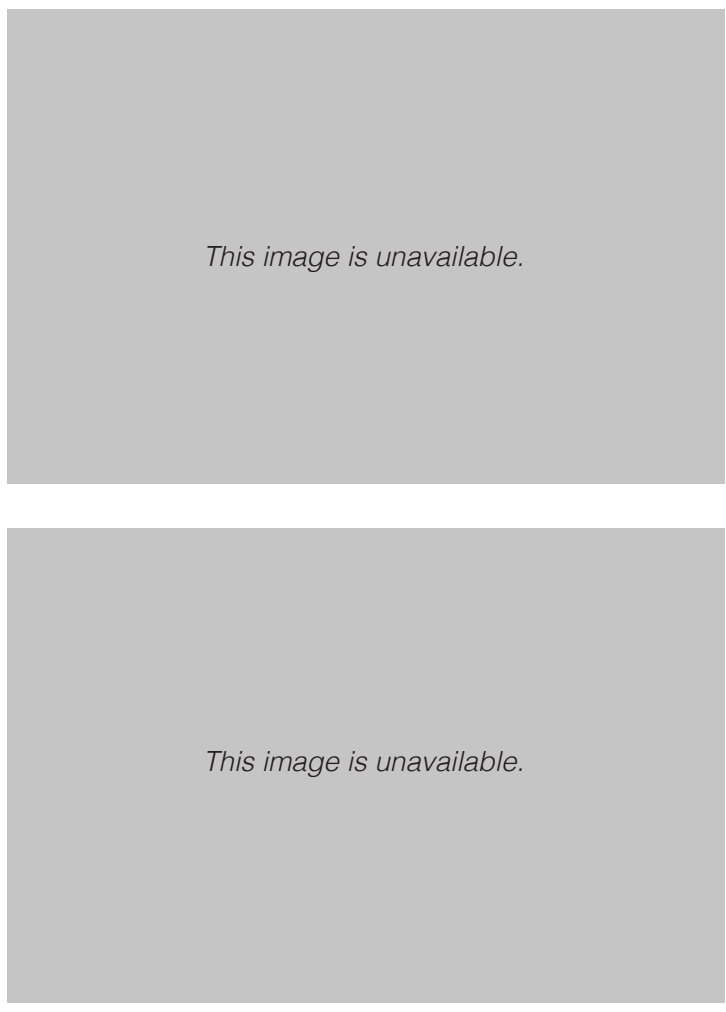

Figure 65. The Rolex Learning Centre designed by Sanaa Architects (Source: Basulto)
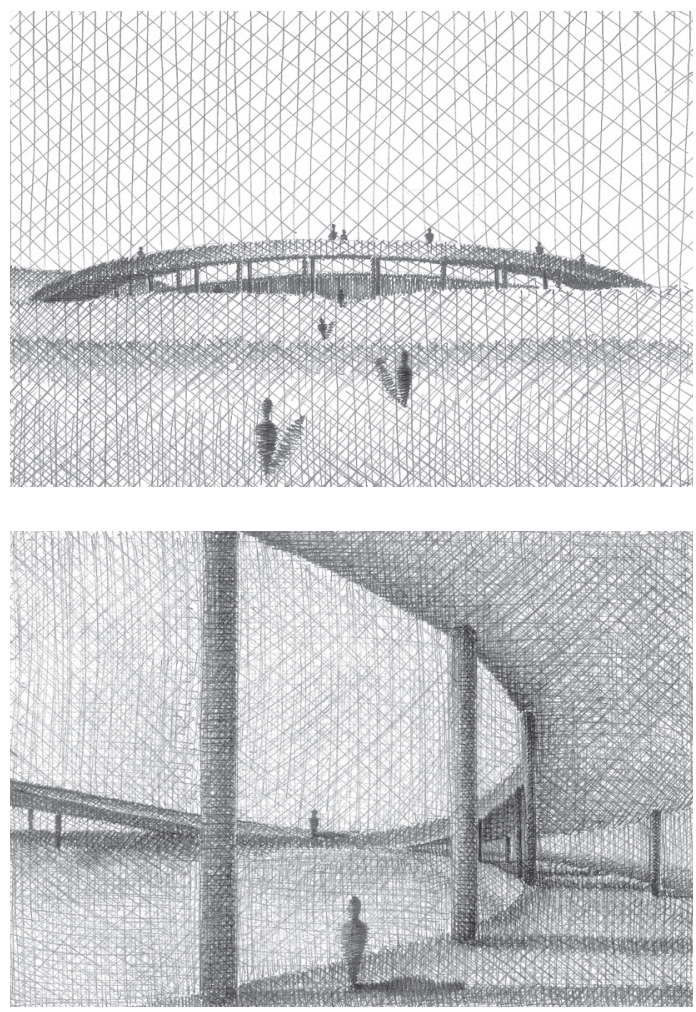

$\wedge$

Figure 66. These drawings show resemblance to the Rolex Learning Centre. 
As I compared my drawings to the Rolex Learning Centre designed by SANAA, I started to see a relevance to my design. Aside from the obvious similarity in the raising of the form, there is also a similarity to the simple interior with its smooth surfaces and vast amounts of glazing. Although I was initially fascinated by Sanaa's design motive to create 'this vacuity, this nothingness' in the interior, which for them defines the space, applying this to my project proved an issue (Garcias).

Despite the circle creating a bold, coherent form, its simplicity viewed from the side (section) is neither inviting nor engaging to the different communities. The simple geometry poses a risk of privileging form over the use-value making me feel uncomfortable. There is also a risk that the interiors expensive appearance with large amounts of glazing and smooth surfaces, will hinder the building's allinclusive attitude.

There is a resemblance between my project and the work of SANAA that has raised a concern about the vacuity of the interior. 
Figure 68. Massey University College of Creative Arts (CoCA) designed by Athfield Architects (Source: Frances).
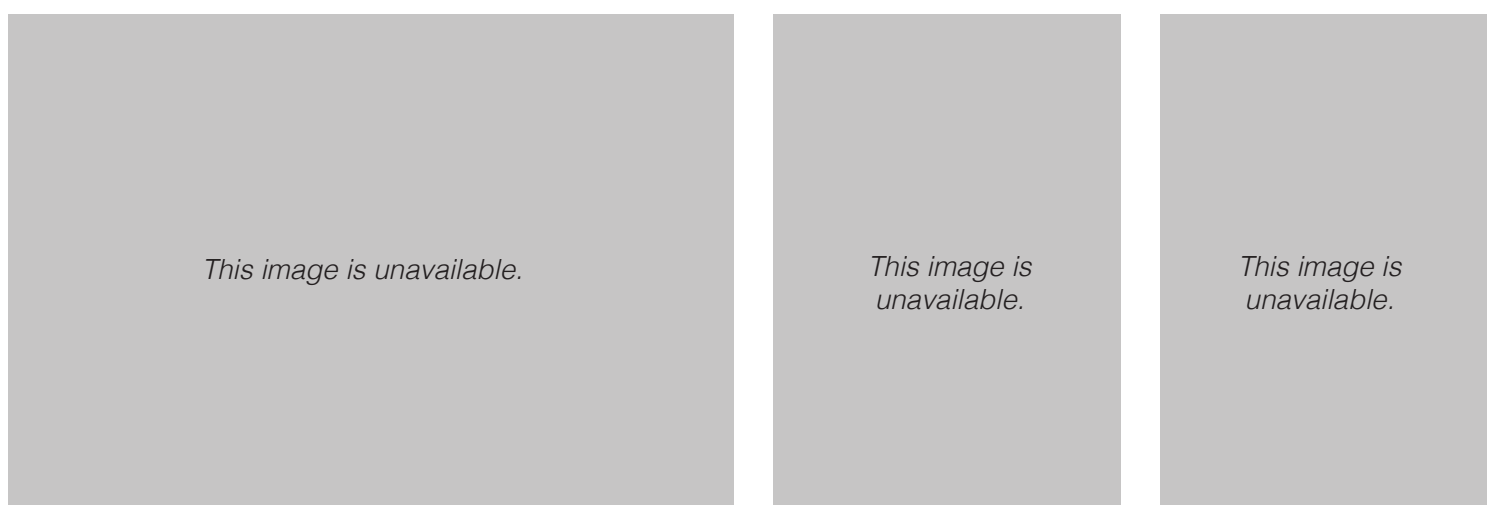

$\wedge$

Figure 67. RMIT Design Hub designed by Sean Godsell (Source: Basulto). 
Given that the form lacks an inviting and engaging user experience, I decided to review a building which for me achieves these qualities. The Massey College of Creative Arts, commonly known as CoCA, has a very inviting feeling about it; as a visitor, I could walk through the building without feeling like I was intruding. The materials that the architects have used provide a feeling of warmth and softness making the space very comfortable to inhabit. This feeling was obvious as the students were even using the floors to work on.

The exterior, however, is somewhat fragmented, making it difficult to read the building as one. The architectural language lacks consistency in that it could be viewed as a series of smaller buildings.
By comparison, the RMIT Design Hub which has a very similar programme, provides a cold internal environment which is seen to be uncomfortable and, therefore, uninviting. Although it lacks the warmth of CoCA, the Design Hub is formally strong with a very consistent and coherent language.

This comparison between CoCA and the Design Hub has raised a very interesting question about which is more successful; a building that is enjoyable from a user's perspective, or a building that has a coherent form and language?

What is considered more successful, a building that is enjoyable from a users perspective or a building that has a coherent form and language? 


\section{How can I create a building which has a strong formal language like the Design Hub, while creating a building that is as engaging and accommodating like CoCA.}

After reading Robert Venturi's book 'Complexity and Contradiction in Architecture', I realised that it is not a question about which building is more successful, rather it is about taking the good aspects of both buildings and getting them to work as one. In his book, Venturi has discussed this as the difficult whole. He explains this as "the difficult unity through inclusion rather than the easy unity through exclusion" (88). He states that the goal is for 'unity rather than simplification'.

Throughout the book he has criticised modern architects for resorting to simplification. He argues that although architects like Mies van der Rohe create beautiful buildings, they tend to be ignorant of the complexities inherent in a project. He states that 'Mies' exquisite pavilions have had valuable implications for architecture, but their selectiveness of content and language is their limitation as well as their strength" (17).

After reading Venturi's discussion about the difficult whole, I have realised that this is the challenge of the thesis; trying to create a building which is both formally coherent, yet addresses the social issues of the communities. 

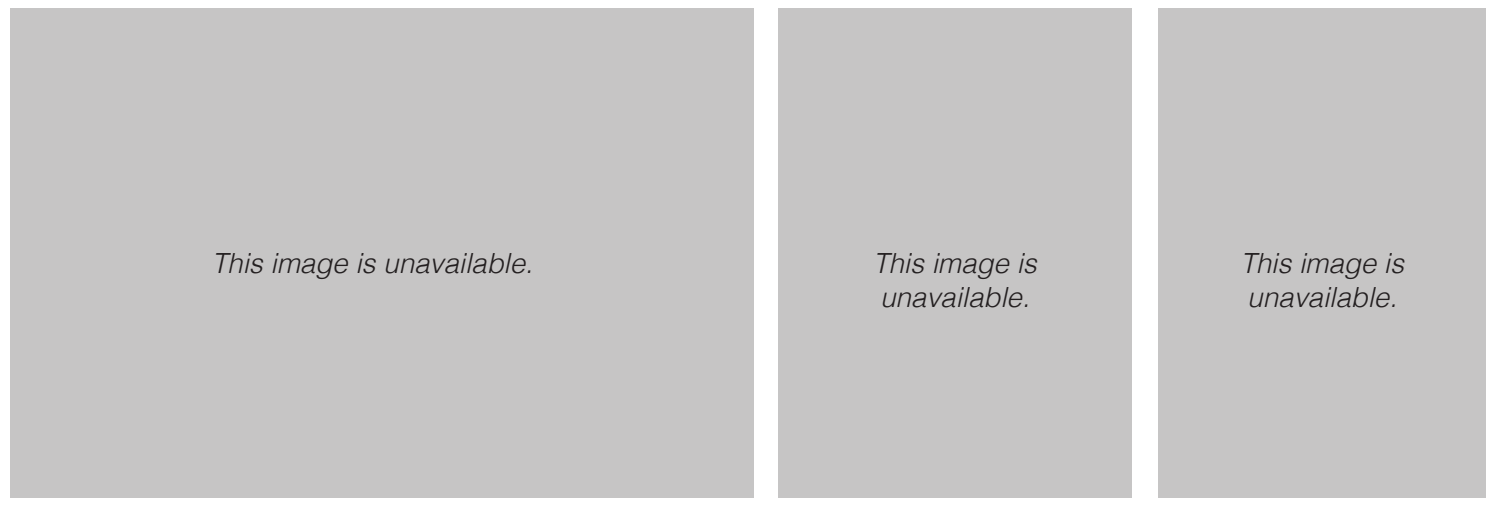

Figure 70. Devonport Library by Athfield Architects (Source: Monsalve).
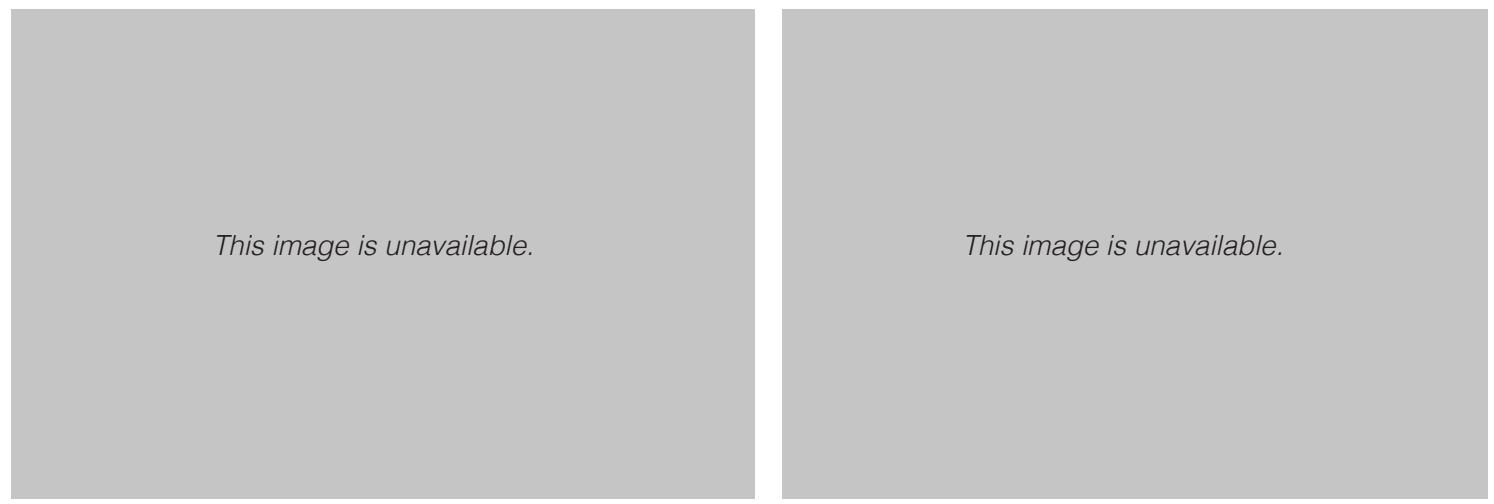

Figure 69. Tuhoe Te Uru Taumatua, designed by Jasmax (Source: McKay).

Given that my drawings started to reveal a simplicity that lacked a connection to the communities, I decided to look at how other architects have designed community buildings to connect with their occupants. In reviewing several community buildings in New Zealand, I have noticed that there is a tendency to design these buildings with a similar aesthetic to CoCA, warm and comfortable. This makes sense as community buildings are for the community and should, therefore, be enjoyed by the community. However, their fragmented forms similar to CoCA, lack clarity and coherence.
After reviewing these different precedents it seems that although the best buildings are concerned with both form and the use-value, it is often that one is compromised for the other. The question is whether there is a strategy which can help architects to achieve a balance between a formally strong building, and a building that addresses the social issues of the design brief. 


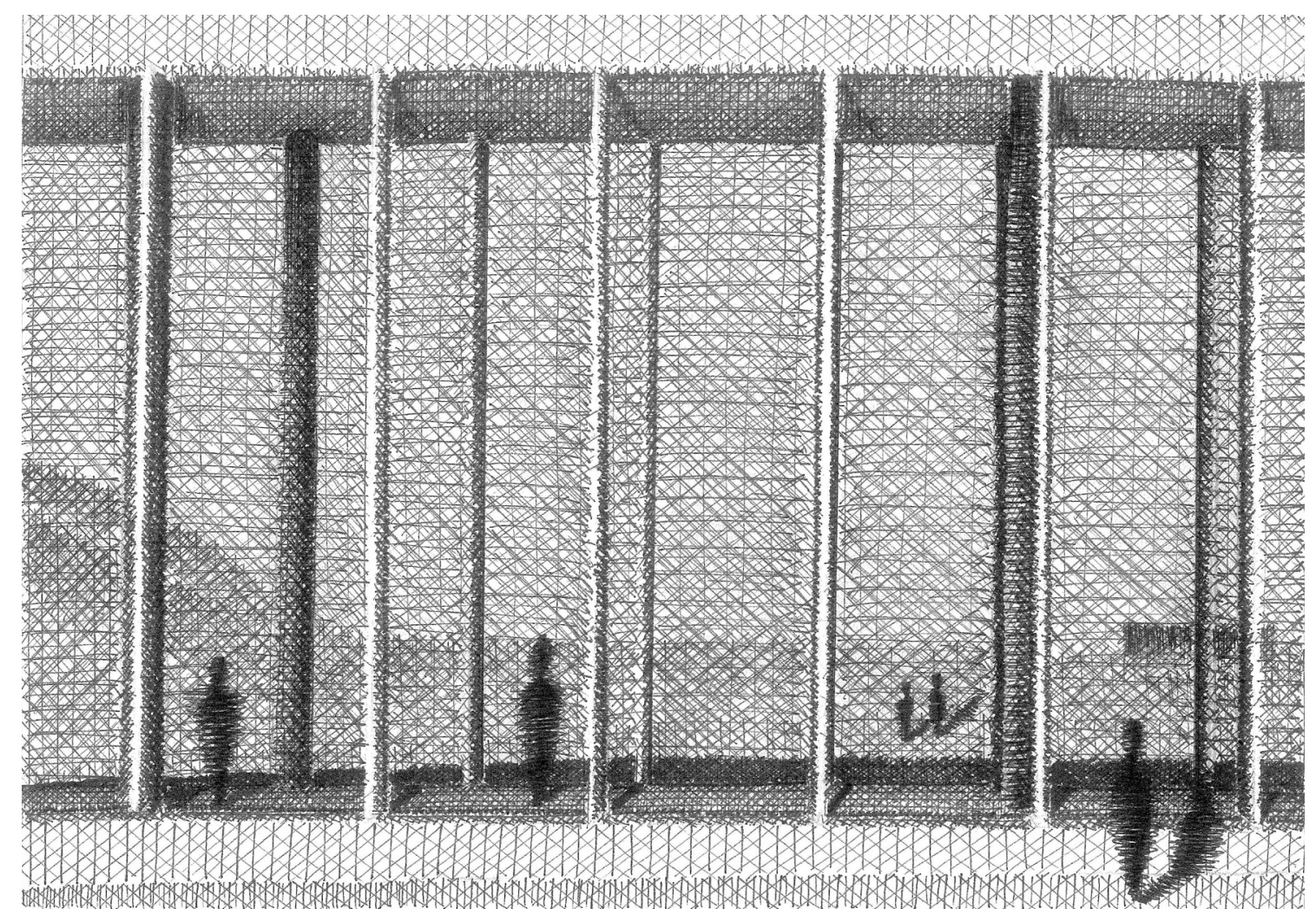

$\wedge$

Figure 71. This drawing of the facade shows the mullions emphasising the verticality of the space.

As I began to realise that the simplicity of the architecture was not captivating the occupant, I started to explore the facade and its details as a way of trying to encourage the occupant to engage with the building. These drawings have become noticeably more inhabitable than the previous drawings. 


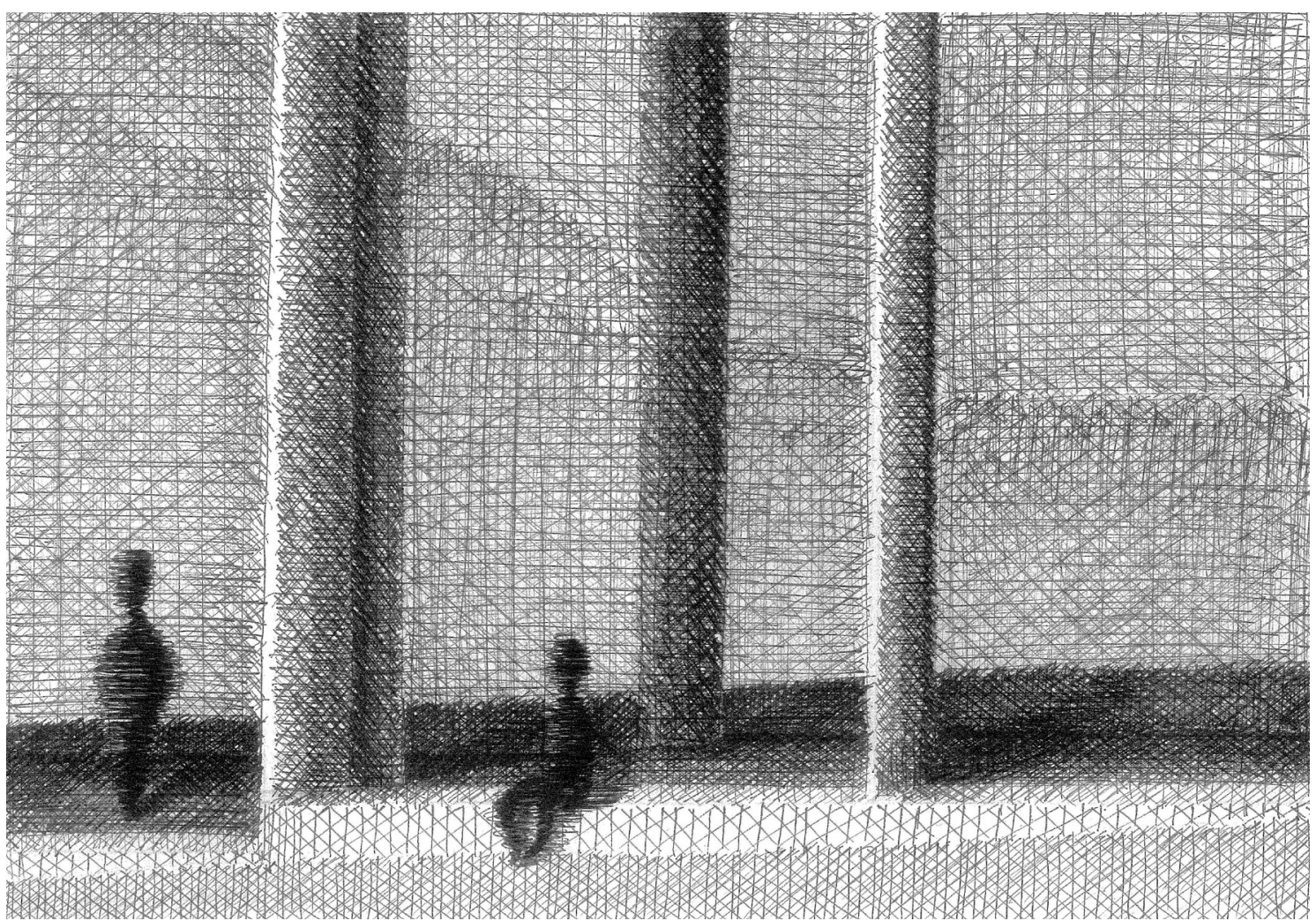

Figure 72. This drawing explores how I could create ledges on the building's facade for seating. 


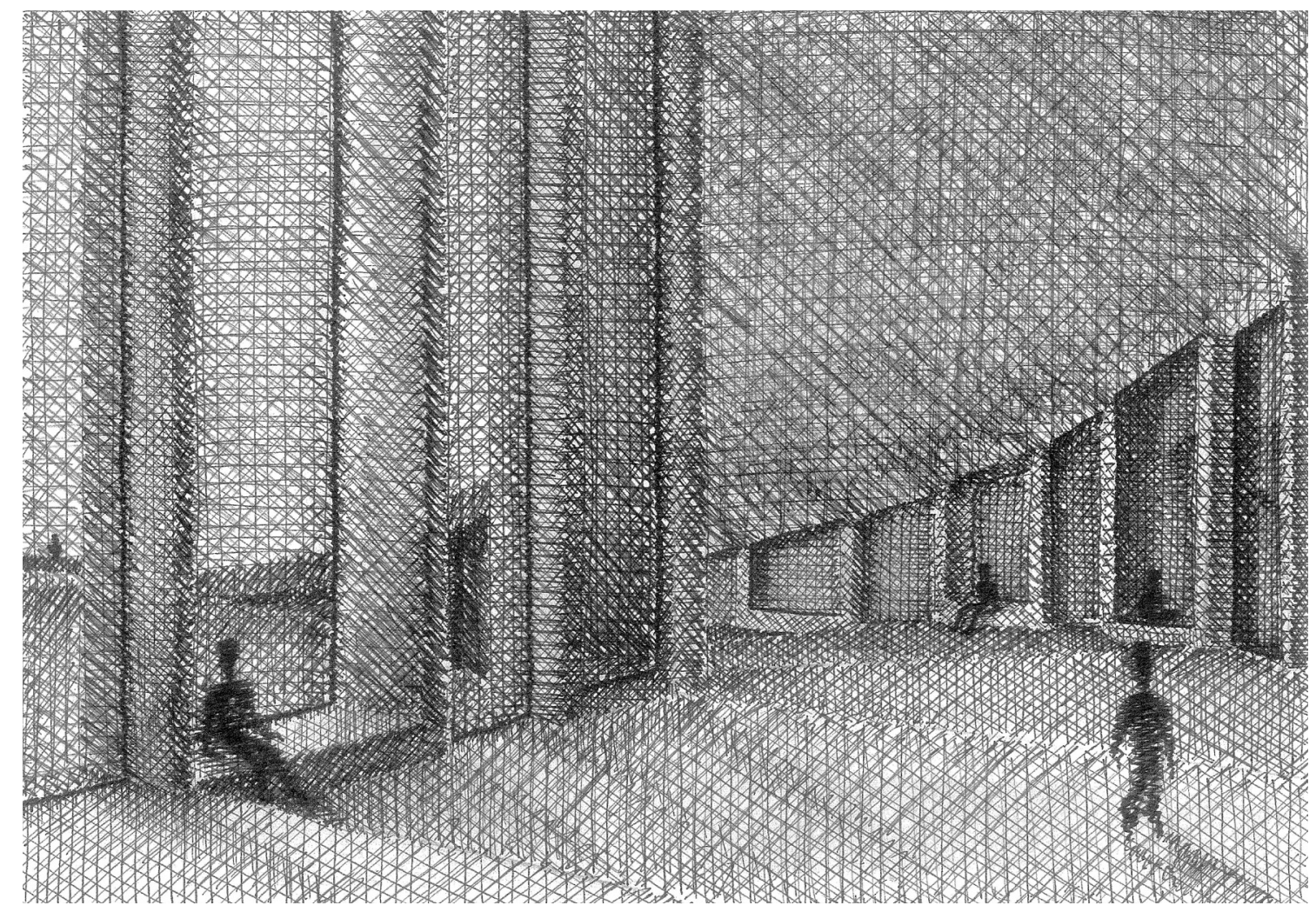

$\wedge$

Figure 73. In this drawing, I was exploring how I might level the building to work with the slope of the site and the sloping roof. 


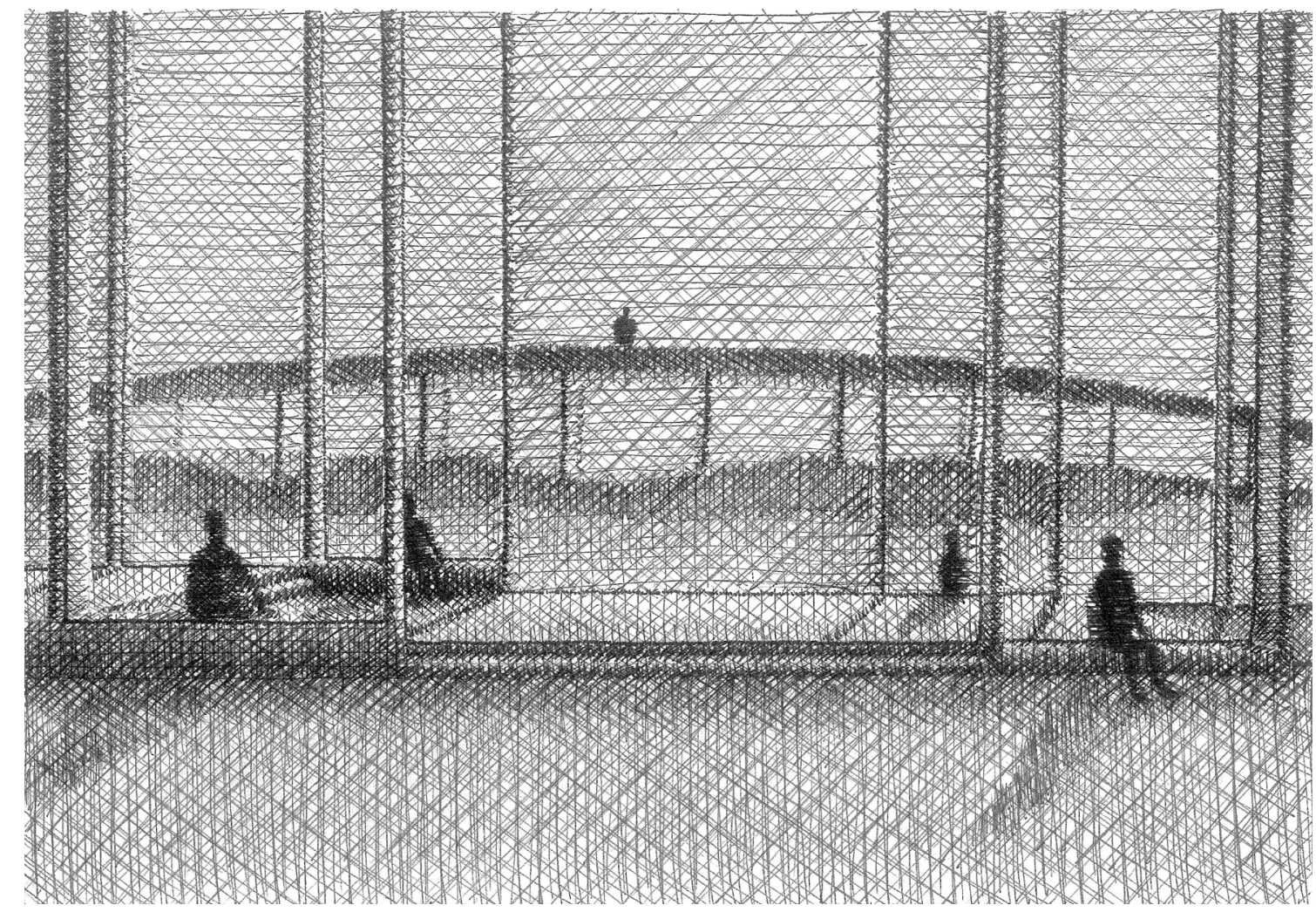
$\wedge$

Figure 74. This drawing illustrates how I could use the levelling of the building to create seating on both the interior and exterior of the facade. 

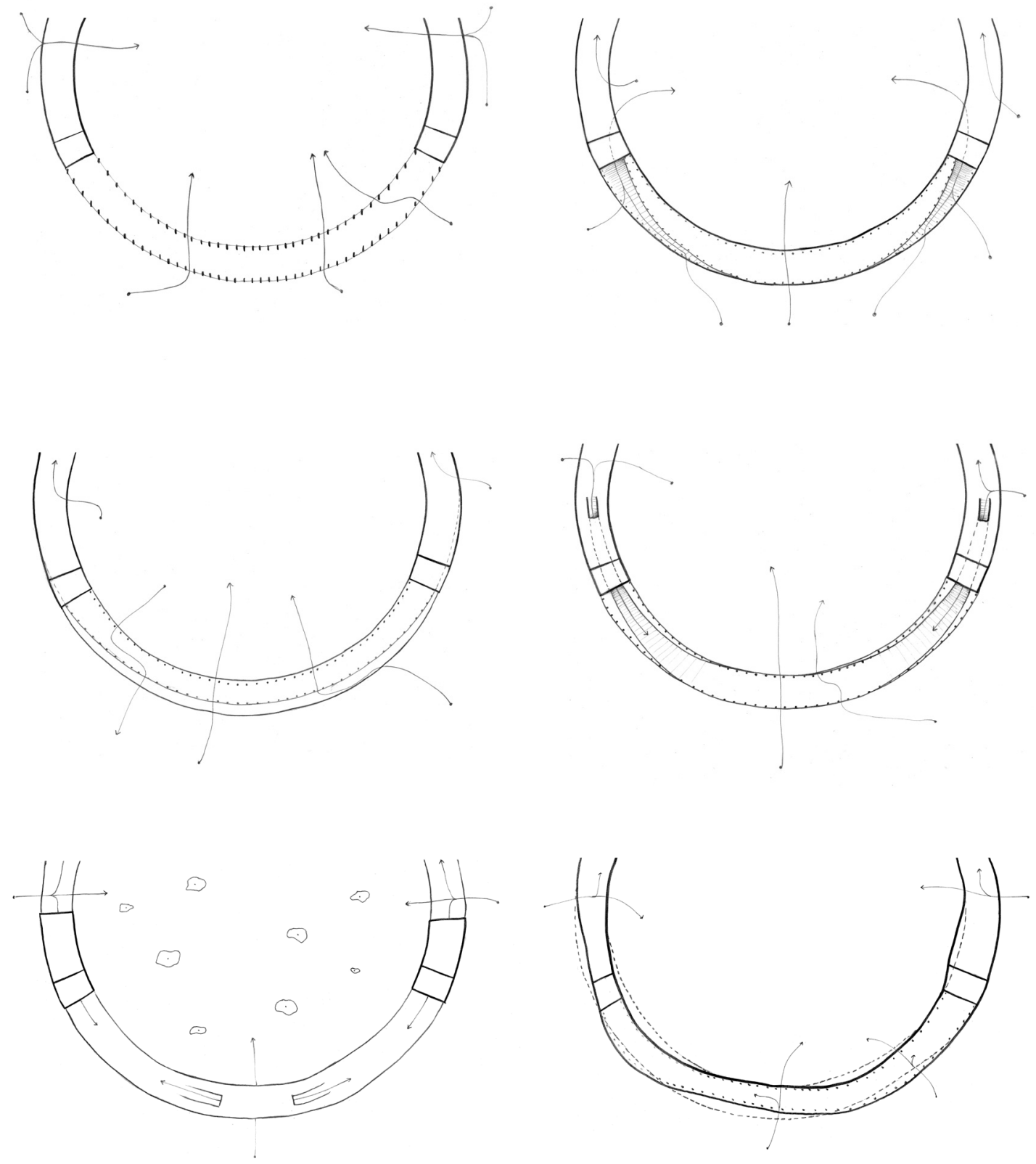

$\wedge$

Figure 75. As I continued to explore the design of the facade, I turned to the plan to start to understand how the circulation might inform the placement of the structure and the entrances.

124 

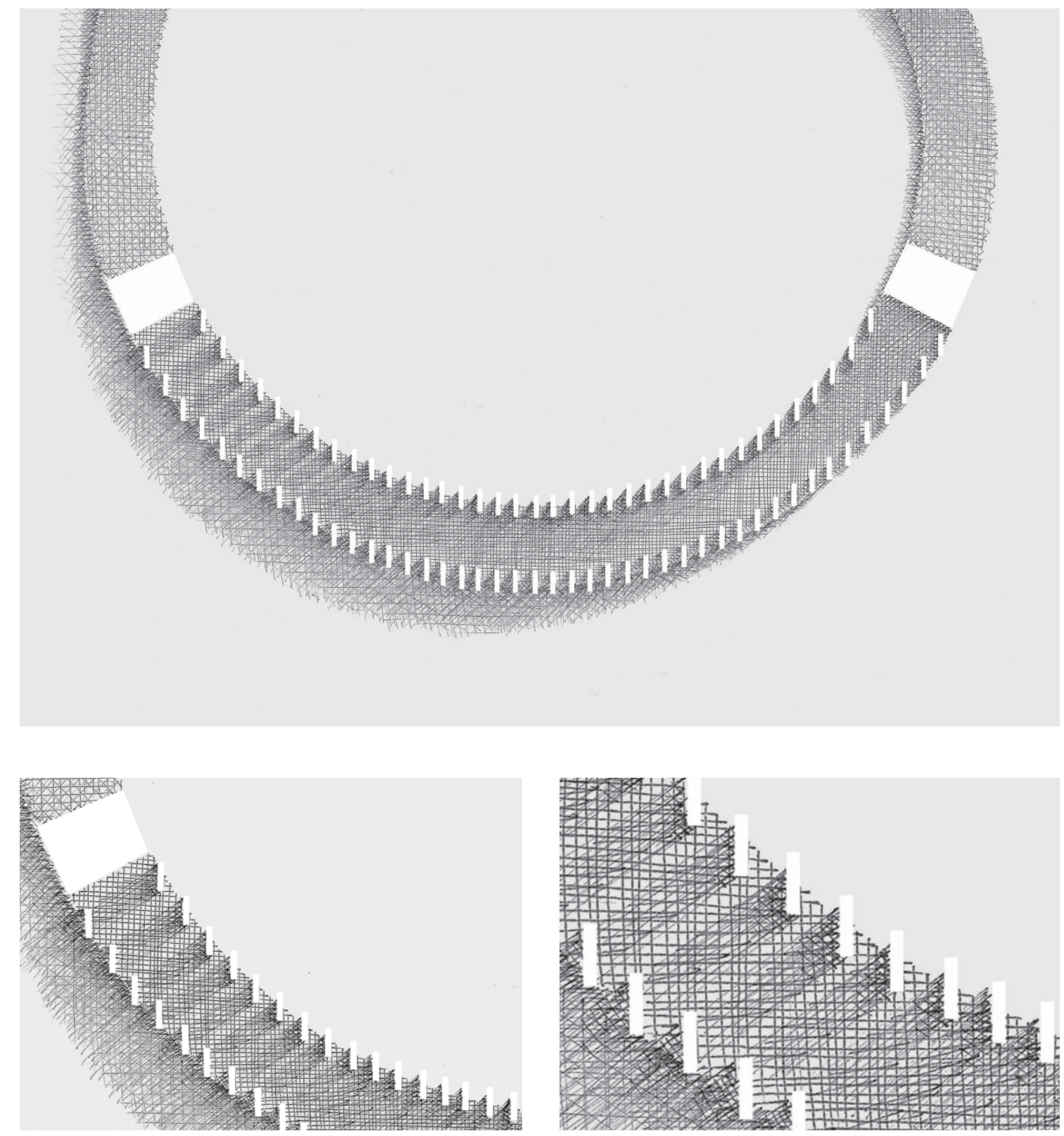

Figure 76. I also explored the plan using this drawing technique with the thought that it might help inform the design. 

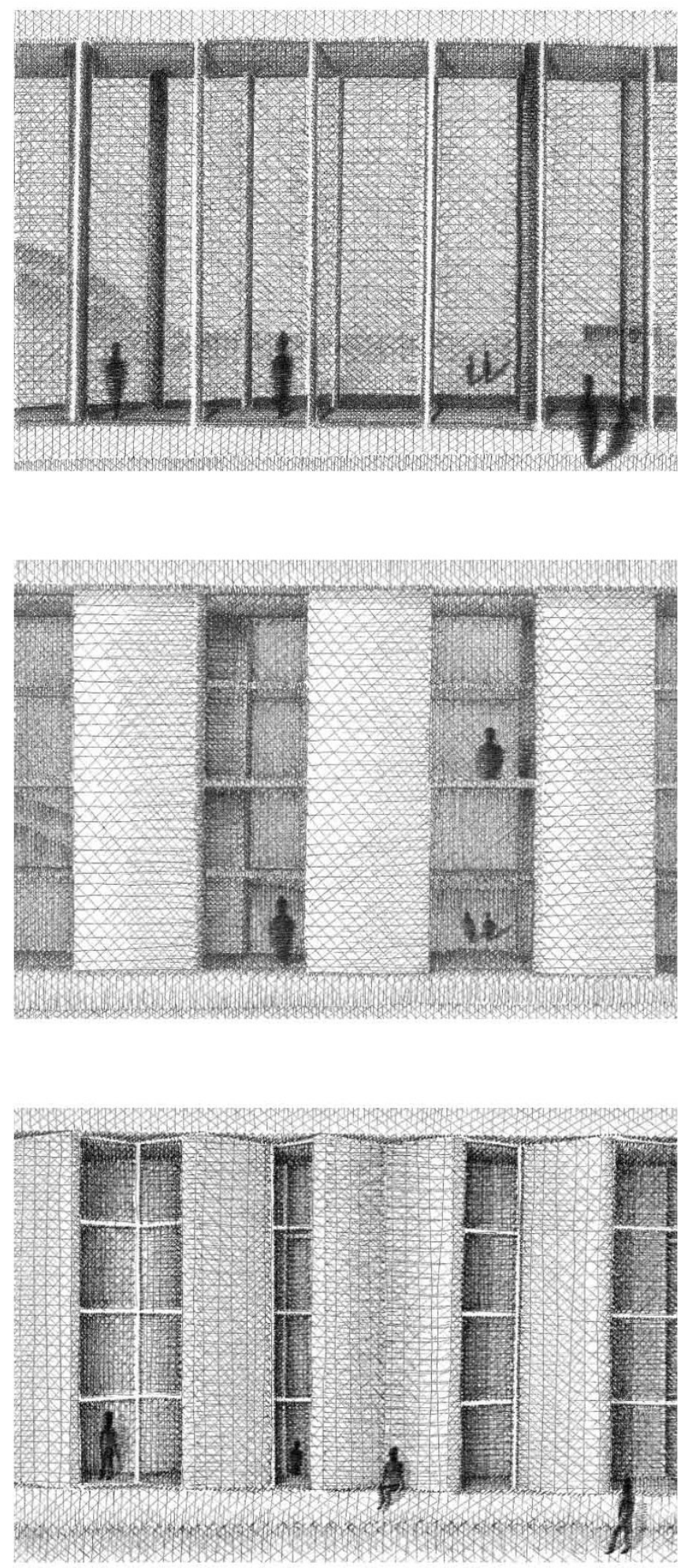

Figure 77. These drawings further explore different facade designs. 
In these drawings I have developed the facade breaking away from the simplicity expressed in the first iteration. This simplicity is associated with being expensive making it inaccessible to the different communities. In breaking up the facade, I was hoping to make the building more accessible.

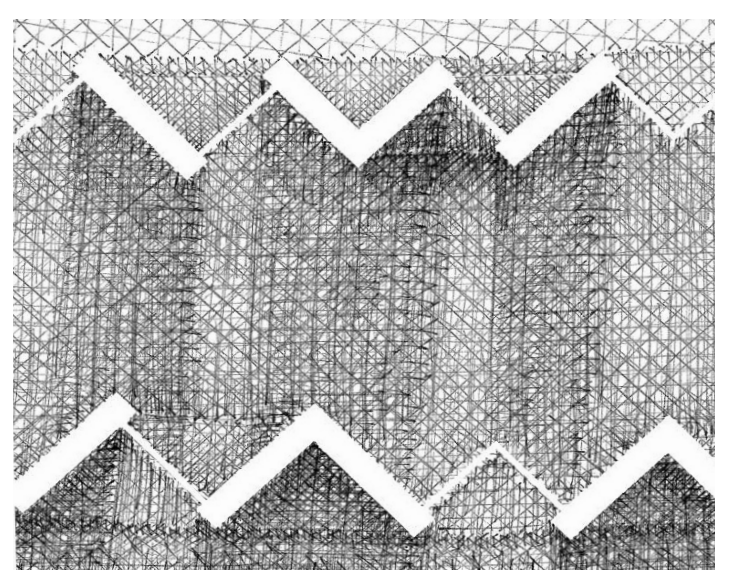

Figure 78. This drawing illustrates the arrangement of structure and glazing in the plan. 

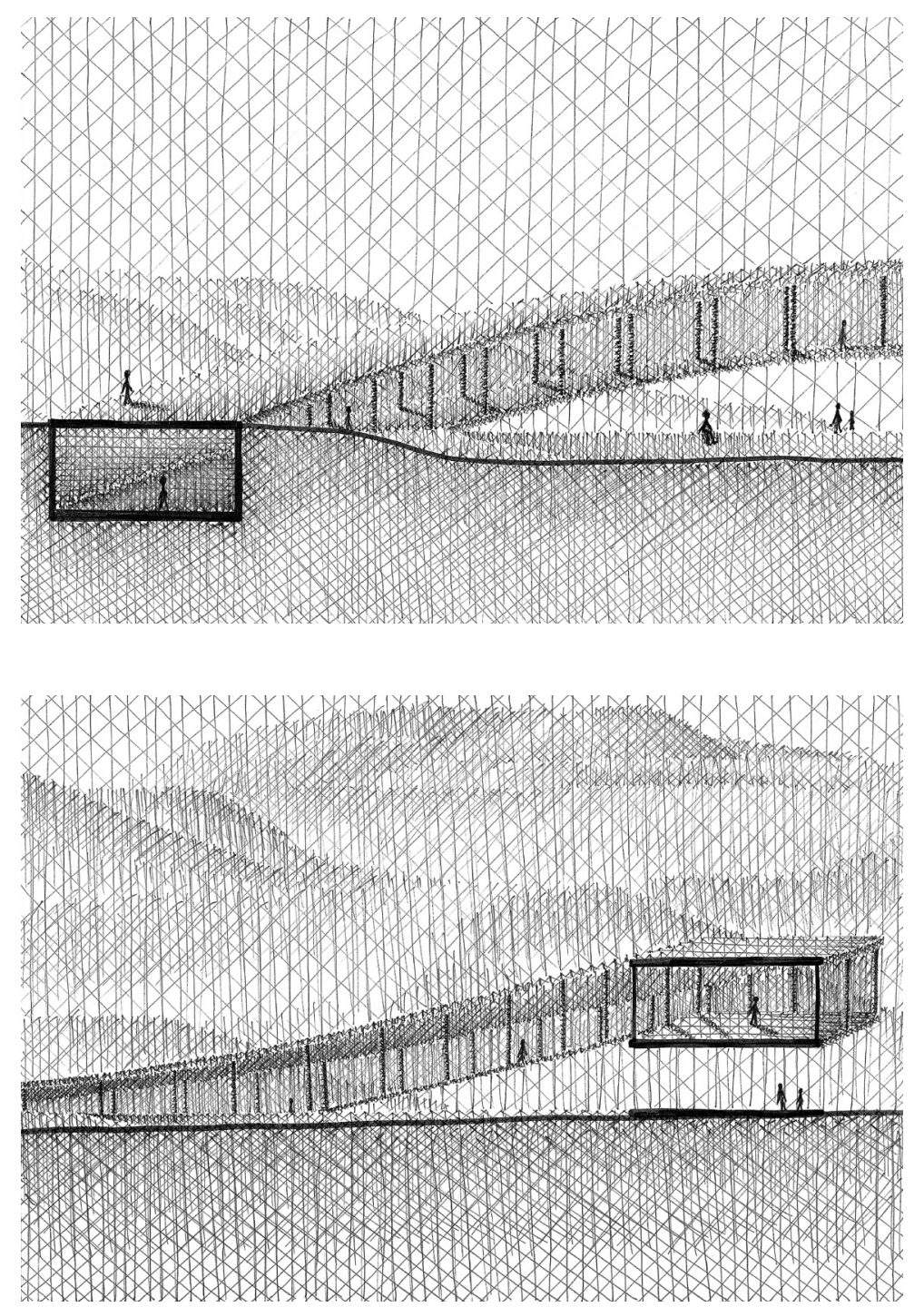

$\wedge>$

Figure 79. In these section drawings, I was exploring the connection between the building and the landscape (above), and the transition from the outside to the inside of the circle (right). 

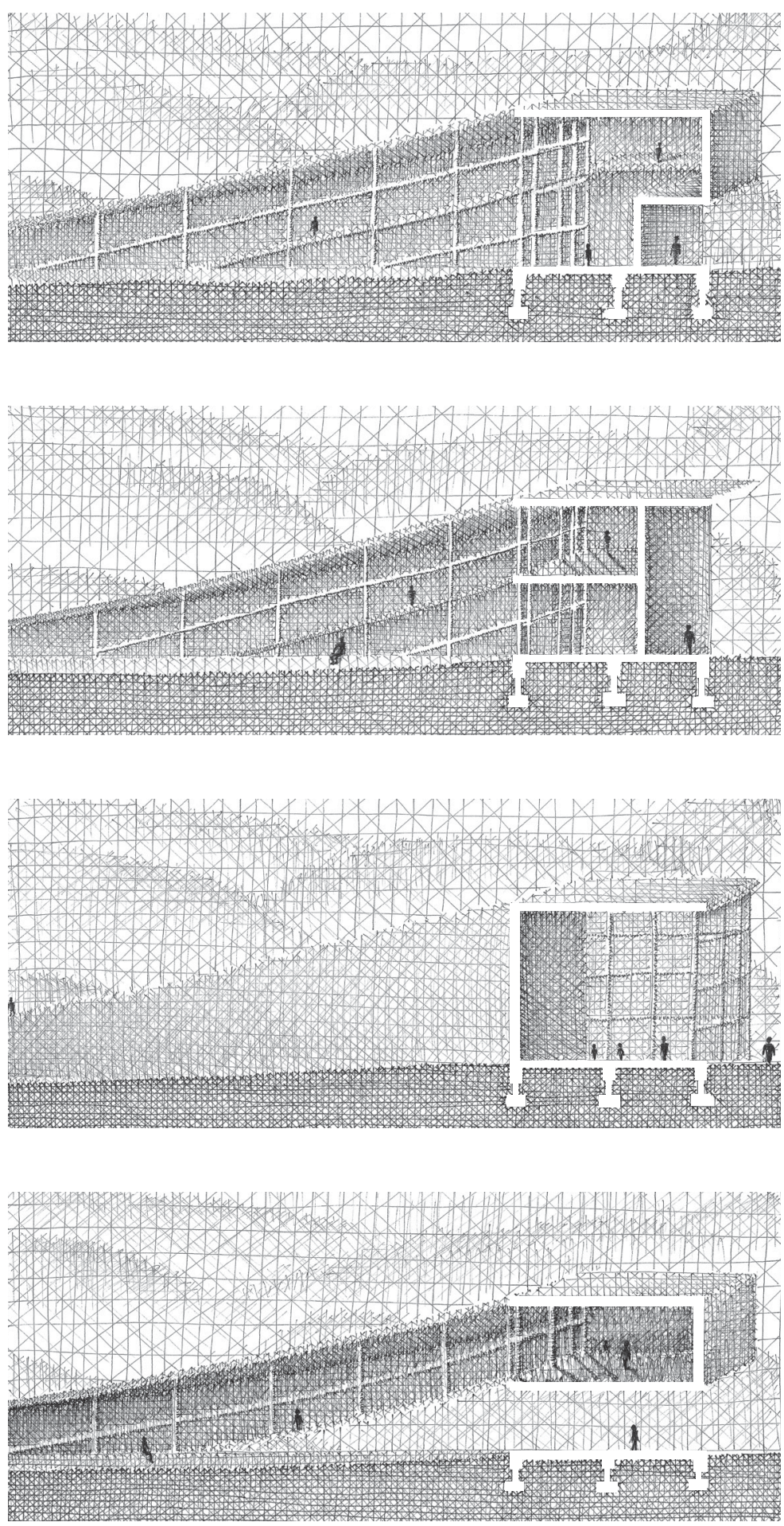
This image is unavailable.

Figure 80. Colosseum section and elevation (Source: Penn State University Libraries Collection).

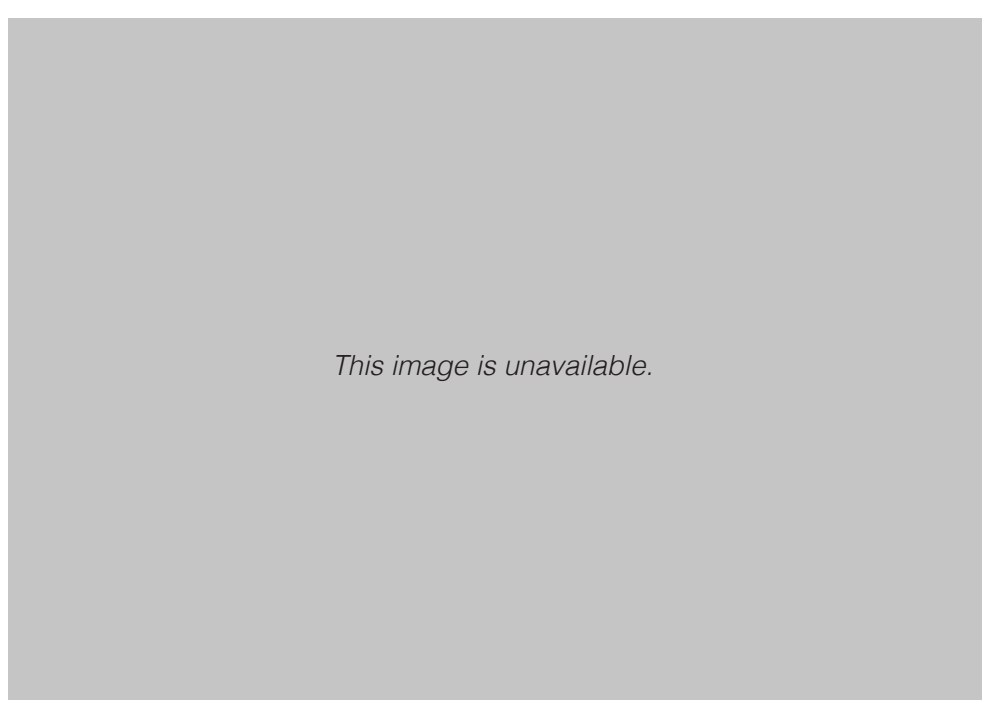

$\wedge$

Figure 81. Pantheon cross-section (Source: Section study, Piranesi) 
As I realised the circular form is a lot more complicated than first envisioned, I decided to look at other circular buildings and how these architects have connected the pure geometry of the circle to its surrounding context. Given that the plan for these precedents is the same, a circle, I was more interested in the overall aesthetic of the building and how it is perceived from the side (section).

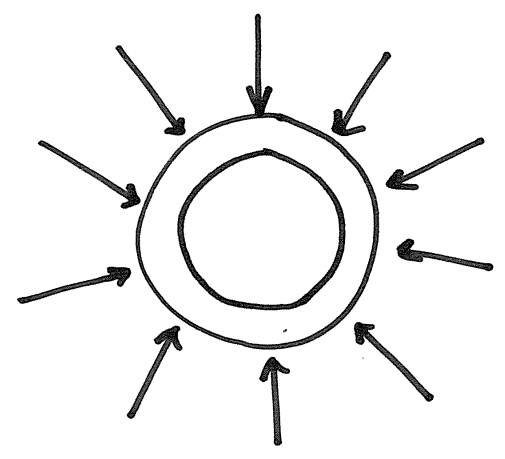

colosseum
Firstly I referred to Ancient Rome to analyse two key circular buildings of that time, the Colosseum and the Pantheon. The main difference between these two precedents is the way people approach and enter the buildings. The Colosseum engages with the street the whole way round the building. It has an entrance at every arch allowing people to enter at any point before making their way up into the stands. The Pantheon, however, has one entrance defined by a portico which leads into the rotunda (circular room enclosed by a dome).

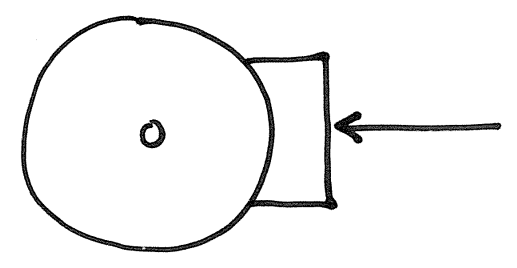

panther on

131 
This image is unavailable. 
This image is unavailable. 
This image is unavailable.
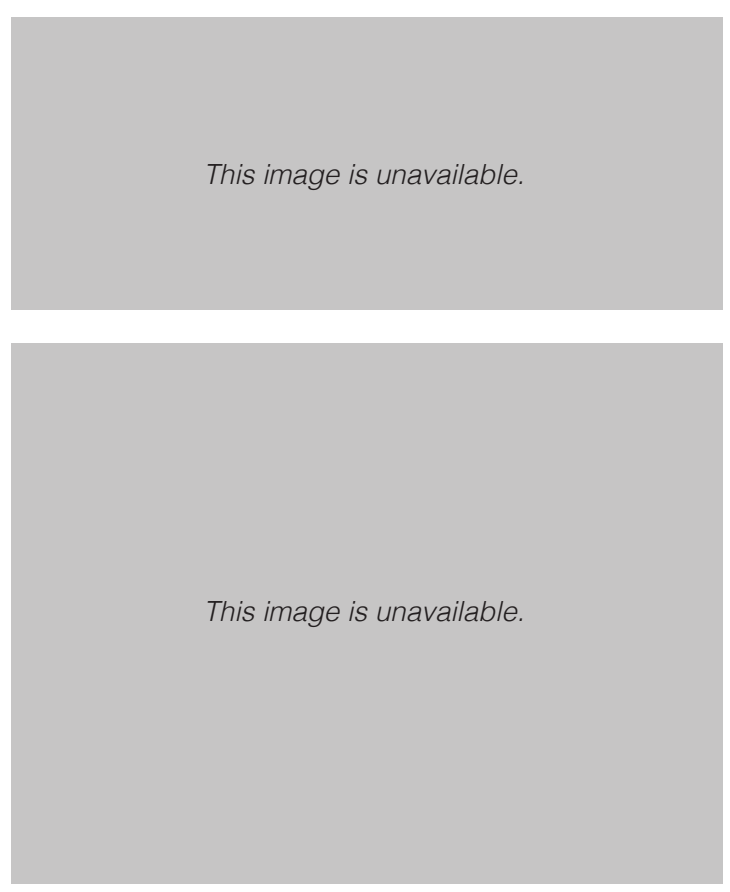

$\wedge$

Figure 83. The Apple Campus II designed by Foster + Partners (Source: Basulto).

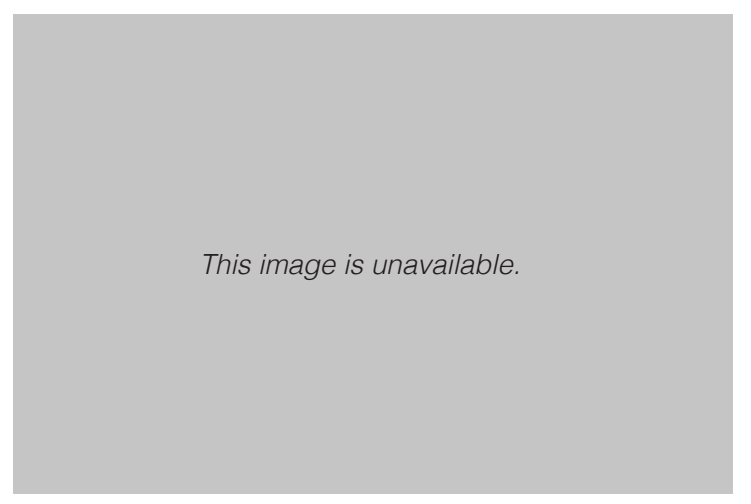

$\wedge$

Figure 85. The MAX IV designed by FOJAB arkiteker \& Snohetta (Source: MAX IV / FOJAB arkitekter + Snøhetta).

$\wedge$

\section{This image is unavailable.}

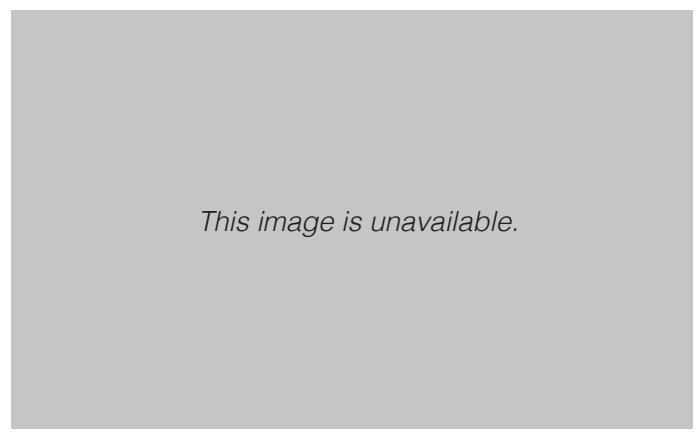

Figure 84. The Hyperloop, designed by BIG (Source: Mairs).

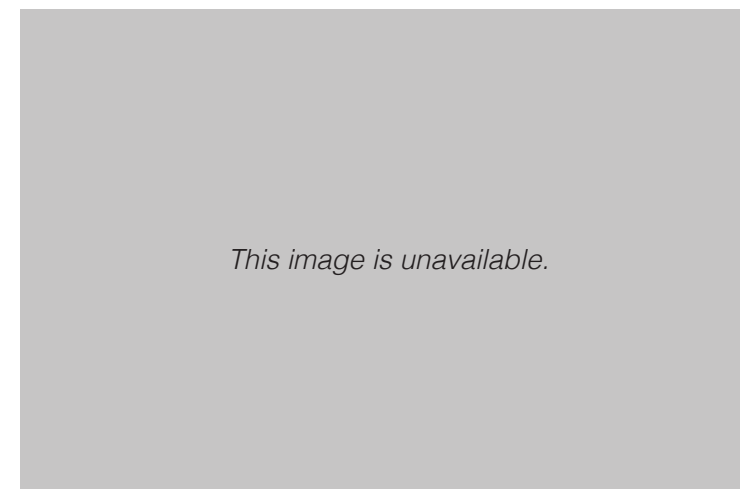

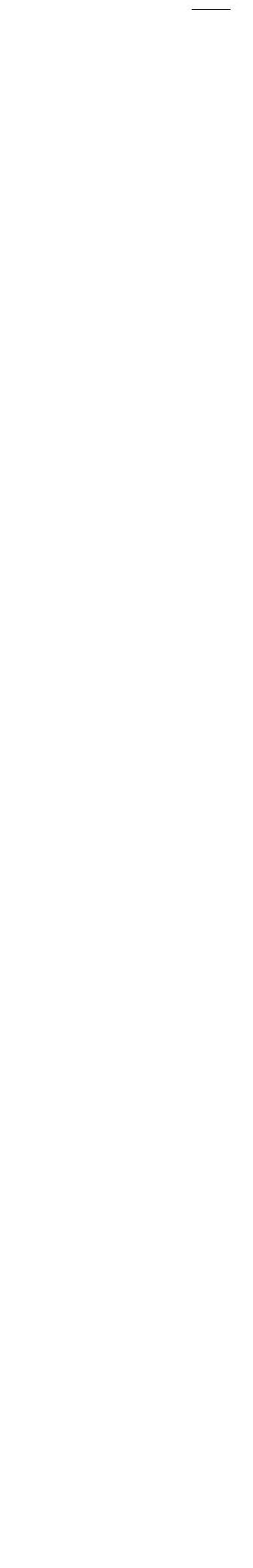


These precedents have recently been proposed or newly built. I have grouped them based on the scale and visual aesthetic of the buildings.

The three buildings to the left are extremely large scale. Due to their size and visual aesthetic, they sit boldly on the landscape. The artificial materials also juxtapose the landscape enhancing the purity of the circle. 


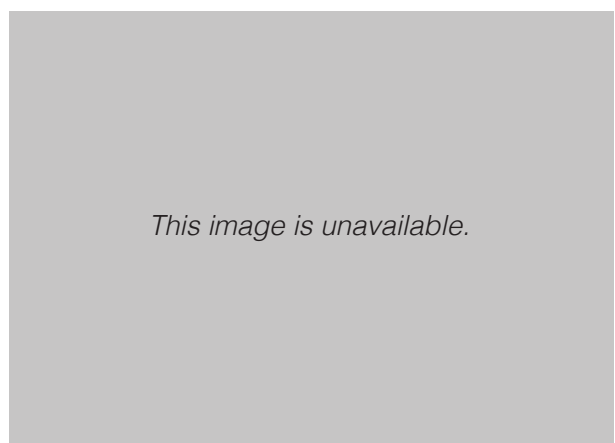

Figure 86. Infinite Bridge designed by Gjøde \& Povlsgaard Arkitekter (Source: The Infinite Bridge).
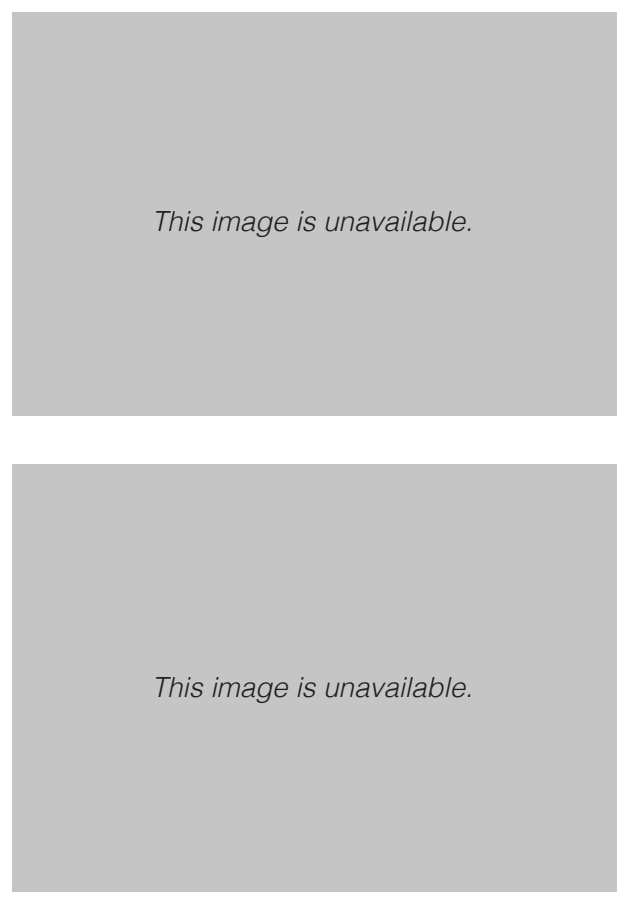

$\wedge$

Figure 87. Hostel Wadi designed by Studio Bernardo Secchi \& Paola Vigano (Source: Hostel Wadi).

Figure 88. The Brick Pit Ring designed by Durbach Block Jagger Architects (Source: The Brick Pit Ring). 
These precedents are of a much smaller scale than the previous buildings. They are also far more graceful in the way they sit in the landscape. The Brick Pit Ring and The Infinite Bridge are both raised above water. Whereas, Hostel Wadi although it is not raised up off the ground, it does consider the landscape carefully in that the architects have retained the existing trees and created a green roof. All three precedents use natural materials in tones that help soften the pure geometry of the circle in the landscape.

The size of these precedents and the connection to the landscape means that these buildings are far more inviting and comfortable than the previous examples. The architects in using the natural materials have disguised the form rather than using artificial materials to emphasise the purity of the circle. 
For a cultural building to really contribute to a city, it must be part of a social ecosystem, not simply a place for tourists to visit. A cultural hub must be connected into a pre-existing cultural vibrancy, supported by decent infrastructure and a community that actually lives there.

(Murray, 1) 
After reviewing the different circular buildings, I found that the buildings which respond with care to the surrounding context are far more inviting and accommodating than the buildings which sit boldly in their context. For that reason, and that the landscape is the common thread which attracts the communities to this area, I decided to focus on the landscape and the connection between the form and the dunes. This connection to the landscape should make the building more accommodating to the communities, and therefore the communities should be more inclined to use it.

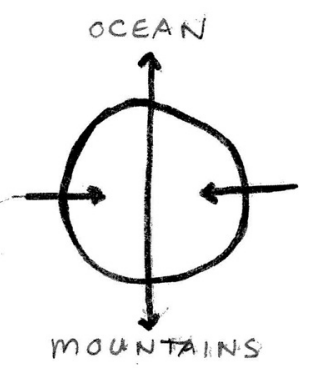




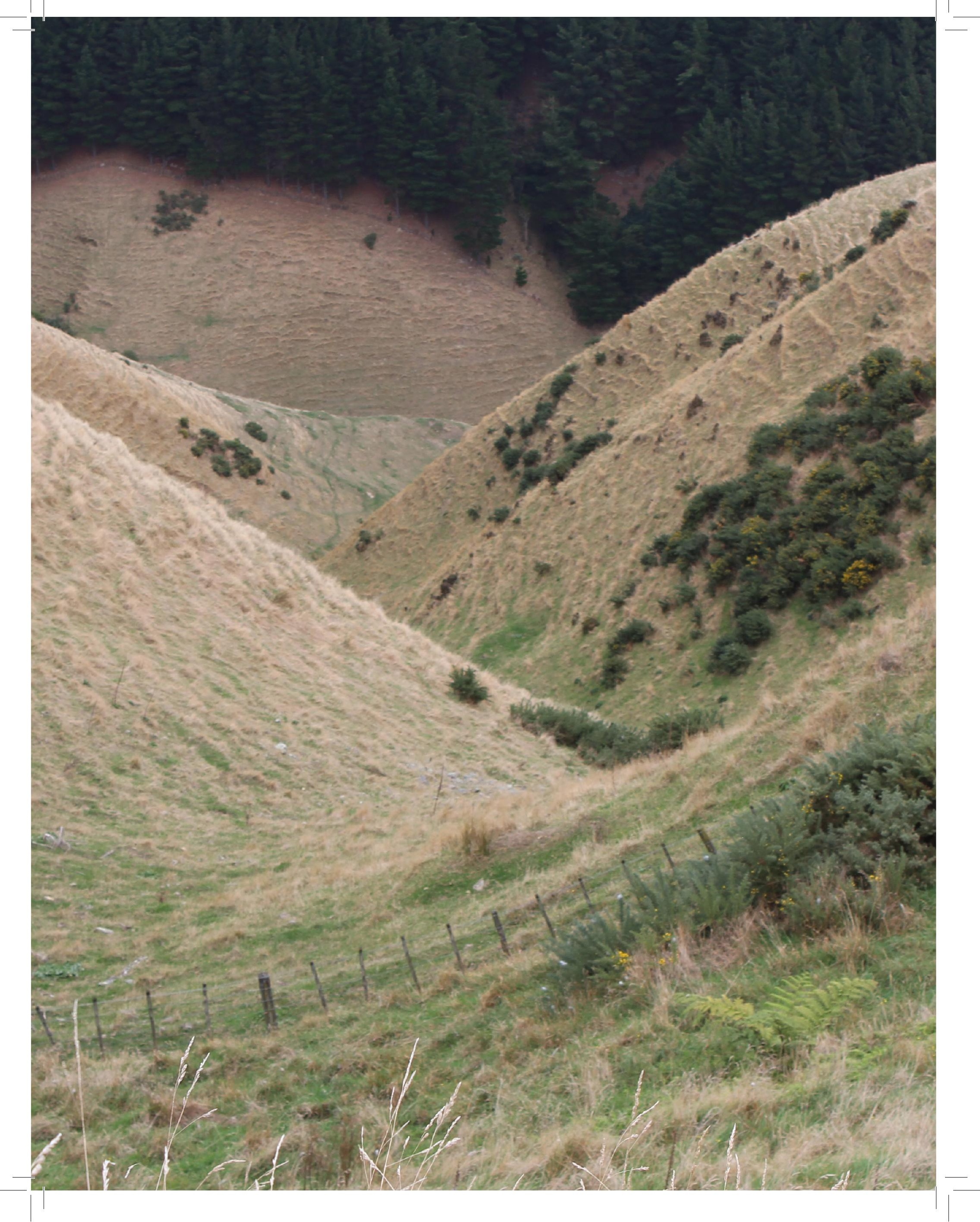




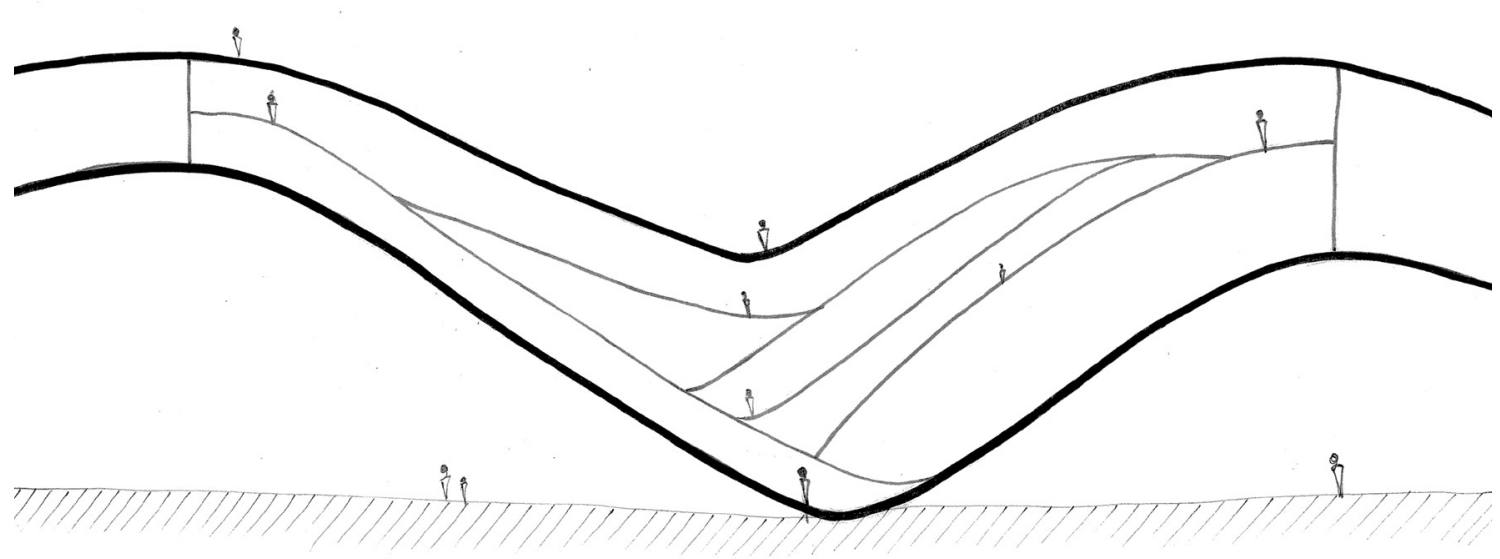

LOW POINT

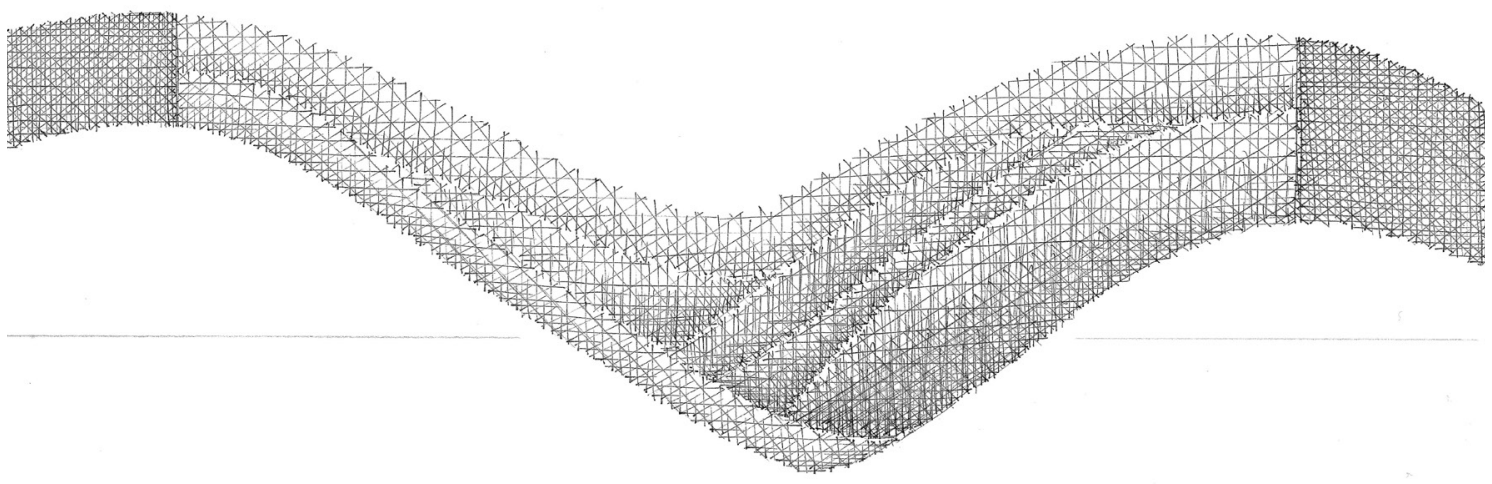

Figure 89. Unsure how to make this connection to the landscape, I produced an abstract drawing of the surrounding hills of the site. In this drawing, I was trying to capture the same feeling you get when moving through the dunes, exposed at the top and sheltered at the bottom. This feeling has been a preoccupation of mine since the first visit to the site. 


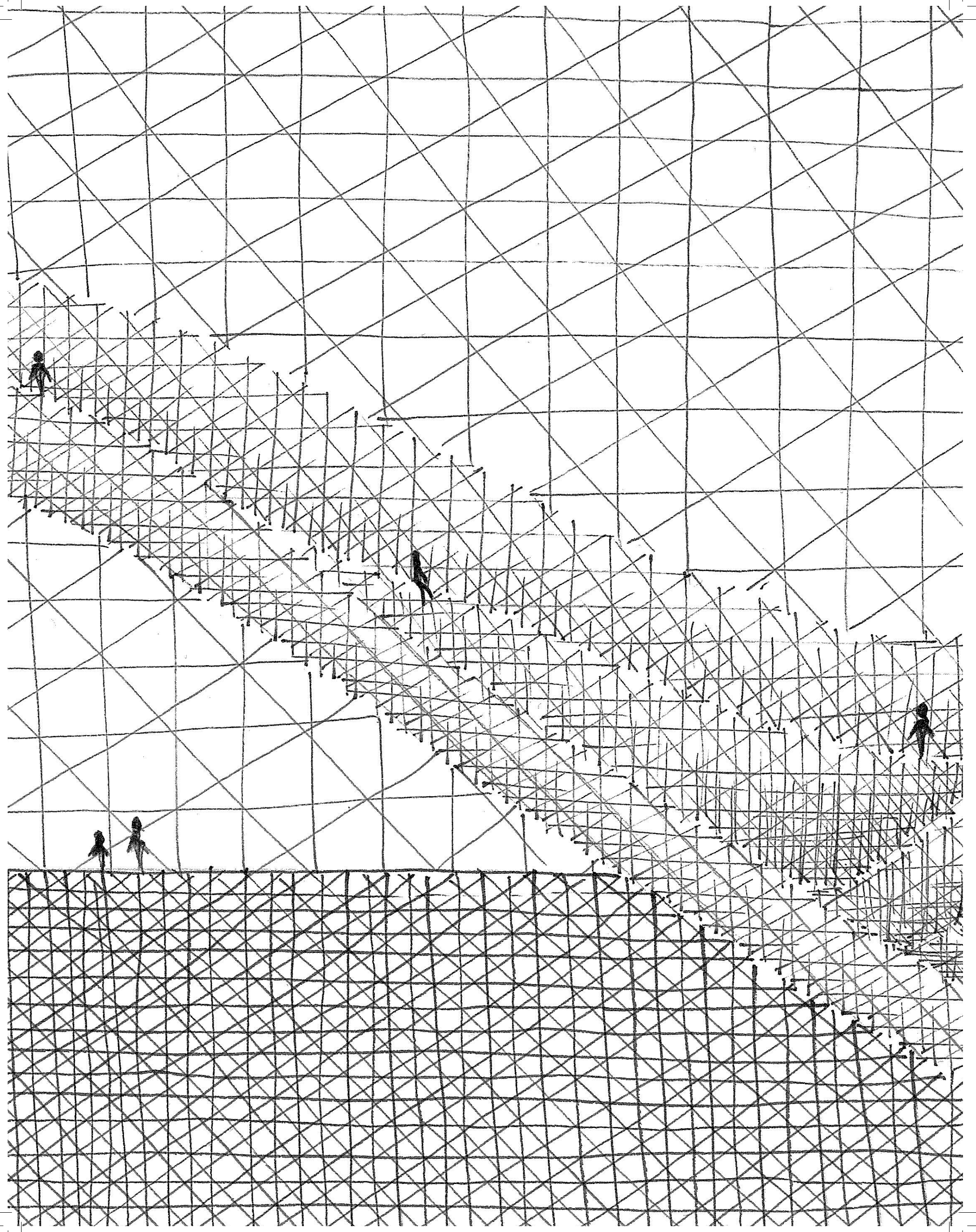




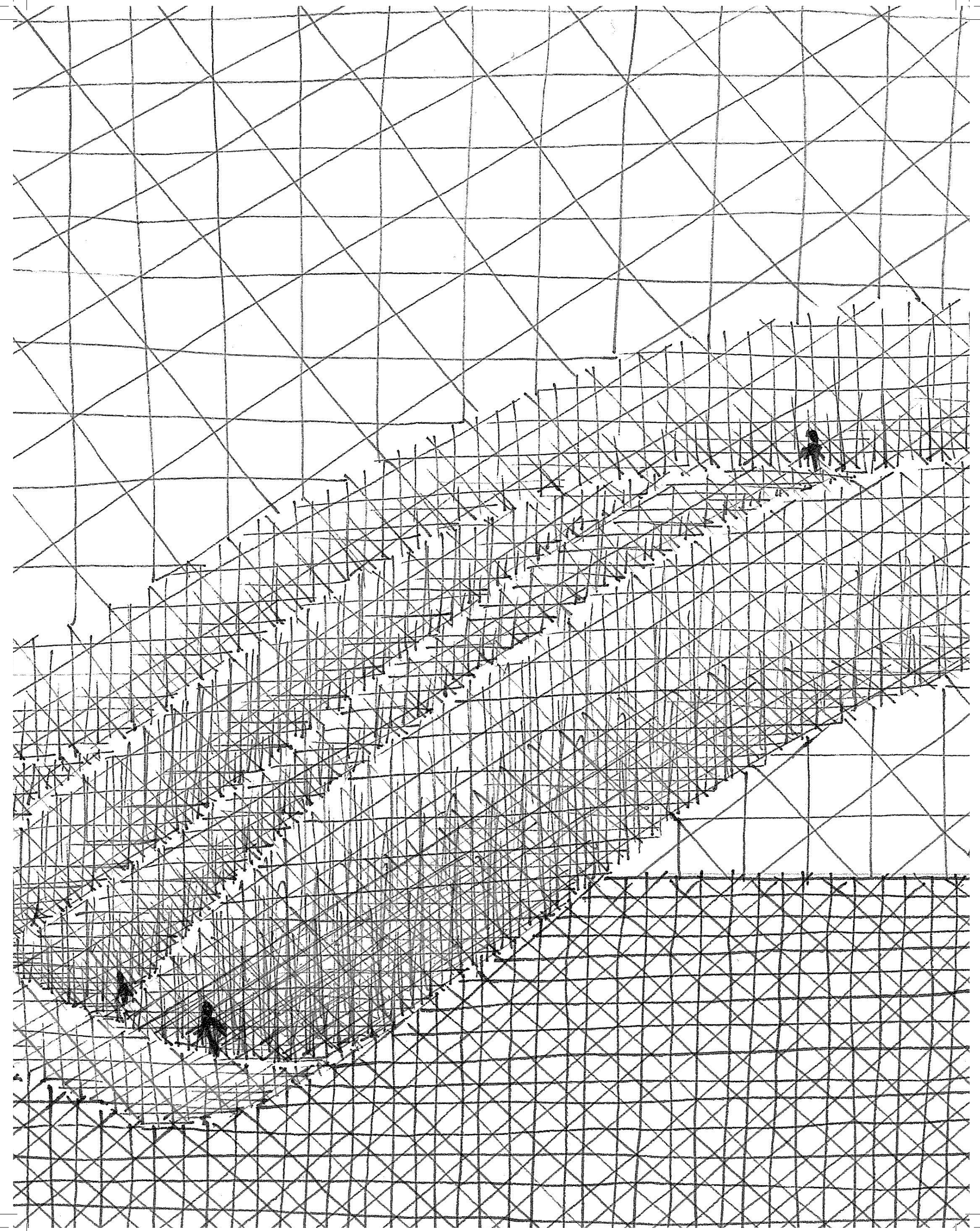


Figure 92. Crematorium in Kakamigahara, designed by Toyo Ito (Source: Gadanho).

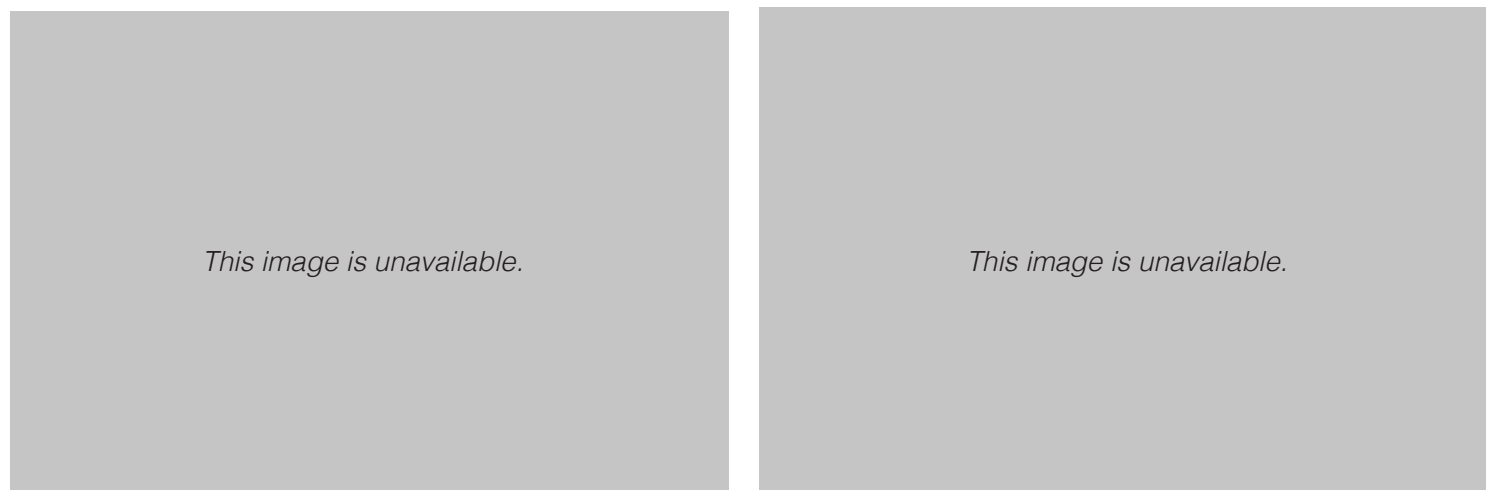

Figure 93. Froelicher High School, designed by Daudre-Vignier \& Associes (Source: Froelicher High School Reconstruction).

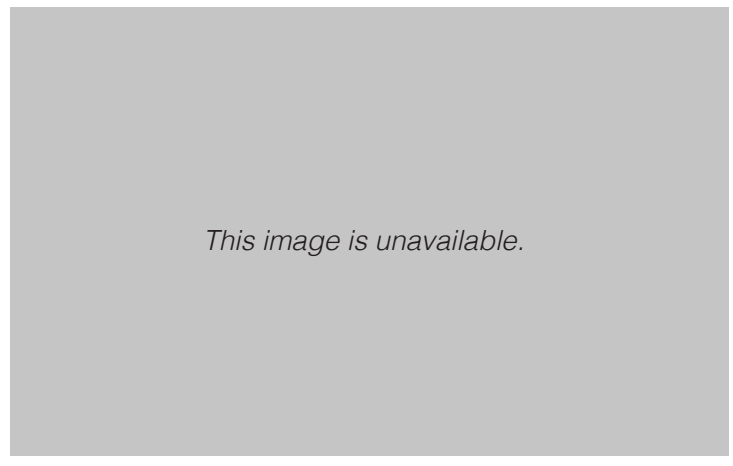

$\wedge$

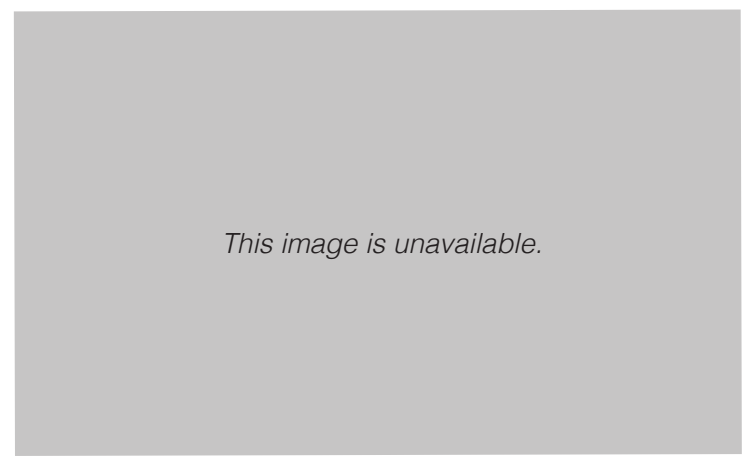

Figure 94. Towada Community Plaza, designed by Kengo Kuma \& Associates (Source: Towada Community Plaza).

$\wedge$

Figure 95. The Rolex Learning Centre, designed by Sanna Architects (Source: Furuto). 
In contrast to the singularity of the circular form, this abstract drawing has revealed a multiplicity which is far more accommodating of the diverse communities. This multiplicity brings a flexibility to the form that allows it to be inhabited by a diverse range of individuals and groups.

These Japanese architects have produced similar undulating forms. These forms which are relatively new are very intriguing from an occupants perspective. With recent technologies, architects have had further opportunities to explore forms similar to this.

In discovering this multiplicity, I have developed a vision of the form being simple in plan yet complex in section. Over the next few experiments the challenge is to get the complexity of the section drawing to work with the simple circular plan. 


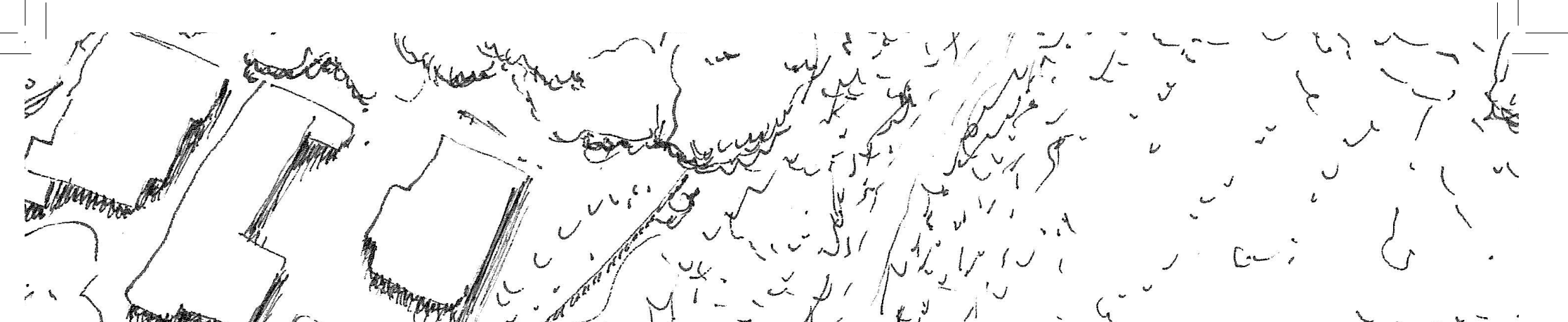

$\therefore<$;

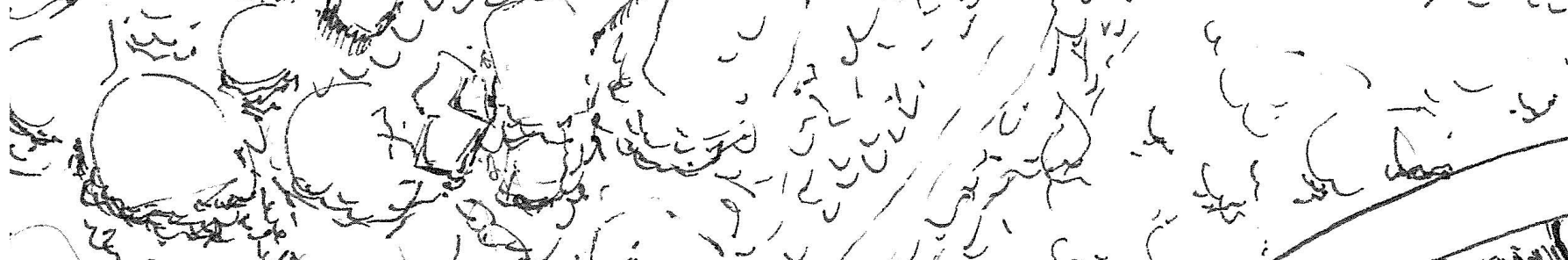

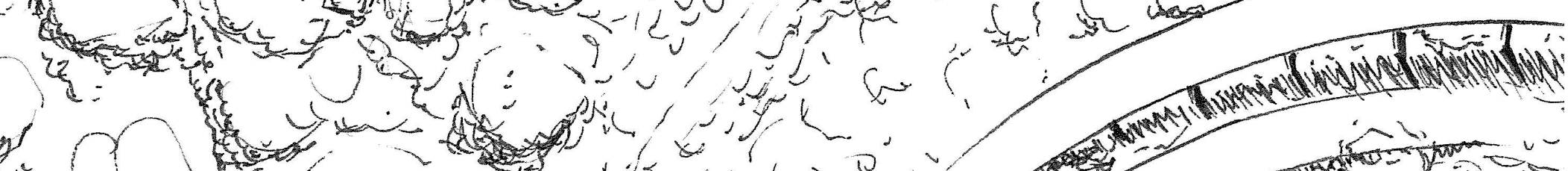
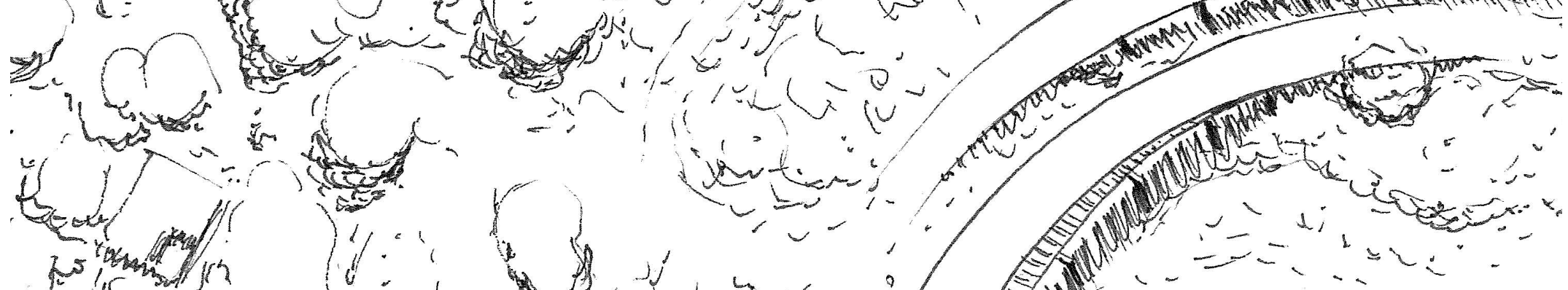

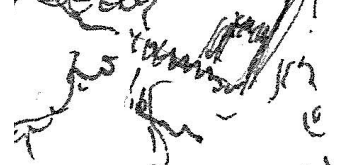

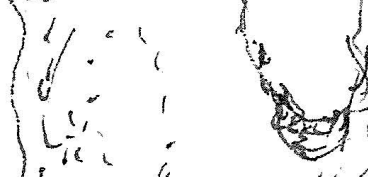

ation

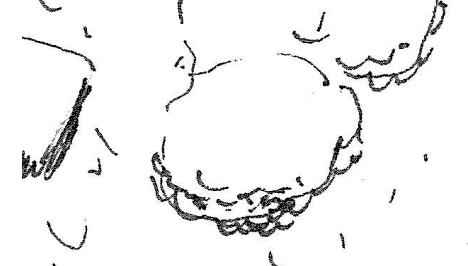
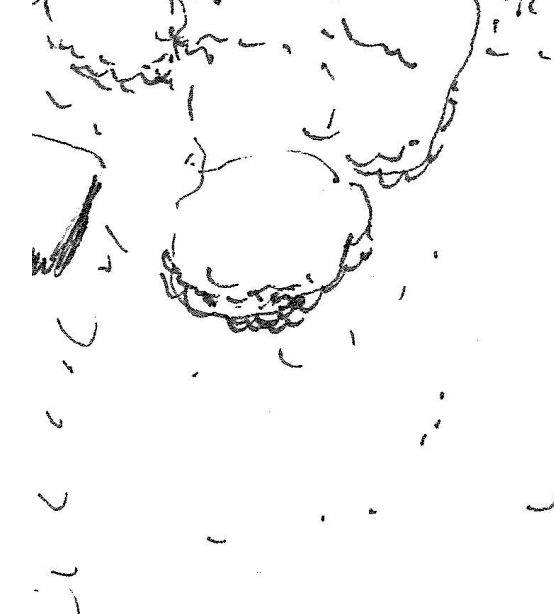

is
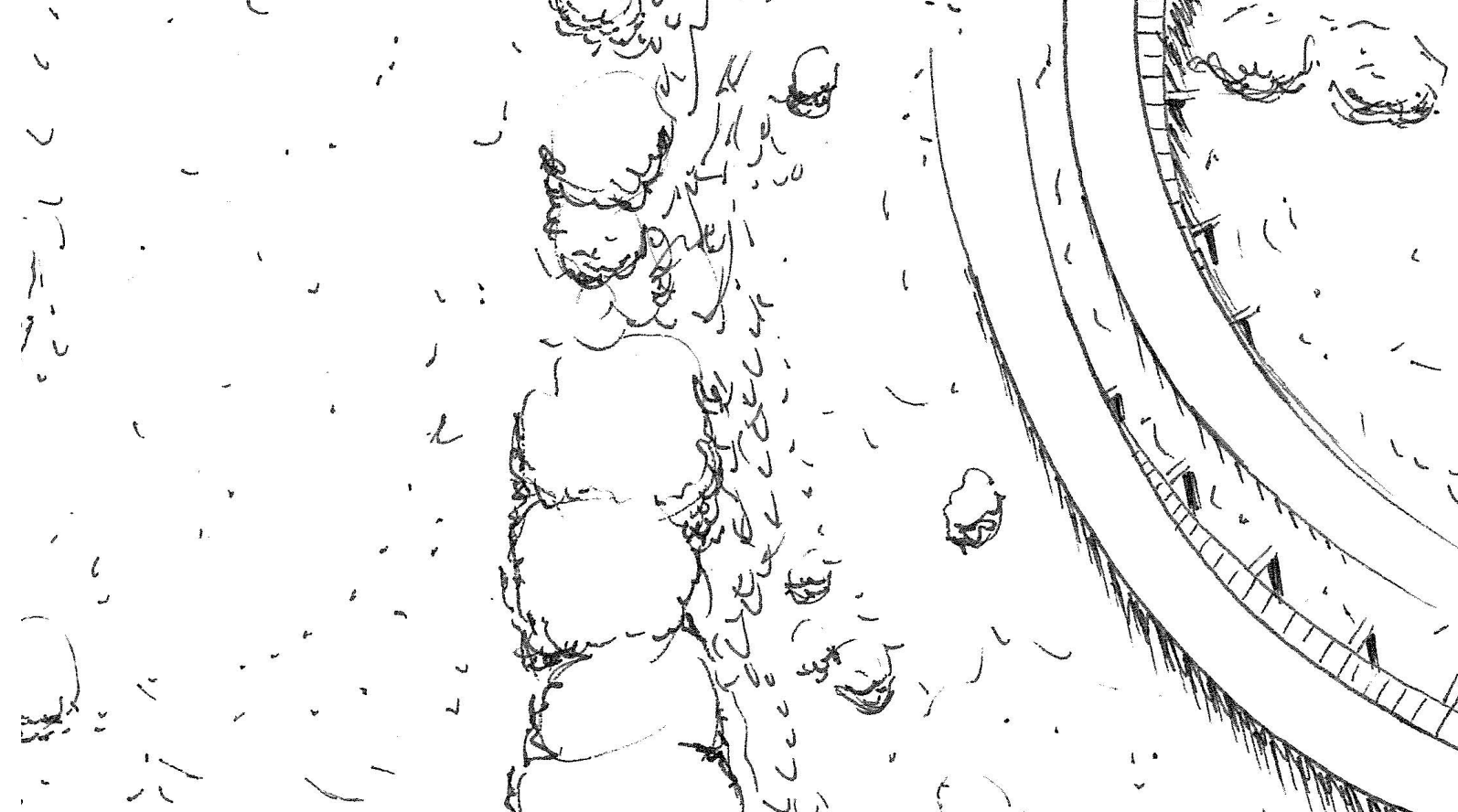

i
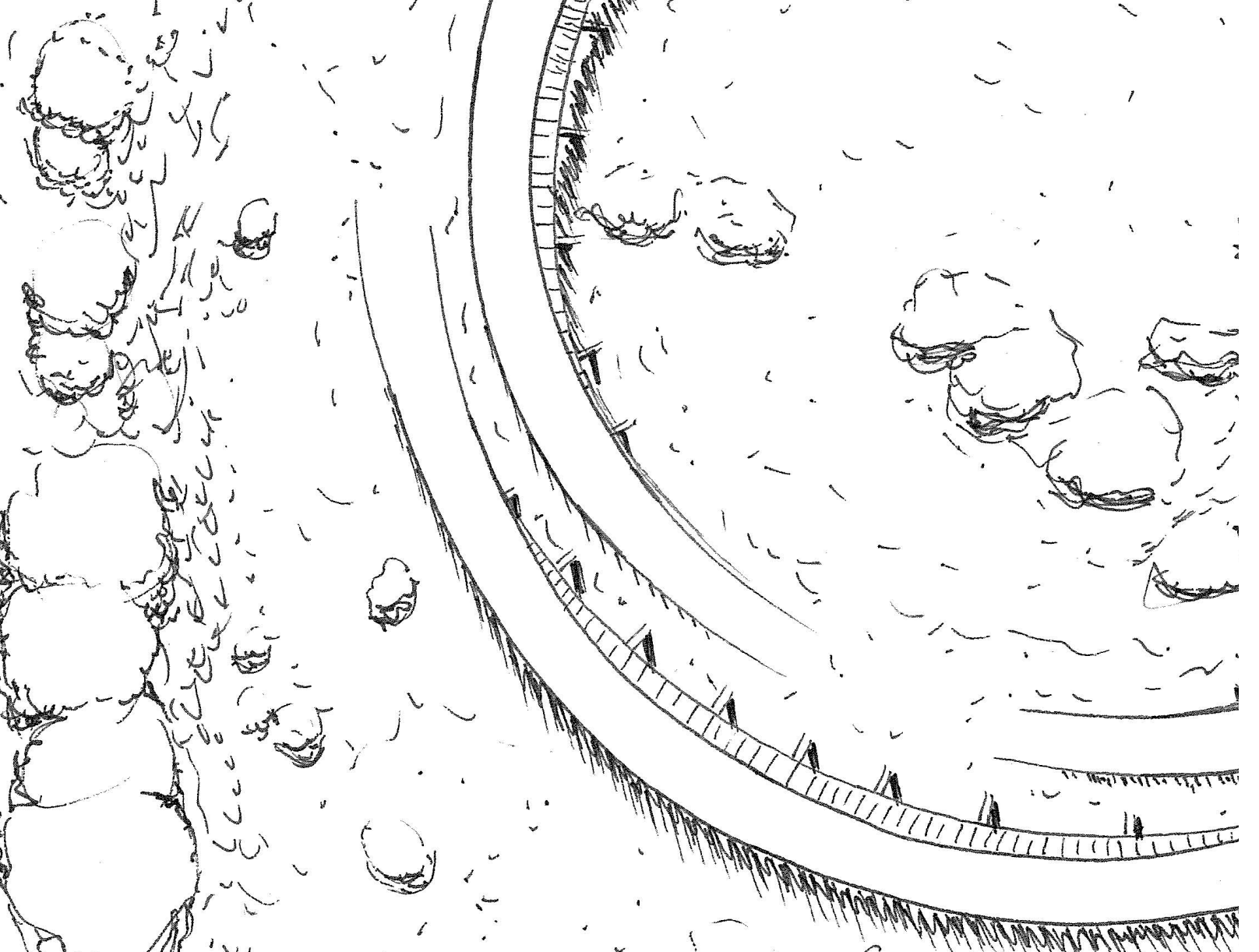


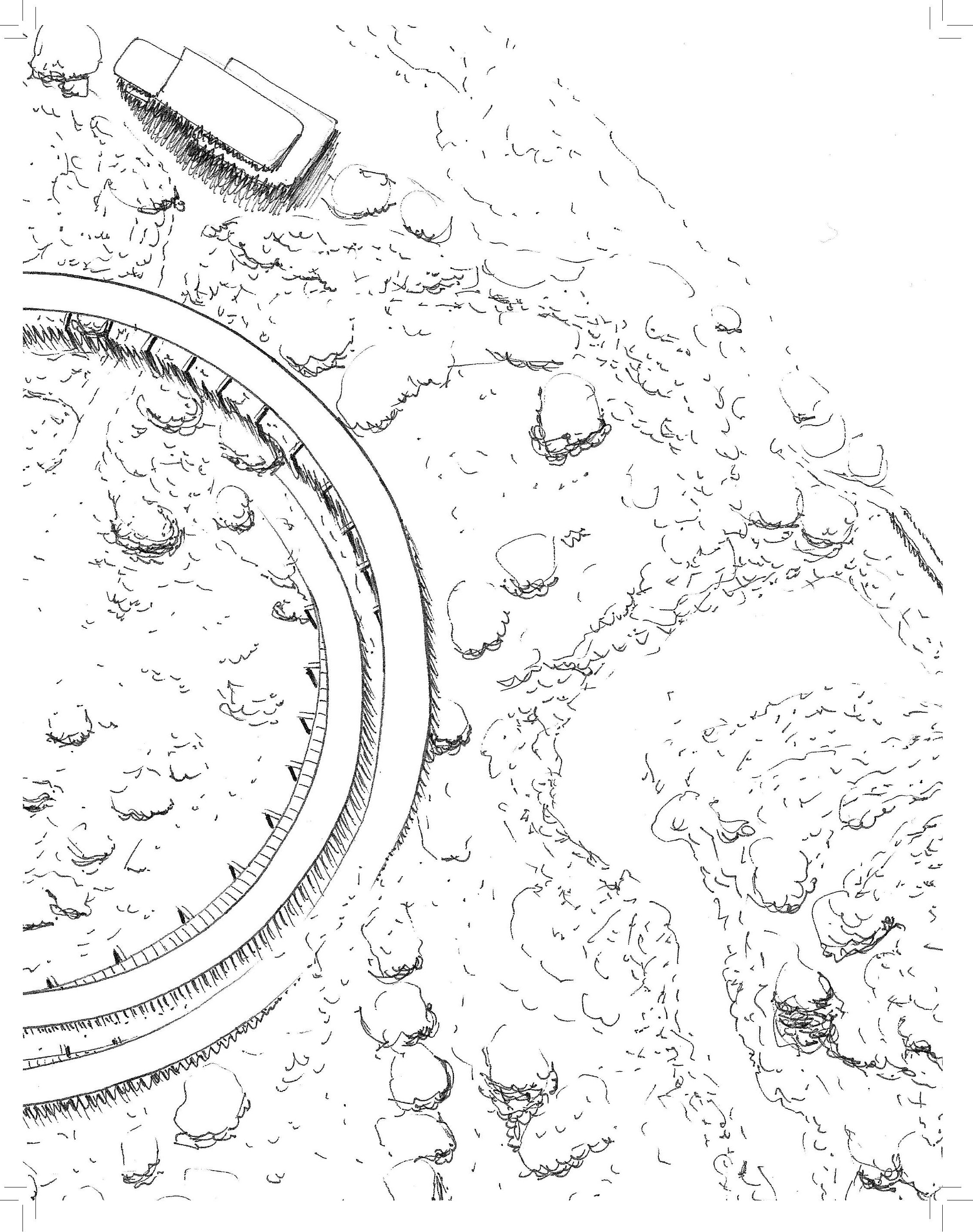



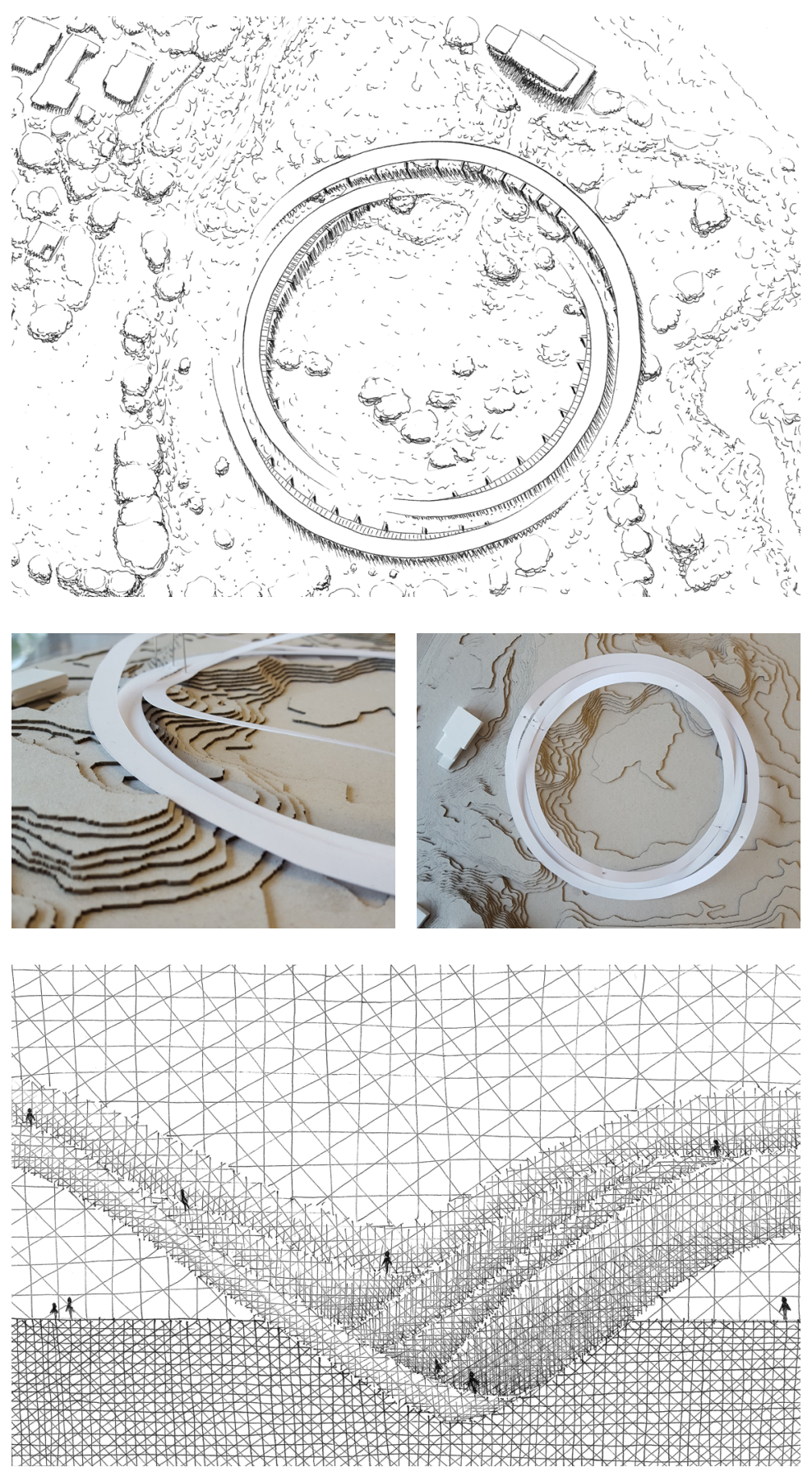

Figure 97. These drawings and models are an example of how I have used a threedimensional medium to help shift between two-dimensional views, plan and section. 


\section{Process Reflection:}

I have used physical models to explore the abstract drawing as a three-dimensional form. This design medium has helped me to shift between the two-dimensional views, section and plan. After discovering how the undulating form might work around the circle, I could then look at drawing it as a plan.

This shift between two-dimensional and threedimensional media, along with the switching between the plan and section, is constant throughout the design process of this thesis. 

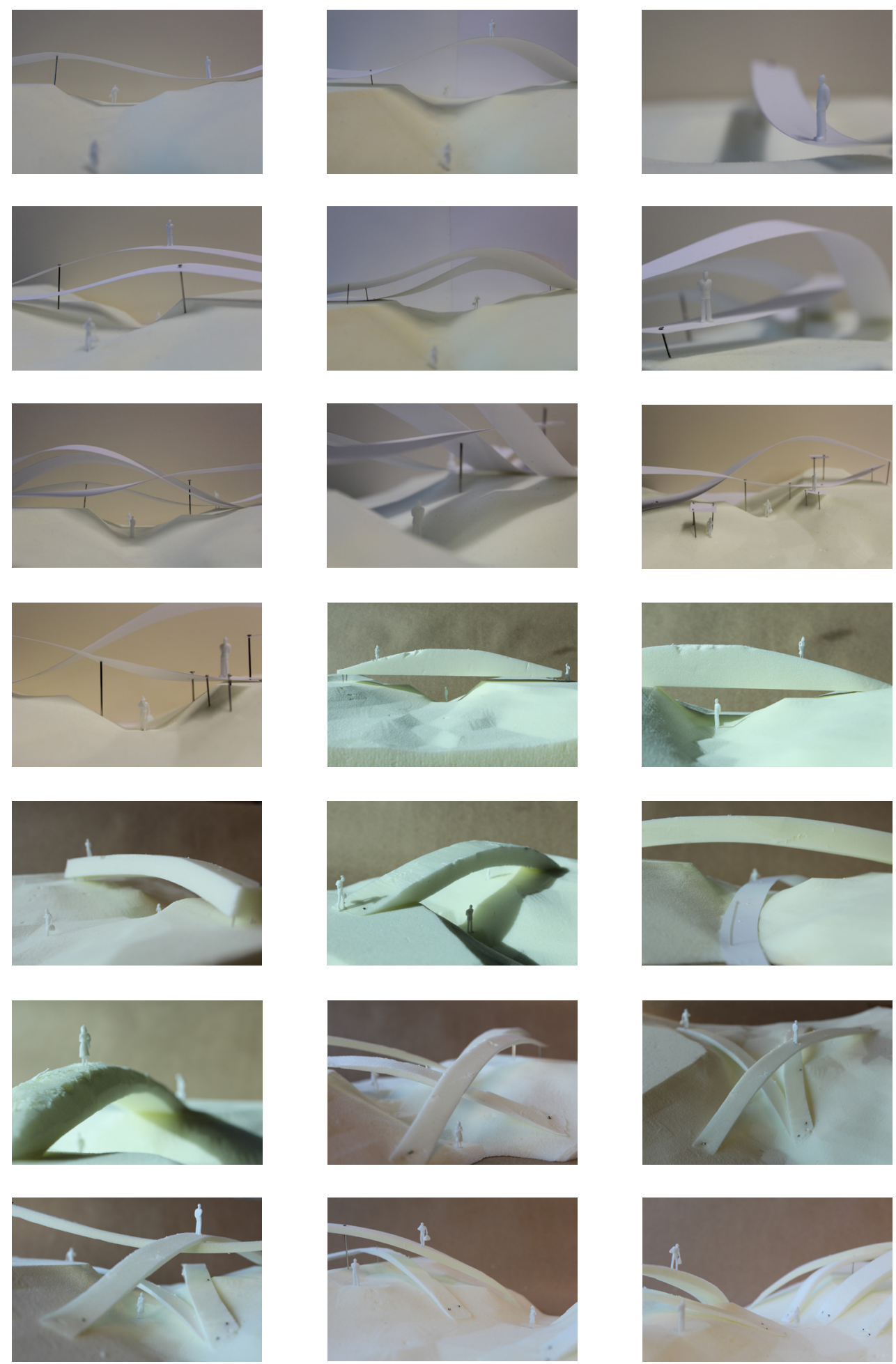

Figure 98. These models specifically explore the threshold between the dunes and how the form might connect, or bridge over the existing landscape. 

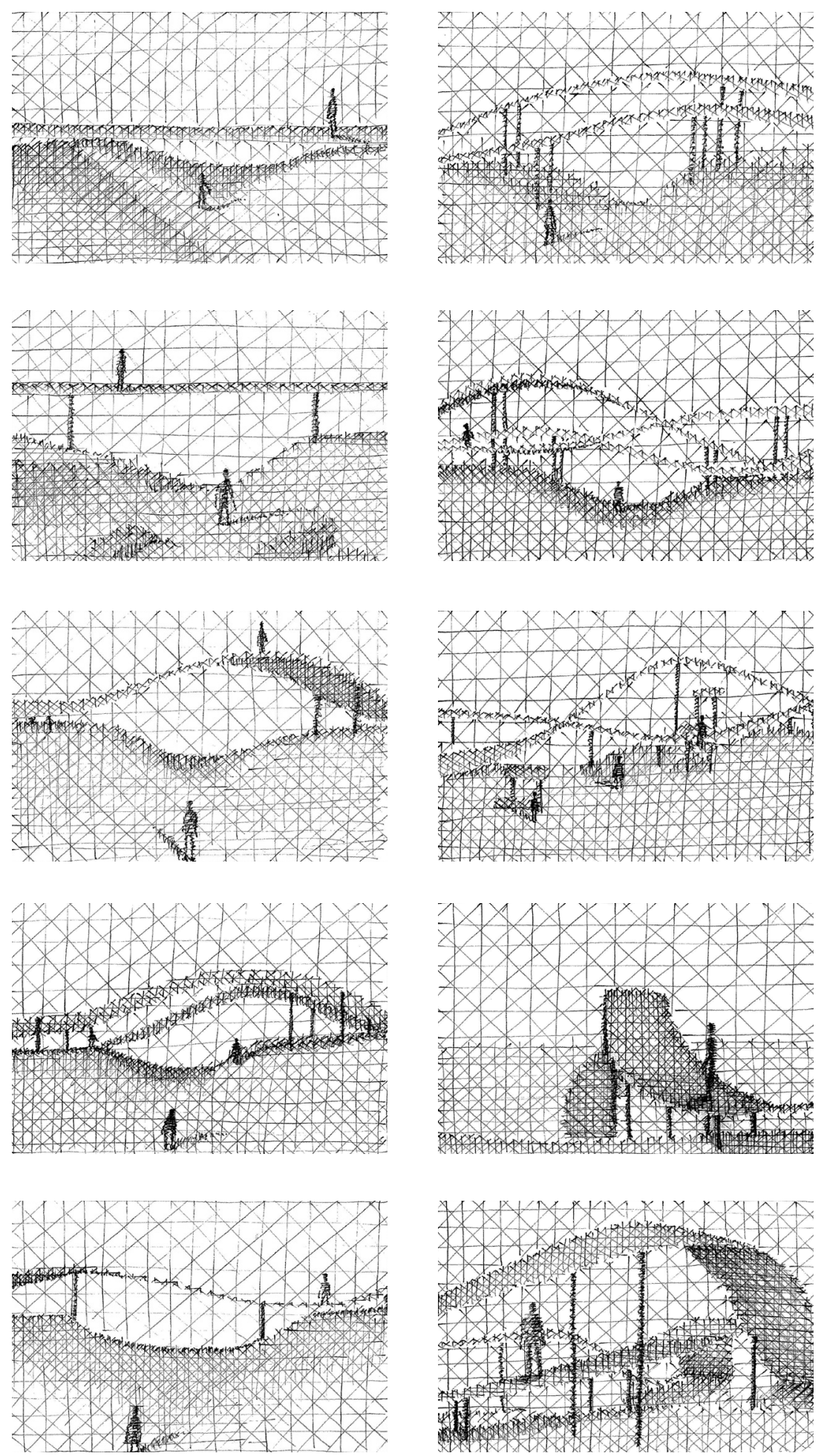

Figure 99. These drawings are a direct reflection of the models to the left. The drawing technique helps to frame the design. This makes it easier to understand the scale of space and how it is inhabited. 

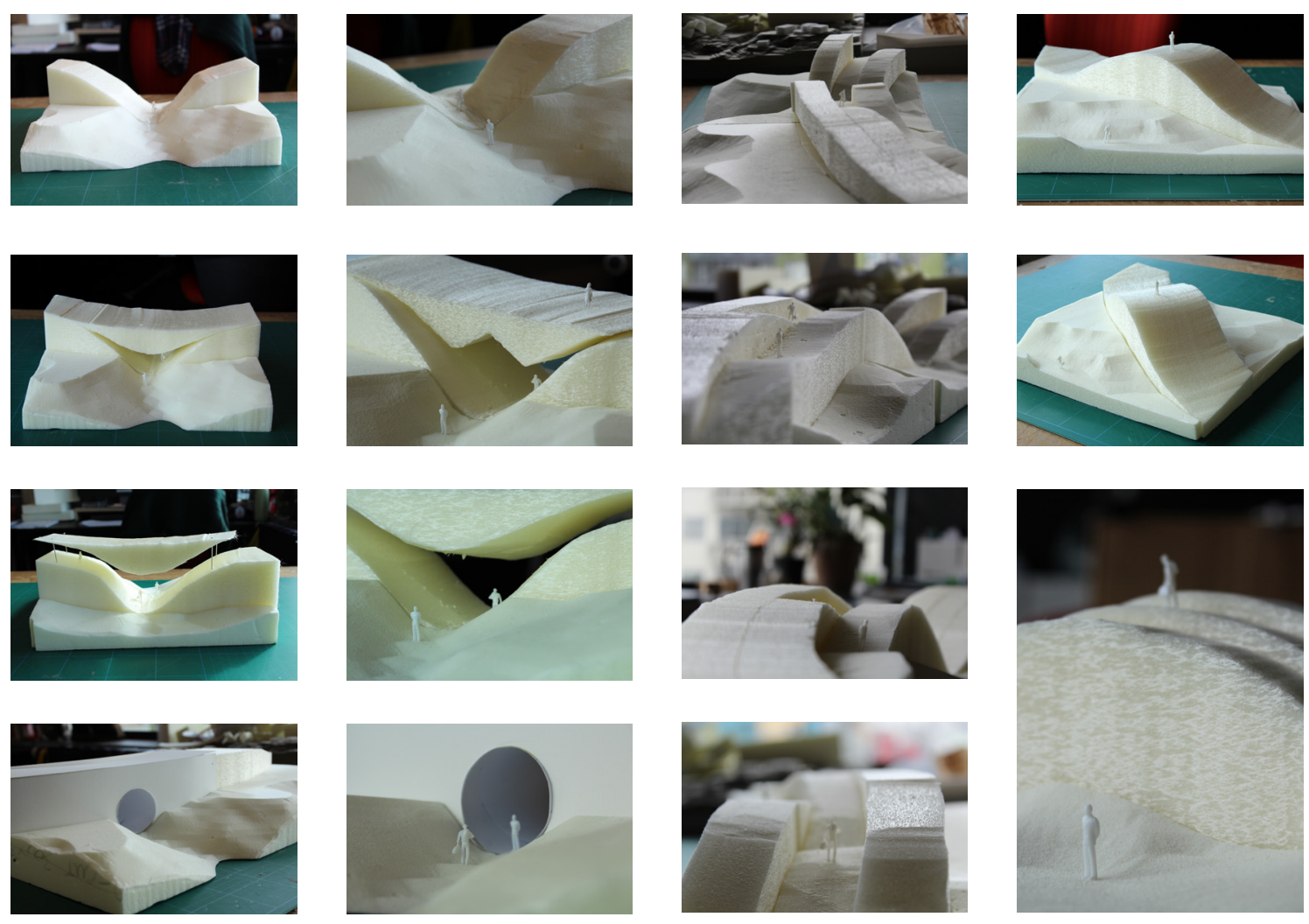

$\wedge$

Figure 100. Continuing the exploration of the threshold between the dunes, I have transitioned to using gold foam as it is easier to visualise what is solid and what is not. In these iterations above I have looked at emphasising the curve of the dunes on each side of the walkway; bridging the gap between the dunes; and even creating a funnel through a pipe like void. 

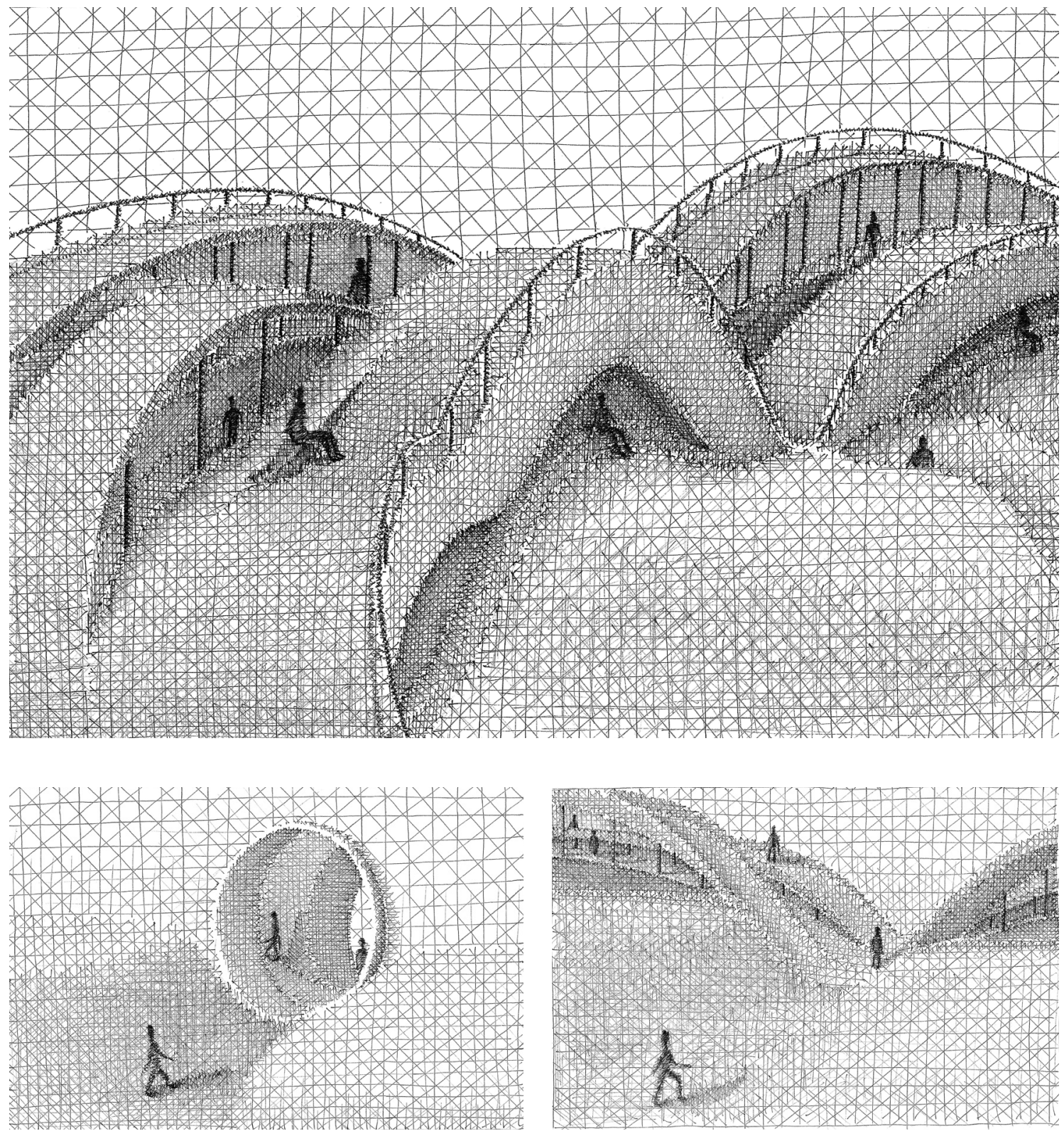

Figure 101. These drawings are a direct representation of the models to the left. 


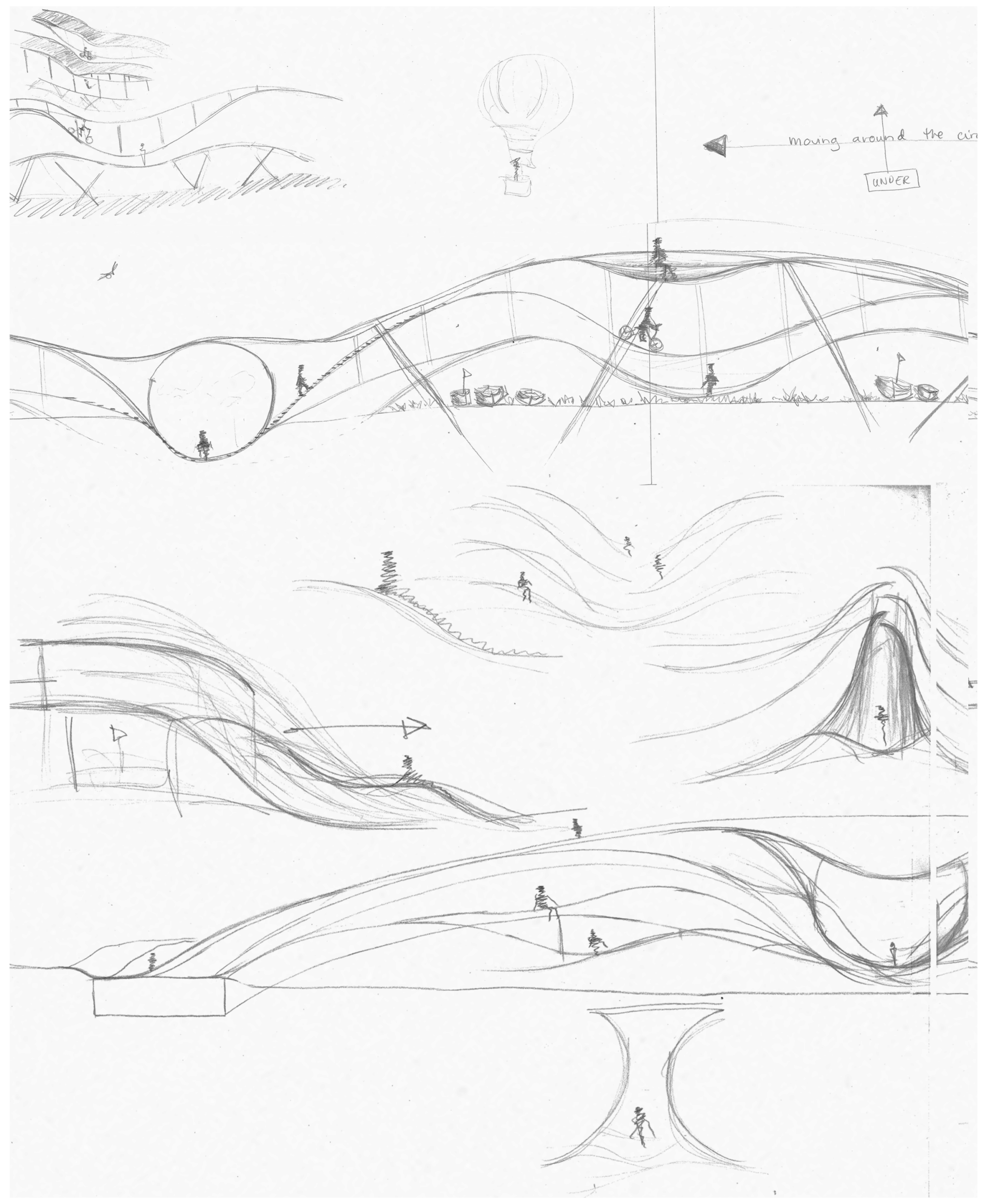



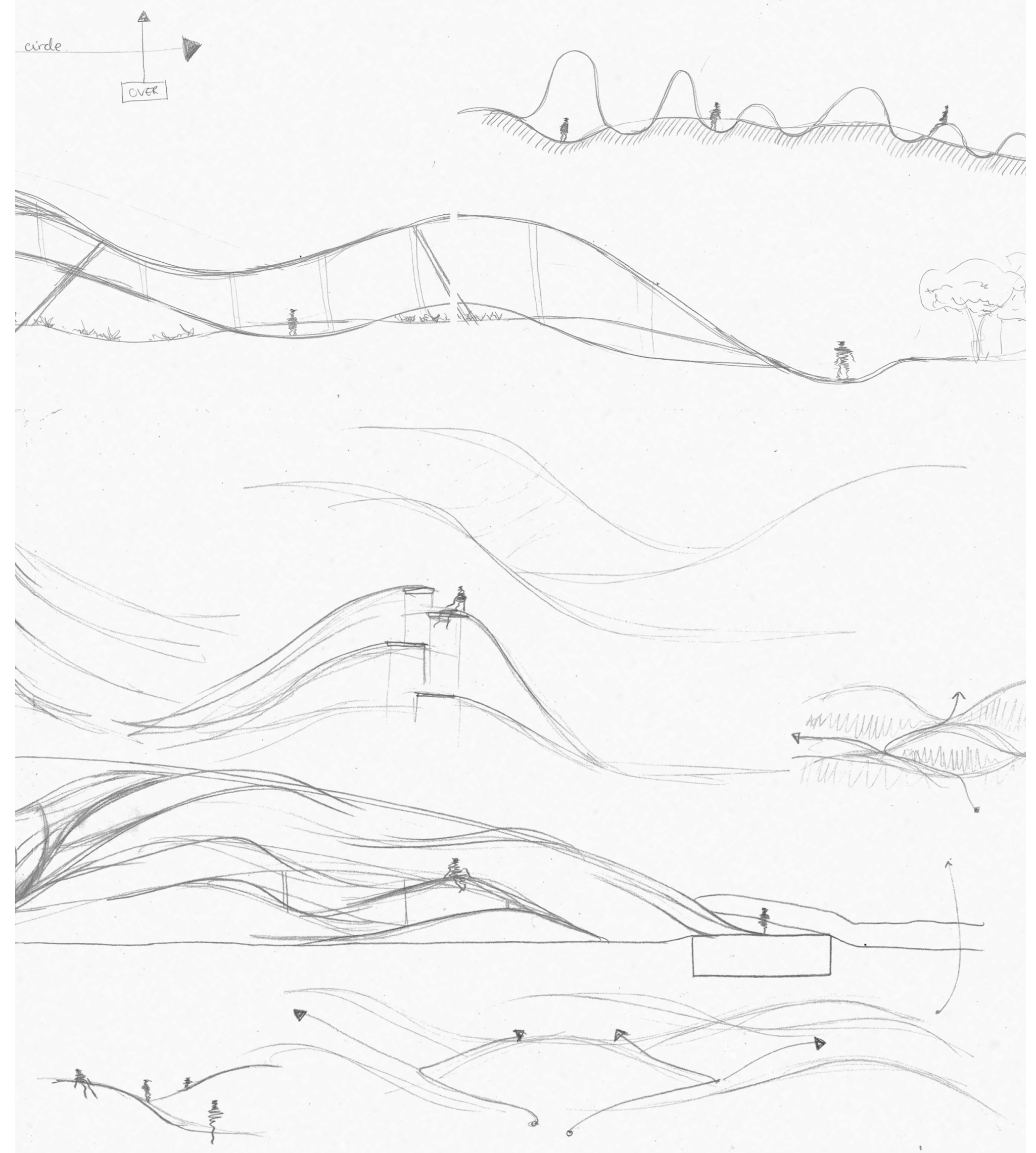


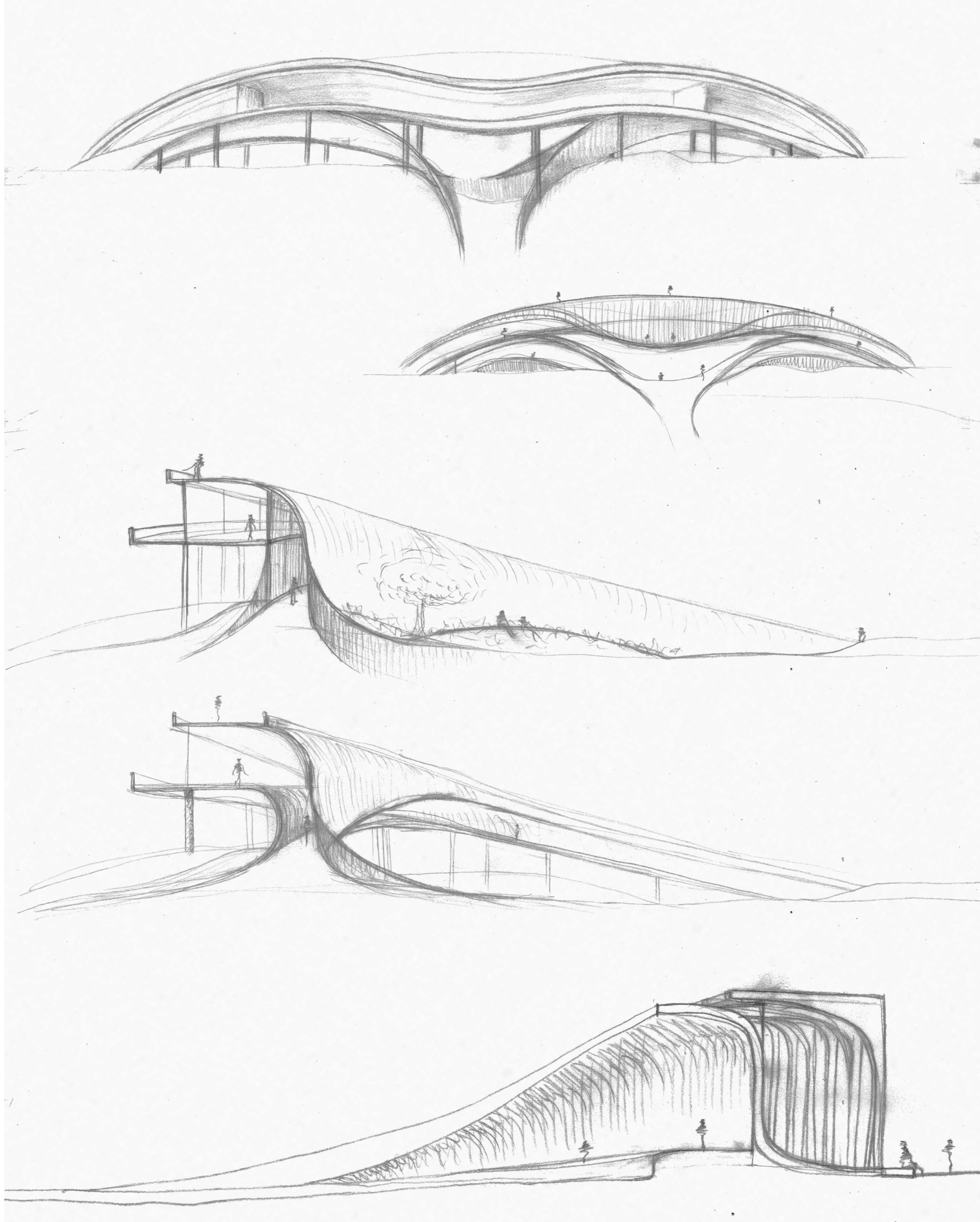$$
7
$$$$
\text { A. }
$$$$
\text { De }
$$ 
As I continued this exploration, it became evident that the complex forms were competing with the existing complex landscape. It also did not help that, with an eye for clarity, I kept wanting to resort back to the simplicity of my earlier form.

At this stage of the process, it was evident that I did not understand the full importance of the complex section and the relevance of these landscape iterations. 


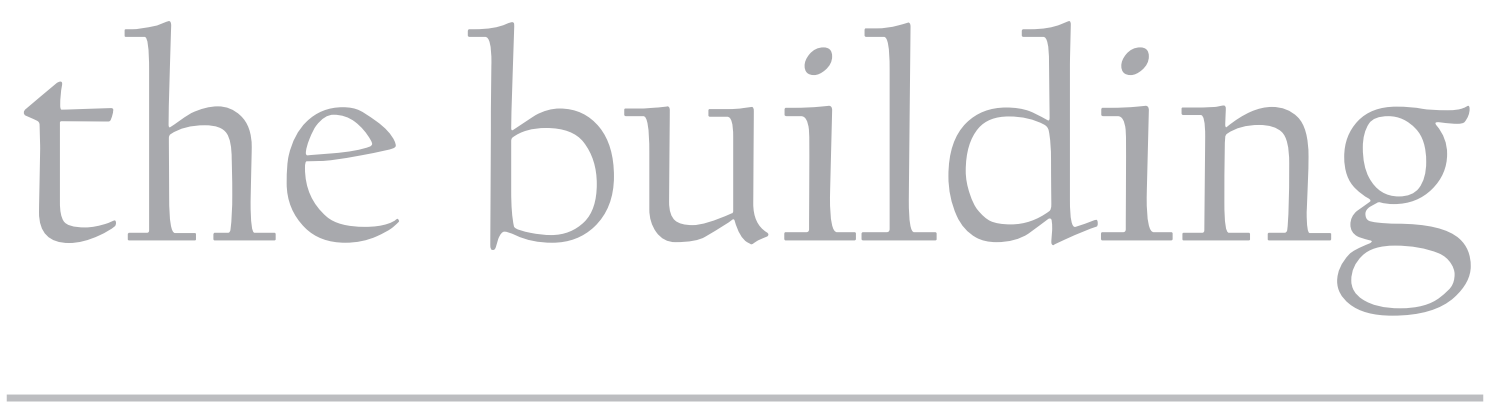


(0) $+£=$ ???

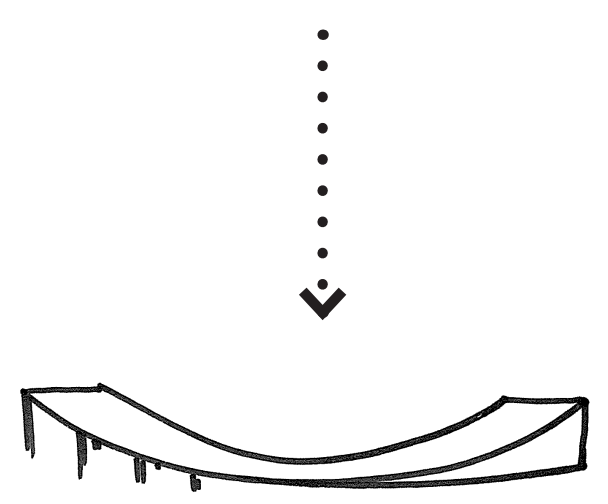


Without realising how detrimental it was at the time, I decided to resort to my original form. With the 'final' review looming in conjunction with the difficulty expressed in the previous experiment, it seemed that scaling down and exploring the simpler form was the right move to make.

Across the cohort, there is a false expectation that, as thesis students, we should present a resolved building at the 'final' review. This pressure is both internal and external. The internal pressure comes from being an architecture student and wanting to present beautiful images of a resolved building for the final review. The external pressure comes from people both inside (peers, guest reviewers) and outside of the discipline asking questions about the building rather than the research. However, the fact is that this thesis has a research scope which in this case is finding a formal strategy to achieve the research question.

In the experiments below, you will begin to see that the practical questions of designing a building have distracted me from getting the simple plan working with the complex section. Instead the experiments are preoccupied with programme, structure, construction and the materiality of the building. 


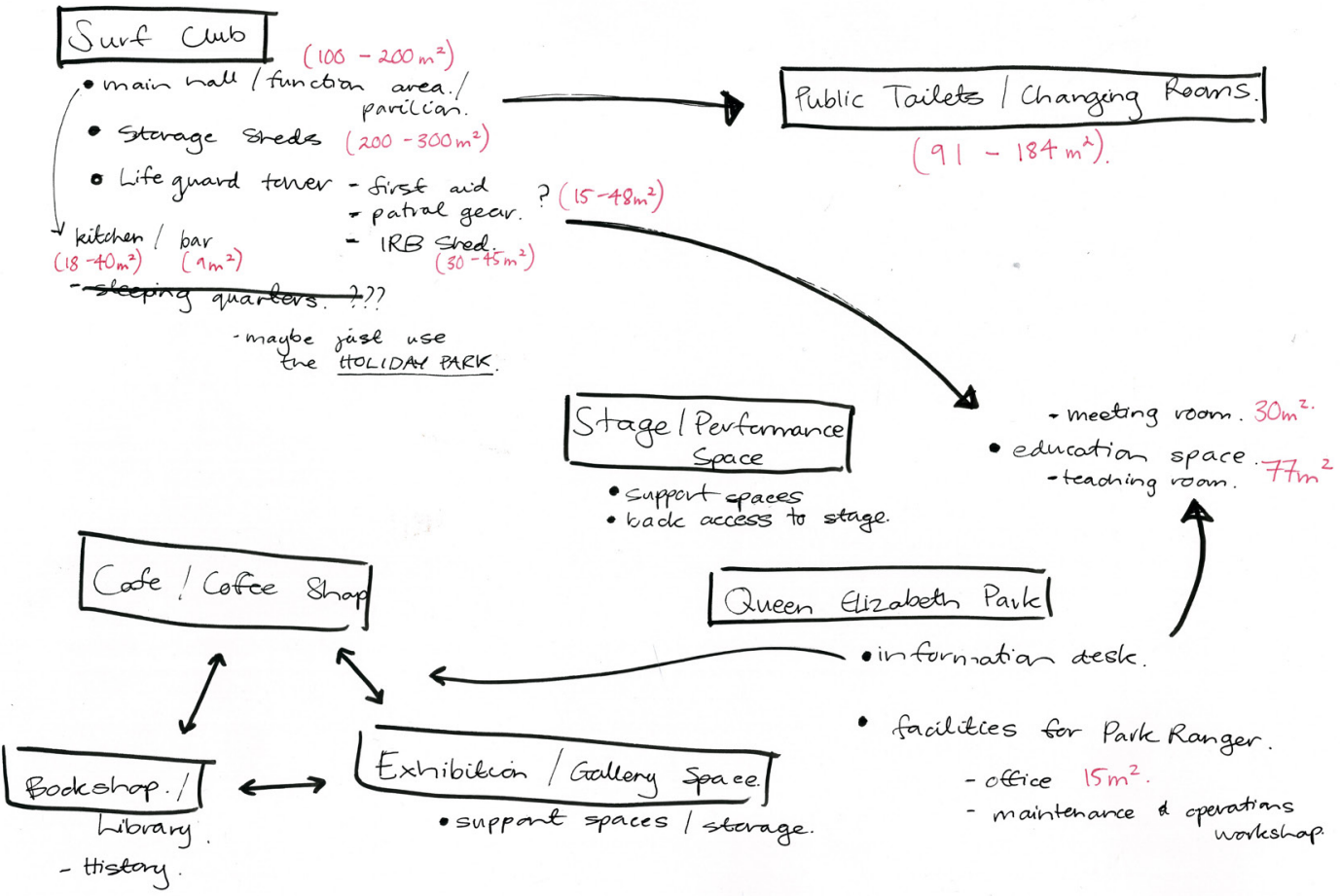

$\wedge$

Figure 104. Rough sketches figuring out what functions to include in the building and the size of space required for each.

Creating a building for the different communities, I have included functions that will encourage each group to use the space. These include; a stage, an exhibition/gallery space, a coffee shop, public toilets, storage space, a surf club and a house for the QE Park Ranger. 


$$
0
$$



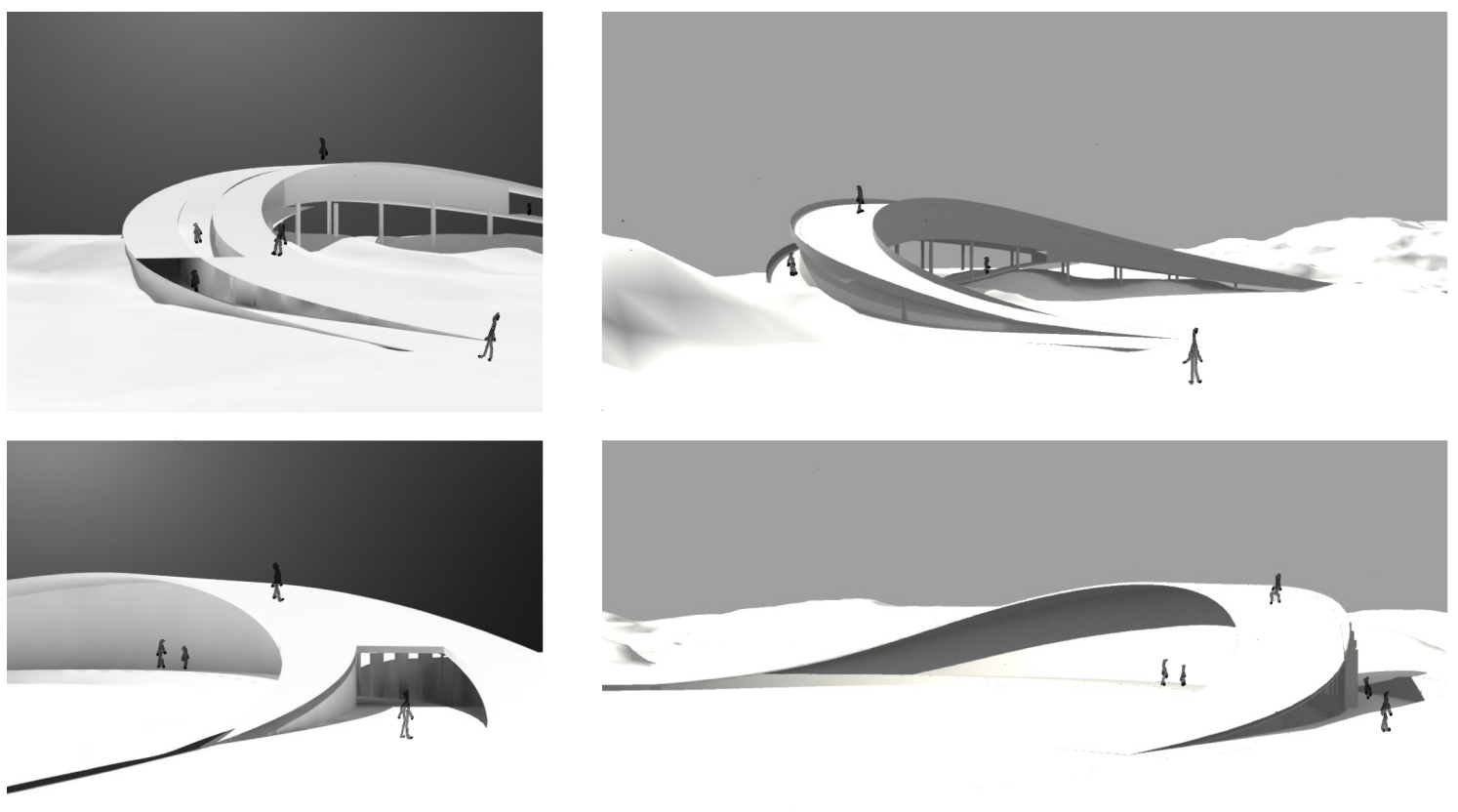

$<\wedge$

Figure 106. As I began to model the ramps which would connect the different functions around the circle, I realised that I would need openings in both the floor and roof plates. In the images above you will see that this has affected the simplicity of the form. As a result, I decided to taper the roof surface so that the occupants could enter from the side of the building. Consequently, this has allowed me to retain the simple form. 


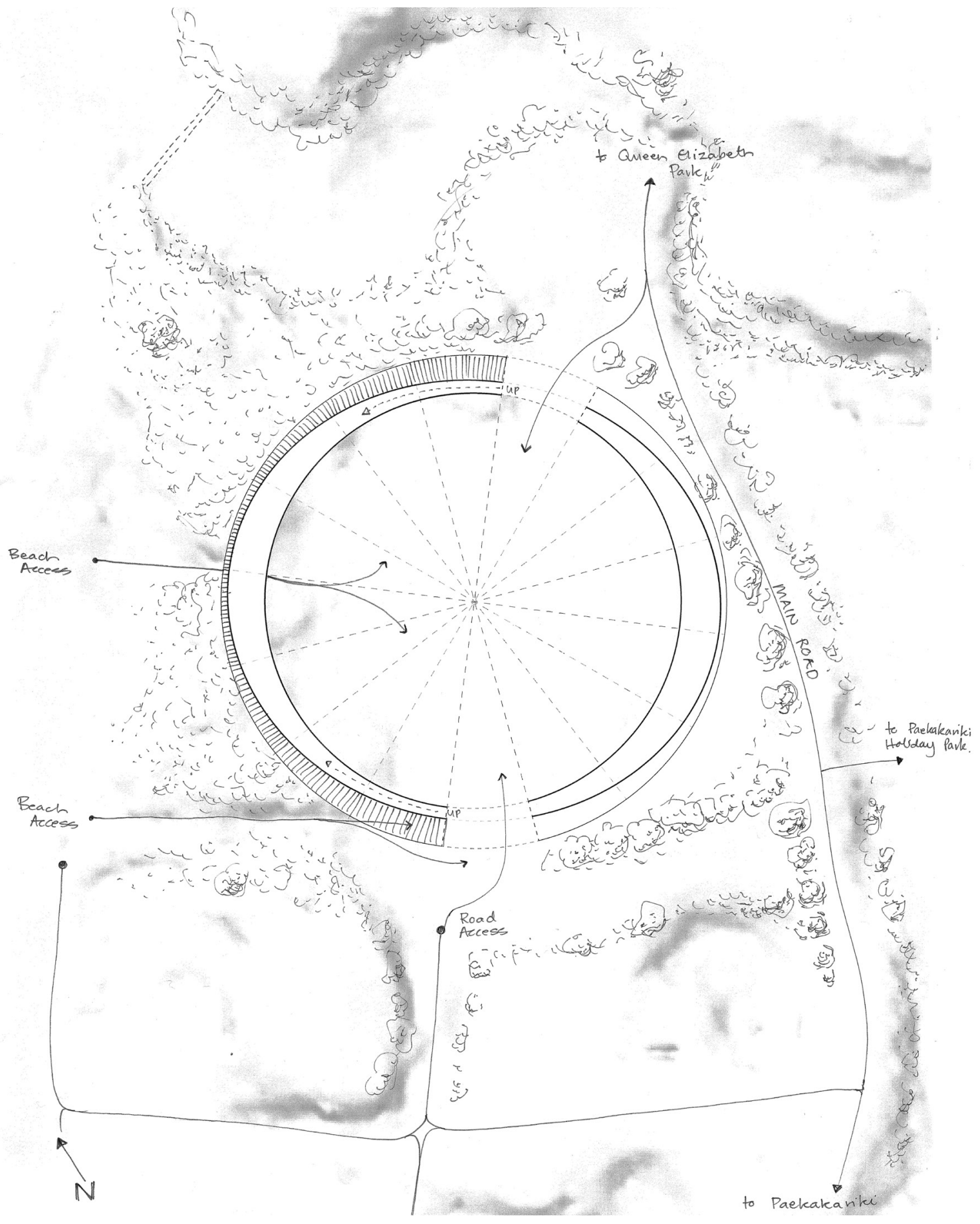

$\wedge$

Figure 107. Site Plan- (not to scale).

166 


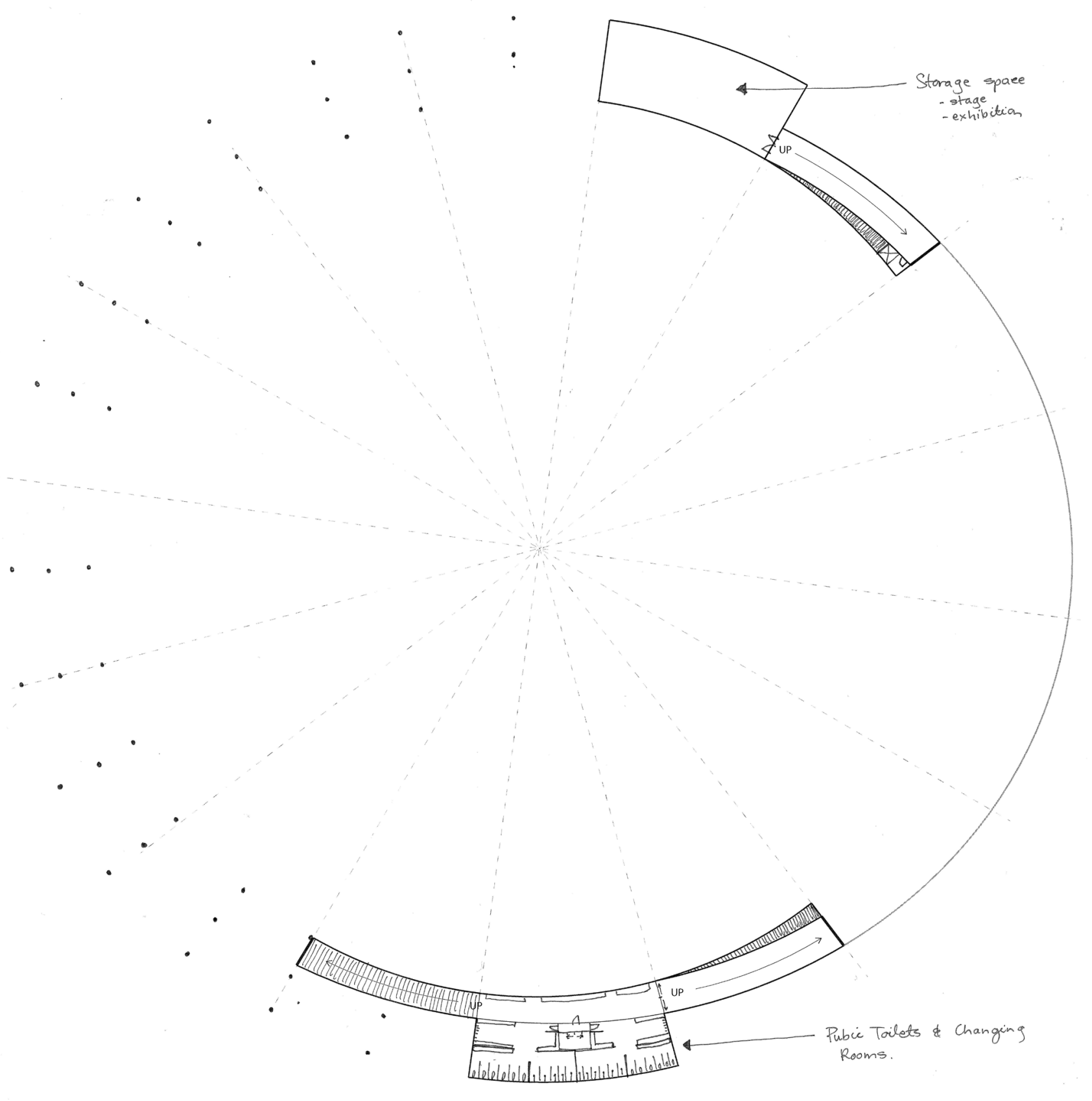

Figure 108. Basement Plan- 1:1000 


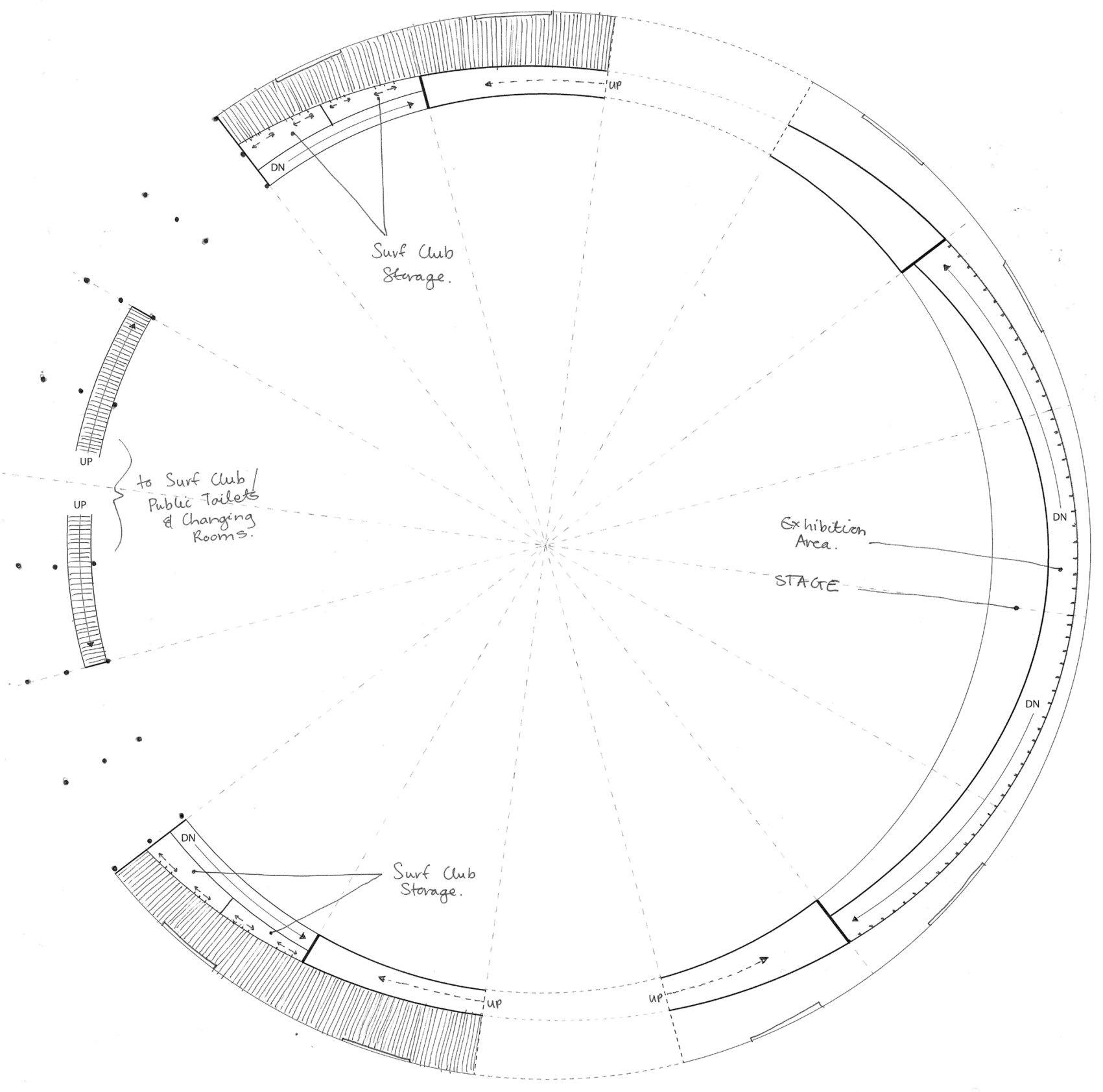

Figure 109. Ground Floor Plan- 1:1000 


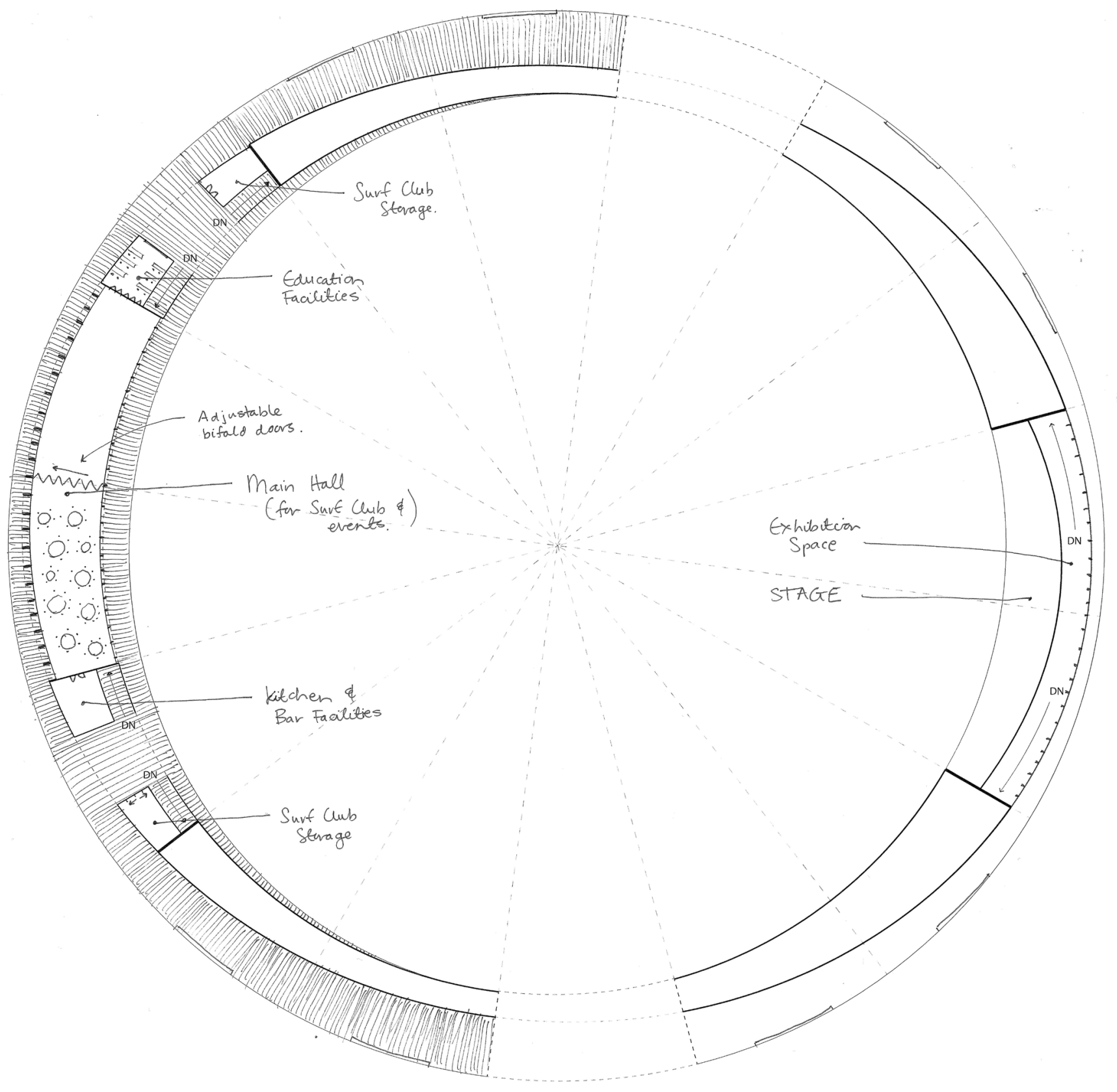

Figure 110. First Floor Plan- 1:1000 

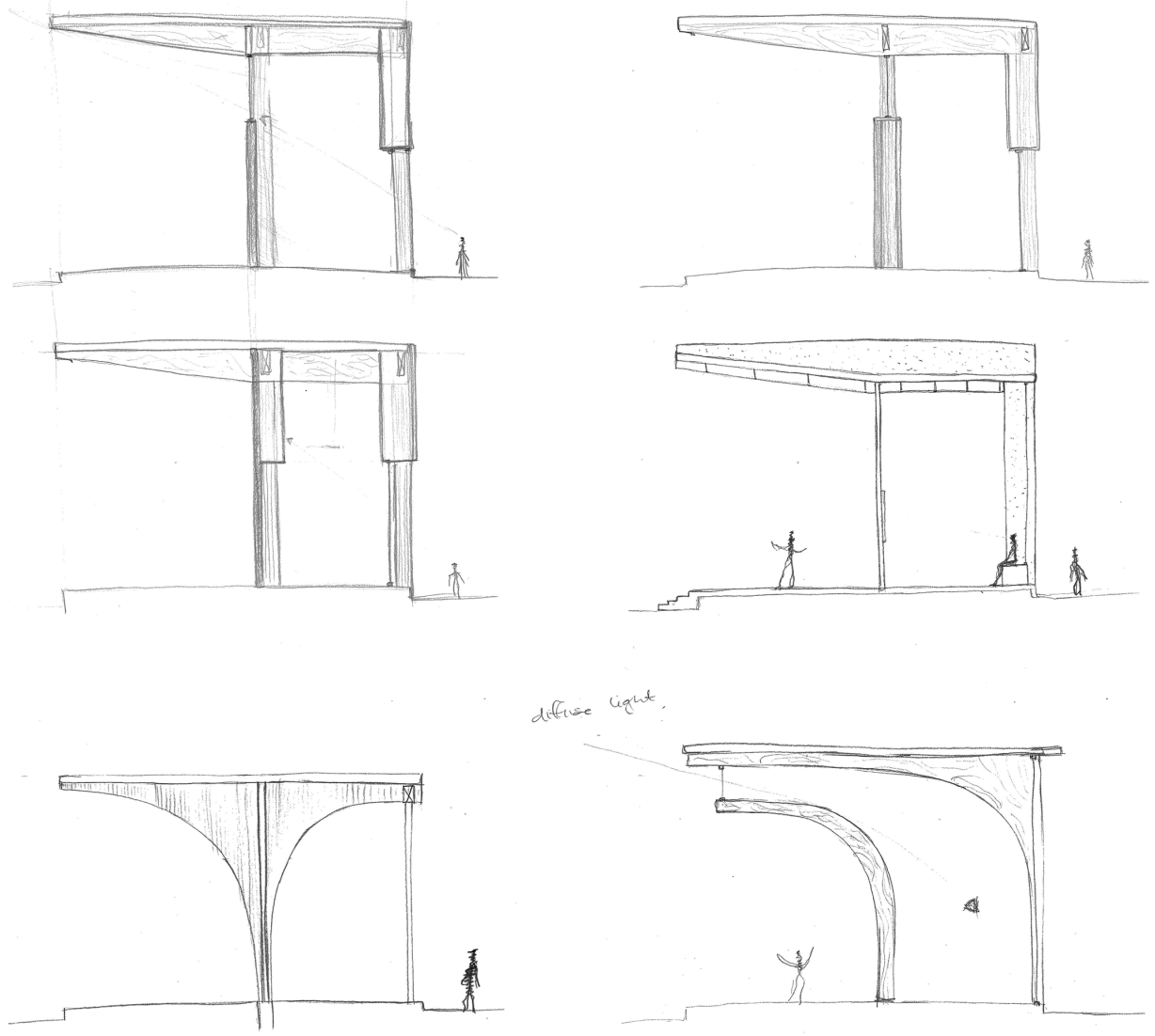

difive light
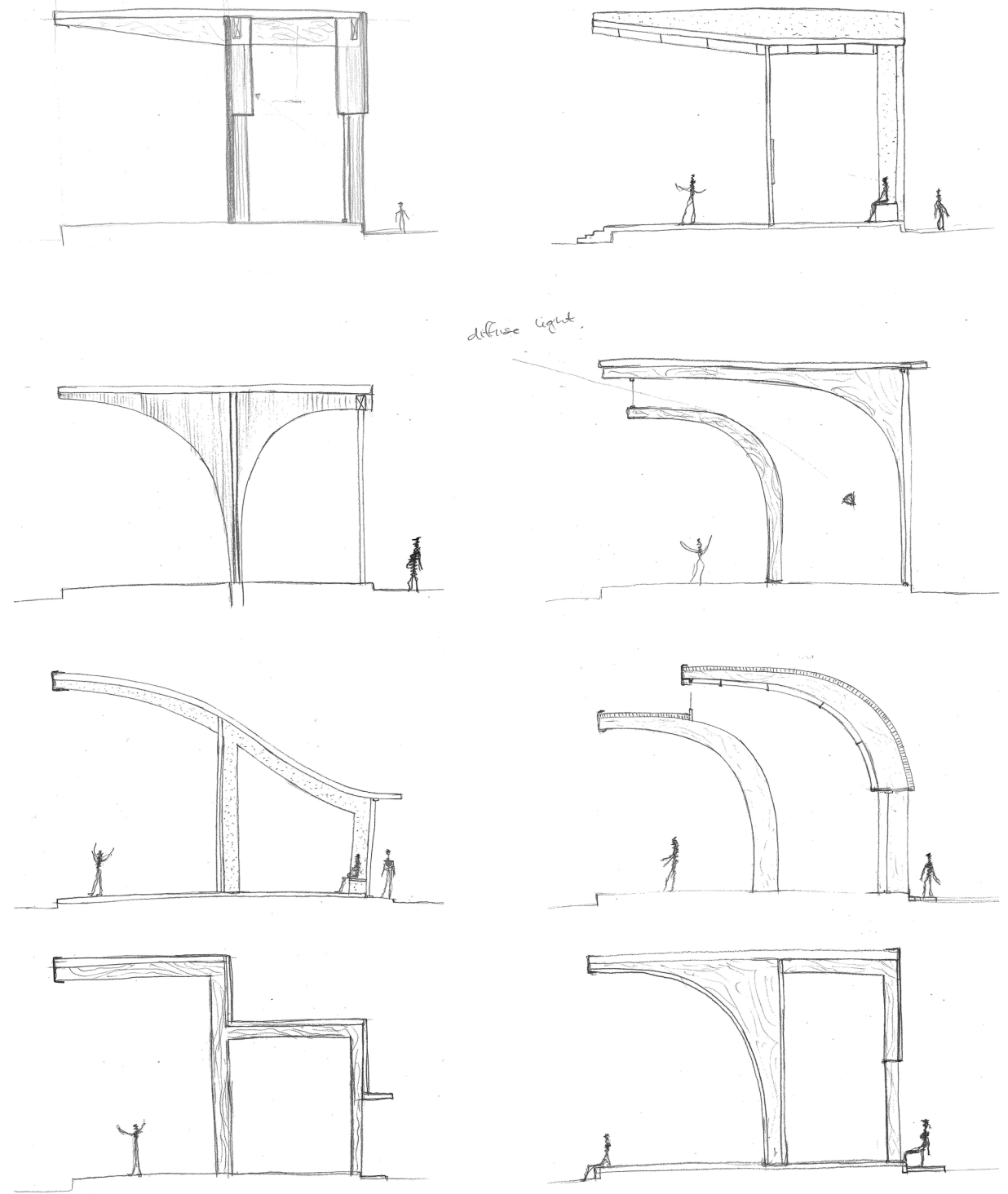

$\wedge$

Figure 111. In these drawings, I was exploring different ways of constructing the transverse section of the roadside building. As I was doing these sketches, I was very conscious that the design of the section would have an effect on the building's facade. 

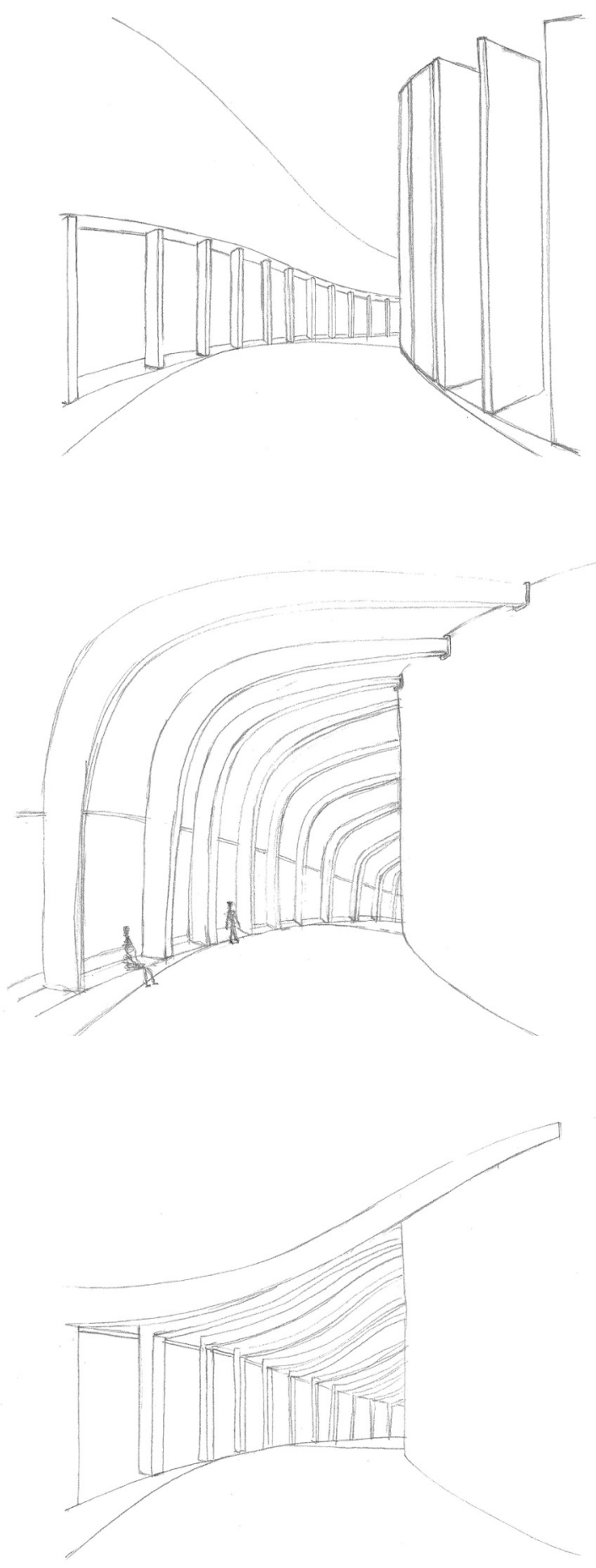

Figure 112. In these sketches, I was exploring different ways of constructing the roadside building and its influence on the interior perspective. 


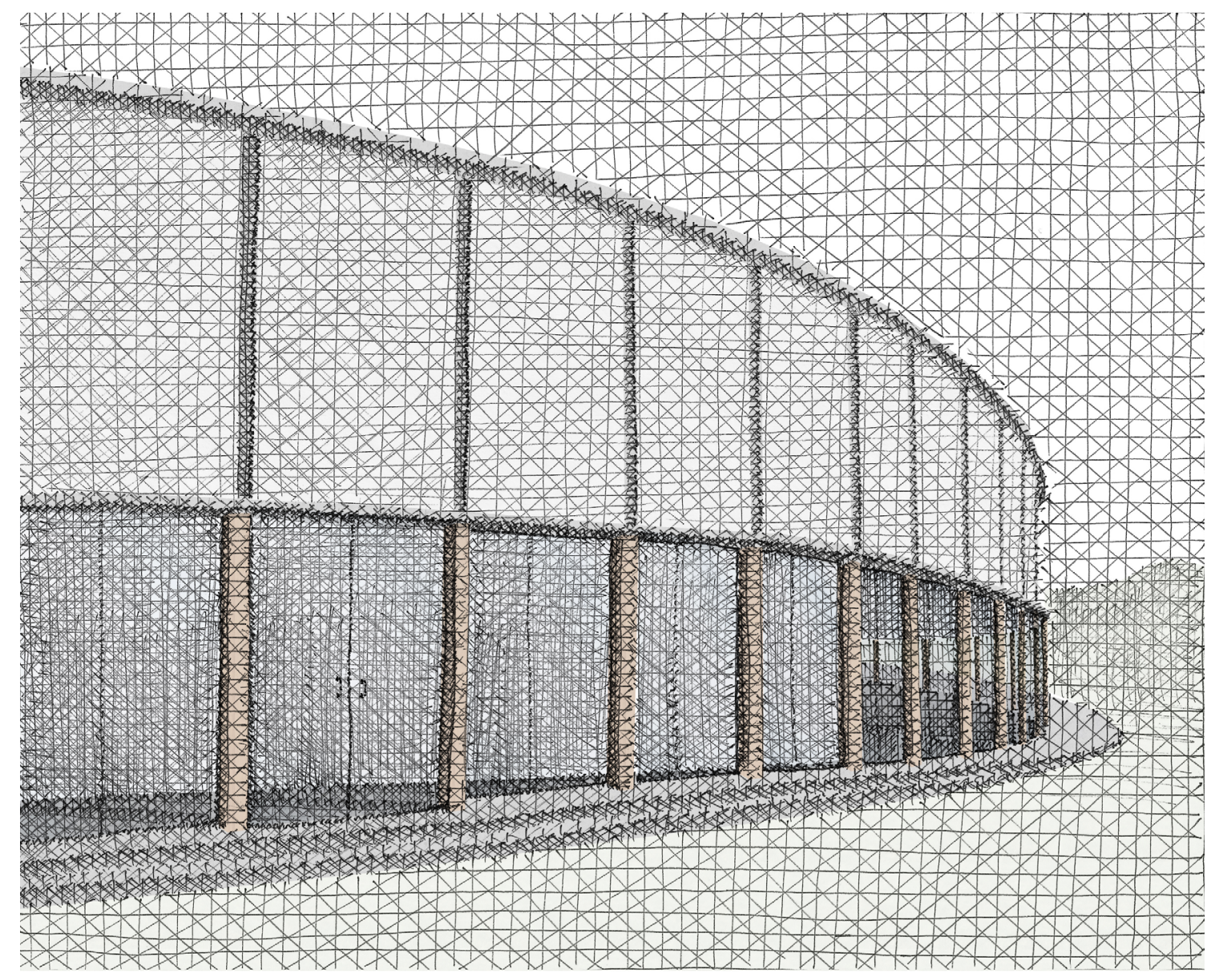

$\wedge$

Figure 113. This drawing focuses on capturing how the building will look from the road. I was also experimenting with the drawing technique and how I can show materiality. 


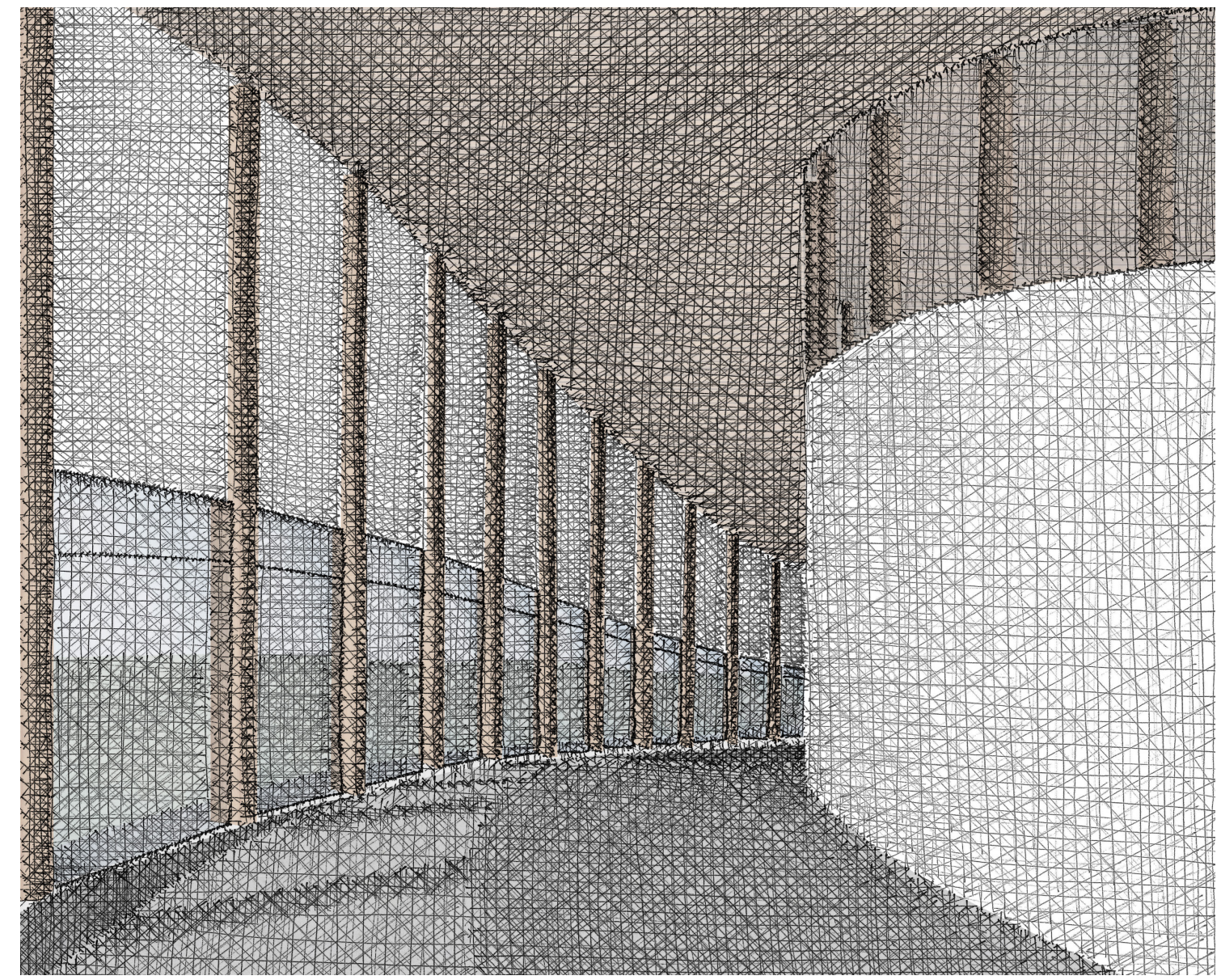

$\wedge$

Figure 114. This drawing illustrates the interior space of the roadside building. 


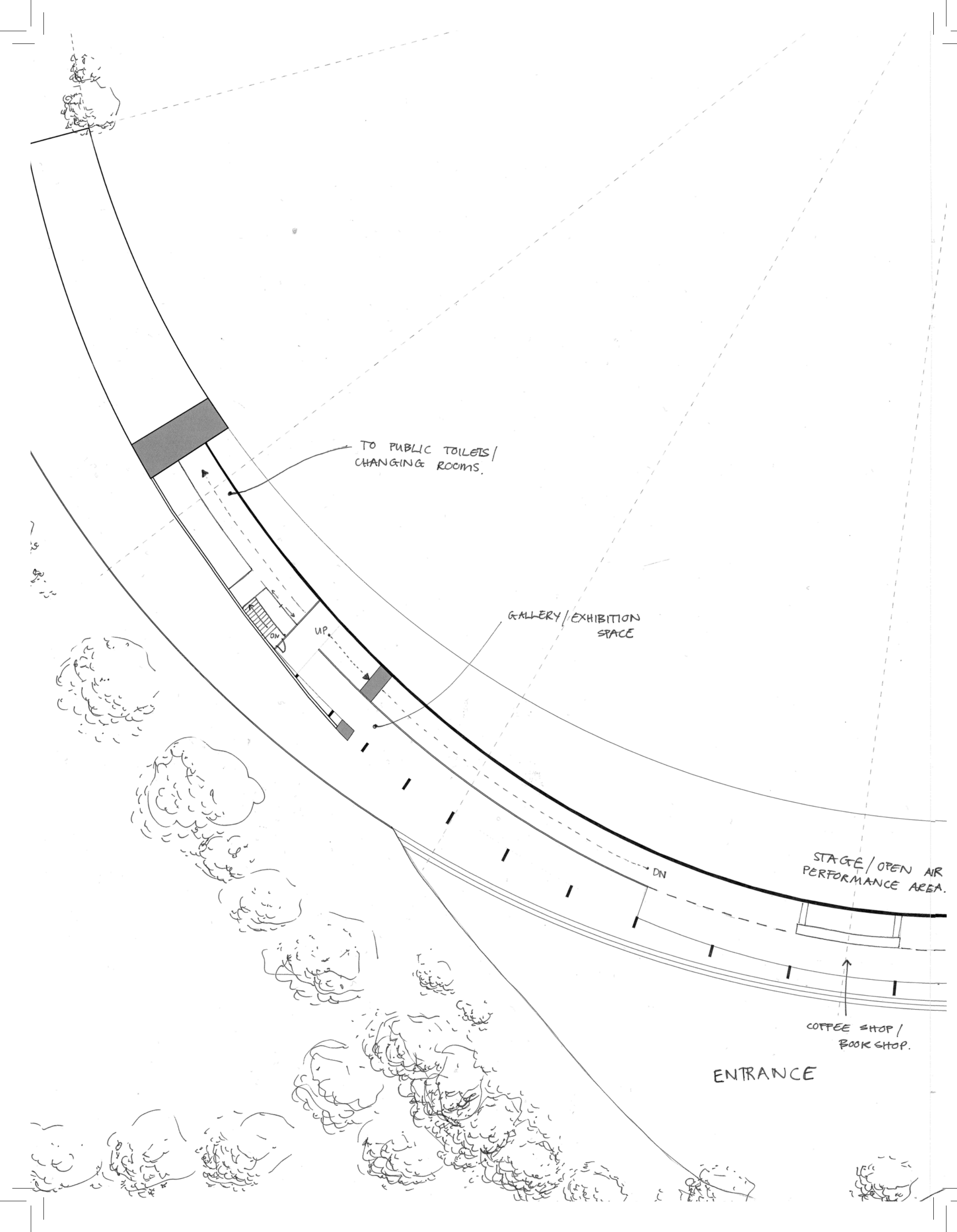



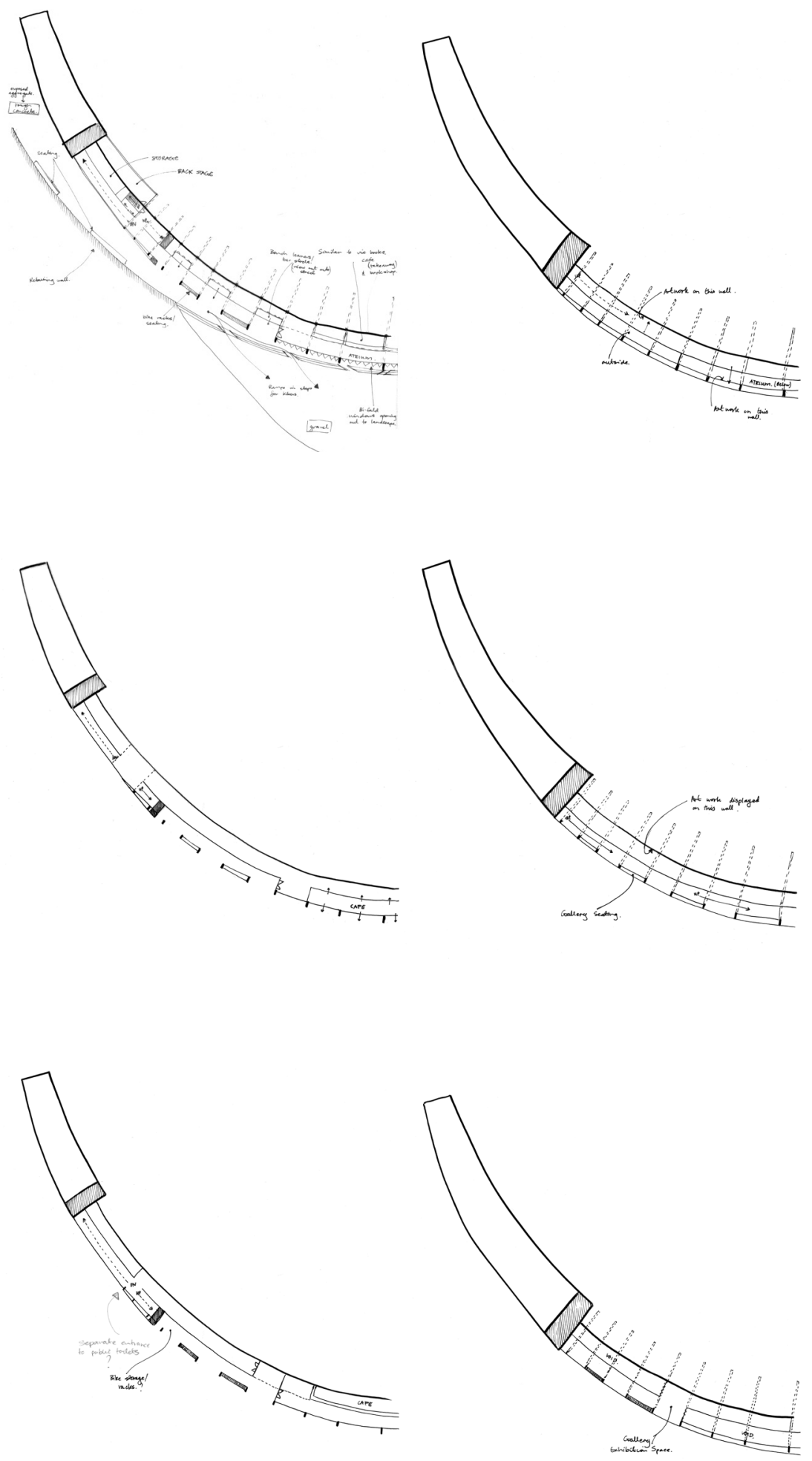

Figure 116. In these sketches above, I have explored three different planning options. Each option has positives and negatives associated with them. These iterations illustrate the challenge of getting the planning to work within the narrow width of the building. I did not want to increase this width as the circumference of the circle is already so large that I was trying to avoid any wasted space. 


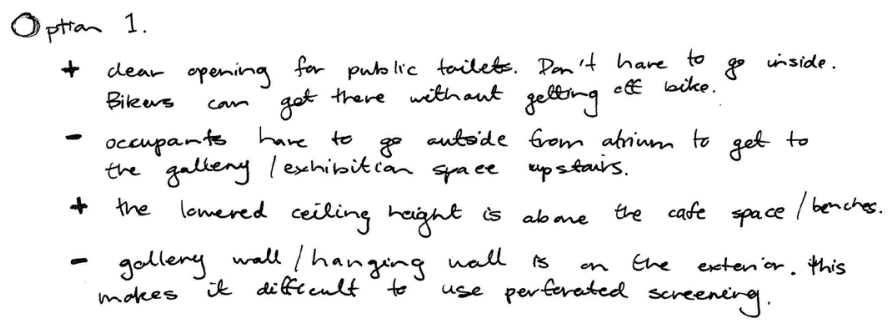

+ dear opening for public tailets. Pan't have to go inside. Bikers can got there with haut getting off - occupants hare to go autide from atrium to get to
the galleny / exhibition space eupstairs.

+ the lomered ceiling height is abone the cafe space/benches.

- gollery wall / hanging wall is on the exterion. This mokes it diffecult to use perforated screening.

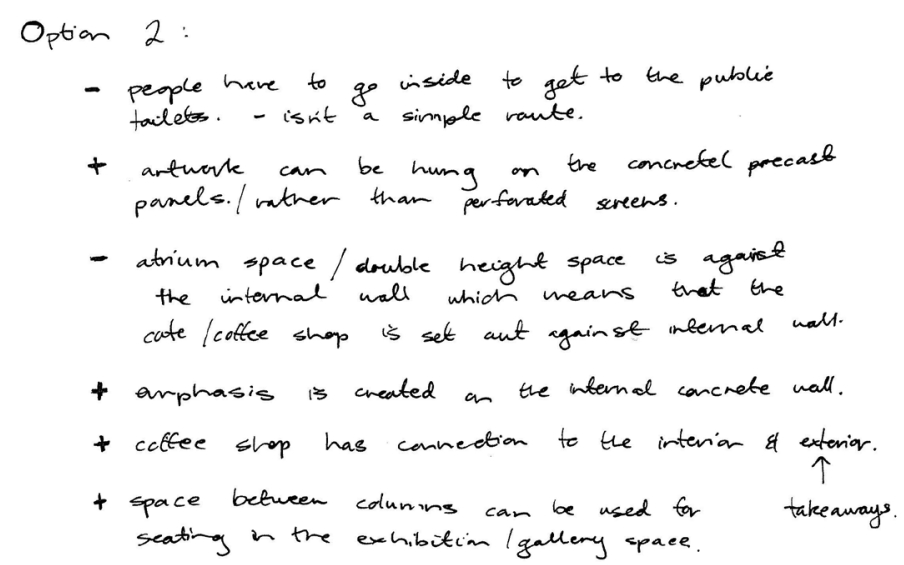

Option 3:

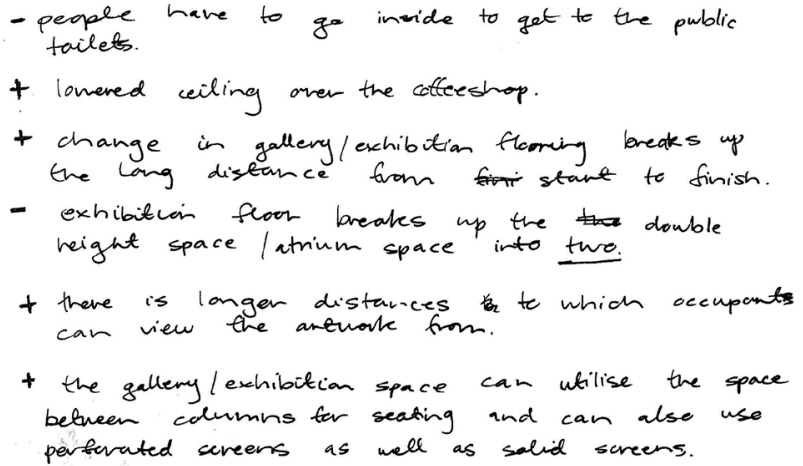



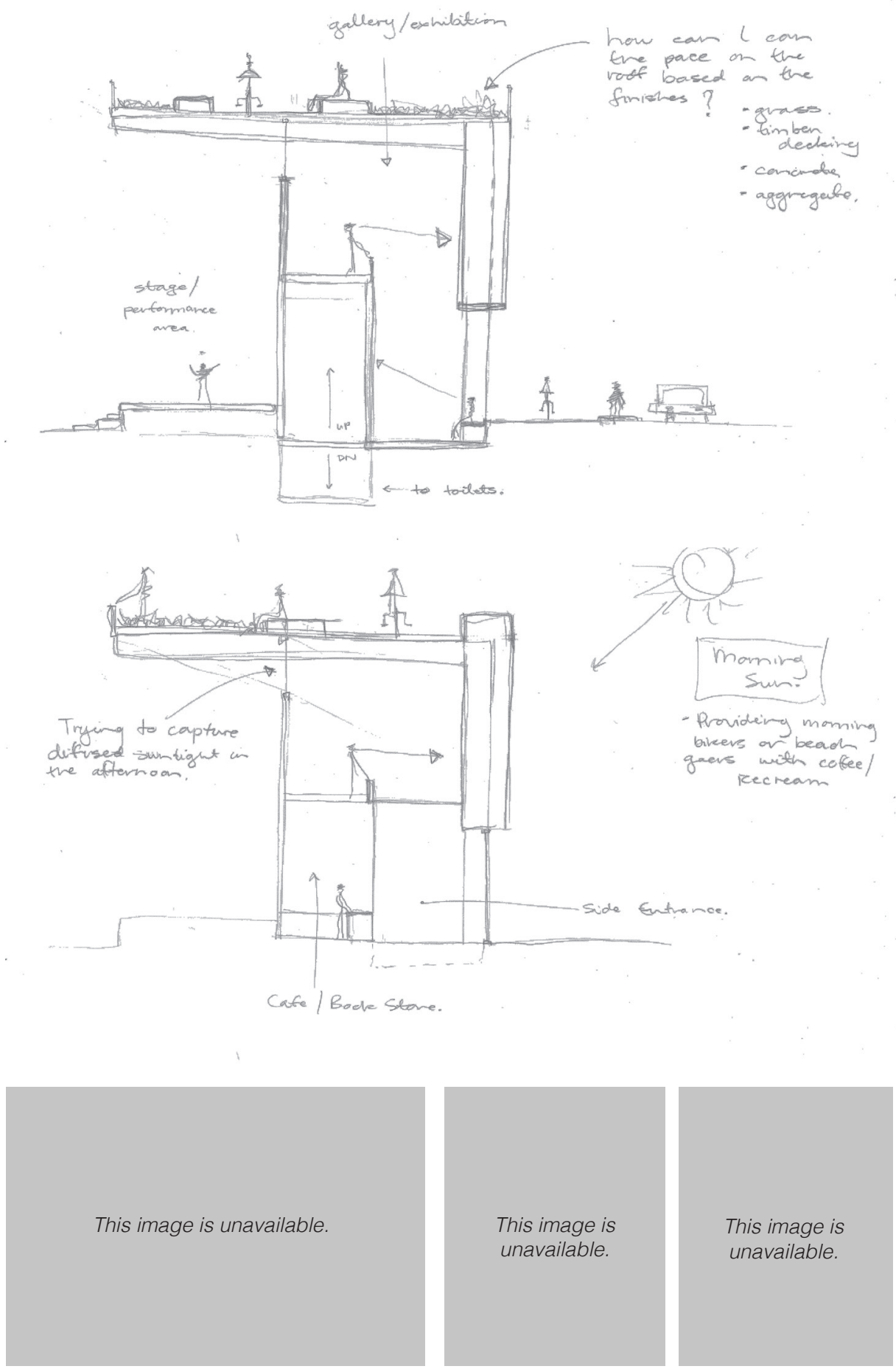

Figure 117. After figuring out the planning, I produced these sketches of the roadside building. These sections show the relationship between the different spaces; including the stage, the coffee shop, the exhibition space, and the rooftop. In resolving this section of the building, I have begun to think about the materiality and the type of atmosphere I want to create in this space. 

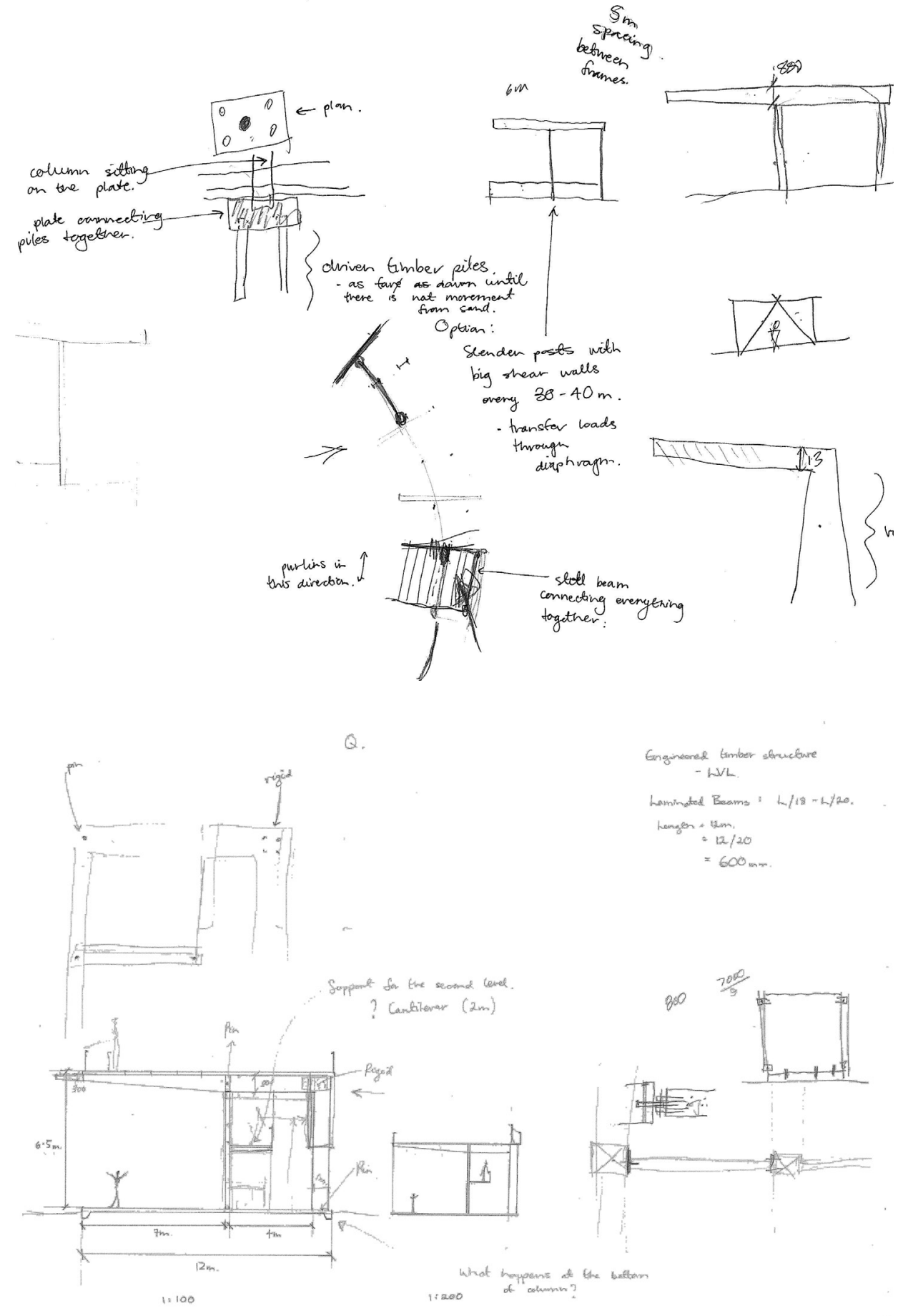

$\wedge$

Figure 118. In these sketches, I was figuring out the structural system and size of members required for this design. Due to the radial nature of the circle, the structural system is reasonably straightforward. There will be a series of beam and columns with a mixture of pin and rigid joints. As identified in the sketches, the primary members will be engineered timber with secondary steel members. 


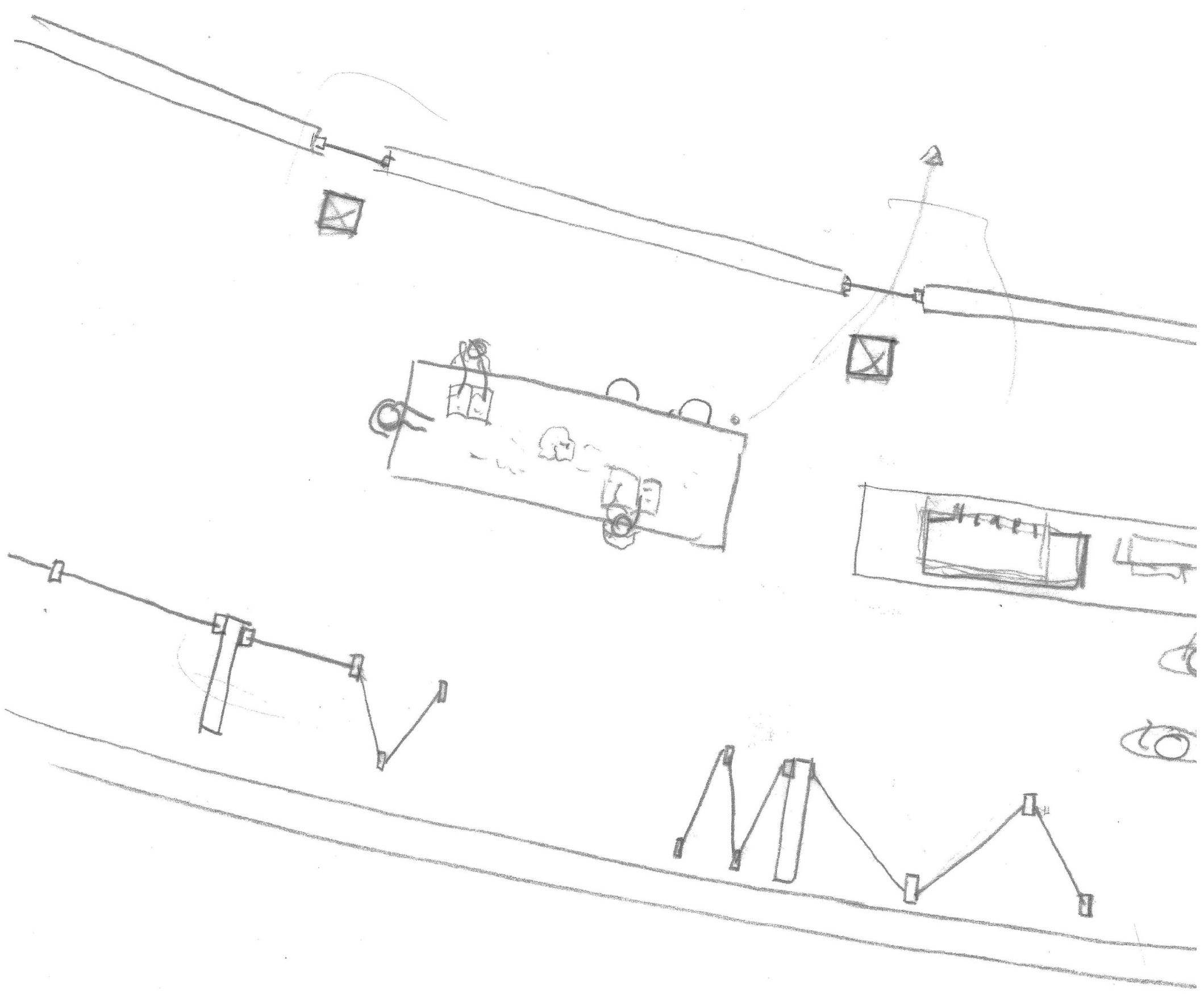

Figure 119. This plan (1:50) shows how the coffee shop could operate within the narrow width of the building. I was also looking at how offsetting the columns could create a visual connection to the stage and the centre of the circle. 


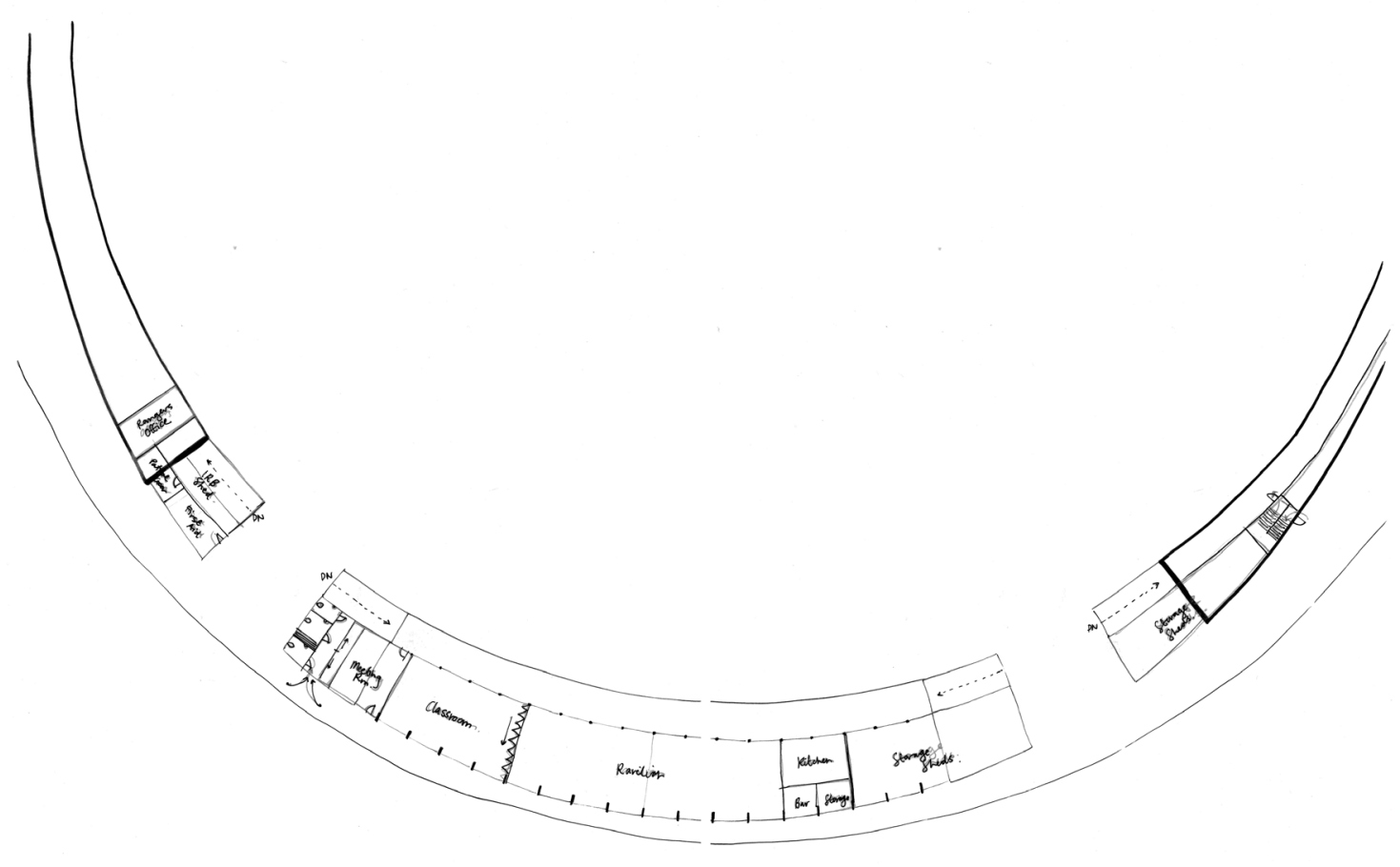

option 1

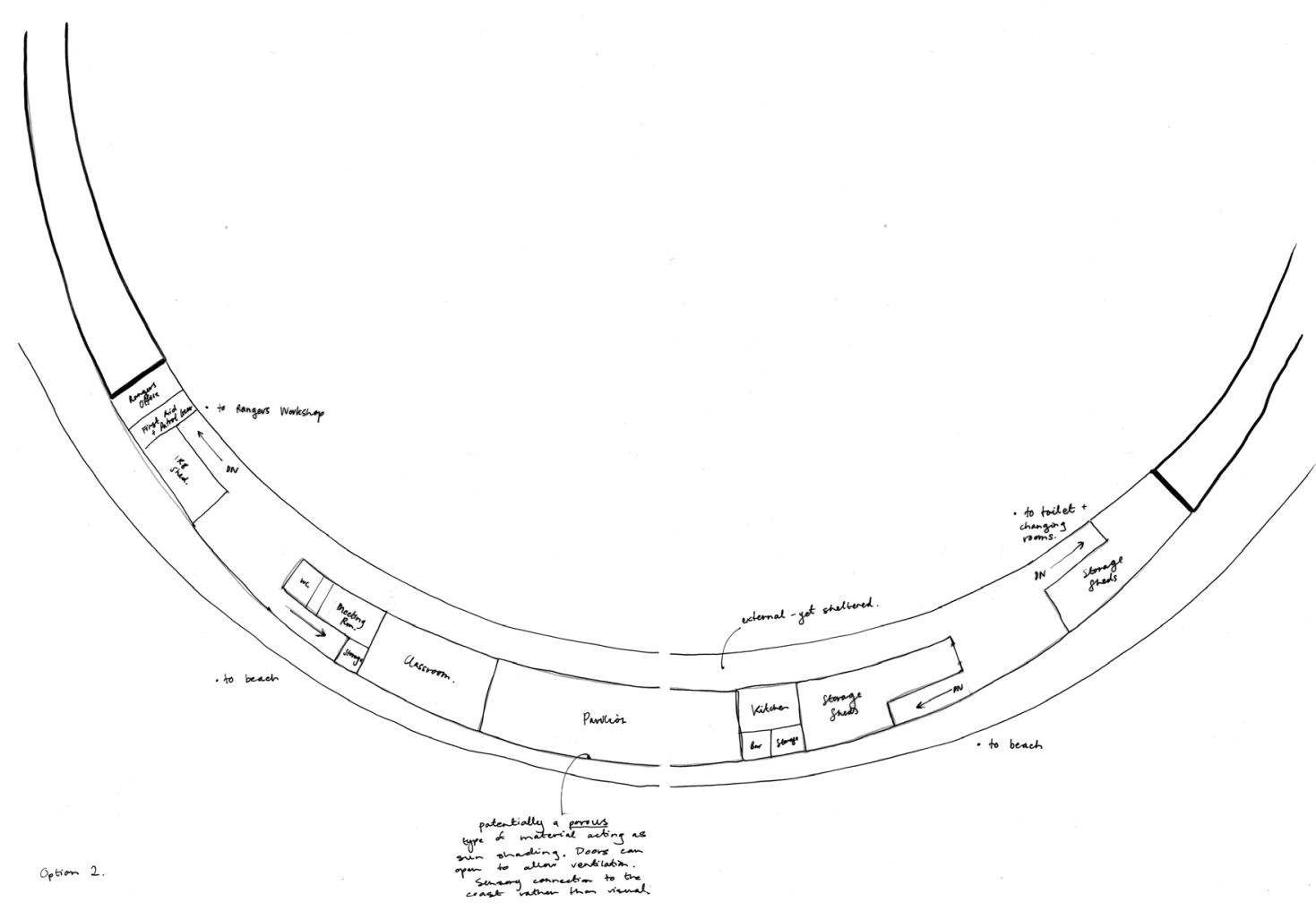

$\wedge$

Figure 120. Shifting to the seaside building, I started to explore different ways in which I could organise the different functions. The biggest challenge in this planning exercise was trying to locate the Park Rangers house so that it is separate from the public functions. As a solution, I have shifted the deck to the inner side of the circle creating enough privacy to situate the house on the outer edge. 

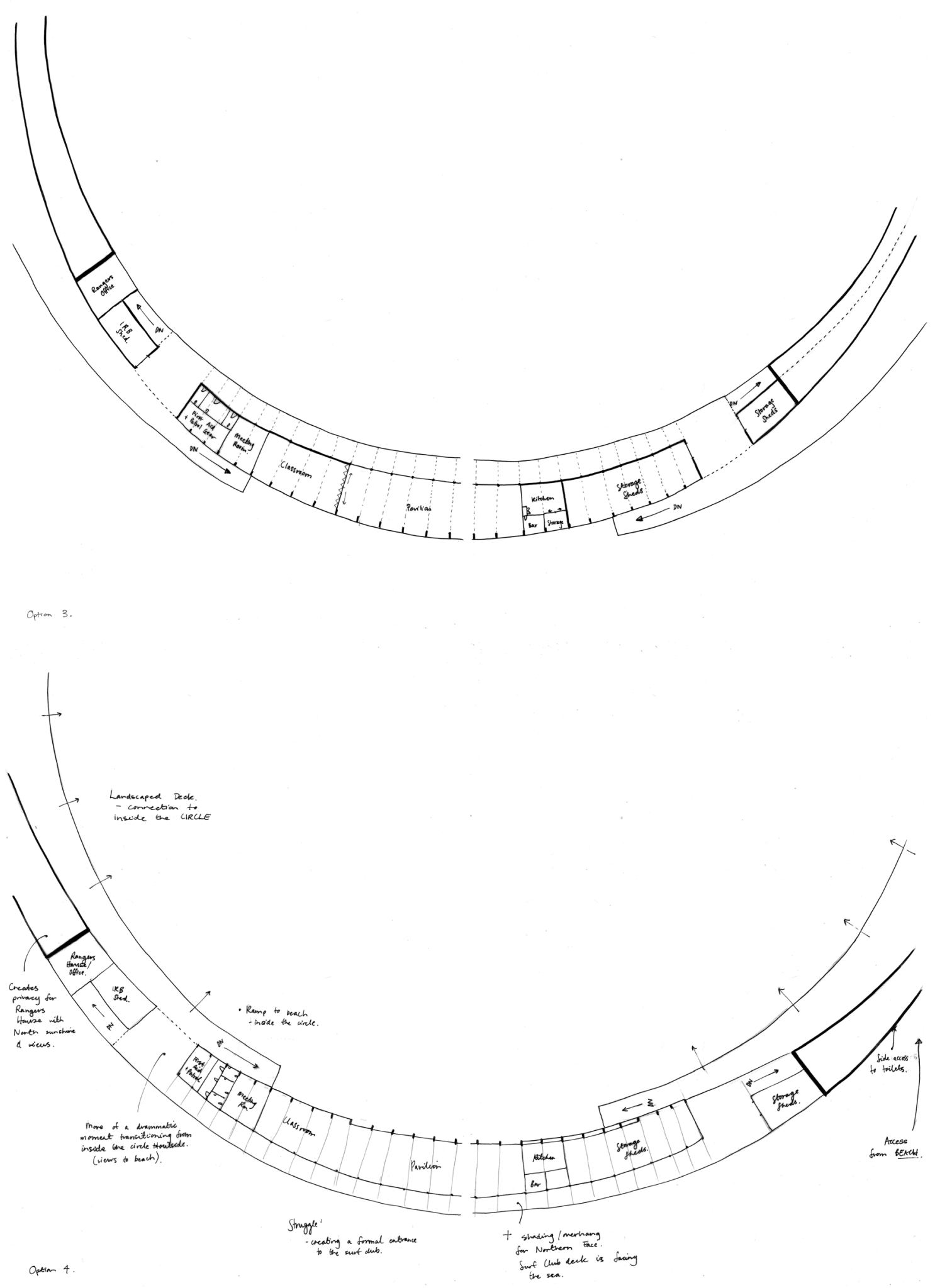


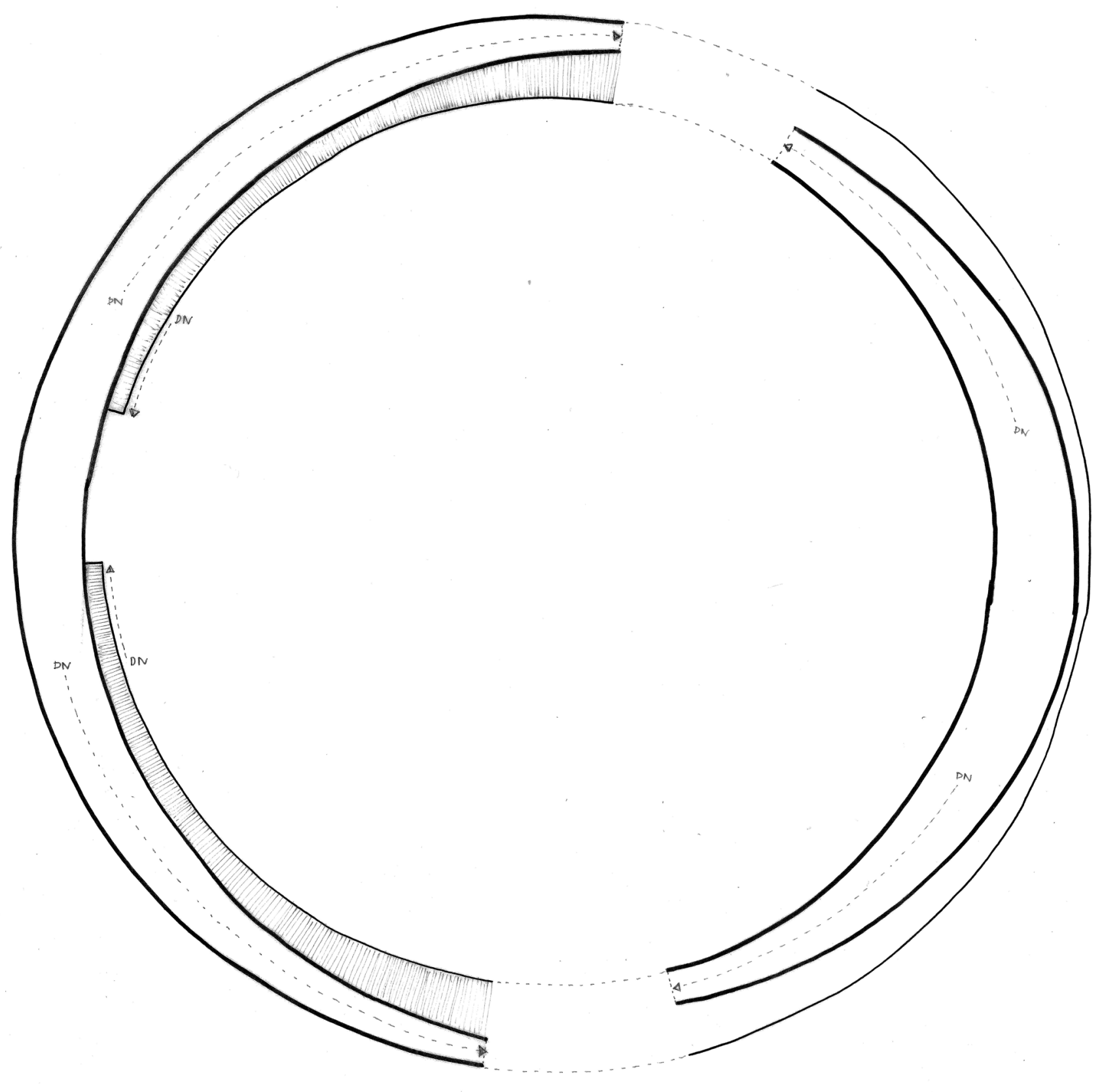

$\wedge$

Figure 121. These plans illustrate how shifting the deck to the inner side of the circle has changed the tapering of the roof. This shift means that the two buildings offset from each other only affecting the arrangement of the basement plan. 

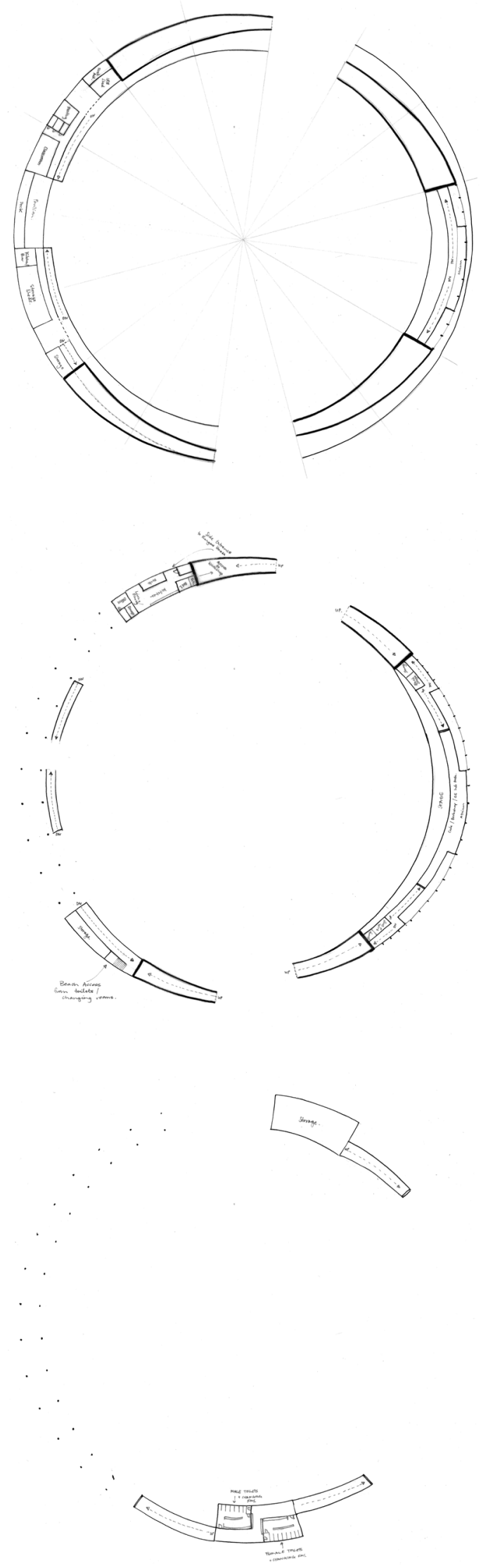

185 


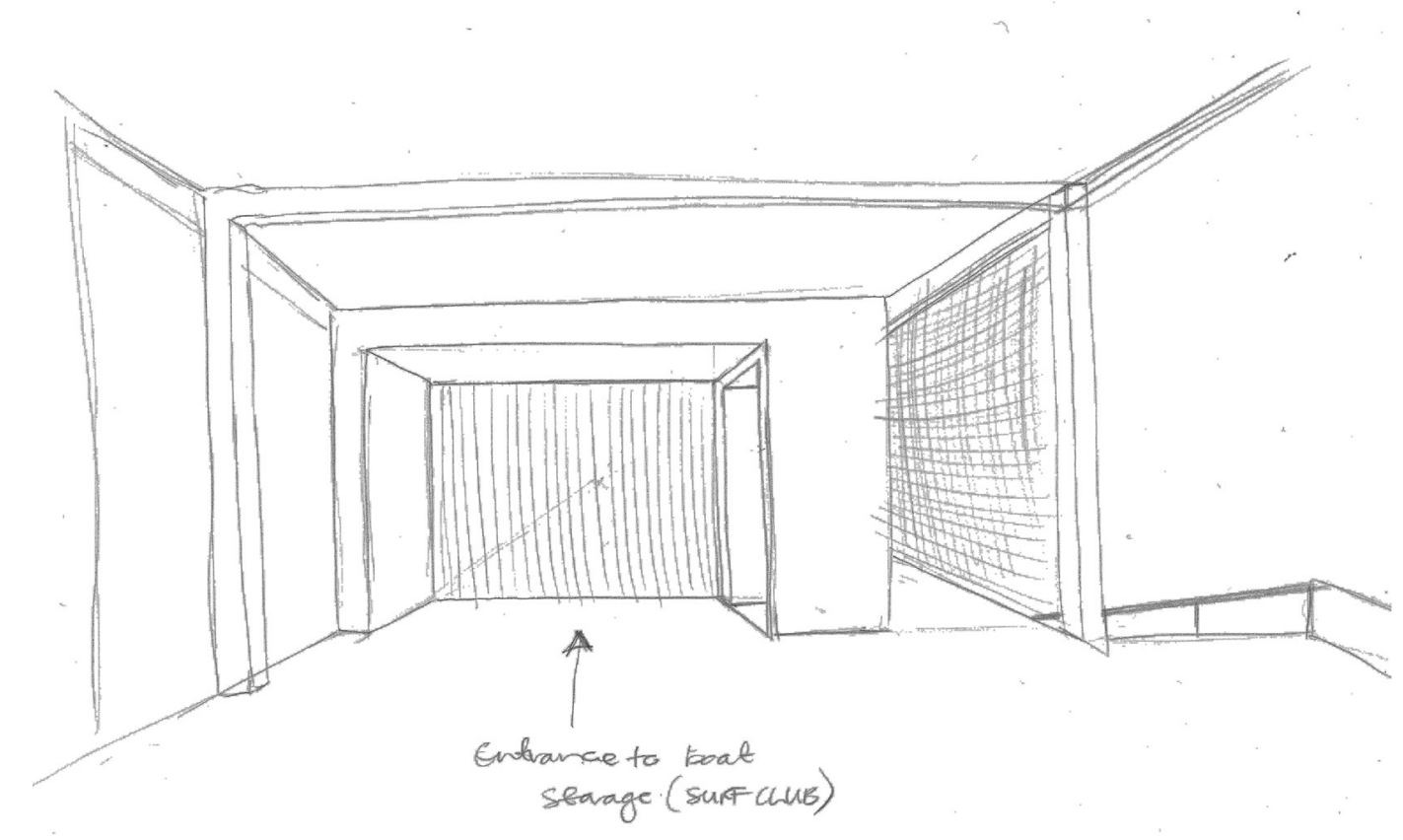

Figure 122. In trying to visualise how the interior space of the seaside building might work, this sketch brings together the different aspects of the plan; the ramp from the beach, the entrance to the boat storage, and the corridor that leads up to the surf clubs main hall.
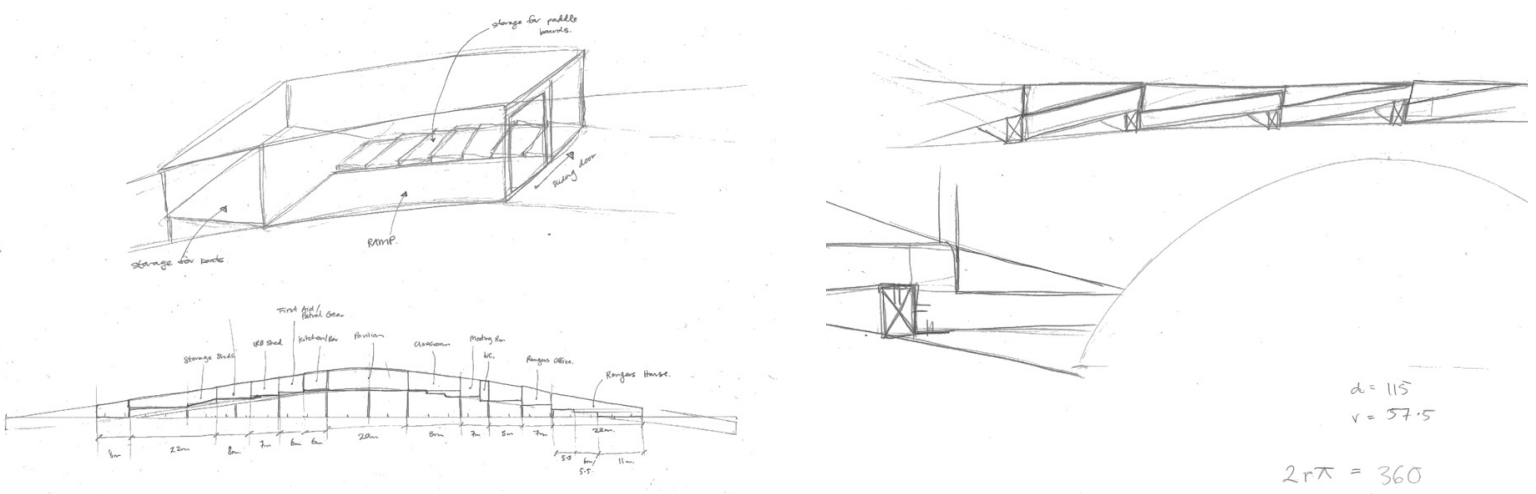

$\wedge$

Figure 123. As I began to model the seaside building on the computer, I realised an issue with trying to occupy a sloping floor. As a result, these sketches above try to equally split and offset the floor so that I can retain the curved form. I will then cover the changing floor level with a panel that maintains a curve similar to the roof. 


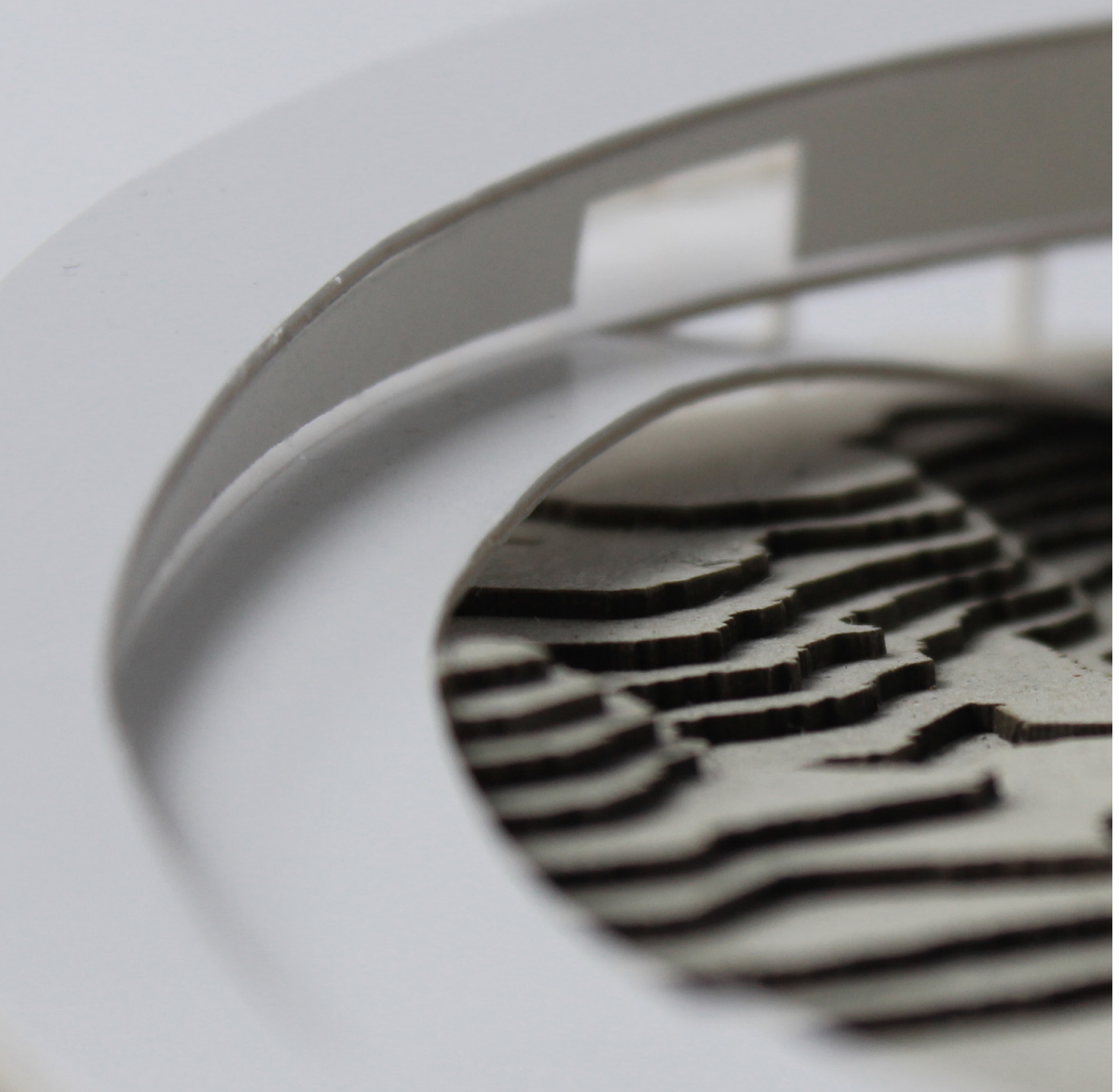




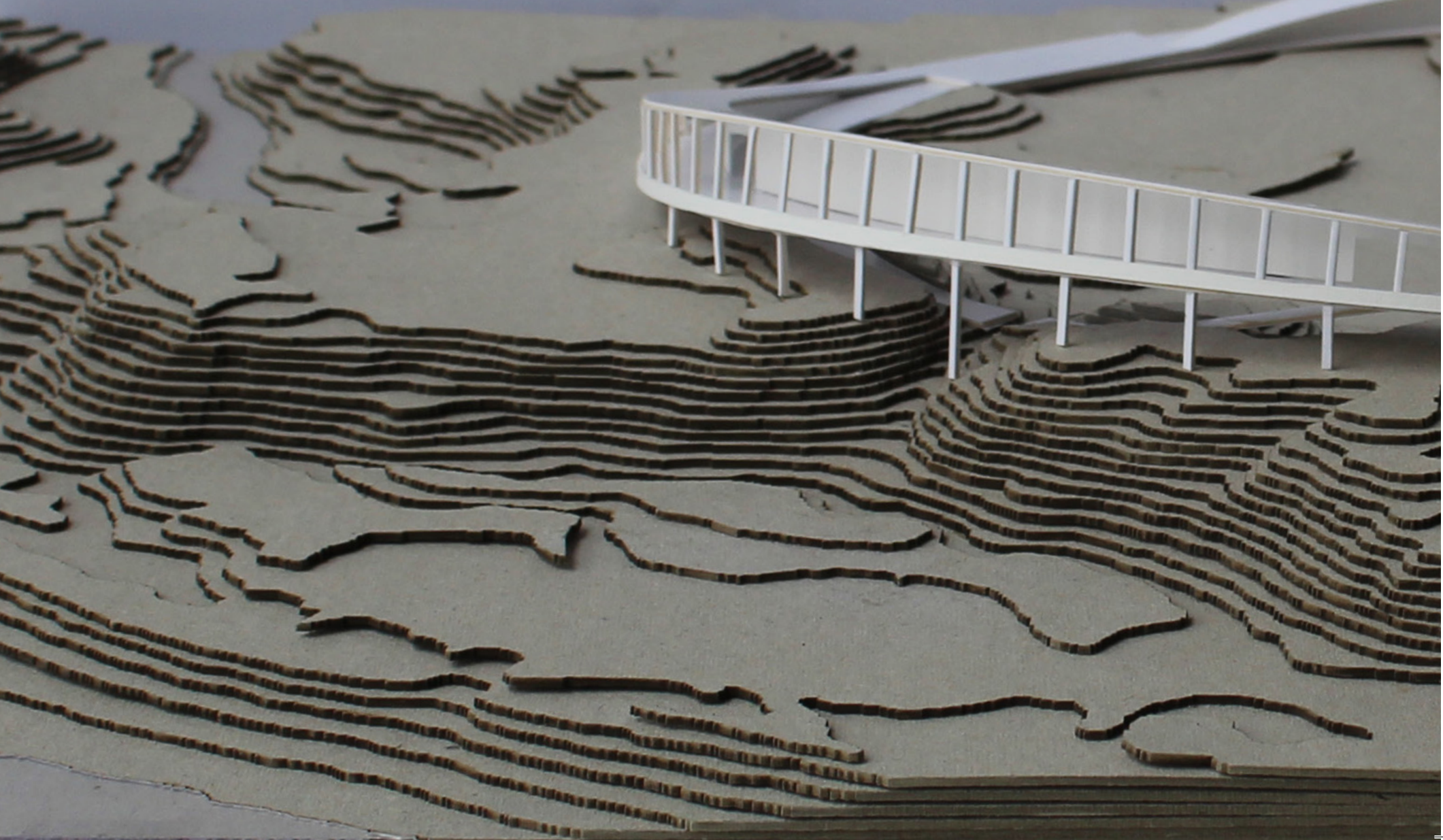




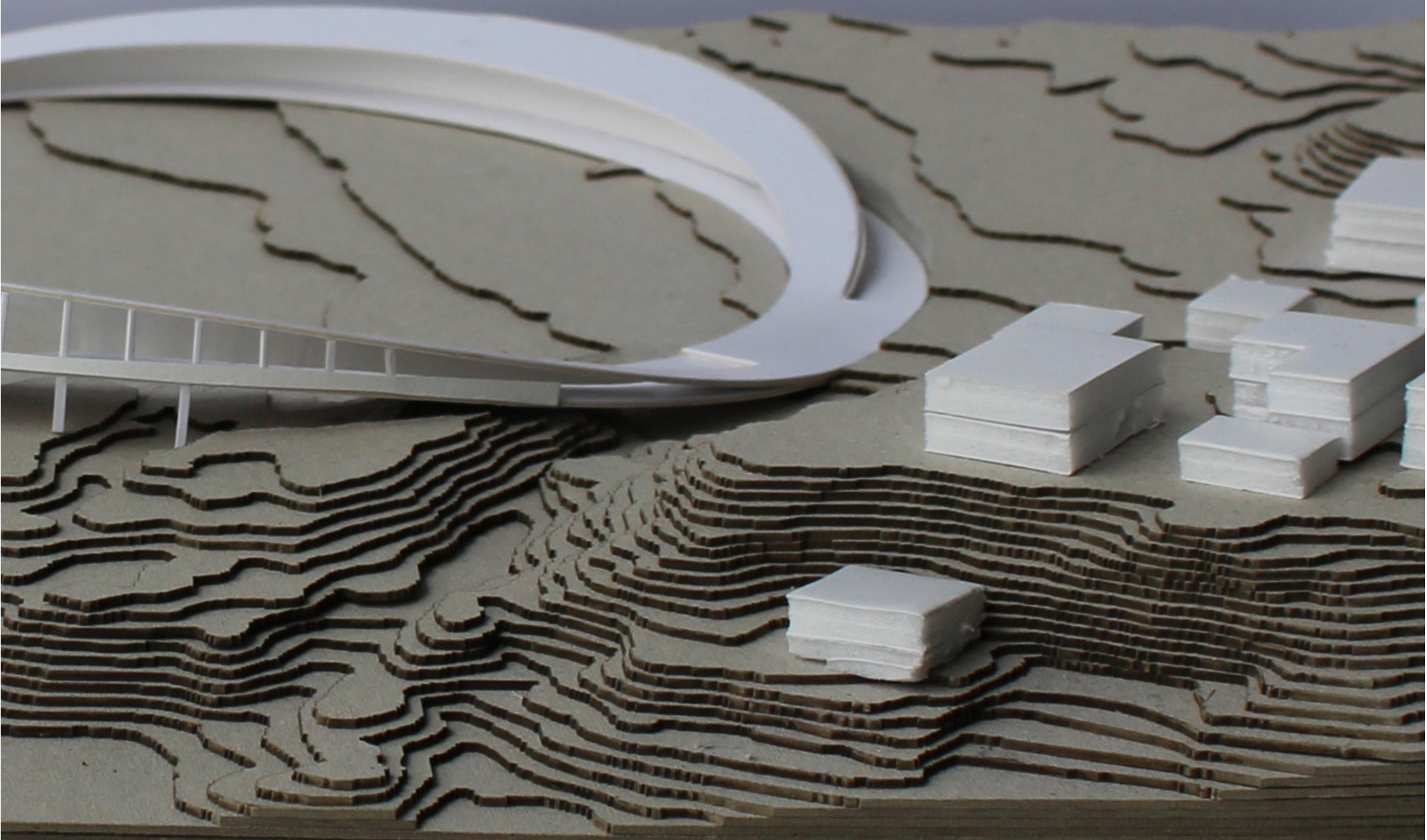



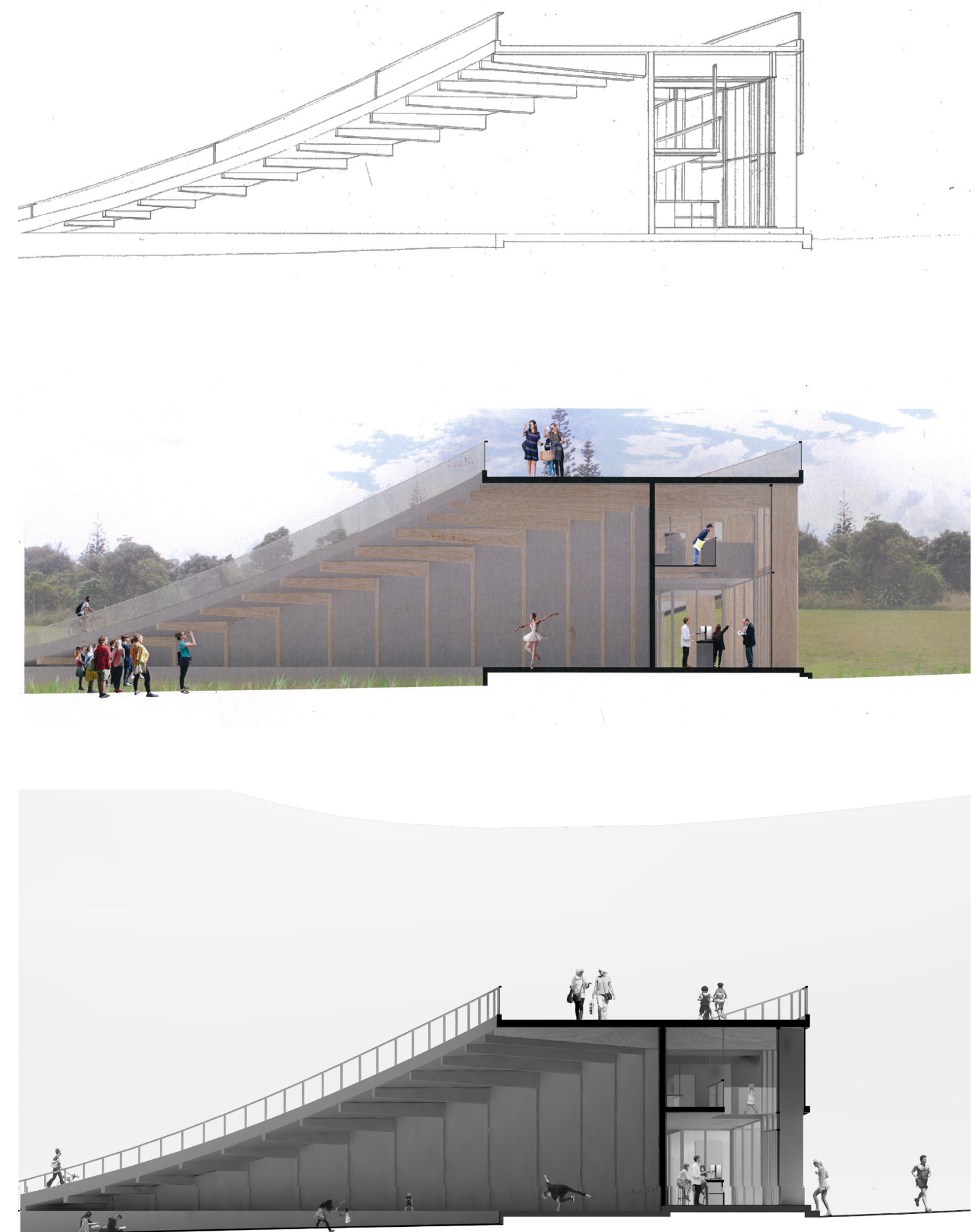
Figure 126. Transverse Section (not to scale) - this section shows the connection between the different functions, the stage, the coffee shop, and the exhibition space. In the three drawings above I was trying to find the best medium to present the building for the final review. The top drawing is a pencil line drawing, and the bottom two drawings are computer renders. I found that the coloured render felt a bit too final hence I resorted to the black and white render. The black and white renders also work well with my hatch drawings. 

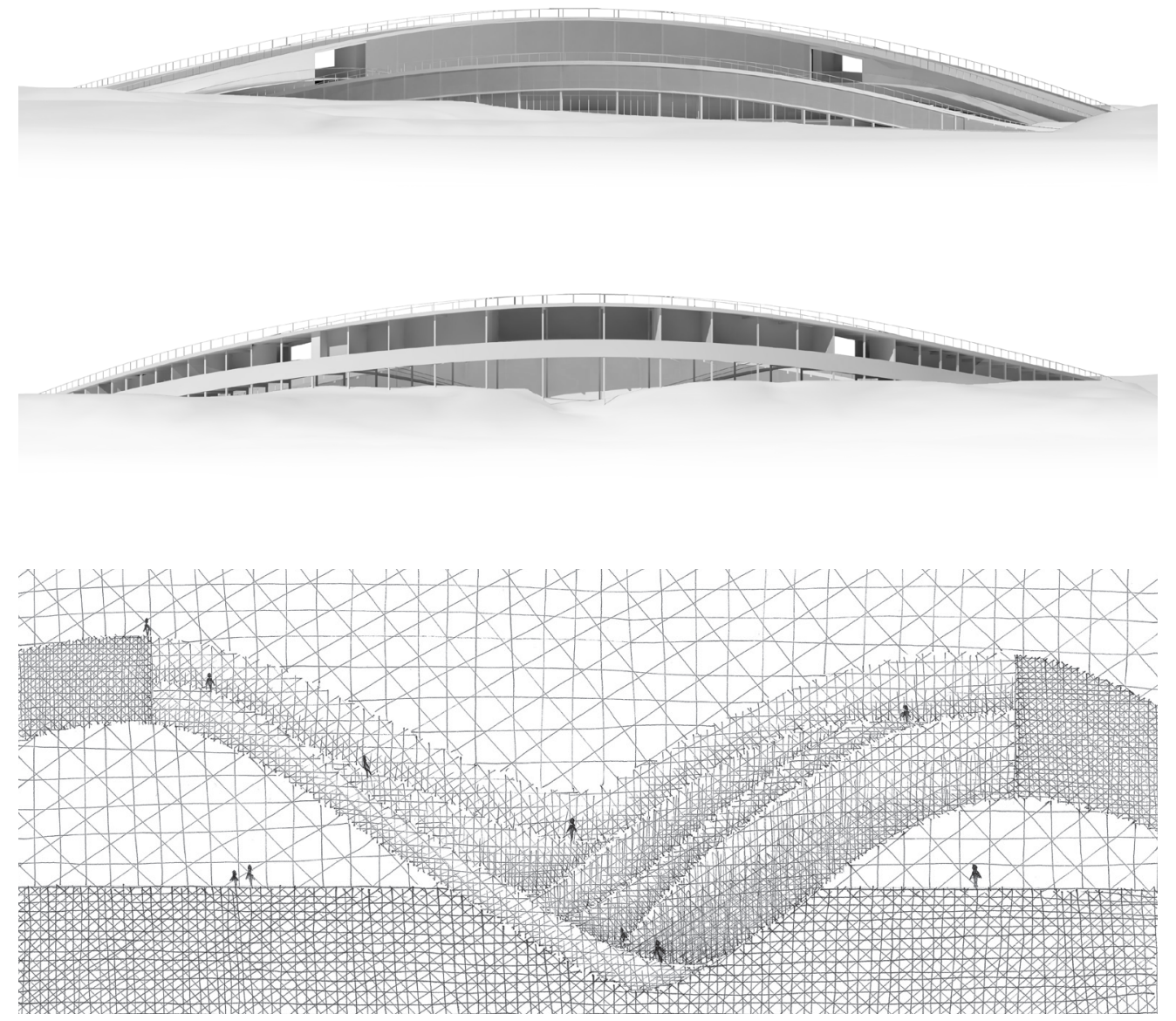

Figure 127. From this comparison, it is clear that the computer drawing lacks the same complexity as the hand drawing. 


\section{Process Reflection:}

In this chapter, it is apparent that the computer drawings lacked the same complexity and playfulness that was captured in the drawings of the landscape. This is influenced by the different drawing techniques. When I draw, it is a lot easier to play with the form. Whereas, when I am working on the computer there are many more constraints. Instead of working on one view at a time, similar to the physical drawings, on the computer it is very easy to get caught up in viewing the building from a $3 \mathrm{D}$ perspective. In this view you can zoom around the building and view it from all different directions. I have found that this slowed my productivity as I would be focused on resolving the whole building instead of focusing on working up a few views of the building at a time. It also does not help that I was forced to simplify the form while I was still learning Rhinoceros, a 3D computer software.

Overall I have found that the computer works better as a delivery mechanism than a design mechanism. 
It was only after I did these experiments and the drawings for the final review (refer to 'The Design' chapter) that I realised the true importance of the landscape iterations. The building that has been drawn and resolved in this last chapter lacks any formal expression of the diversity distinct of the different communities. The complexity that was revealed in the landscape iterations is far more expressive of this diversity than the simplicity evident in the final design. After realising this I came to understand how important it is to achieve a balance between creating formally strong (simple plan) and socially accommodating (complex section) architecture.

Where simplicity cannot work, simpleness results. Blatant simplification means bland architecture. Less is bore. (Venturi, Pg. 16) 

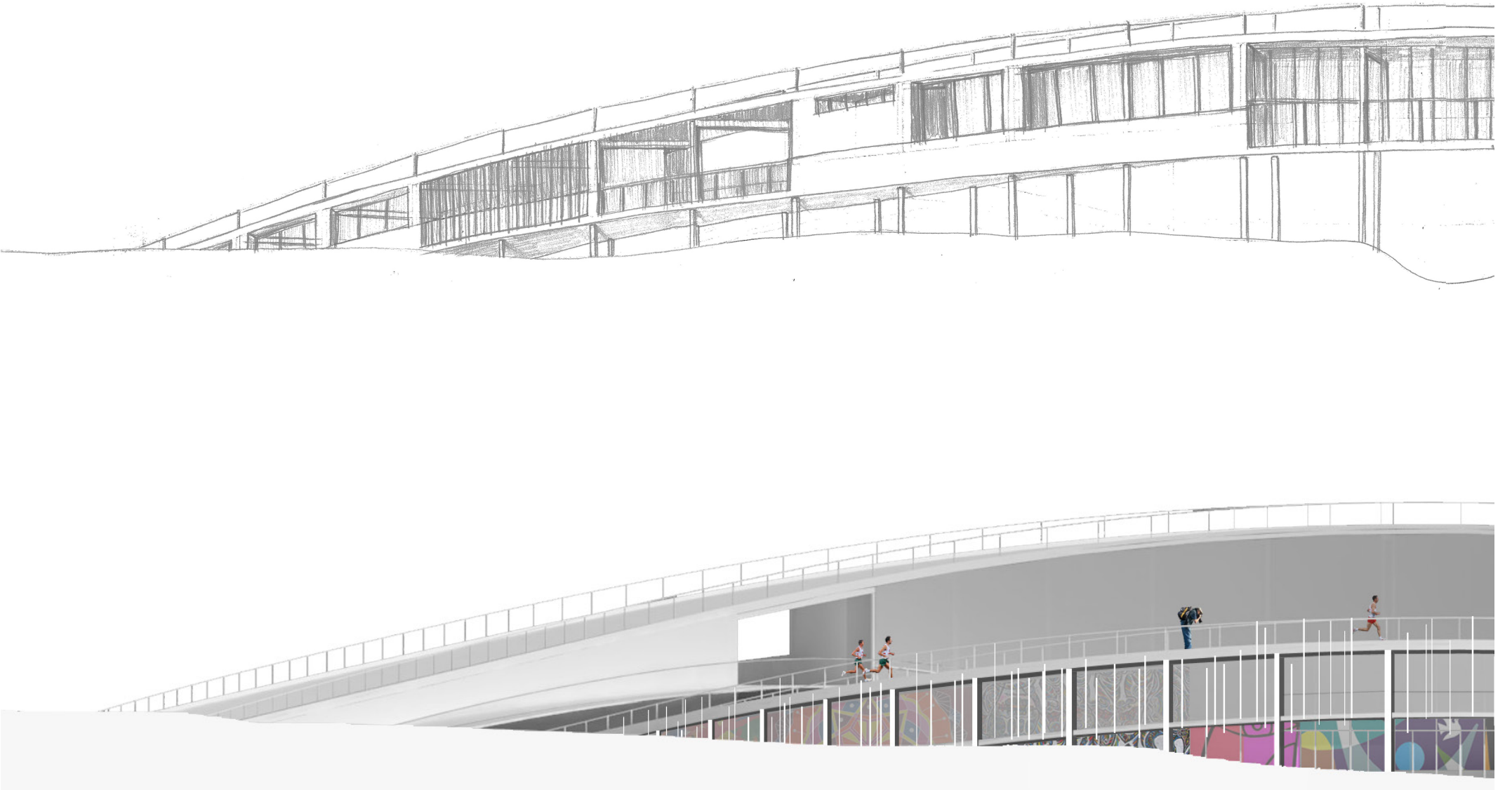

Figure 128. In these drawings, I was trying to bring this complexity back into the building. I have tried to do this through the design of the facade. In the top drawing, I was focused on breaking up the continuous rhythm of the facade, whereas the bottom drawing starts to bring colour into the facade through the addition of a graffiti wall. 

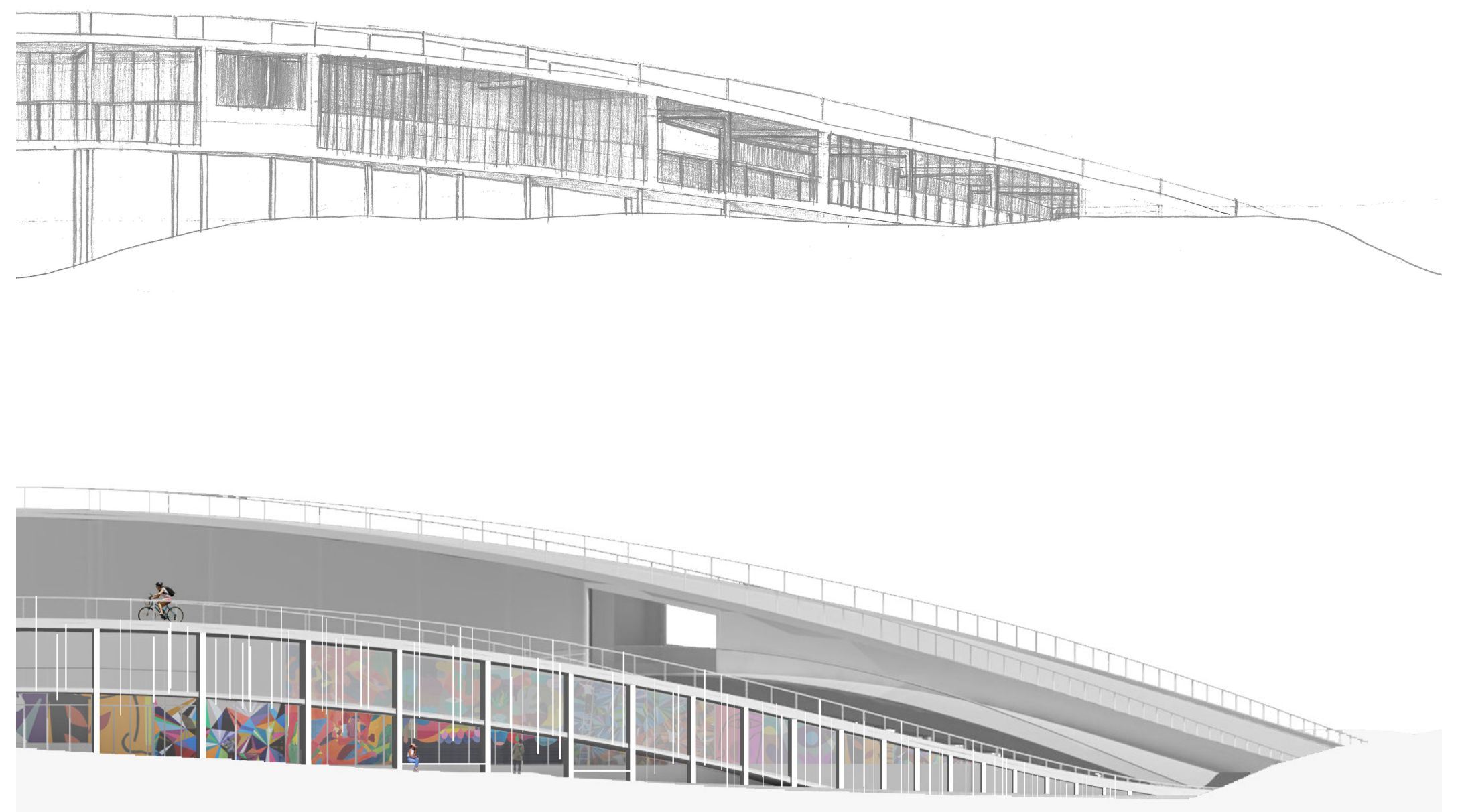


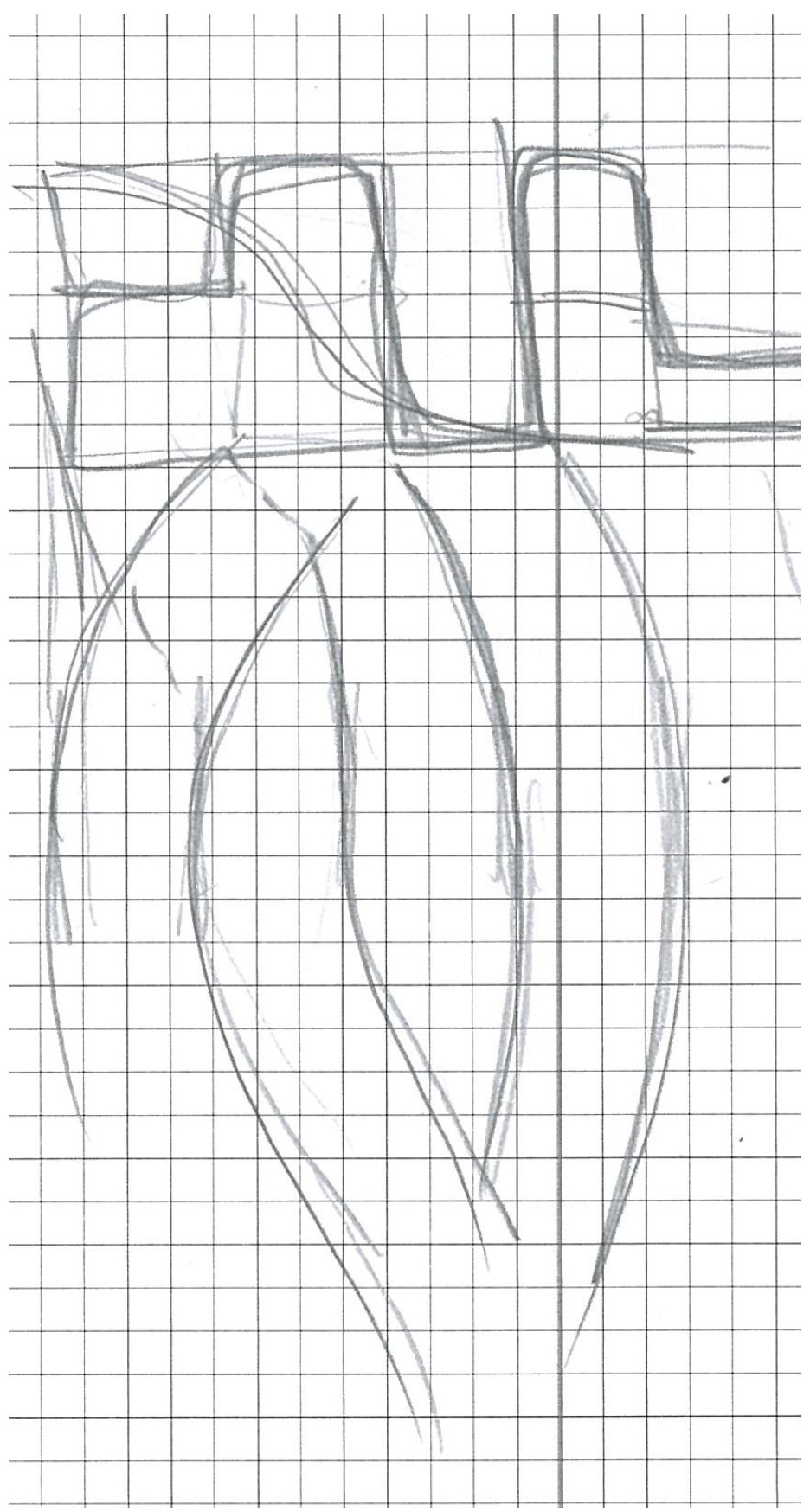

Figure 129. Final drawing of my design and where it might lead to next. 


\section{where to next?}

In lacking this complexity, I began to explore how colour and proportion of the facade might express the diversity of the different communities. As a result, it has become apparent to me how difficult it is to change the expression of a building at this level of detail.

In that case, if I were to continue on, I would turn back to my formal experiments of the landscape and focus on getting the complexity of the form to work with the simple plan of the circle. 
'You know when you don't have it and then somehow you know, intuitively, when you have an idea. It's very hard to describe but the most important dimension; selfcriticism, and being doubtful about whether you're there or not. You can't be in a hurry; architecture takes time".

(Forbes, Pg. 18) 


\section{conclusion}

This thesis, Circling Communities, has explored a design process and formal strategy for addressing both the social and formal issues of designing on a site like this. As a result of shifting between drawing techniques and physical models I have found that the plan and section can have opposing formal qualities.

After a series of experiments exploring the form through diagrams and mass models, I decided on a circle as it fits neatly in the existing topography and addresses each of the communities evenly. However, as I started to explore the circle from a side on perspective, the drawings began to blur the connection between the form and the landscape. This ambiguity revealed a complexity to the form that contrasted the simplicity of the circle. As I scaled down to continue exploring the section, the simplicity of the form became more obvious as the dunes were lost from view. Although this simplicity of the circle works in the plan, it disregards the diversity of the communities in the section.

After realising this issue, I turned to the landscape in search for the complexity that was seen in the earlier drawings. These iterations revealed a multiplicity to the form which contrasts the singularity of the circle. This multiplicity provides various spaces allowing the building to be inhabited by a diverse range of communities.
After discovering these qualities, simplicity and complexity, I decided to use the plan and section as a way of splitting up the project so I could consider the form as both. However, translating the twodimensional views into a three-dimensional form proved challenging. As the undulating section was competing with the already undulating landscape, I decided to resort to the simpler form so I could focus on resolving the building for the final review. However, at this scale of detail, it was difficult to achieve the same quality of complexity that was evident in the formal experiments of the landscape.

In that case, I ended up presenting a building which achieved the simple plan yet lacked the complex section. As a result, this thesis reinforces Venturi's perspective that "the whole (simple plan and complex section) is difficult to achieve" (88). It also reinforces why architects often be it subconsciously, focus on one element of the design at a time, ie. formal or social. However, this exploration was undertaken with the intention of finding a design strategy that can resolve multiple issues at a time. Therefore, this thesis shows that more strategies need to be explored through design research to create a more successful approach. 


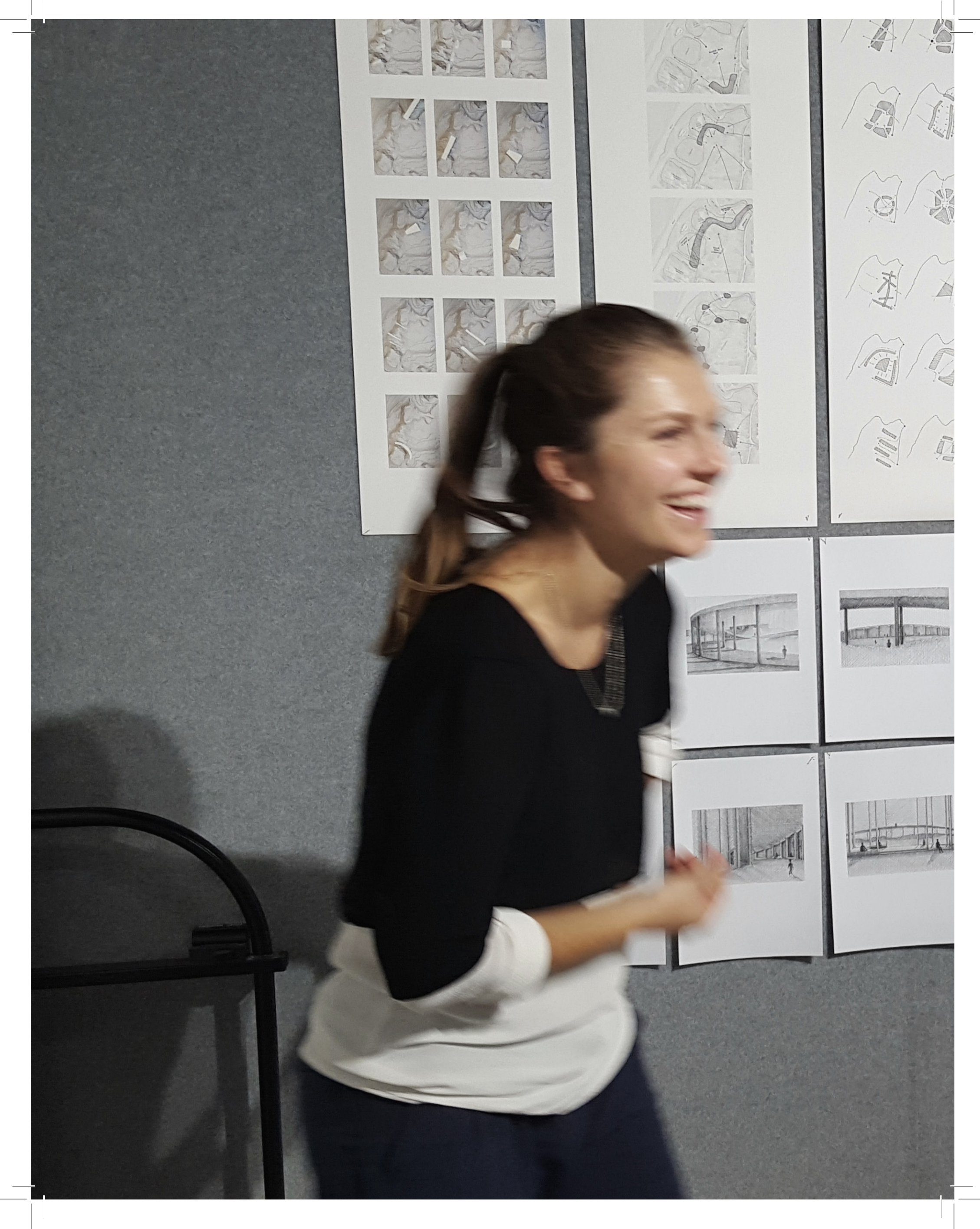




\section{bibliography}

Basulto, David. "Rolex Learning Center/SANAA." ArchDaily. 18 Feb. 2010. Web. 05 Dec. 2016. <http://www.archdaily. com/50235/rolex-learning-center-sanaa/>

Forbes, Karen, ed. Site Specific: Conversations with Peter Zumthor, Steven Holl, Roisin Heneghan, Bjarne Mastenbroek, Bjarke Ingels, Joshua Prince-Ramus, Patrick Schumacher, Kjetil Thorsen, Craig Dykers, and Harry Gugger. ORO Editions, 2015. Print

Frances, Helen. "Massey's University's College of Creative Arts (CoCA)." ArchDaily. 27 Sep. 2012. Web. 13 Dec. 2016. $<$ http://architecturenow.co.nz/articles/massey-universitys-college-of-creative-arts/>

Gadanho, Pedro, ed. A Japanese Constellation: Toyo Ito, Kazuyo Sejima, SANAA, Ryue Nishizawa, Sou Fujimoto, Akihisa Hirata, Junya Ishigami. New York: The Museum of Modern Art, 2016. Print.

Garcias, J, dir. Le Rolex Learning Center. France, 2012. Web. 07 Dec, 2016. <https://www.youtube.com/ watch?v=fCKFqtOkrh8>

Greater Wellington Regional Council. History, Queen Elizabeth Park. 29 Nov. 2016. Web. 21 Dec. 2016. <http://www. gw.govt.nz/History-4/>

KCDC, Kapiti Coast District Council. Paekakariki Town. NZ Govt. 2016. Web. 21 Dec. 2016. <http://www.kapiticoast.govt. nz/whats-on/things-to-do-in-kapiti/Heritage-Trail/paekakariki/paekakariki-town/>

Maxwell, Joel. "Paekakariki wants to buy home for beloved resident who can't afford to stay there". 21 Dec. 2016. Web. 22 Dec. 2016. <http://www.stuff.co.nz/business/property/87809909/paekakariki-wants-to-buy-home-for-beloved-resident-who-cant-afford-to-stay-there>

Murray, Christine. "The Culture Issue." The Architectural Review, 1427. Jan. 2016: 1-2. Print.

Ngati Toa Rangatira. “Iwi Origins.” 2010. Web. 19 Feb. 2017. <http://www.ngatitoa.iwi.nz/ngati-toa/iwi-origins/>

Paekakariki Holiday Park, About. 2016. Web. 21 Dec, 2016. <http://www.paekakarikiholidaypark.co.nz/campinggrounds-kapiti > 
Paekakariki Station Museum. A Chronological History of Paekakariki Area and the Railway. 2016. Web. 21 Dec. 2016. $<$ http://stationmuseum.co.nz/history/>

Paekakariki Surf Lifeguards, History. Web. 21 Dec. 2016. <http://www.paekakarikisurflifeguards.org.nz/about-us/history/>

Queen Elizabeth Park, Resource Statement. Wellington: Greater Wellington Regional Council, Nov, 2008. Web. 21 Dec. 2016. <http://www.gw.govt.nz/assets/Parks-and-Recreation/Misc/QEP-resource-statement.pdf>

“RMIT Design Hub/Sean Godsell." ArchDaily. 22 Feb. 2013. Web. 13 Dec. 2016. <http://www.archdaily.com/335620/ rmit-design-hub-sean-godsell/>

Statistics New Zealand. 2013 Census QuickStats about a place: Paekakariki. 2013. Web. 20 Dec. 2016. <http://www. stats.govt.nz/Census/2013-census/profile-and-summary-reports/quickstats-about-a-place.aspx?request_value=14341 \&tabname=Populationanddwellings>

Venturi, Robert. Complexity and Contradiction in Architecture. New York: The Museum of Modern Art, 1977. Print. 


\section{list of figures}

8, 12 LINZ Data Service, 'Wellington 0.3m Rural Aerial Photos Index Tiles (2012-2013)'. 11 Mar, 2014. Web. 26 Nov, 2016.<https://data.linz.govt.nz/layer/1870-wellington-03m-rural-aerial-photos-2012-2013/>

23 A crowd at the surf club, Paekakariki beach. Smith, Sydney Charles, 1888-1972: Photographs of New Zealand. Ref: 1/2-045892-G. Alexander Turnbull Library, Wellington, New Zealand. <http://natlib.govt.nz/ records/22421983>

Paekakariki beach. Smith, Sydney Charles, 1888-1972: Photographs of New Zealand. Ref: 1/2-045891-G. Alexander Turnbull Library, Wellington, New Zealand. <http://natlib.govt.nz/records/23179920>

24 Kapiti Coast District Council. U.S. Marine Corps Camps. 2016. Web. 03 February. 2016. <http://www kapiticoast.govt.nz/whats-on/things-to-do-in-kapiti/Heritage-Trail/paekakariki/us-marine-corps-camps/>

Alberto Giacometti. Pinterest. Web. 15 Feb. 2017. <https://nz.pinterest.com/explore/alberto-giacometti/>

Basulto, David. “Rolex Learning Center/SANAA.” ArchDaily. 18 Feb. 2010. Web. 05 Dec. 2016. <http://www. archdaily.com/50235/rolex-learning-center-sanaa/>

67 "RMIT Design Hub / Sean Godsell." Archdaily, 22 Feb. 2013. Web. 20 Feb. 2017. <http://www.archdaily. com/335620/rmit-design-hub-sean-godsell>

Frances, Helen. "Massey's University's College of Creative Arts (CoCA)." ArchDaily. 27 Sep. 2012. Web. 13 Dec. 2016.<http://architecturenow.co.nz/articles/massey-universitys-college-of-creative-arts/>

69 McKay, Bill. "Te Uru Taumatua, Te Wharehou O Tūhoe," Architecture Now, 22 July. 2014. Web. 20 Feb. 2017. $<$ http://architecturenow.co.nz/articles/te-uru-taumatua-te-wharehou-o-tuhoe/> 2007. Web.2017. <https://www.flickr.com/photos/psulibscollections/5833318084> 
82 "Giovanni Battista Nolli-Nuova Pianta di Roma." Wikimedia Commons. 30 Oct. 2015. Web. 21 Feb. 2017. <https://commons.wikimedia.org/wiki/File:Giovanni_Battista_Nolli-Nuova_Pianta_di_Roma_(1748)_08-12. JPG $>$ Web. 21 Feb.2017. <http://www.archdaily.com/160044/more-about-foster-partners-new-apple-campus-incupertino/>

Mairs, Jessica. "BIG reveals full designs for Dubai Hyperloop in new video," Dezeen. 8 Nov. 2016. Web. 21 Feb, 2017.<https://www.dezeen.com/2016/11/08/big-designs-dubai-abu-dhabi-hyperloop-one-new-videotechnology-news/>

"MAX IV / FOJAB arkitekter + Snøhetta," ArchDaily. 26 Aug. 2016. Web. 21 Feb. 2017. <http://www.archdaily. com/794060/max-iv-fojab-arkitekter-plus-snohetta/>

"The Infinite Bridge / Gjøde \& Povlsgaard Arkitekter". ArchDaily. 14 Jul. 2015. Web. 21 Feb. 2017. <http:// www.archdaily.com/770084/the-infinite-bridge-gjode-and-povlsgaard-arkitekter/>

"Hostel Wadi / Studio Bernardo Secchi \& Paola Viganò," ArchDaily. 16 Mar. 2015. Web. 21 Feb. 2017. <http:// www.archdaily.com/609436/hostel-wadi-studio-bernardo-secchi-and-paola-vigano/> Akihisa Hirata, Junya Ishigami. New York: The Museum of Modern Art, 2016. Print.

"Froelicher High School Reconstruction / Daudre-Vignier \& Associes." Archdaily, 04 May. 2016. Web. 29 Jan. 2017.<http://www.archdaily.com/786640/froelicher-high-school-reconstruction-daudre-vignier-andassocies/> www.archdaily.com/625914/towada-community-plaza-kengo-kuma-and-associates/>

Furuto, Alison. "Rolex Learning Center Photographic Project / Johann Watzke, Anne-Fanny Cotting \& Aurélie Mindel of EPFL." Archdaily, 20 Aug. 2011. Web. 29 Jan. 2017. <http://www.archdaily.com/161853/rolexlearning-center-photographic-project-johann-watzke-anne-fanny-cotting-aurelie-mindel-of-epfl/> 
